Serviço a +-us-Gradução EESC/USP

EXEMPLAA REVISADO

Data de entrada no Serviço:..1...................

Ass.:..................orniol...........

Fernanda Cristina da Silva

\title{
ANÁLISE DE SEGURANÇA E CONFIABILIDADE \\ DE FUNDAÇÕES PROFUNDAS EM ESTACAS
}

\author{
Volume I
}

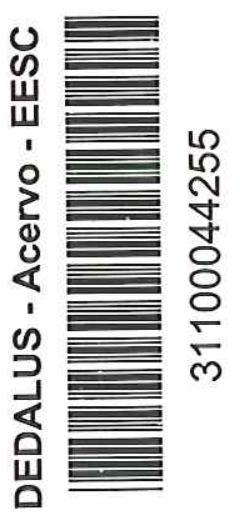

\begin{abstract}
Dissertação apresentada à Escola de Engenharia de São Carlos da Universidade de São Paulo, como parte dos requisitos para a obtenção do título de Mestre em Engenharia Civil: Geotecnia.
\end{abstract}

Orientador: Prof. Dr. Nelson Aoki

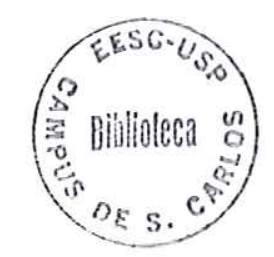

São Carlos

2003 
FOLHA DE JULGAMENTO

Candidata: Engenheira FERNANDA CRISTINA DA SILVA

Dissertação defendida e julgada em 28-10-2003 perante a Comissão Julgadora:

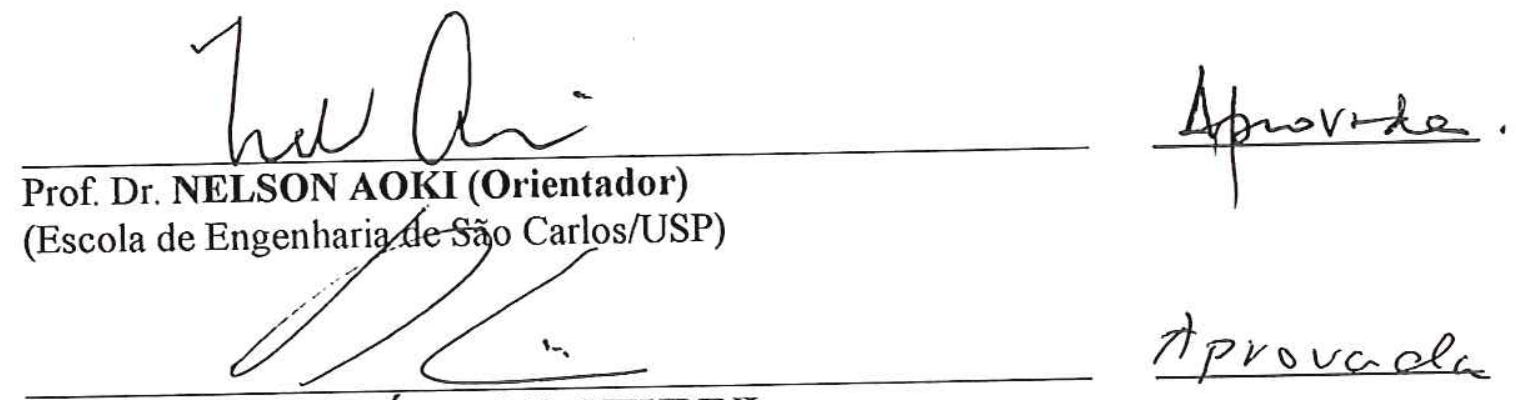

Prof. Tit. WILSON SÉRGIO VENTURINI

(Escola de Engenharia de São Carlos/USP)

Prof. DT MARCDS PEIGASPACHECO

(Universidade Estadual do Rio de Janeiro/UERJ)

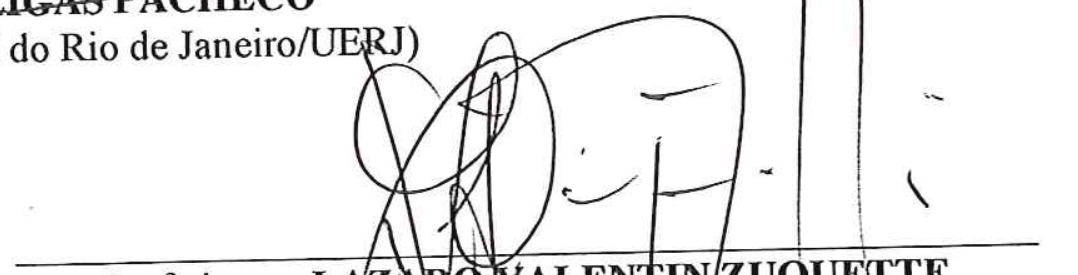

Prof. Assoc. LAZARQ Coordenador do Programã de Pós-Guaduação em Geotecnia

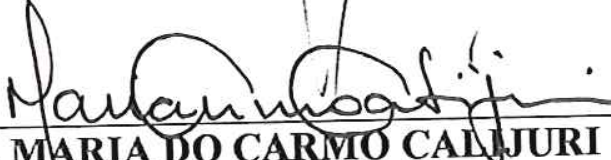

Profa. Assoc. MIARIA DO CARIMO CAINJURI

Presidente da Comissão de Pós-Graduação da EESC 
À Deus, pela oportunidade da vida Aos meus amados pais, José P. Silva e Geny Silva, meus exemplos de vida e à todos que de alguma forma estão presentes em minha vida. 


\section{AGRADECIMENTOS}

À Deus, pela graça que me concedeu de realizar este trabalho e à meu pai e à minha mãe, meus primeiros professores e meu porto seguro. Agradeço imensamente aos meus pais pelo apoio dedicado em todos os momentos de minha vida.

Ao Prof. Dr. Nelson Aoki, que com muita dedicação orientou esta dissertação, pela inestimável ajuda para que se tornasse realidade este trabalho. Pela confiança em mim depositada, pela cordialidade, amizade e pelo decisivo e incondicional apoio prestado no decorrer deste trabalho, meus sinceros agradecimentos.

À todos professores e amigos da Universidade Federal de Uberlândia, onde me graduei em Engenharia Civil, que muito contribuíram para tornarem realidade minhas aspirações, em especial à Núbia Saad e à Maria Elisa Borges Resende pelo apoio e amizade dedicados.

Aos amigos Luis Fernando Seixas, Jorge Avelar, Cláudio R. Santos, Márcio Constanzi, Aristotelina Silva, Darcília Ruani, Jeselay Reis, Indira Macambira, Isabella Chaves, e a todos os demais amigos e amigas do Departamento de Geotecnia, pela amizade e companheirismo.

À Universidade de São Paulo pelo mestrado realizado.

À todos os professores do Departamento de Geotecnia: Nelson Aoki, José Carlos A. Cintra, Orêncio Monje Vilar, João Batista Nogueira, Antenor B. Paraguassu, José Eduardo Rodrigues, Tarcísio Barreto Celestino, Airton Bortolucci, Benedito de Souza Bueno, Gene Stancati, Osni Pejon e Lázaro Valentin Zuquette, Edmundo Esquivel; que direta ou indiretamente colaboraram para o aprimoramento dos meus conhecimentos, meus sinceros agradecimentos.

Aos funcionários do Departamento de Geotecnia, Maristela Batissaco, Álvaro Nery, Herivelto M. Santos, Neiva M. Rosalis, por toda gentileza e pela inestimável colaboração.

Aos professores José Carlos A. Cintra e Maximiliano Malite, pelas sugestões apresentadas no exame de qualificação, agradeço pela gentil e cordial ajuda recebida.

À CAPES, agência financiadora que me concedeu a bolsa de estudos, meu muito obrigado.

E finalmente, à todos que contribuíram para que fosse possível a realização deste trabalho. 


$\begin{array}{ll}\text { "O dia mais belo? } & \text { Hoje. } \\ \text { A coisa mais fácil? } & \text { Errar. } \\ \text { O maior obstáculo? } & \text { O medo. } \\ \text { O maior erro? } & \text { O abandono. } \\ \text { A raiz de todos os males? } & \text { O egoismo. } \\ \text { A distração mais bela? } & \text { O trabalho. } \\ \text { A pior derrota? } & \text { O desânimo. } \\ \text { Os melhores professores? } & \text { As crianças. } \\ \text { A primeira necessidade? } & \text { Comunicar-se. } \\ \text { O que mais traz felicidade? } & \text { Ser útil aos demais. } \\ \text { O maior mistério? } & \text { A morte. } \\ \text { O pior defeito? } & \text { O mau humor. } \\ \text { A pessoa mais perigosa? } & \text { A mentirosa. } \\ \text { O pior sentimento? } & \text { O rancor. } \\ \text { O presente mais belo? } & \text { O perdão. } \\ \text { O mais imprescindível? } & \text { O lar. } \\ \text { A rota mais rápida? } & \text { O caminho certo. } \\ \text { A sensação mais agradável? } & \text { A paz interior. } \\ \text { A proteção mais efetiva? } & \text { O sorriso. } \\ \text { O melhor remédio? } & \text { O otimismo. } \\ \text { A maior satisfação? } & \text { O dever cumprido. } \\ \text { A força mais potente do mundo? A fé. } \\ \text { As pessoas mais necessárias? } & \text { Os pais. } \\ \text { A mais bela de todas as coisas? } & \text { O amor." }\end{array}$




\section{SUMÁRIO}

LISTA DE ABREVIATURAS E SIGLAS ................................................. i

LISTA DE SÍMBOLOS …...........................................................................

RESUMO

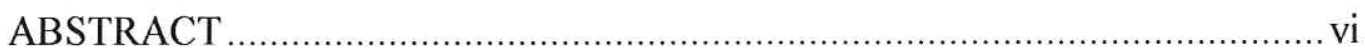

VOLUME I

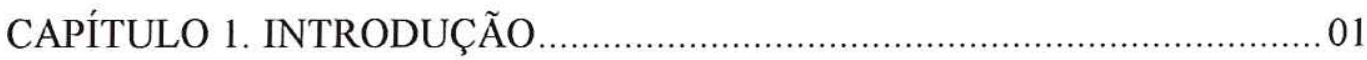

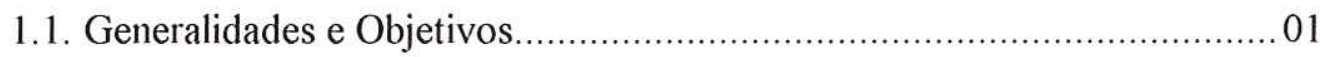

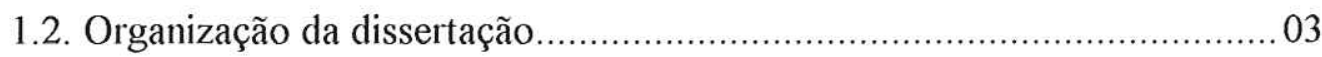

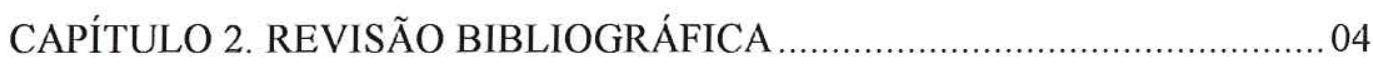

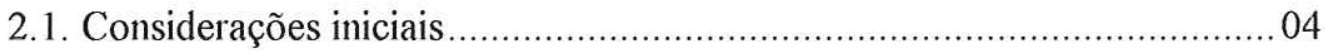

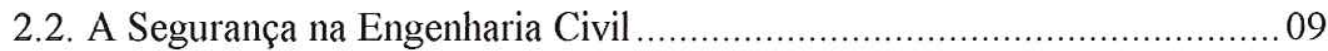

2.2.1. Considerações preliminares a respeito da Segurança .....................09

2.2.2. Avanços na introdução da Segurança na Engenharia Civil ............. 13

2.2.3. Revisão do conceito de Segurança .......................................... 16

2.3. A Segurança na Engenharia de Fundações ........................................... 18

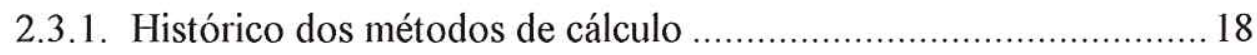

2.3.2. O Método das Cargas Admissíveis .................................................222

2.3.3. O Método dos Estados Limites..................................................... 24

2.3.3.1. Estados Limites - Conceitos básicos................................ 26

2.3.3.1.1. O Estado Limite Último ...................................227

2.3.3.1.2. O Estado Limite de Utilização ......................... 29

2.3.3.2. Valores Característicos e Valores de Cálculo ................... 31

2.3.3.3. Os Coeficientes Parciais de Segurança ............................. 33

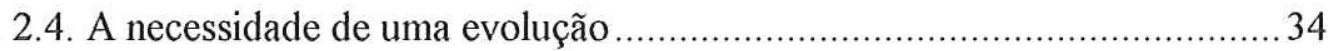

2.4.1. A NBR 6122/1996 e a atual conjuntura de projeto .......................34

2.4.2. As deficiências do Coeficiente de Segurança Global ..................... 42 
CAPÍTULO 3. CONFIABILIDADE DE SISTEMAS DE ENGENHARIA.........45

3.1. Confiabilidade de Sistemas ................................................................. 45

3.2. Análise e verificação da Confiabilidade .....................................................46

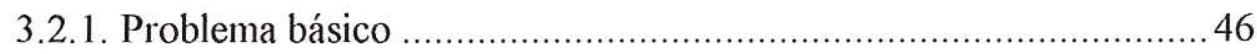

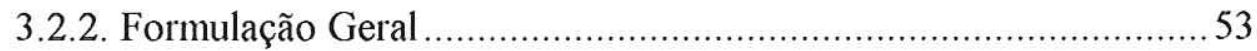

3.3. Formulação pelo Segundo Momento …................................................... 56

3.3.1. Funções Lineares de Desempenho.................................................58

3.3.2. Funções de Desempenho não Lineares ...................................... 70

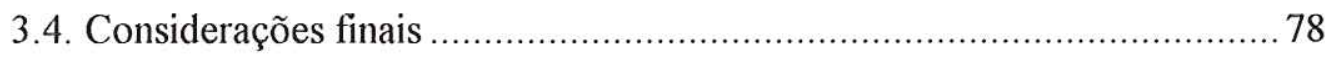

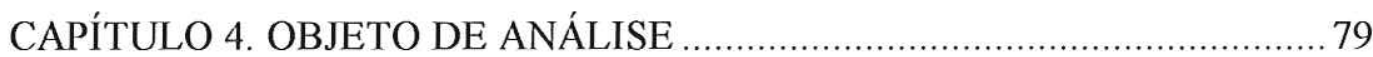

4.1. A Necessidade de rever conceitos na Engenharia de Fundações .............. 79

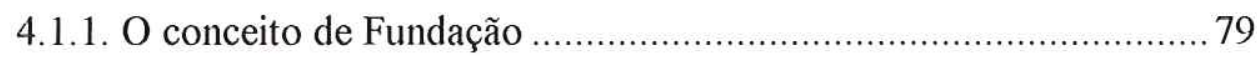

4.1.2. Equilíbrio estático de um Elemento Isolado de Fundação ..............85

4.2. Superfície Resistente - Objeto de Análise ............................................ 88

CAPÍTULO 5. AS INCERTEZAS NA ENGENHARIA DE FUNDAÇÕES ......91

5.1. A Complexidade de introduzir Segurança na Engenharia de Fundações...91

5.2. Variabilidade da Resistência................................................................. 93

5.3. Variabilidade da Solicitação ................................................................96

5.3.1. Ações e Solicitações ........................................................................ 96

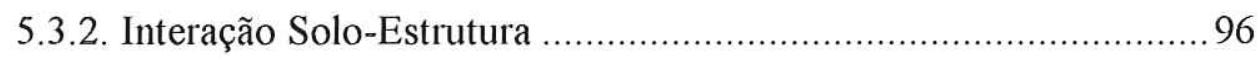

CAPÍTULO 6. CARGA ADMISSÍVEL - PROPOSTA...................................... 99

6.1. Carga Admissível baseada na Probabilidade de Ruína.............................99

6.2. Algumas considerações sobre a metodologia proposta .......................... 101

6.2.1. Probabilidade de Ruína aceitável .............................................. 102

6.2.2. Probabilidade de Ruína de um Elemento Isolado de Fundação ...... 104

6.2.3. Variáveis aleatórias: Resistência e Solicitação ............................... 106 


\section{CAPÍTULO 8. SEGURANÇA E CONFIABILIDADE DE FUNDAÇÕES ........ 113}

8.1. Provas de carga estática executadas em estacas tipo hélice contínua........ 115

8.1.1. Variabilidade da resistência ...................................................... 115

8.1.2. Análise de Segurança e Confiabilidade .......................................... 119

8.1.3. Comentários finais ..................................................................... 133

8.2. Fundação em estacas pré-moldadas cravadas na Formação Guabirotuba 136

8.2.1. Análise dos dados................................................................ 136

8.2.2. Análise de Segurança e Confiabilidade...................................... 143

8.2.2.1. Análise de todas as estacas em termos de tensões............. 144

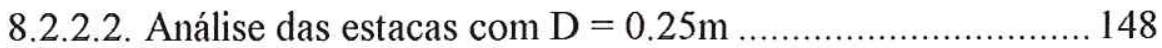

8.2.3. Comentários finais. ..................................................................... 153

8.3. Fundações em estacas centrifugadas de concreto armado ...................... 155

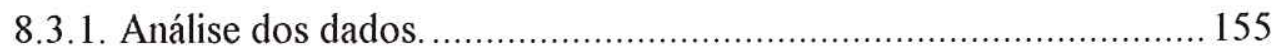

8.3.2. Análise de Segurança e Confiabilidade ........................................ 157

8.3.2.1. Carga admissível - "Resistência 1" e "Solicitação 1" ........ 158

8.3.2.2. Carga admissível - "Resistência 2" e "Solicitação 2" ........ 165

8.3.3. Comentários finais. ..................................................................... 168

8.4. Análise das fundações em estacas ômega executadas em Paulínia/SP ...... 171

8.4.1. Características Geotécnicas do Maciço de Solos ......................... 171

8.4.2. Projeto da Fundação .................................................................. 171

8.4.2.1. Elemento estrutural de fundação ................................... 171

8.4.2.2. Esforços solicitantes nas estacas ..................................... 172

8.4.3. Apresentação dos resultados dos ensaios realizados ..................... 173

8.4.4. Análise de todas as estacas em termos de tensões......................... 175

8.4.5. Comentários finais .................................................................... 176

8.5. Estacas pré-moldadas cravadas em Duque de Caxias/RJ ...................... 178

8.5.1. Características Geotécnicas do Maciço de Solos ........................... 178

8.5.2. Informações sobre o Projeto da Fundação...................................... 179

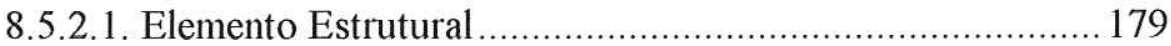

8.5.2.2. Esforços nas Estacas....................................................... 179

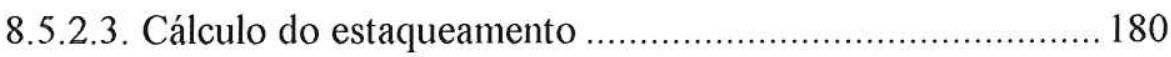


8.5.3. Apresentação das Análises

8.5.3.1. Ensaios realizados.

8.5.3.2. Análise de todas as estacas em termos de tensões.

8.5.3.3. Análise das estacas em termos de carga admissível

8.5.4. Comentários finais

8.6. Estacas metálicas cravadas na Formação Tremembé ................................ 188

8.6.1. Características Geotécnicas do Maciço de Solos. .......................... 188

8.6.2. Informações a respeito do elemento estrutural de fundação........... 188

8.6.3. Análise dos dados dos ensaios realizados ................................ 190

8.6.3.1. Investigação geotécnica ................................................. 190

8.6.3.2. Provas de carga dinâmica de energia crescente................. 191

8.6.3.3. Resistências previstas...................................................... 192

8.6.3.4. Resistências previstas x medidas - Efeito executivo ........... 195

8.6.4. Análise de Segurança e Confiabilidade ......................................... 198

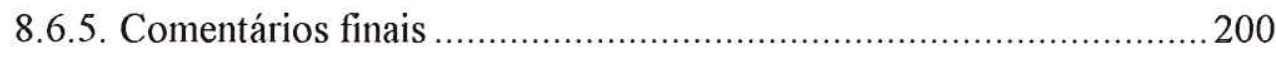

8.7. Fundação em estacas pré-moldadas cravadas no Rio de Janeiro. .............201

8.7.1. Características Geotécnicas do Maciço de Solos .......................... 201

8.7.2. Informações a respeito do elemento estrutural de fundação............201

8.7.3. Análise dos resultados dos ensaios realizados............................... 202

8.7.3.1. Investigação Geotécnica - Sondagem à percussão (SPT).. 202

8.7.3.2. Provas de carga dinâmica de energia crescente................. 204

8.7.3.2.1. Ruptura dos sistemas isolados de fundação ...... 204

8.7.3.2.2. Mobilização da resistência estática ..................205

8.7.3.2.3. Resistência estática lateral unitária ..................208

8.7.3.2.4. Resistência estática lateral unitária acumulada .. 210

8.7.4. Análise de Segurança e Confiabilidade ....................................... 210

8.7.4.1. Análise de todas as estacas em termos de tensões.............2 211

8.7.4.2. Análise dos dois grupos de estacas com mesmo diâmetro. 213

8.7.4.2.1. Análise das estacas com $\mathrm{D}=0.50 \mathrm{~m} \ldots \ldots \ldots \ldots \ldots . .214$

8.7.4.2.2. Análise das estacas com $\mathrm{D}=0.42 \mathrm{~m} \ldots \ldots \ldots \ldots \ldots .215$

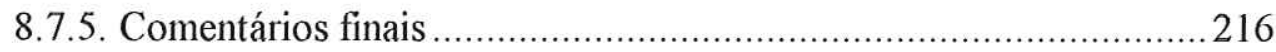


CAPÍTULO 10. CONSIDERAÇÕES FINAIS 221

10.1. Conclusões. 221

10.2. Sugestões para pesquisas futuras 223

REFERÊNCIAS BIBLIOGRÁFICAS 226

VOLUME II

APÊNDICE A. Fundações em estacas tipo hélice contínua. 01

APÊNDICE B. Estacas pré-moldadas cravadas na Formação Guabirotuba .90

APÊNDICE C. Fundações em estacas pré-moldadas centrifugadas 130

APÊNDICE D. Estacas ômega executadas em Paulínia/SP. 188

APÊNDICE E. Estacas de concreto protendido cravadas em Caxias/RJ 202

APÊNDICE F. Estacas metálicas cravadas na Formação Tremembé 216

APÊNDICE G. Fundação em estacas pré-moldadas de concreto 274

ANEXO A. Resumo teórico sobre Estatística e Probabilidade 322

ANEXO B. Multiplicadores de Lagrange 344

ANEXO C. Série de Taylor 346

ANEXO D. Probabilidade de falha segundo Ang \& Tang (1984). 350

ANEXO E. Relação: Coeficiente de Segurança e Índice de Confiabilidade 354 
LISTA DE ABREVIATURAS E SIGLAS

$\begin{array}{ll}\text { CASE } & \text { Case Institute of Technology. } \\ \text { CAPWAP } & \text { Case Pile Wave Analysis Program. } \\ \text { CAPWAPC } & \text { Case Pile Wave Analysis Program Continuous Version. } \\ \text { CEB } & \text { Comitê Europeu de Concreto. } \\ \text { CPT } & \text { Cone Penetration Test. } \\ \text { DIET } & \text { Dynamic Increasing Energy Test. } \\ \text { FORM } & \text { First Order Reliability Method. } \\ \text { FOSM } & \text { Second Moment First Order. } \\ \text { ISE } & \text { Interação Solo-Estrutura. } \\ \text { ISO } & \text { International Standards Organization. } \\ \text { LRFD } & \text { Load and Resistance Factor Design. } \\ \text { LSD } & \text { Limit States Design. } \\ \text { MEC } & \text { Mercado Comum Europeu. } \\ \text { SLS } & \text { Serviceability Limit State. } \\ \text { SPT } & \text { Standard Penetration Test. } \\ \text { PDA } & \text { Pile Drying Analyzer. } \\ \text { ULS } & \text { Ultimate Limit State. } \\ \text { WSD } & \text { Working Stress Design. }\end{array}$




\section{LISTA DE SÍMBOLOS}

\section{Letras romanas maiúsculas}
A Área da seção transversal da estaca.
CV Coeficiente de variação.
CS Coeficiente de segurança global.
D Diâmetro da estaca.
$\mathrm{D}_{\mathrm{F}} \quad$ Domínio de falha.
$\mathrm{D}_{\mathrm{S}} \quad$ Domínio de segurança.

DMX Máximo deslocamento da estaca obtido por instrumentação.

E Espessura da parede da estaca com seção circular vazada.

F Função de distribuição acumulada.

$\bar{G} \quad$ Vetor gradiente.

L Comprimento da estaca.

N Distribuição normal.

$\mathrm{N}_{\text {SPT }} \quad$ Valor do SPT ao longo do fuste da estaca.

P Probabilidade de ocorrência de um evento qualquer.

$\mathrm{P}_{\mathrm{adm}} \quad$ Carga admissível do estaqueamento.

R Resistência.

$\mathrm{R}_{\mathrm{t}} \quad$ Resistência total (estática + dinâmica).

$\mathrm{R}_{\mathrm{d}} \quad$ Resistência dinâmica.

$\mathrm{R}_{\mathrm{u}} \quad$ Máxima resistência estática mobilizada.

$\mathrm{R}_{\mathrm{p}} \quad$ Resistência estática de ponta.

$\mathrm{R}_{1} \quad$ Resistência estática de atrito.

$\mathrm{R}_{\mathrm{m}} \quad$ Resistência média.

$\mathrm{R}_{\mathrm{k}} \quad$ Resistência característica.

S Solicitação.

$\mathrm{S}_{\mathrm{m}} \quad$ Solicitação média.

$\mathrm{S}_{\text {máx }} \quad$ Solicitação máxima.

$\mathrm{S}_{\mathrm{k}} \quad$ Solicitação característica

T Transformação isoprobabilística.

$\mathrm{T} \quad$ Intervalo de tempo máximo previsto para a vida útil da estrutura. 


$\begin{array}{ll}\bar{X} & \text { Vetor de variáveis aleatórias. } \\ X & \text { Variável aleatória resistência. } \\ X^{\prime} & \text { Variável aleatória resistência no espaço reduzido. } \\ \text { Y } & \text { Variável aleatória solicitação. } \\ Y^{\prime} & \text { Variável aleatória solicitação no espaço reduzido. } \\ Z & \text { Função margem de segurança no espaço fisico. } \\ Z^{\prime} & \text { Função margem de segurança no espaço reduzido. }\end{array}$

\section{Letras romanas minúsculas}

Coeficiente de forma da curva de Van der Veen.

b

Intercepto no eixo dos recalques da curva de Van der Veen.

c

Coesão do solo.

$\mathrm{f}$

Função de densidade de probabilidade.

$\mathrm{f}_{\mathrm{cd}}$ Resistência à compressão do concreto de cálculo.

$\mathrm{f}_{\mathrm{ck}}$ Resistência característica do concreto à compressão.

$\mathrm{f}_{\mathrm{cm}} \quad$ Resistência média do concreto à compressão.

$\mathrm{f}_{\mathrm{y}} \quad$ Resistência do aço.

n Número de variáveis aleatórias.

$\mathrm{p}_{\mathrm{F}} \quad$ Probabilidade de falha.

$\mathrm{p}_{\mathrm{R}} \quad$ Probabilidade de ruína.

k Parcela elástica do deslocamento na seção (repique elástico)

s $\quad$ Parcela permanente do deslocamento ou penetração no solo (nega)

$\mathrm{t}$ Instante de tempo qualquer maior que $\mathrm{t}_{0}$.

$\mathrm{x} \quad$ Valor específico da variável aleatória $\mathrm{X}$.

x' Valor específico da variável aleatória $X^{\prime}$.

y Valor específico da variável aleatória $Y$.

y' Valor específico da variável aleatória $Y^{\prime}$.

z Valor específico da variável aleatória Z

z' Valor específico da variável aleatória Z'.

\section{Letras gregas maiúsculas}

$\Phi$ Distribuição normal padrão.

$\mathfrak{R} \quad$ Espaço dos números reais. 


\section{Letras gregas minúsculas}

$\beta \quad$ Índice de Confiabilidade.

$\delta \quad$ Variância.

$\phi \quad$ Ângulo de atrito.

$\mu \quad$ Média.

$v \quad$ Direção de Integração.

$\rho \quad$ Recalque.

$\sigma \quad$ Desvio padrão. 


\section{RESUMO}

SILVA, F. C. (2003). Análise de Segurança e Confiabilidade de Fundações Profundas em Estacas. Dissertação (Mestrado) - Escola de Engenharia de São Carlos, Universidade de São Paulo, São Carlos, 2003.

A norma Brasileira NBR 6122/1996 - Projeto e Execução de Fundações utiliza o conceito de coeficiente de segurança global e parcial na verificação da segurança de fundações. Esta dissertação ressalta que essa verificação, utilizada na prática, é necessária, para que se atenda às exigências da norma, porém, não é suficiente para garantir a segurança de uma fundação. Pois, qualquer medida de segurança deve estar associada a uma determinada probabilidade de ruína. Neste contexto, apresenta-se nessa dissertação uma metodologia de verificação da segurança na qual, a escolha da carga admissível de um estaqueamento é baseada na probabilidade de ruína de um elemento isolado de fundação, e a aplicação dessa metodologia em diversas fundações executadas em diferentes regiões do país.

Palavras-Chave: carga admissível; coeficiente de segurança; índice de confiabilidade; probabilidade de ruína; fundação profunda; estaca. 


\begin{abstract}
SILVA, F. C. (2003). Analysis of Safety and Reliability of Deep Foundations in Pile. Dissertação (Mestrado) - Escola de Engenharia de São Carlos, Universidade de São Paulo, São Carlos, 2003.

The Brazilian code NBR 6122/1996 for Foundation Design and Execution is based on the concept of Limit States Design (LSD) and on the traditional Working Stress Design (WSD). This paper shows that this approach, as usually carry out in the foundation engineering practice, although being necessary, is not enough to assure a safe foundation, once any safety measurement should be associated to a given probability of failure. Therefore, in the proposed methodology, the safety verification of the piling allowable load is based on the probability of failure of an isolated foundation element.
\end{abstract}

Keywords: allowable load; safety factor; reliability index; probability of failure; deep foundation; pile. 
CApítulo

INTRODUÇÃO

\subsection{Generalidades e Objetivos}

Segurança em Engenharia Civil é um tema atual, tendo em vista, a crescente necessidade de projetos econômicos e que garantam um desempenho adequado. Especialmente na Engenharia de Fundações, o tema segurança, é ainda hoje, apesar das normas existentes, um tema de muita discussão e polêmica. Pois, a norma brasileira NBR 6122/1996 dá margem a interpretações que podem, dependendo da situação, levar a situações ambíguas.

Neste contexto, esta dissertação visa abordar o tema Segurança de Fundações em estacas, de forma a contribuir para a redução das dificuldades encontradas na execução de projetos de fundações com níveis de segurança adequados. Pois, na Engenharia de Fundações devido à responsabilidade envolvida e o custo proporcionalmente limitado das fundações, a tendência é, geralmente, pecar pelo excesso de conservadorismo, ou seja, subestimar a capacidade de carga das fundações. Isso ocorre devido a uma série de indefinições e incongruências encontradas nas normas de projeto de fundações, seja no Brasil, seja no exterior, aliadas a uma prática de projeto de fundações, muitas vezes, empírica e pouco racional.

Sendo assim, o principal objetivo deste trabalho é estabelecer, através de uma avaliação estatística e de uma abordagem probabilística, uma metodologia racional de 
projeto e avaliação da segurança de fundações em estacas, que considerem as incertezas e as variabilidades existentes de forma a projetar fundações com segurança adequada.

Na presente pesquisa, é proposta uma nova metodologia de projeto de fundações baseada numa abordagem probabilística, que visa contemplar as complexidades do comportamento geológico-geotécnico e dos materiais estruturais, reconhecendo as limitações inerentes aos modelos e às teorias.

O interesse principal é analisar a aleatoriedade das variáveis envolvidas nos modelos empregados no estudo das fundações e introduzir o estudo da confiabilidade, que atualmente ainda é utilizado aquém de suas possibilidades, especialmente no ramo da Engenharia Civil Geotécnica e de Fundações, na determinação, por exemplo, da probabilidade de uma determinada fundação atingir a ruína.

A validação da metodologia proposta será baseada em dados reais de obras (ensaios in situ e provas de carga estáticas e dinâmicas), com os quais será possível mostrar a importância do uso dos conceitos probabilísticos nos projetos de fundações ressaltando as suas aplicações práticas. Projetos estes, que implicam em grande responsabilidade por parte dos projetistas e da equipe responsável pela execução, devido às graves conseqüências que podem advir de um erro no projeto.

Esta pesquisa parte da idéia de que para elaboração de projetos de fundações realmente eficientes faz-se necessário uma maior compreensão das incertezas e variabilidades existentes, e neste aspecto, o trabalho apresentado pretende oferecer uma singela contribuição.

Destaca-se que a realização, no futuro, de estudos mais detalhados sobre Segurança em Fundações deverão propiciar o embasamento científico necessário para uma melhor compreensão do comportamento das mesmas, conduzindo à otimização do projeto, atualmente ainda muito norteado por procedimentos empíricos.

Neste contexto, esta pesquisa, visa contribuir para o aperfeiçoamento da análise de Segurança na Engenharia de Fundações. Espera-se que as conclusões apresentadas nesta dissertação tenham repercussão direta sobre os procedimentos referentes ao projeto e dimensionamento de fundações profundas no país e que estas sirvam de subsídio para pesquisas futuras. 


\subsection{Organização da dissertação}

A presente dissertação consta de dois volumes. Optou-se pela elaboração de dois volumes para maior facilidade de análise. O primeiro volume está subdividido em dez capítulos e apresenta todo o trabalho desenvolvido, enquanto que o segundo volume apresenta os apêndices e anexos necessários à compreensão da mesma.

O Capítulo 1 apresenta uma introdução ao tema abordado e trata dos objetivos e organização da dissertação.

O Capítulo 2 apresenta uma revisão bibliográfica comentada dos aspectos ligados ao tema central.

No Capítulo 3 são apresentados os princípios básicos a respeito da Teoria da Confiabilidade necessários ao desenvolvimento dessa dissertação.

O Capítulo 4 apresenta, em linhas gerais, qual será o objeto de análise dos estudos realizados nesta dissertação.

O Capítulo 5 apresenta algumas das inúmeras incertezas relacionadas ao projeto de uma fundação.

No Capítulo 6 é apresentada uma nova formulação para o cálculo da carga admissível de uma fundação com base na probabilidade de ruína.

O Capítulo 7 apresenta a metodologia utilizada na realização das análises desenvolvidas e comenta sobre os dados utilizados nas análises.

No Capítulo 8 são apresentadas todas as análises realizadas. Este capítulo traz os resultados do estudo de 25 fundações, com base nos resultados de 201 provas de carga realizadas (estática e dinâmica), e os comentários relativos a esses resultados.

O Capítulo 9 apresenta uma sucinta discussão sobre os resultados obtidos nas análises desenvolvidas no Capítulo 8 .

O Capítulo 10 apresenta as conclusões e as sugestões para futuras pesquisas. 


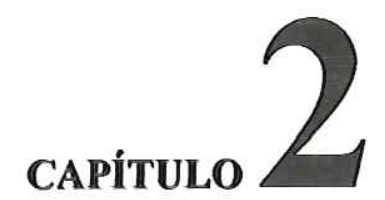

REVISÃO BIBLIOGRÁFICA

\subsection{Considerações iniciais}

Essas considerações iniciais têm como objetivo apresentar uma visão geral do contexto histórico responsável pela motivação da escolha do tema dessa dissertação. Motivação esta, que se baseia nas dificuldades encontradas durante a realização de projetos de fundações que possuam níveis de segurança adequados e que sejam, ao mesmo tempo, economicamente viáveis.

A atual filosofia de projeto e execução de fundações basea-se na crença científica que esteve vigente até o início do século $\mathrm{XX}$, fundamentada no determinismo científico. Pois, a maioria das inovações e desenvolvimentos importantes que ocorreram nos últimos anos na Engenharia de Fundações ainda não considera, de modo satisfatório, a natureza aleatória das várias variáveis envolvidas nos projetos. Apesar disso, o determinismo reinante vem sendo gradativamente substituído pela visão sistêmica e probabilista que norteia a ciência atual.

No contexto tradicional, a Engenharia de Fundações é o ramo da Engenharia Civil que se dedica ao projeto e à execução da fundação de uma obra, ou melhor, dos elementos estruturais de fundação de uma obra, sendo o seu escopo projetar e executar fundações otimizadas, que sejam ao mesmo tempo seguras, econômicas e duráveis, o que segundo Velloso \& Lopes (1996), requer conhecimentos de Geotecnia (ciência que 
abrange a Mecânica dos Solos, a Mecânica das Rochas, e a Geologia de Engenharia) e de Engenharia Estrutural (Análise estrutural e dimensionamento de Estruturas em concreto armado, concreto protendido, em aço e em madeira).

A Engenharia Civil sempre procurou acompanhar a evolução científica, mas a dificuldade de um conhecimento profundo e abrangente em todo o seu campo de atuação exigiu a sua divisão em áreas especificas, as quais não tiveram um desenvolvimento paralelo, algumas evoluindo mais rapidamente que outras. Neste contexto, um dos campos básicos da Engenharia Civil que por último se desenvolveu foi a Mecânica dos Solos que estuda o comportamento do solo sob o aspecto da Engenharia Civil (BUENO \& VILAR, 1984). Assim, para o engenheiro civil, a necessidade do conhecimento das propriedades do solo vai além do seu aproveitamento como material de construção, pois o solo exerce um papel especial nas obras de engenharia, porquanto cabe a ele absorver as cargas aplicadas na sua superficie, e mesmo interagir com obras implantadas no seu interior. Entretanto, durante muitos séculos, o aproveitamento do solo como elemento de fundação e material de construção, seguiu dentro de um empirismo racional e da observação de métodos empregados com êxito em obras similares (BUENO \& VILAR, 1984).

Segundo Tschebotarioff (1973), os inúmeros estudos sobre solos realizados com finalidades alheias à Engenharia Civil não puderam ter seus resultados diretamente aplicados aos problemas de fundações. Pois, é o estudo sistemático de comportamento dos solos submetidos a tensões, que constitui o principal interesse dos engenheiros civis e, embora houvesse estudos exaustivos sobre solos conduzidos por geólogos e agrônomos, estes naturalmente visavam as suas próprias especialidades.

Logo, os engenheiros civis viram-se, desse modo, compelidos a resolver seus próprios problemas sobre solos e um dos primeiros esforços nesse sentido foi feito por Coulomb em 1776, que determinou os empuxos de terra em muros de arrimo (TSCHEBOTARIOFF, 1973). Entretanto, no início do século XX, graças ao avanço técnico alcançado pela Engenharia Civil, principalmente na área da Teoria das Estruturas, houve a necessidade de se estudar a Mecânica dos Solos de maneira mais sistemática, pois as catástrofes ocorridas em obras projetadas com requinte em cálculo estrutural tiveram, quase sempre, como causa o mau dimensionamento das fundações (BUENO \& VILAR, 1984). 
Um avanço particularmente importante foi o trabalho desenvolvido por Karl Terzaghi, que em 1923 publicou uma solução rigorosamente matemática da velocidade de adensamento de argilas submetidas a pressões (TSCHEBOTARIOFF, 1973).

Segundo Tschebotarioff (1973) e Bueno \& Vilar (1984), a Mecânica dos Solos surgiu como ciência em 1925, quando Terzaghi publicou um de seus livros intitulado "Erdbaumechanik Auf do denphysikalisher Grundlage", que pode ser traduzido como "Mecânica das Construções de Terra baseada na Física dos Solos", onde a expressão "Mecânica dos Solos" foi empregada pela primeira vez.

Atualmente, a Mecânica dos Solos situa-se dentro de uma área mais ampla denominada Geotecnia, que tem como objetivo, estudar as propriedades físicas dos materiais geológicos (solos e rochas) e suas aplicações em obras de Engenharia Civil, quer como material de construção, quer como elemento de fundação (BUENO \& VILAR, 1984).

Porém, mesmo atualmente, com os métodos mais modernos de reconhecimento e ensaio de solos, ainda não é possível obter informações precisas sobre as suas reais propriedades e comportamento e, provavelmente, jamais poderão fazê-lo. Isso faz com que a Engenharia de Fundações conserve sua característica de arte, permanecendo a Mecânica dos Solos na posição de sua mais importante ciência auxiliar (TSCHEBOTARIOFF, 1973).

Dessa forma, é fácil compreender a definição de que a Engenharia é uma arte de aplicar conhecimentos científicos e empíricos e certas habilitações específicas à criação de estruturas, dispositivos e processos que se utilizam para converter recursos naturais em formas adequadas ao atendimento das necessidades humanas (FERREIRA, 1986).

Nesta definição de Engenharia está implícita um pouco da sua evolução histórica. Pois, a Engenharia Civil surgiu e se desenvolveu em função do conhecimento e das necessidades humanas em cada época de sua história, e como estes, vem se aprimorando gradativamente ao longo do tempo. Antes do desenvolvimento do que conhecemos hoje pelo nome de "ciência", a Engenharia Civil era baseada no conhecimento empírico adquirido através da experiência, e por isso, ganhou a conotação de arte. Porém, com o advento da ciência, a Engenharia começou a elaborar métodos mais racionais de projeto e de execução possibilitando seu contínuo desenvolvimento.

Nesse sentido, a Mecânica dos Solos foi estabelecida com o propósito de estudar o comportamento dos solos, segundo formulações teóricas de embasamento científico. 
Procurou-se, a partir de bases físicas, de modelos reológicos e de observações de campo, elaborar teorias explicativas de seu comportamento (BUENO \& VILAR, 1984).

Com o desenvolvimento da análise experimental, foram sendo obtidas definições cada vez mais completas e claras do comportamento reológico dos materiais e dos seus correspondentes critérios de resistência, com a conseqüente possibilidade da verificação experimental das teorias, completando e dirigindo tal desenvolvimento até os dias atuais (BERNARDO, 1999). Mas, todas as teorias desenvolvidas baseiam-se em leis deterministas, ou seja, em leis onde, estabelecidas as condições iniciais, essas determinam o resultado final (SÁLES et al., 2000).

Logo, a prática de fundações exibe a idéia determinista presente no início da era científica, quando Newton na tentativa de explicar a atração existente entre os planetas e as massas terrestres estabeleceu a Idéia das Causas, segundo a qual, tudo no universo poderia ser explicado pelo princípio de Causa e Efeito (BRONOWSKI, 1977).

Mas, antes da Idéia das Causas, a idéia que reinava era a Idéia da Ordem. A Idéia da Ordem era a estrutura do pensamento da Idade Média, que baseada nos pensamentos de Aristóteles acerca da natureza da matéria, ordenava o mundo em diferentes categorias de coisas terrenas (aquáticas, aéreas e ígneas) e acreditava que o universo era animado pelo conflito entre esses elementos na busca pelo seu lugar estável e legítimo (BRONOWSKI, 1977).

A Idéia das Causas foi um dos subprodutos da Revolução Científica do século XVII, que ocorreu devido ao espírito inquiridor do Renascimento que levou astrônomos como Copérnico (473-543), Kepler (1571-1630) e Galileu (1564-1642) a descartar a noção medieval da Terra como o centro do universo, proposta por Ptolomeu. Porém, todos eles não foram além da descrição matemática das trajetórias dos planetas, apesar de todos indagar sobre o princípio que pudesse explicar a atração existente entre os planetas e as massas terrestres (BRONOWSKI, 1977).

Foi Newton, porém, que o formulou, ao estabelecer que o movimento das massas, quer seja entre uma maçã e a terra ou entre a lua, a terra, o sol e os planetas é produzido por forças gravitacionais que as atraem e que são essas forças que mantêm os planetas em gravitação. Em suas obras Principia e Opticks, Newton mostra, diferentemente dos demais cientistas, a união do racional com o empírico, dos fatos com os pensamentos, da teoria com a experiência prática, sendo ele o maior representante do que se chamou de Era Científica (BRONOWSKI, 1977).

Porém, a Idéia das Causas não conseguiu explicar todos os fenômenos da 
ciência, gerando muita discussão. É neste contexto que surge Einstein, que descobriu a falha da teoria newtoniana da gravidade, mostrando com a sua física relativista que o tempo e o espaço estão inextricavelmente interligados e são aspectos de uma única realidade, acrescentando uma nova dificuldade à definição de causalidade (BRONOWSKI, 1977).

Em 1900, Max Plank deu o passo fundamental para a criação da Física Quântica ao descobrir que a energia, assim como a matéria não é um contínuo. Com a Física Quântica, campo em que Einstein também promoveu notáveis progressos, surgem idéias que não se harmonizavam com o clássico mecanismo das partículas, pois não havia como descrever o passado e o futuro dessas ínfimas partículas e fenômenos, de sorte que pareçam completamente determinados. Isso foi estabelecido num princípio formal em 1927 pelo físico alemão Heisenberg e foi-lhe dado o nome de "Princípio da Incerteza". Heisenberg mostrou que toda descrição da natureza contém determinada incerteza, ou seja, que não se pode descrever a natureza como um rígido mecanismo de causas e efeitos (BRONOWSKI, 1977).

Com o princípio de incerteza, tem-se o surgimento da Idéia do Acaso. A ciência moderna avança em direção a essa idéia, onde não se usa outro princípio além do princípio da previsão, com a máxima segurança possível, mas não mais do que a possível. Isto é, idealiza o futuro desde o início, não como completamente determinado, mas como determinado dentro de uma área definida de incerteza (BRONOWSKI, 1977).

O propósito da ciência sempre foi descrever o mundo numa linguagem ou esquema que permita prever, na medida do possível, o seu comportamento futuro. Com este propósito, a historia da ciência foi marcada por três idéias principais, que foram, cada uma por seu turno, centrais na história da ciência ocidental: a Idéia da Ordem, a Idéia das Causas e a Idéia do Acaso (BRONOWSKI, 1977).

Entretanto, deve-se observar que a ciência não é estática, mais sim um mecanismo em contínua autocorreção que modifica nossos valores de dois modos: injeta novas idéias na cultura tradicional e sujeita-a a pressão da mudança técnica, até converter imperceptivelmente toda a base da nossa cultura (BRONOWSKI, 1977).

A Idéia do Acaso é relativamente nova e pouco familiar. Não estamos habituados a usá-la. Por isso, não parece ter o cunho incisivo das simples leis de causa e efeito. Parece que nos encontramos na terra do "às vezes" e do "porventura", quando esperávamos continuar a viver com os "sempre" e a "certeza". Porém, acostumar-nos- 
emos às novas idéias tão logo que a tal nos dispusermos e a tal formos compelidos (BRONOWSKI, 1977).

Os modelos matemáticos, os de simulação, assim como os modelos de laboratórios usados em Engenharia são representações idealizadas da realidade, sendo muitas vezes, representações imperfeitas do universo real. Sendo assim, o projeto e a análise da engenharia exige a resolução de incertezas (BERNARDO, 1999).

Nos problemas geotécnicos de ordem prática, o engenheiro civil deve ter consciência das limitações das teorias utilizadas, e nunca esperar o valor exato nas grandezas obtidas, senão uma ordem de grandeza. Logo, embora as teorias determinísticas se prestem melhor a elaboração de doutrinas, pois sendo de fácil apreensão, fornecem fundamentos racionais para a explicação de fenômenos observados, a heterogeneidade dos solos com propriedades variáveis, de ponto a ponto, tem conduzido ao uso acentuado de teorias probabilísticas (BUENO \& VILAR, 1984).

Partindo dessas idéias, apresenta-se esta dissertação como uma pequena contribuição onde se pretende estudar as diversas variabilidades e incertezas inerentes à prática da Engenharia Civil, e mais precisamente da Engenharia de Fundações, fazendo uso das idéias presentes na ciência atual, com o intuito de contribuir, de alguma forma, na análise da Segurança e Confiabilidade, introduzindo conceitos probabilísticos e estatísticos ao projeto de Fundações.

\subsection{A Segurança na Engenharia Civil}

\subsubsection{Considerações preliminares a respeito da Segurança}

No projeto de uma estrutura deve existir a preocupação de que a mesma desempenhe as funções a que se destina com o máximo de eficiência. Para assegurar a eficiência de uma estrutura, deve-se buscar um projeto econômico, mas que permita que a estrutura tenha condições de segurança, o que em síntese significa apresentar-se resistente, estável e duradoura (SÁLES et al., 2000). Logo, os principais objetivos de um projeto de engenharia são: segurança, funcionalidade e economia (OLIVEIRA, 1998; ANG, 1975; LEGGET, 1979).

Os conceitos básicos de segurança em estruturas em geral, abrangem estudos sobre as ações, a vida útil, o estado de desempenho e a segurança propriamente dita, e costumam ter dois aspectos que, algumas vezes, costumam ser confundidos: o aspecto 
qualitativo e o aspecto quantitativo. No entanto, é possível perceber que existe uma diferença bastante nítida entre eles (OLIVEIRA, 1998; SÁLES et al., 2000). O primeiro aspecto, o qualitativo, aplica-se quando se quer definir se uma determinada estrutura possui ou não segurança, enquanto o segundo aspecto, o quantitativo, é bem mais complexo, por ter como objetivo quantificar a segurança, tentar mensurá-la, ou seja, estabelecer um número que sirva como medida da segurança existente (SÁLES et al., 2000; WHITMAN, 1984).

Analisando a segurança estrutural sob o aspecto qualitativo, diz-se que uma estrutura segura, é aquela que possui condições de suportar, ilesa, todas as ações que vierem a solicitá-la, em condições normais de utilização, desde a fase de sua construção até o final da vida útil para a qual foi projetada, não apresentando, falsos sinais de alarme sob ações previstas, e os apresentando sob ações imprevistas. Entende-se como ações, as causas externas capazes de produzirem esforços internos e deformações na estrutura. Logo, durante sua vida útil, as estruturas não devem apresentar falhas, que impeçam ou mesmo prejudiquem a utilização para a qual foram concebidas e sim, preservar às suas características de projeto, sua integridade e sua funcionalidade, a um custo razoável de manutenção (FERREIRA \& CUNHA, 2000; OLIVEIRA, 1998; SÁLES et al., 2000).

Quanto ao segundo aspecto, o quantitativo, a segurança em estruturas compõe um problema complexo, e para sua melhor compreensão será feita uma analogia. Imagine o projeto estrutural de uma obra como um experimento, no qual seu universo comporta-se sob total controle. Ou seja, é possível determinar, com absoluta precisão, as máximas solicitações que a estrutura experimentará e a sua real capacidade resistente. Logo, será possível projetar a estrutura de tal forma que ela estará, exatamente, no limite entre a situação em que ela pode suportar a solicitação e a situação onde ela falha, com a total certeza de que a situação limite não será ultrapassada. Entretanto, a realidade apresenta-se muito diferente. (BERNARDO, 1999; DITLEVSEN, 1997).

Em nenhum projeto estrutural, existe o conhecimento completo de todas as informações necessárias à sua realização, pois são inúmeras as incertezas e as variações existentes, tanto nas solicitações, quanto na capacidade resistente do sistema (por exemplo: a variabilidade das características resistentes dos materiais, os inevitáveis erros, o não cumprimento das especificações de projeto, as diferenças entre o comportamento real da estrutura e o previsto pelos modelos de análise, etc.) (OLIVEIRA, 1998). É neste contexto que surge o problema de segurança: "Como se 
deve proceder na realização de um projeto estrutural para que este conduza a construções seguras?".

A primeira tentativa de solucionar esse problema foi estabelecer o que se denomina de margem de segurança, que consiste em adotar valores um pouco "distantes" dos valores reais de resistência e de solicitação, de forma a considerar as incertezas existentes sobre estes, no intuito de se evitar uma possível falha. Surge então a seguinte questão: "Quanto maior deve ser adotado o valor da solicitação ou quanto menor deve ser adotada a capacidade resistente do sistema, para que se possa garantir que a estrutura não falhará em serviço, ou seja, para que a situação limite não seja ultrapassada ?". A diferença entre esses dois valores é a denominada margem de segurança (BERNARDO, 1999; DITLEVSEN \& MADSEN, 1996).

Logo, os projetos sempre foram realizados sob condições de incertezas quanto às ações e às resistências e, por isso, o critério básico de qualquer projeto, independente do método ou filosofia adotada, é o de que a capacidade resistente do sistema deve exceder às solicitações com uma margem aceitável de segurança. Por isso, as estruturas sempre foram projetadas para terem uma resistência superior às solicitações esperadas. Assim, as duas maiores causas de mau funcionamento estrutural são aquelas quantificáveis e aquelas devidas a causas irracionais como erro humano. As causas quantificáveis são as coincidências de resistência inferior às solicitações atuantes, sendo este o domínio das normas de cálculo estrutural. Elas afetam os valores dos coeficientes que fornecem os níveis de segurança, como por exemplo: os coeficientes de segurança, os coeficientes de ponderação das ações e das resistências (BERNARDO, 1999; OLIVEIRA, 1998).

Para prever o desempenho estrutural e introduzir segurança ao seu projeto, foram desenvolvidas várias filosofias e métodos de projeto que não permaneceram estagnados, mas tem mudado e evoluído com o passar dos anos, em resposta a um crescente aumento do conhecimento, às maiores exigências sociais, aos avanços da tecnologia, e a uma maior diversidade de estruturas. Sendo que, todas essas mudanças exigiram uma crescente estruturação da informação, isto é, análises mais racionais e a descrição das experiências, que permitam a tomada de decisões ótimas. Porém, estas mudanças devem sempre ter como base à experiência anterior acumulada na avaliação da segurança (BERNARDO, 1999; OLIVEIRA, 1998; BECKER, 1996a).

De acordo com a introdução de segurança no projeto, têm-se os seguintes métodos (BECKER, 1996a, 1996b; MEYERHOF,1995): 
(1) Método das Cargas Admissíveis: que consiste na aplicação de um coeficiente de segurança global;

(2) Método dos Estados Limites: baseado na aplicação dos coeficientes parciais de segurança;

(3) Métodos Probabilísticos: baseados em análises de Confiabilidade.

Sendo que as principais diferenças entre eles reside na forma de comparação das solicitações com as resistências para a avaliação da segurança, ou seja, na maneira de estabelecer o nível de segurança e na forma de estabelecer os valores dos parâmetros de projeto. Porém, nunca se deve esquecer que a função dos métodos de introdução de segurança nas construções, independente do critério utilizado, tem como objetivo atender aos aspectos qualitativos de segurança (OLIVEIRA, 1998).

O nível de segurança a ser considerado no projeto dependerá diretamente da magnitude das perdas potenciais e, também, do grau de incerteza envolvido (BECKER, 1996a). As perdas potenciais em obras de terra e fundações podem ser classificadas em:

- perdas catastróficas de vidas e propriedades;

- perdas de vidas e propriedades;

- sérias perdas financeiras, sem perdas de vidas;

- perdas financeiras toleráveis, sem perdas de vidas.

Sob o ponto de vista econômico, quanto mais importante é a estrutura e mais sérias as conseqüências de uma ruína, maior deverá ser o nível de segurança utilizado no projeto, pois deve-se considerar: os custos da construção, os custos de uma eventual ruína ou desempenho insatisfatório e os danos decorrentes da mesma (FREUDENTHAL, 1975; OLIVEIRA, 1998).

As exigências de segurança nas construções tendem a ser mais rigorosas, à medida que as sociedades se desenvolvem. Porém, as especificações do nível de segurança de uma obra não devem ser influenciadas pelos erros grosseiros ou pelos eventuais casos isolados de desastres que não estavam previstos e para os quais o nível de segurança não foi especificado. Pois, a especificação de níveis de segurança mais elevados, não tornará tais obras seguras, e sim, um maior controle de qualidade na fase de projeto e de execução (BOLTON, 1989; OLIVEIRA, 1998).

Nos próximos itens serão discutidos os diversos métodos de introdução da segurança, apresentando a sua formulação e sua crítica, procurando mostrar até onde, dentro das perspectivas atuais, se pretende chegar nesse campo, bem como até onde já foi possível chegar. 


\subsubsection{Avanços na introdução da Segurança na Engenharia Civil}

Métodos diversos foram desenvolvidos e aperfeiçoados na tentativa de se quantificar o nível de segurança das estruturas. Os primeiros métodos, procuravam apenas obter construções seguras, pois ainda não havia a preocupação de quantificar a segurança. Esses métodos, procuravam introduzir segurança por meio de concepções estruturais baseadas na intuição dos projetistas e construtores. Intuição essa, que poderia ser pura, baseada na perícia dos projetistas e construtores, ou mais comumente, condicionada por sucessos e insucessos de construções similares já executadas, ou seja, com base na experiência adquirida. A aplicação desses métodos conseguia atingir o objetivo de garantir uma construção segura, porém conduziam, de um modo geral, a estruturas, que hoje, seriam consideradas antieconômicas (SÁLES et al., 2000).

Depois, com os coeficientes de segurança globais cujos valores diminuíam ou aumentavam em função do sucesso ou insucesso da experiência anterior e das conseqüências de ruína, começou-se a produzir estruturas aceitáveis e, em geral, seguras e econômicas. Porém, com o tempo, esse processo empírico foi deixando de ser viável, pois a aquisição da experiência leva tempo e os novos esquemas estruturais que surgem, devido ao avanço da tecnologia do concreto e do aço, exigem rapidez de aceitação e um maior controle para se evitar possíveis falhas causadas pelo mau funcionamento estrutural (BERNARDO, 1999; KAY; 1993).

Para fazer a verificação da segurança de maneira mais científica, métodos estatísticos e conceitos probabilísticos começaram a ser aplicados. Pois, vários pesquisadores perceberam a possibilidade de quantificar os juízos e as incertezas, que são a base dos coeficientes de segurança globais, usando a Teoria da Probabilidade. Foi dessa forma que surgiu a primeira geração de normas de cálculo baseada em estados limites (BERNARDO, 1999; VARGAS, 1996).

Porém, como foi difícil usar os preceitos probabilísticos explicitamente, estes foram aplicados implicitamente através do juízo coletivo dos engenheiros, construtores e calculistas quando da escolha dos coeficientes de segurança aplicáveis, segundo o critério: quanto mais sérias as conseqüências da ruína ou quanto maior a incerteza na ação ou na resistência, maior o coeficiente de segurança. Assim, o uso da probabilidade foi feito somente de maneira indireta e subjetiva (BERNARDO, 1999; SIMONS, 1981).

O Método dos Estados Limites foi delineado no século XVII através dos trabalhos de Hooke, Newton, Euler, e outros. Porém, o conceito de estado limite foi 
introduzido em normas apenas em meados dos anos 40 na antiga União Soviética. Os trabalhos pioneiros em Segurança Estrutural devem-se a Freudenthal e Torroja. Quanto aos países europeus, esses começaram a desenvolver o Método dos Estados Limites na Engenharia de Estruturas na década de 60, sendo este adotado como base para a elaboração de normas internacionais de estruturas em 1973, pela International Standards Organization (ISO) (BERNARDO, 1999; OLIVEIRA, 1998).

Com a criação do Mercado Comum Europeu (MCE) foi feito, um esforço no sentido de unificar o mercado da construção, eliminando as diferenças técnicas e legais que afetam os produtos usados no setor da construção e os regulamentos que tratam da segurança das estruturas. Deste modo, surgiu a idéia de elaborar os Eurocodes. Em 1978, começou-se a trabalhar no Eurocode 1 que diz respeito a regras unificadas comuns a vários tipos de construções e materiais e, nos Eurocodes 2 e 3 que se referem às construções de concreto e aço, respectivamente. Em 1980, foi firmado entre o MCE e a "International Society for Soil Mechanics and Foundation Engineering" um acordo, pelo qual, essa sociedade deveria fazer o levantamento dos códigos existentes nos países membros e rascunhar um código que pudesse ser adotado como o Eurocode 7 para fundações. Esse documento foi preparado no estilo do Código Dinamarquês, ou seja, dentro da filosofia dos estados limites e dos coeficientes parciais (OLIVEIRA, 1998).

Em 1964, o Comitê Europeu de Concreto (CEB) adotou os coeficientes parciais de segurança e introduziu o conceito estatístico de resistência e ações características, os descrevendo como uma aproximação "semi-probabilística". Neste modelo, a Estatística foi usada somente para definir os valores característicos e não para determinar os coeficientes parciais de cálculo, pois é deixado claro que os coeficientes adotados para modificar os valores característicos são destinados a considerar aqueles aspectos ainda não avaliados por tratamento estatístico (BERNARDO, 1999).

A abordagem aleatória das variáveis iniciou-se com a necessidade do estabelecimento de diretrizes de projeto baseadas em processos estatísticos e probabilísticos, que tornassem possível tratar as incertezas presentes nas variáveis (BERNARDO, 1999; SOARES, 2001).

O rápido desenvolvimento da ciência e tecnologia após a Segunda Guerra mundial tem provido a Engenharia Civil com os mais eficazes modelos para descrever as incertezas e a natureza aleatória das cargas atuantes e com os modelos mais precisos para descrever o comportamento físico das construções a serem projetadas (TAVARES, 1999). Os resultados anteriores têm permitido o desenvolvimento da moderna Teoria da 
Confiabilidade (ANG \& TANG, 1975, 1984) e o mesmo tem sugestionado um amplo espectro de novas soluções tecnológicas.

Em Tavares (1999), a evolução do processo de projeto na Engenharia Civil é discutida e os cinco maiores modelos de paradigmas são identificados:

$\checkmark$ Modelo empírico,

$\checkmark$ Modelo determinístico estático,

$\checkmark$ Modelo estocástico estático,

$\checkmark$ Modelo estocástico dinâmico,

$\checkmark$ Critério de otimização.

O projeto e a análise da engenharia exigem a resolução de incertezas e estas, quer sejam associadas com a variabilidade inerente ou com erros de previsão, podem ser avaliadas em termos estatísticos, e a sua importância na segurança e no desempenho estrutural pode ser sistematicamente analisada usando conceitos e métodos probabilísticos. Em concordância, critérios de projeto deveriam também ser desenvolvidos por meio de uma formulação probabilística (BERNARDO, 1999).

Deve ser enfatizado que a aplicação da probabilidade não é limitada à descrição de dados experimentais ou à avaliação das estatísticas associadas (tais como média, desvio padrão e coeficiente de variação). De fato, as funções mais importantes dos conceitos probabilísticos estão na utilização dessas informações para a formulação de bases para a tomada de decisões e para o projeto (BERNARDO, 1999; TANG, 1993).

Um importante componente do progresso durante este século foi a emergência de normas que regulamentam o cálculo e a construção de edifícios e outras estruturas. Códigos e normas começaram a ser desenvolvidos e, por volta da virada do século até 1920, um conjunto destas normas já estava disponível para a maioria dos tipos de construção. O aparecimento e evolução das normas técnicas direcionaram a construção civil, estabelecendo "regras" a serem cumpridas pelos projetistas e construtores (CASTRO, 1997).

Com o tempo, o aumento do número de normas e as modificações nas existentes, contribuíram para o progresso na área, apesar dos desenvolvimentos e mudanças em normas de cálculo serem lentos e graduais. Pois, mudanças de filosofia não são, a princípio, bem aceitas. No entanto, a transição pode ser alcançada com um mínimo de perturbação, como mostra a experiência já vivida por alguns países (BERNARDO, 1999; ELLINGWOOD, 2000). 
A década de 90 do século XIX foi um período de progressos, porém estes avanços na construção não ocorreram isoladamente, mais se desenvolveram paralelamente ao desenvolvimento de várias ciências. O período de 1950-1990 foi um tempo de alimentação e realização da Engenharia Civil. Entre as teorias que amadureceram neste período podem-se mencionar as seguintes: Teoria da Plasticidade, Teoria da Confiabilidade, Análise em Elementos Finitos, Análise Dinâmica, entre outras. Em particular, a pesquisa na aplicação de métodos estocásticos tem representado, neste contexto, um dos mais proveitosos esforços de pesquisa dos últimos quarenta anos (CASTRO, 1997). Assim, métodos e procedimentos probabilísticos e estatísticos têm sido encontrados mais amplamente e em aplicações mais extensas na Engenharia Civil e, em formas mais ou menos sofisticadas, são a base da maioria das recentes versões de normas estruturais ao redor do mundo, por serem uma alternativa importante no tratamento das incertezas nos modelos e na interpretação de dados (BERNARDO, 1999; DITLEVSEN \& MADSEN; 1996; HONJO et al., 2000a).

\subsubsection{Revisão do conceito de Segurança}

Um dos principais objetivos do cálculo estrutural na Engenharia Civil é garantir a segurança e o desempenho satisfatório das estruturas com o máximo de economia possível. Todavia, atingir esse objetivo geralmente não é um problema simples, devido às inúmeras incertezas e variabilidades que não permitem afirmar que uma estrutura não falhará (ANG \& TANG, 1984).

No caso de uma estrutura, sua segurança, é função da máxima ação (ou combinação de ações) que lhe pode ser imposta durante sua vida útil e dependerá também da resistência ou capacidade resistente dessa estrutura ou de seus componentes, de suportar essas ações. Como a máxima ação da vida útil de uma estrutura e sua capacidade real são difíceis de serem previstas exatamente e qualquer previsão está sujeita a incertezas, os sistemas estruturais podem falhar ao desempenhar as suas funções, pois ainda não é possível projetar uma estrutura que seja totalmente segura e infalível, com risco zero de colapso. Na realidade, segurança ou desempenho somente podem ser garantidos em termos da probabilidade de que a resistência será suficiente para resistir à máxima ação ou combinação de ações que poderão ocorrer durante a vida útil da estrutura (BERNARDO, 1999; OLIVEIRA, 1998). 
Entretanto, a maioria dos projetos estruturais podem ser bem sucedidos sem o conhecimento completo das informações necessárias, mas a garantia da segurança não será perfeita. Muitas decisões requeridas durante a realização do projeto e cálculo são tomadas, invariavelmente, sob condições de incertezas. Portanto, há sempre alguma probabilidade de ruína ou mau desempenho. O risco será sempre inevitável. Sob tais condições, não é viável prática e/ou economicamente garantir segurança ou desempenho absolutos para as estruturas de engenharia (FREUDENTHAL, 1975).

Quando muito, poder-se-á avaliar sua probabilidade de ruína, dentro de um certo intervalo de tempo, em geral, o previsto para a sua vida funcional (vida útil). Logo, é a probabilidade de ruína que mede, na realidade, a segurança de uma estrutura (OLIVEIRA, 1998). Na prática, o que se pode fazer, é tentar restringir a probabilidade de ruína da estrutura a níveis razoáveis baseados, por exemplo, na probabilidade de casos históricos reais. Para conseguir este intento, a utilização de modelos probabilísticos e estatísticos é necessária e vital para o tratamento apropriado das incertezas. Assim, a Teoria da Probabilidade tem uma posição importante em todos os aspectos do planejamento e do projeto de engenharia, incluindo a modelagem e avaliação do desempenho do sistema sob as condições de incerteza e o desenvolvimento de critérios de projeto considerando a importância e a influência dessas incertezas (BERNARDO, 1999; KOUTSOFTAS, 2001).

Convencionalmente, as incertezas são tratadas como quantidades determinísticas pela aplicação de coeficientes de segurança. Entretanto, pode-se demonstrar que os coeficientes de segurança são imperfeitos, uma vez que o nível de segurança não é claramente definido. Portanto, fica-se diante de uma situação na qual existem estruturas econômicas, mas pouco seguras; ao mesmo tempo em que existem estruturas muito seguras, mas pouco econômicas (CASTRO, 1997)

Segundo os conceitos probabilísticos de segurança, esse é um problema essencialmente baseado em probabilidades, pois, as incertezas e as variabilidades, são inevitáveis no projeto e planejamento dos sistemas estruturais. Incertezas estão presentes na quantificação dos parâmetros envolvidos no dimensionamento (ações e propriedades resistentes dos materiais), nos métodos de cálculo (os distanciamentos entre modelos matemáticos de interpretação de um fenômeno e a realidade), além das variabilidades e dos erros de projeto e de execução (OBONI, 1989; PLI \& GAO, 1993).

A análise estrutural probabilística é a arte da formulação de um modelo matemático dentro do qual pode-se responder à seguinte questão: "Qual é a 
probabilidade de um sistema estrutural comportar-se de um modo específico, considerando que uma ou mais de suas propriedades físicas e/ou geométricas são de natureza aleatória (ou não conhecida completamente), e/ou que as ações na estrutura têm propriedades aleatórias (ou não completamente conhecidas) ?". Enquanto que a análise estrutural determinística é a arte da formulação de um modelo matemático dentro do qual pode-se responder à questão: "Como é o comportamento de um sistema estrutural quando as suas propriedades físicas e/ou geométricas, assim como as ações que nele atuam, são consideradas únicas, ou seja, determinadas ?". Assim, a análise probabilística pode ser considerada uma extensão da análise estrutural determinística, porque as quantidades determinísticas podem ser interpretadas como variáveis de natureza aleatória praticamente insignificante (DITLEVSEN \& MADSEN, 1996).

A dispersão das propriedades dos materiais e das diversas ações deve ser modelada como funções de distribuição estocásticas e a sensibilidade do comportamento estrutural com relação a essa dispersão deve ser investigada (BERNARDO, 1999; OLIVEIRA, 1998). Para isso, faz-se necessário à utilização dos princípios de Probabilidade, Estatística e de Confiabilidade.

Em resumo, segundo a concepção das condições de segurança, têm-se os métodos determinísticos de cálculo, onde os parâmetros que definem a segurança são considerados como grandezas não aleatórias e os métodos probabilísticos de cálculo, onde os parâmetros que definem a segurança são considerados como grandezas aleatórias e que visam quantificar a segurança associando-a a probabilidade de sobrevivência da estrutura (MELCHERS, 1987; OLIVEIRA, 1998).

\subsection{A Segurança na Engenharia de Fundações}

\subsubsection{Histórico dos métodos de cálculo}

Os projetos geotécnicos são tradicionalmente baseados na filosofia determinística. As incertezas são consideradas com o uso de parâmetros conservadores baseados no julgamento subjetivo dos projetistas e no uso do coeficiente de segurança para se ter um nível de segurança adequado (LI et al., 1993).

Na Engenharia de Fundações, durante muito tempo, a fixação das margens de segurança foi feita empiricamente. Os valores atuais dos coeficientes de segurança empregados no Método das Cargas Admissíveis foram consagrados num lento processo 
de observação dos resultados de sua utilização. Os coeficientes de segurança globais foram sendo assim paulatinamente reduzidos à medida que um melhor comportamento das fundações sugeria tal possibilidade de redução (OLIVEIRA, 1998).

Entretanto, com o advento dos conceitos probabilísticos de segurança, a especificação dos níveis de segurança passou a ser subordinada a critérios de racionalidade, ou seja, tornou-se necessário quantificar os critérios qualitativos de segurança (BRZAKALA \& PULA, 1996; OLIVEIRA, 1998).

Sob o aspecto qualitativo, as fundações são consideradas seguras quando há um grau de convicção suficiente de que, durante a sua vida útil, não será atingido nenhum estado de ruína (OLIVEIRA, 1998; WHITMAN; 2000).

O Método das Cargas Admissíveis foi o primeiro método racional de projeto de fundações desenvolvido. Antes de seu advento, as fundações eram projetadas com base na experiência. $\mathrm{O}$ projeto com base em experiência funcionava bem, pois geralmente se trabalhava com os mesmos materiais, métodos construtivos e obras de pequeno e médio porte. Entretanto, com o advento da revolução industrial e o surgimento de novos materiais e metodologias de construção, o panorama começou a mudar rapidamente, inviabilizando o projeto baseado somente em experiência. Para acomodar essas mudanças rápidas, os engenheiros tiveram que desenvolver um método mais racional de projeto (GOBLE, 2000; OLIVEIRA, 1998).

Neste contexto, foi desenvolvido o Método dos Estados Limites. Problemas envolvendo estados limites em Geotecnia podem ser encontrados nas teorias de empuxos de terra, estabilidade de taludes e capacidade de carga desenvolvidas nos séculos XVIII e XIX. Os primeiros trabalhos empregando os conceitos de estados limites em Geotecnia incluem o trabalho de Coulomb (1773) que, baseado em considerações de estados limites, calculou a altura crítica de um aterro em um solo coesivo e o trabalho de Rankine (1857), que estabeleceu estados limites para empuxos de terra (OLIVEIRA, 1998).

O desenvolvimento histórico do Método dos Estados Limites em Geotecnia foi sumariado por Meyerhof (1970, 1984, 1993, 1995), Ovesen (1981,1993), Ovesen e Orr (1991) e por outros.

Meyerhof (1995) apresenta o histórico desenvolvimento do Método dos Estados Limites na Engenharia Geotécnica desde o tempo da classificação de Terzaghi, que em 1943, dividiu os problemas da mecânica dos solos em dois grupos principais de problemas: 
$\checkmark$ Problemas de estabilidade;

$\checkmark$ Problemas de elasticidade;

representando os estados limites últimos e de serviço, respectivamente.

Os problemas de estabilidade (estados limites últimos) devem ser analisados em condições imediatamente antes da ruptura por deformação plástica, sem considerar a deformação. Enquanto que nos problemas de elasticidade (estados limites de utilização) deve ser considerada a deformação do solo devido a seu peso próprio ou devido às forças externas, sem considerar a ruptura (BAUER \& PULA, 2000; OLIVEIRA, 1998).

Aparentemente a Engenharia Geotécnica foi a primeira a despertar interesse na aplicação da filosofia dos estados limites, antes mesmo de sua aplicação na Engenharia de Estruturas (OLIVEIRA, 1998). Esta idéia teve como pioneiros os estudos de Taylor (1948) e Hansen $(1953,1956)$.

Taylor (1948) introduziu coeficientes de segurança diferentes aos parâmetros de resistência do solo (coesão e atrito) para a análise de estabilidade de taludes. Este procedimento foi formalizado e generalizado para estacas e estruturas de contenção por Hansen $(1953,1956)$, que após várias propostas de coeficientes de segurança globais, estabeleceu uma filosofia de projeto baseada no princípio de estados limites e, na aplicação de coeficientes parciais de segurança às cargas e aos parâmetros de resistência do solo para os estados limites últimos e utilização (MEYERHOF, 1995).

Segundo Hansen $(1953,1956)$, os valores característicos das cargas seriam multiplicados por seus respectivos coeficientes parciais para serem obtidos os valores de cálculo, por outro lado, os parâmetros característicos de resistência do solo seriam divididos por seus respectivos coeficientes de segurança resultando em parâmetros de cálculo para o cálculo da resistência (OLIVEIRA, 1998).

Os valores numéricos dos coeficientes de segurança parciais propostos por Hansen (1953, 1956), foram calibrados de forma a proporcionar o mesmo nível de segurança que o Método das Cargas Admissíveis. Esses valores, não permaneceram inalterados, mas sofreram alterações com o passar dos anos decorrente da experiência adquirida através da aplicação do método. Atualmente, os valores dos coeficientes parciais têm sido definidos através de métodos probabilísticos, com base em medidas da variabilidade das cargas, parâmetros de resistência do solo e outros parâmetros de projeto (LI \& LAM, 2001; OLIVEIRA, 1998).

Vários códigos baseados no Método dos Estados Limites para aplicações geotécnicas foram desenvolvidos nos últimos anos. Alguns desses códigos tem coberto 
todos os aspectos de projeto geotécnico, enquanto outros têm se interessado somente com as fundações (GOBLE, 2000).

A primeira norma geotécnica baseada no Método dos Estados Limites foi a Danish Standard for Foundations, 1956 (Norma Dinamarquesa de Fundações), que nasceu baseada nos trabalhos de Hansen $(1953,1956)$. Entretanto, com o passar do tempo, a filosofia original dos projetos baseados em estados limites, tem sido modificada, devido ao desenvolvimento e à aplicação desta filosofia de projeto em vários códigos de fundações em diferentes países (OLIVEIRA, 1998).

Como exemplo, pode-se destacar que existe uma sensível diferença entre o projeto baseado nos estados limites desenvolvido na Europa e àquele desenvolvido na América do Norte. Entre os países europeus essa diferença foi atenuada a partir da criação do Eurocode 7 (LI et al.; 1993, OLIVEIRA, 1998).

Os primeiros códigos em LRFD foram adotados nos anos 60 nos Estados Unidos e Europa. Eles foram desenvolvidos independentemente e por razões diferentes, sendo que nenhuma das organizações que desenvolveram os códigos estava ciente da outra. Nos Estrados Unidos o American Concrete Institute adaptou o código de projeto de construções de reforço de concreto, que tinha um LRFD formato, enquanto que na Europa, foi realizada uma mudança, dirigida por engenheiros geotécnicos, no código da Dinamarca (GOBLE, 2000; TANDJIRIA et al., 2000).

Logo, a concepção de projeto em estados limites com o uso de coeficientes parciais de segurança, foi desenvolvida de modo diferente na América do Norte e Europa. Em ambos os casos para a verificação da segurança, a resistência de cálculo deve ser maior ou igual à solicitação de cálculo. A diferença básica consiste na forma como é obtida a resistência de cálculo para a verificação do estado limite último, pois, as solicitações de cálculo são obtidas de modo idêntico, apesar dos diferentes coeficientes e combinações de cargas usados em cada um dos casos (OLIVEIRA, 1998).

Na Europa, os coeficientes parciais são aplicados diretamente aos parâmetros de resistência do solo. Esta metodologia segue o trabalho original de Hansen $(1953,1956)$ e da Norma Dinamarquesa de Fundações, onde os coeficientes parciais especificados são aplicados à coesão e ao ângulo de atrito, antes que estes sejam introduzidos no modelo para o cálculo da resistência e, a resistência obtida é então chamada de resistência de cálculo. Já na América do Norte, os parâmetros de resistência do solo são introduzidos no modelo de cálculo da resistência, sem que lhes sejam aplicados os coeficientes parciais de segurança. Os coeficientes de segurança são aplicados 
diretamente sobre o valor da resistência obtida pelo modelo de cálculo, a resistência obtida após a aplicação do coeficiente de segurança é então chamada de resistência de cálculo. Na Europa esse procedimento é denominado de Resistência Fatorada e na América do Norte de Resistência não Fatorada (BECKER, 1996a; OLIVEIRA, 1998).

Há vantagens e desvantagens em ambos os métodos, e essas são opostas. O projeto baseado em Resistências não Fatoradas (América do Norte) tem a vantagem de combinar todas as incertezas associadas ao cálculo da resistência do solo num único coeficiente de segurança. A desvantagem é que os coeficientes parciais de segurança não são aplicados diretamente às variáveis que contribuem para o cálculo da resistência, o que permite uma margem de segurança mais uniforme, o que é feito no método baseado em Resistências Fatoradas, sendo esta a sua maior vantagem. Por isso, o método baseado em Resistências Fatoradas (Europa) é considerado uma método mais sofisticado de aplicação do Método dos Estados Limites; entretanto, ele tem a desvantagem de não permitir que outras fontes de incerteza, que não à dos parâmetros de resistência do solo sejam consideradas (BECKER, 1996a; 1996b, OLIVEIRA, 1998).

A estrutura básica desses e de outros códigos é comparativamente revisada e criticada por GOBLE (2000), particularmente com respeito à determinação da capacidade de carga com base em provas de carga e com relação aos coeficientes parciais de segurança para as resistências e solicitações usados nos vários códigos.

\subsubsection{O Método das Cargas Admissíveis}

Na filosofia de projeto baseada no Método das Cargas Admissíveis a segurança é garantida pela limitação das máximas cargas atuantes em serviço a valores admissíveis, através da aplicação de um coeficiente de segurança único à capacidade de carga última da fundação, o qual considera todas as incertezas associadas ao projeto sem fazer distinção entre as incertezas associadas às resistências e àquelas associadas ao carregamento aplicado. O coeficiente de segurança é dito "global" e este assegura um nível de segurança à fundação com base na experiência adquirida com estruturas semelhantes e em condições similares (GENEVOIS; 1991; PACHECO \& LIMA, 1996).

Aoki (2000b) comenta, a respeito dessa filosofia, que a carga admissível de um estaqueamento é fixada por cada profissional que se julgue especialista neste tipo de fundação. $\mathrm{O}$ valor numérico por ele fixado, decorre de sua experiência pessoal com aquele tipo específico de fundação, naquela formação geológica e quando executado 
com o equipamento daquela firma especializada. Neste contexto, a prática de fundações é uma arte e as decisões de engenharia dependerão da sensibilidade e experiência do projetista.

Segundo a NBR 6122/1996, este critério deve ser usado quando os dados relativos às cargas provenientes das ações nas estruturas resumem-se a um único tipo de carregamento, sem especificação das ações combinadas.

Essa metodologia se caracteriza por não levar em consideração a dispersão existente nos valores de resistência e solicitação, pois se trabalha apenas com a média, estabelecendo sempre uma relação entre as solicitações e a resistências através do coeficiente de segurança global, que é fixo e independe do grau de controle do processo. Assim, no Método dos Estados Limites as resistências e as solicitações são consideradas determinísticas, ou seja, representadas por valores únicos. Entretanto, as resistências e as solicitações dependem de uma série de variáveis ou parâmetros, ou seja, na realidade existe variabilidade nas solicitações e resistências, e essa variabilidade implica na existência de distribuições de freqüência para ambas às partes (OLIVEIRA, 1998).

A NBR 6122/1996 define carga admissível como sendo a força aplicada sobre a estaca ou o tubulão isolado, provocando apenas recalques que a construção pode suportar sem inconvenientes e oferecendo, simultaneamente, segurança satisfatória contra a ruptura ou o escoamento do solo ou do elemento estrutural de fundação.

Nota-se que no Método das Cargas Admissíveis, o termo "carga admissível" pode ser comandado pelo critério de ruptura ou recalque. Pois, o Método das Cargas Admissiveis considera estes dois estados limites, mas não o faz explicitamente, o que pode causar confusão entre engenheiros ao utilizar o termo "admissível".

Verifica-se também que existem dois limites para a ruptura no Método das Cargas Admissíveis: o primeiro refere-se à capacidade do elemento estrutural de receber e transmitir a carga para o solo e o segundo, à capacidade do solo de suportar as cargas transmitidas pelo elemento estrutural de fundação. Entretanto, na maioria dos casos, a carga admissível é comandada pelo solo, que apresenta um valor de capacidade de carga na ruptura menor que a resistência na ruptura do elemento estrutural de fundações.

Nesta abordagem, a carga admissível $\left(\mathrm{P}_{\mathrm{adm}}\right.$ ), é obtida dividindo a resistência média do conjunto de elementos isolados de fundação $\left(R_{m}\right)$ por um coeficiente de segurança global (CS) e, com a solicitação máxima que pode atuar no elemento de fundação $\left(\mathrm{S}_{\text {máx }}\right)$, a segurança é verificada fazendo:

$$
\mathrm{S}_{\text {máx }} \leq \mathrm{P}_{\mathrm{adm}}=\mathrm{R}_{\mathrm{m}} / \mathrm{CS}
$$


De acordo com a NBR 6122/1996 os coeficientes globais de segurança são:

Tabela 2.1. Coeficientes de Segurança Globais Mínimos (NBR 6122/1996).

\begin{tabular}{|c|c|}
\hline Condição & Coefíciente de Segurança \\
\hline Capacidade de carga de fundações superficiais & 3.0 \\
\hline Capacidade de carga de estacas e tubulões sem prova de carga & 2.0 \\
\hline Capacidade de carga de estacas e tubulões com prova de carga & 1.6 \\
\hline
\end{tabular}

Quanto aos deslocamentos máximos permitidos pela estrutura, a carga admissível deve ser obtida aplicando-se um coeficiente de segurança maior ou igual a 1.5 sobre os valores obtidos através de cálculos ou experimentalmente.

\subsubsection{O Método dos Estados Limites}

$\mathrm{O}$ projeto de fundações seguiu os mesmos caminhos trilhados pelo projeto estrutural de aço, concreto e madeira. As mudanças nos conceitos relativos ao projeto de fundação, mostram nitidamente a passagem de uma metodologia de projeto determinista (Método das Cargas Admissíveis) para uma metodologia semiprobabilística (Método dos Estados Limites) (KULHAWY, 1996).

O Método dos Estados Limites pode ser entendido como uma transição entre o tradicional Método das Cargas Admissíveis e os futuros métodos probabilísticos. Pois, no estágio atual dos conhecimentos, ainda não é possível a adoção de um método totalmente probabilístico dos estados limites ao projeto de estruturas e de fundações, por não existir, ainda, informações em quantidade e qualidade suficientes que possibilite tal aplicação. Por isso, para aplicações práticas, o método de cálculo mais moderno adotado em norma (Método dos Estados Limites) é ainda um método semiprobabilístico, que renuncia-se a calcular a probabilidade de ruína da estrutura, e contenta-se apenas na especificação de níveis aceitáveis de segurança através da consideração de alguns dos diversos fatores que intervêm na avaliação da segurança (CHERUBINI et al., 1991).

Uma das maiores diferenças entre o Método dos Estados Limites e o Método da Carga Admissível está no fato de que o primeiro faz uso da Teoria da Probabilidade para considerar, com bases mais racionais, algumas incertezas presentes nos projetos geotécnicos (LI et al., 1993).

O Método dos Estados Limites foi introduzido na Engenharia civil, na tentativa de disciplinar todos os aspectos da análise de segurança em estruturas. É um critério 
usado para definir um limite acima do qual um elemento da estrutura não poderá mais ser utilizado (Estado Limite de Utilização), ou acima do qual será considerado inseguro (Estado Limite Último).

O Método dos Estados Limites consiste em transformar valores característicos em valores de cálculo pela aplicação dos denominados coeficientes parciais de segurança, sendo a verificação da segurança é feita para cada estado limite, através da comparação das solicitações de cálculo com as resistências de cálculo. No Método dos Estados Limites as solicitações de cálculo não podem exceder as resistências de cálculo. (BILFINGER, 2002; OLIVEIRA, 1998).

$\mathrm{O}$ Método dos Estados Limites tem como principal característica à tentativa de realizar a consideração racional dos fatores que influem na segurança de determinada estrutura. No Método dos Estados Limites as incertezas associadas a cada uma das variáveis são consideradas através da aplicação dos coeficientes de segurança parciais (BILFINGER, 2002). Nesta filosofia, segurança de uma estrutura, é a capacidade que ela apresenta de suportar as diversas ações que vierem a solicitá-la durante a sua vida útil, sem atingir qualquer estado limite.

A filosofia de projeto baseada no Método dos Estados Limites envolve os seguintes procedimentos:

(1) Identificação de todas as potenciais formas de ruína ou estados limites que a estrutura possa apresentar;

(2) Verificar separadamente cada estado limite;

(3) Demonstrar que a possibilidade de ocorrência dos estados limites é improvável ou aceitável.

No Método dos Estados Limites a verificação da segurança deve abranger tanto os estados limites últimos quanto os estados limites de utilização, mantendo a probabilidade de atingi-los abaixo de um valor previamente estabelecido .

A condição de verificação da segurança no Método dos Estados Limites é que, para cada estado limite considerado, as solicitações de cálculo (solicitações características majoradas por um coeficiente parcial de segurança) não excedam as resistências de cálculo (resistências características minoradas pela aplicação de um coeficiente parcial de segurança) (MEYERHOF, 1969; ORR, 2000).

Em resumo, a verificação da segurança no Método dos Estados Limites baseiase no seguinte conjunto de procedimentos:

- Majoram-se as ações e os esforços solicitantes de modo que seja pequena a 
probabilidade destes valores serem ultrapassados;

- Reduzem-se os valores das resistências de modo que seja pequena a probabilidade de que os valores reais sejam atingidos;

- Equaciona-se a situação de ruína, comparando o esforço solicitante de cálculo com o esforço resistente de cálculo por meio da seguinte inequação: $S_{d} \leq R_{d}$.

Apesar do Método dos Estados Limites estar sendo usado nas normas estruturas por aproximadamente 20 anos, há poucos estudos teóricos do seu uso aplicado a análises de dados geotécnicos (LI et al., 1993). Entre os poucos existentes, pode-se citar o excelente trabalho de Becker (1996a, 1996b), Honjo et al (2000a) e Li et al. (1993).

Honjo et al. (2000a) apresenta um relatório desenvolvido sobre os quatro maiores códigos de projetos existentes no Japão. A experiência existente, a área de aplicação, a estrutura do código, os planos futuros, a harmonização com os demais códigos, a relação com códigos internacionais, os métodos de projeto e os valores dos coeficientes de segurança são discutidos.

$\mathrm{Li}$ et al. (1993) discute as bases probabilísticas para o projeto em estados limites na Engenharia Geotécnica. Traz os procedimentos para a formulação das equações de estado limite e para a determinação dos coeficientes parciais de segurança, assim como algumas recomendações sobre a implementação dos Métodos dos Estados Limites nas normas geotécnicas. A importância do uso das distribuições de probabilidade na formulação dos códigos geotécnicos em estados limites é discutida e ilustrada com um exemplo.

\subsubsection{Estados Limites - Conceitos básicos}

A NBR 6122/1996 exige que a segurança nas fundações seja estudada por duas análises: a do estado limite último e a do estado limite de utilização. Os estados limites são estados além dos quais a estrutura não mais satisfaz às exigências do projeto, não significando necessariamente o esgotamento da capacidade de carga do sistema de fundação.

Entende-se por segurança de uma obra sua capacidade de satisfazer as exigências de comportamento que lhe são impostas, durante toda a sua vida útil, com a finalidade expressa de evitar a ocorrência de qualquer estado de ruína.

O conceito de ruína, abrange uma multiplicidade de estados que caracterizam algum comportamento insatisfatório, na qual, a estrutura deixa de atender aos requisitos 
para os quais foi projetada. Logo, o termo ruína, não significa, necessariamente, esgotamento da capacidade de carga da estrutura.

$\mathrm{O}$ aparecimento de um estado limite decorre de uma mudança de comportamento da estrutura. Essa mudança de comportamento é delimitada por estados particulares da estrutura considerada, e estes estados são denominados de estados limites.

Os estados limites são associados com o colapso ou instabilidade. Esses estados podem ser classificados segundo dois critérios distintos, dando origem a dois tipos de estados limites, contra os quais, deve ser garantida a segurança (LI et al., 1993):

- Estados Limites Últimos (ULS): são caracterizados por ter sido alcançada a máxima capacidade de suporte do sistema de fundação,

- Estados Limites de Utilização (SLS): decorrem de critérios de utilização normal, funcionalidade e durabilidade da superestrutura associada ao sistema de fundação.

A separação entre ULS e SLS é uma das maiores vantagens da utilização do método semiprobabilístico dos estados limites. De forma geral, os critérios básicos que um projeto baseado em estados limites deve satisfazer são:

- Estados Limites Últimos

Resistência de cálculo > Solicitações de cálculo

- Estados Limites de Utilização

Recalques previstos $<$ Recalques toleráveis

Logo, as estruturas geotécnicas devem ser projetadas para satisfazer a determinadas exigências como: a capacidade de suportar a superestrutura sem romper e sem apresentar recalques excessivos (LI et al., 1993).

\subsection{O Estado Limite Último}

Os estados limites últimos são caracterizados pelo alcance à máxima capacidade de suporte do sistema de fundação. Eles afetam a estabilidade da estrutura e, por isso, não devem ser atingidos em condições normais de utilização das mesmas, devendo existir margens efetivas de segurança contra tais estados limites. Estes estados deverão ter uma probabilidade de ocorrência muito pequena devido às graves conseqüências que podem provocar, como por exemplo, a perda de vidas humanas e/ou de propriedades.

O estado limite último caracteriza-se pelo esgotamento da capacidade da estrutura em termos de material, ou seja, no mínimo um dos materiais que faz parte da 
estrutura não suporta mais as ações de projeto. Tomando como exemplo uma estaca, o estado limite último seria a ruptura da estaca, seja como elemento estrutural, seja na interface solo-estaca, não sendo mais possível aumentar a carga (BILFINGER, 2002).

Segundo Oliveira (1998), os estados limites últimos correspondem aos estados do sistema de fundação nos quais é esgotada a sua capacidade de suporte (ruptura real ou convencional). Assim, por exemplo, na verificação do estado limite último de ruptura do solo que compõe o sistema de fundação, quando da realização de uma prova de carga, tem-se:

- Ruptura Física: corresponde a ruptura nítida do sistema, é definida como o limite da relação do acréscimo do recalque da ponta da estaca pelo acréscimo de carga, tendendo ao infinito.

- Ruptura Convencional: quando a ruptura nítida do sistema não ocorre, pode-se utilizar critérios para estabelecer um valor para a carga de ruptura.

Para a determinação da carga de ruptura do solo de forma teórica, geralmente adota-se o Método do Equilíbrio Limite, onde modelo reológico adotado é o rígidoplástico perfeito (o comportamento do solo até atingir o estado limite último é ignorado). O método consiste, inicialmente, em se construir um mecanismo de colapso arbitrário, constituído por formas geométricas simples ou associadas. Em seguida, garantindo-se o atendimento ao critério de escoamento em todos os pontos da superfície de escoamento analisa-se o equilíbrio estático dos blocos que compõem o mecanismo de colapso (OLIVEIRA, 1998).

No Eurocode 7 são especificados alguns estados limites últimos para as fundações superficiais e profundas (VELLOSO, 1987). Estes estão transcritos abaixo:

(1) Fundações superficiais:

- formação de um mecanismo na massa de solo que contêm a fundação (sic), correspondente a uma perda de estabilidade global;

- formação de um mecanismo na interface entre a fundação e o terreno (sic), correspondente a uma ruptura por deslizamento;

- tombamento da fundação (sic);

- formação de um mecanismo na estrutura da fundação (sic);

- formação de um estado limite que envolve a perda de equilíbrio estático ou ruptura de uma seção crítica da estrutura em decorrência de movimento da fundação (sic). 
(2) Fundações profundas:

Ocorrem quando movimentos da fundação acarretam graves danos estruturais em outras partes da estrutura. Normalmente, são o resultado de movimentos diferenciais entre estacas ou entre estacas e outros elementos da fundação. Ocorrem quando se forma no terreno um mecanismo de colapso em conseqüência de:

- ruptura de um talude;

- subpressão;

- ruptura de cisalhamento no solo abaixo e em torno de uma estaca isolada ou de um grupo de estacas;

- ruptura estrutural da estaca.

$\mathrm{Na}$ análise do estado limite último (análise de ruptura), os valores de cálculo das ações em sua combinação última, são comparados aos valores de cálculo da capacidade de carga ou carga de ruptura do solo e do elemento estrutural de fundação. Admite-se que há segurança quando os valores de cálculo das ações, na sua combinação mais desfavorável (combinação últimas das ações), não ultrapassam a capacidade de carga limite correspondente aos valores de cálculo da capacidade de carga. Os valores de cálculo são obtidos aplicando diferentes coeficientes de segurança aos valores característicos ou nominais das ações e da capacidade de carga (HONJO et al., 2000b).

\subsection{O Estado Limite de Utilização}

Os estados limites de utilização se devem à mudança de comportamento da estrutura geotécnica sob as condições de serviço como, por exemplo, deformação ou ruptura de paredes não estruturais devido aos recalques das fundações (LI et al., 1993).

O estado limite de utilização significa o não atendimento aos requisitos funcionais ou de durabilidade. Os estados limites de utilização ocorrem quando as limitações dos estados em que o comportamento do sistema de fundação é julgado satisfatório para a utilização normal da superestrutura é ultrapassado.

Para esses estados limites, maior probabilidade de ocorrência poderá ser tolerada, pelo fato de não representarem situações tão perigosas quanto às apresentadas pelos estados limites últimos (LACASSE \& GOULOIS, 1989).

Estes estados limites estão associados aos movimentos permitidos para as fundações, cujos limites são função de fatores como: a interação solo-estrutura, a finalidade da construção, fissuração nociva, vibração e distorção. Os limites utilizados 
para a avaliação da segurança contra estes estados limites geralmente são deformações excessivas (recalques totais e diferenciais), inclinações, vibração, fissuração e distorção angular. Logo, este estado limite não causa o colapso, mas a perda, em parte, do potencial funcional da fundação (OLSSON et al., 1989).

Por exemplo, um estado limite de utilização se caracteriza por deslocamentos excessivos da estaca quando solicitada, comprometendo o funcionamento da superestrutura por ela suportada, porém sem esgotar a sua capacidade de suporte (BILFINGER, 2002).

Quando se atinge um dos estados limites de utilização como, por exemplo, o estado de deformações ou de fissuração, nos quais são ultrapassados valores limites préfixados, em princípio deles não decorre, de imediato, o impedimento da utilização da construção. Por essa razão, aos estados de deformação e de fissuração são usualmente associados comportamentos limites, os quais definem estados limites de utilização.

No Eurocódigo 7 são especificados alguns estados limites de utilização para as fundações superficiais e profundas (VELLOSO, 1987). São eles:

(1) Fundações superficiais:

- a ocorrência de recalques ou outros movimentos da fundação que afetam a aparência ou o uso eficiente da estrutura ou causa prejuízo a acabamentos ou outros elementos não-estruturais;

- a ocorrência de vibrações excessivas na estrutura em conseqüência, por exemplo, de ressonância no sistema solo-estrutura;

- a percolação d'água através de uma fundação em radier.

(2) Fundações profundas: análogos aos definidos para as fundações superficiais.

A NBR 6122/1996 estabelece que a análise de deformações deve ser feita calculando-se os deslocamentos da fundação submetida aos valores dos esforços na estrutura no estado limite de utilização. A análise de deformação no estado limite de utilização consiste em garantir que os deslocamentos da fundação, submetidos aos esforços provenientes da estrutura, não causem danos que prejudiquem seu funcionamento. No cálculo dos deslocamentos da fundação para a verificação dos estados limites de utilização (análise de deformações) é utilizada a Teoria da Elasticidade considerando o solo como elástico linear e isotrópico.

Admite-se que há segurança quando os recalques causados pelas ações de cálculo (em suas combinações de utilização), não ultrapassam os recalques limites, além dos quais as condições de utilização da superestrutura não são aceitáveis por apresentar 
deformações exageradas, ou seja, os recalques das fundações devem ser inferiores aos limites admitidos como adequados para o tipo de construção. Esses recalques, sejam eles totais ou diferenciais, devem ser definidos pelos projetistas estruturais, com base na comparação do comportamento da construção sujeita às ações correspondentes de sua utilização (e conseqüentemente, seus recalques) com o comportamento esperado para que tenha as condições funcionais e de durabilidade especificadas (KAY, 1976).

Mas, na maioria das vezes, os valores limites para os recalques das fundações são resultantes da experiência na observação de obras, portanto, influenciados pela redistribuição de esforços devido à rigidez da superestrutura. Entretanto, os modelos usuais para previsão dos recalques não consideram a rigidez da superestrutura. Sendo assim, a aplicação destes limites nos projetos só se justifica devido aos resultados satisfatórios usualmente obtidos, mas não deixa de ser necessário à formulação de modelos mais completos, que incluam a superestrutura na previsão dos recalques (interação solo-estrutura) (MOURA, 1995).

\subsubsection{Valores Característicos e Valores de Cálculo}

A aplicação do Método dos Estados Limites em estruturas geotécnicas requer o uso dos coeficientes parciais de segurança e a seleção de valores característicos dos parâmetros do solo (CARDOSO \& FERNANDES, 2001).

Considerando uma variável qualquer de interesse para a segurança das fundações, pode-se definir como valor característico dessa variável o valor que tenha uma certa probabilidade pré-fixada de não ser ultrapassado por valores desfavoráveis à segurança estrutural.

Tanto as solicitações como as resistências têm sempre seu valor característico calculado a partir de suas curvas de distribuição, sendo usual, no Método dos Estados Limites, aproximar as curvas de distribuição estatísticas auferidas das coletas de dados referentes à solicitação e resistência para curvas de distribuição normal. Mas, quando a determinação de valores característicos é inexeqüível, por não se ter um conhecimento estatístico suficiente, é usual recorrer a valores característicos nominais para a implementação do Método dos Estados Limites (CARDOSO \& FERNANDES, 2001).

Segundo Cherubini (2001), conhecendo a média e o desvio-padrão, é possível determinar o denominado valor característico de acordo com o Eurocode 7 e de posse 
dos valores característicos é possível determinar os valores de cálculo das variáveis de projeto.

Os valores de cálculo são os valores a serem adotados na verificação da segurança da estrutura ao estado limite último e de utilização. Eles correspondem aos valores característicos ponderados pelos coeficientes de majoração ou pelos coeficientes de minoração, apresentados no próximo item.

(1) Valor característico das resistências

Para os materiais, os valores característicos das resistências são determinados considerando-se a dispersão dos resultados de ensaios experimentais. Admite-se que a distribuição seja normal, sendo o valor característico definido pela expressão apresentada a seguir, que corresponde ao quantil de $5 \%$ da respectiva distribuição, ou seja, pelo menos $95 \%$ dos valores das resistências dos resultados experimentais devem ser superiores a $R_{k}$ :

$$
\mathrm{R}_{\mathrm{k}}=\mathrm{R}_{\mathrm{m}}-1.65 . \sigma
$$

Sendo:

- $\mathrm{R}_{\mathrm{m}}$ : valor médio das resistências dos vários resultados experimentais;

- $\mathrm{R}_{\mathrm{k}}$ : valor característico da resistência;

- $\sigma$ : desvio padrão dos resultados experimentais.

(2) Valor característico das ações e solicitações

Para a obtenção dos valores característicos das ações e solicitações, é considerada a incerteza na previsão ou no cálculo do seu valor. Os valores característicos das ações devem ser determinados através de dados estatísticos relativos à dispersão dos valores das ações considerados. Não se dispondo de tais dados, os valores característicos das ações são especificados pelas normas.

Os valores característicos das solicitações são determinados com o valor característico das ações. Esses valores característicos são determinados aceitando-se uma probabilidade a priori de $5 \%$ das solicitações efetivas serem superiores a eles:

$$
\mathrm{S}_{\mathrm{k}}=\mathrm{S}_{\mathrm{m}}+1.65 \cdot \sigma
$$

Sendo:

- $\mathrm{S}_{\mathrm{m}}$ : valor médio da solicitação;

- $\mathrm{S}_{\mathrm{k}}$ : valor característico da solicitação;

- $\sigma$ : desvio padrão. 
De acordo com NBR 8681/1984, os valores característicos das ações são definidos em função de sua classificação (variável, permanente, excepcional) e da variabilidade de sua intensidade, ou seja, de dados estatísticos relativos aos valores das ações consideradas.

\subsubsection{Os Coeficientes Parciais de Segurança}

O Método dos Estados Limites consiste na aplicação dos chamados coeficientes parciais de segurança como ferramenta na verificação da segurança, sendo estes coeficientes de segurança específicos a cada estado limite e individuais a cada variável do problema, e tem a função de levar em conta as incertezas do projeto, tais como, aquelas relacionadas às cargas, às propriedades dos materiais, aos modelos teóricos adotados e, à variabilidade inerente ao substrato geológico-geotécnico (FANG, 1997).

Meyerhof (1969) faz uma homenagem ao professor Brinch Hansen comentando sobre seu trabalho e sobre suas contribuições ao desenvolvimento da Engenharia Geotécnica. Em Meyerhof (1969) é possível visualizar os coeficientes de segurança globais mínimos e os coeficientes parciais de segurança mínimos que devem ser aplicados aos parâmetros de resistência do solo (coesão e ângulo de atrito) e às cargas, propostos por Brinch Hansen em 1953. Esses coeficientes são similares aos sugeridos por Brinch Hansen e os que contêm o Danish Code of Practice for Foundation Engineering.

De acordo com a NBR 6122/1996, item 5.6.1.4, o valor de cálculo da resistência (ou capacidade de carga) de um elemento de fundação pode ser determinado de três maneiras:

a) a partir de provas de carga, quando se determina inicialmente sua resistência (ou capacidade de carga) característica;

b) a partir de método semi-empírico ou empírico, quando se determina inicialmente sua resistência (ou capacidade de carga) característica nominal;

c) quando se empregam métodos teóricos.

Segundo o item 5.6.1.5., no primeiro caso deve-se aplicar o terceiro coeficiente de ponderação conforme a Tabela 2.2. No segundo caso, deve-se aplicar um dos primeiros coeficientes de ponderação da Tabela 2.2, dependendo do tipo de fundação. No terceiro caso, uma vez que os parâmetros de resistência do solo foram reduzidos por coeficientes de ponderação, conforme Tabela 2.3, para uso nos cálculos, o resultado 
obtido já é o valor de cálculo da resistência (ou capacidade de carga) do elemento de fundação.

Tabela 2.2. Coeficientes de ponderação da capacidade de carga de fundações (NBR 6122/1996).

\begin{tabular}{|c|c|}
\hline Condição & Coeficiente $^{\text {Cundação superficial (sem prova de carga) }}{ }^{(\mathrm{A})}$ \\
\hline Fundação profunda (sem prova de carga) $^{(\mathrm{A})}$ & 2.2 \\
\hline Fundação com prova de carga & 1.5 \\
\hline
\end{tabular}

(A) Capacidade de carga obtida por método semi-empírico.

Tabela 2.3. Coeficientes de ponderação das resistências (NBR 6122/1996).

\begin{tabular}{|c|c|c|c|}
\hline Parâmetros & In situ $^{(\mathrm{A})}$ & Laboratório $^{\left(\text {Correlações }^{(\mathrm{B})}\right.}$ \\
\hline Tangente do ângulo de atrito & 1.2 & 1.3 & 1.4 \\
\hline Cocsão (estabilidade e empuxo de terra) & 1.3 & 1.4 & 1.5 \\
\hline Coesão (capacidade de carga de fundações) & 1.4 & 1.5 & 1.6 \\
\hline
\end{tabular}

(A) Ensaios CPT, Palheta (Vane, Pressiômetro, conforme a NBR 10905).

(B) Ensaios SPT, Dilatômetro.

As ações que podem atuar simultaneamente numa estrutura devem ser combinadas de forma a acarretarem os efeitos mais desfavoráveis. Estas combinações devem ser feitas com os valores de cálculo das solicitações.

A norma brasileira de Ações e Segurança nas Estruturas NBR 8681/1984 fornece as combinações das ações para os estados limites últimos e para os estados limites de utilização, assim como todos os coeficientes parciais de segurança necessários à aplicação do Método dos Estados Limites. Maiores informações podem ser encontradas na própria norma e em Sáles et al.(2000).

\subsection{A necessidade de uma evolução}

\subsubsection{A NBR 6122/1996 e a atual conjuntura de projeto}

Neste item serão feitas algumas considerações a respeito da norma brasileira de fundações NBR 6122/1996 e a respeito da prática corrente na engenharia de fundações no Brasil com relação a atual conjuntura de projeto.

As normas são documentos de referência, estabelecidos por consenso e aprovados por um organismo reconhecido, que visam fornecer informações suficientes, 
de modo claro, consistente e conciso para auxiliar o engenheiro a tomar decisões corretas de forma a produzir um projeto seguro e econômico.

As normas devem dar atenção à praticidade e à economia, mas a sua principal função é assegurar níveis mínimos de segurança, que sejam considerados adequados. Logo, o papel das normas de cálculo é apresentar recomendações que garantam a segurança de todas as estruturas construídas sob sua jurisdição e a função de um engenheiro é, então, projetar estruturas que atendam às exigências mínimas das normas com relação à segurança, e que sejam, ao mesmo tempo, práticas e econômicas (BERNARDO, 1999; OLIVEIRA, 1998).

É importante destacar que o aparecimento e evolução das normas técnicas direcionam a construção civil, estabelecendo regras a serem cumpridas pelos projetistas e construtores. Uma boa norma deve ser fácil de consultar e usar e não deve impedir o uso de recursos e procedimentos alternativos, desde que justificados e com a salvaguarda do nível de segurança que a norma estipula (JEARY, 1997).

Quando um novo código é proposto, é necessário avaliar a sua performance na prática. A calibração do código é o termo usado para este processo. É importante reconhecer, entretanto, que as estruturas projetadas por um novo método, em princípio, serão mais ou menos "robustas" que outras projetadas previamente, o que é perfeitamente aceitável (BOLTON, 1989).

As normas de fundações, geralmente fornecem regras gerais para a realização de investigações preliminares, para a escolha dos valores dos parâmetros geotécnicos envolvidos no projeto, apresentam modelos de cálculos e fornecem coeficientes de segurança (OLIVEIRA, 1998).

As normas devem especificar os coeficientes de segurança objetivando introduzir no projeto um nível de segurança adequado (WHITE, 1993). Os coeficientes de segurança especificados ajudam a levar em conta as incertezas no projeto, tais como:

- aquelas relacionadas às cargas;

- às propriedades dos materiais;

- aos modelos teóricos adotados;

- à variabilidade inerente ao solo.

As especificações de projeto precisam atender a todas as condições de construção e uso. Para isso, o código precisa dar detalhes a respeito dos estados limites e das situações de projeto que precisam ser consideradas num projeto e, os estados 
limites especificados precisam ser representativos dos modos de comportamento que são considerados insatisfatórios para a estrutura na classe em consideração (BOLTON, 1989; CHERUBINI et al., 1992).

A Norma Brasileira de Fundações, NBR 6122/1996: "Projeto e Execução de Fundações", dedica todo o capítulo 5 ao assunto "Cargas e Segurança nas fundações". A abordagem dada neste capítulo ao assunto segurança nas fundações apresenta duas linhas, a primeira empregando coeficientes de segurança globais e a segunda, coeficientes de segurança parciais. A escolha do tipo de abordagem é, segundo a norma, função do fornecimento ou não, no projeto estrutural, da especificação dos tipos de ações atuantes (BILFINGER, 2002).

Entretanto, a norma NBR 6122/1996 não trata da variabilidade das cargas advindas da estrutura (com exceção das cargas de vento), das combinações entre cargas permanentes e variáveis e das combinações das diversas cargas acidentais. No capítulo da norma que trata de coeficientes parciais de segurança, não há menção às ações. Os coeficientes parciais de segurança fornecidos se referem somente aos esforços resistentes. Porém, a NBR 8681/1984: “Ações e Segurança nas Estruturas” apresenta uma discussão bastante detalhada sobre os coeficientes de segurança que deverão ser aplicados às ações. Com relação às resistências, está norma não quantifica os coeficientes parciais de segurança, tendo em vista que estes dependem da variabilidade associada a cada material (BILFINGER, 2002).

A verificação da segurança na Engenharia de Fundações é ainda hoje, apesar das normas existentes, um tema que gera muita discussão e polêmica, devido às normas darem diferentes definições de segurança e diferentes valores de coeficientes de segurança mínimos (SIMONS, 1981). Pois, a discussão sobre o uso de coeficientes de segurança parciais ou globais, e a própria definição de coeficiente de segurança, não são um consenso no meio da Engenharia Geotécnica, embora a Norma NBR 6122/1996: "Projeto e Execução de Fundações", revisão de abril de 1996, tenha gerado avanços significativos neste sentido (BILFINGER, 2002).

O conceito de coeficiente de segurança global é simples e aplicável, mas existem problemas na sua utilização prática, porque não é especificado em norma sobre qual parâmetro ele dever ser aplicado. A ambigüidade pode ser eliminada se os procedimentos de projeto para a determinação da capacidade de carga do solo, da análise e do cálculo, forem estabelecidos pelas normas, entretanto isso raramente acontece, resultando em falta de uniformidade entre os engenheiros. 
Um exemplo dessa falta de uniformidade é o da escolha do valor de resistência última ou capacidade de carga a ser utilizado no projeto. Esse valor pode ser obtido de diversas maneiras resultando em valores diferentes para um mesmo projeto. Por exemplo, um engenheiro pode escolher o valor médio das resistências calculadas, enquanto outro pode escolher o valor mínimo, que é um valor mais conservador. Assim, para um mesmo valor numérico de coeficiente de segurança global os níveis de segurança serão diferentes.

Kulhawy (1996) apresenta um interessante exemplo em que foi pedido para um número de experientes projetistas que calculassem a capacidade de carga de uma determinada fundação usando suas práticas normais de cálculo e adotando um $\mathrm{CS}=3.0$ (por motivos ilustrativos apenas). O exercício resultou em cinco diferentes filosofias de projeto e capacidades de carga que variavam, em média, na proporção de dois.

A NBR 6122/1996 trouxe profundas alterações nos conceitos relativos ao projeto de fundações. A cultura da carga admissível, calcada na experiência prática e, baseada no uso de um coeficiente de segurança global, foi redirecionada para uma nova cultura da carga característica, baseada na aplicação de coeficientes de segurança parciais. Porém, esta mudança foi proposta sem uma devida divulgação dos pressupostos científicos em que foi baseada, gerando insegurança e resistência na sua adoção (OLIVEIRA \& AOKI, 1998).

Em 1996, a aprovação da norma de fundações brasileira NBR 6122/1996, deveria promover a aproximação entre os projetos estruturais e os projetos de fundações, pela incorporação do método semiprobabilístico dos estados limites. No entanto, o projeto de fundações, em sua grande maioria, ainda faz uso do Método das Cargas Admissíveis, devido, em parte, pela grande resistência dos engenheiros em mudar seus hábitos de projeto; resistência essa, devida não apenas a uma questão cultural, mas também, devida à evidente falta de informações que os possibilitem utilizar o novo método.

Segundo Simons (1981), o método dos coeficientes parciais de segurança está presente em várias normas e recomendações de projeto em todo o mundo, entretanto, o seu uso ainda não prevalece na Engenharia de Fundações devido a este ainda ser pouco compreendido e difundido entre os engenheiros de fundações.

Para a aplicação do método semiprobabilístico dos estados limites são necessárias duas alterações essenciais nas rotinas de trabalho dos projetistas de 
fundações: calcular os valores de cálculo e subordinar as etapas de projeto aos possíveis estados limites da fundação considerada.

Entretanto, a obtenção dos valores de cálculo das solicitações e resistências traz inúmeras dificuldades de ordem prática, devido às muitas controvérsias sobre a definição e a obtenção dos valores característicos na Engenharia de Fundações. Porém, a subordinação das etapas de projeto aos possíveis estados limites traz um aprimoramento geral da técnica de projetar fundações, evitando-se omissões que podem conduzir a colapsos catastróficos. Mas, para isso, faz-se altamente necessário que na normalização do projeto de fundações sejam especificados os estados limites, os coeficientes de ponderação, as regras de combinação das ações, e os recalques limites para estruturas convencionais envolvidos na verificação da segurança.

Neste contexto, é válida a observação do Committee on Reliability Methods for Risk Mitigation in Geotechnical Engineering, em 1995 (KULHAWY, 1996), ao afirmar que na prática da Engenharia Geotécnica, principalmente nas áreas mais convencionais, como a Engenharia de Fundações e Barragens, onde existem métodos consagrados disponíveis que refletem décadas de prática profissional, os engenheiros têm visto pouca necessidade de mudar de métodos que os servem bem, para novos e não-testados métodos com benefícios potenciais questionáveis.

Essa observação é contestada veementemente por Kulhawy (1996) ao afirmar que não se deve considerar como boa a prática convencional de projeto na Geotecnia, por apresentar, relativamente, poucos colapsos. Isso não significa, necessariamente, que a prática de projeto é ótima ou mesmo satisfatória, mas pode significar que há muito conservadorismo embutido no processo de projeto e que talvez as fundações nunca tiveram que suportar as reais solicitações de projeto.

Pode-se assim dizer com certeza que, em nosso país, a técnica de projeto de fundações não tem recebido o tratamento científico adequado. Essa afirmação pode ser comprovada ao se considerar quão pequeno é o número de conceitos gerais estabelecidos com base científica e utilizados na técnica das fundações (VELLOSO \& LOPES, 1996).

A escolha dos valores dos parâmetros geotécnicos é função de vários fatores e sujeita a muitas variabilidades e incertezas (OLIVEIRA, 1998). Não há resposta única para questões, tais como:

- Que valores de parâmetros de resistência e de deformação são mais apropriados para fins de projeto?; 
- Como proceder para obter o valor característico a partir de provas de cargas ?;

- Qual deve ser o tipo e o número de ensaios?;

- Qual é o valor característico nominal a ser adotado quando mais de um ensaio é utilizado para determinar a capacidade de carga do solo ?.

Na NBR 6122/1996 não fornece a definição de valor característico, assim dependendo da experiência e julgamento, diferentes engenheiros podem interpretar de diferentes formas e chegar a valores de cálculo os mais diversos e incoerentes para um mesmo projeto.

O Eurocode 7 sugere, sob forma de recomendação, que o valor característico deve ser obtido a partir de resultados experimentais, porém, reconhecendo as dificuldades de obtenção de dados para análises estatísticas, permite a adoção de valores nominais para os parâmetros de resistência do solo (CHERUBINI, 2000).

Segundo a NBR 6122/1996, o valor da capacidade de carga pode ser determinado de três diferentes maneiras: a partir de provas de carga, a partir de métodos teóricos e a partir de modelos semi-empíricos ou empíricos. Como nos dois últimos casos, a capacidade de carga é, geralmente, calculada através de modelos baseados em parâmetros de resistência do solo obtidos em laboratório ou em alguns poucos ensaios in situ, em número insuficiente para constituir estudo estatístico, convencionou-se chamar a capacidade de carga obtida através destes métodos de capacidade de carga característica nominal.

Quando se utilizam métodos teóricos, a capacidade de carga de cálculo é obtida introduzindo em um modelo analítico os valores de cálculo dos parâmetros de resistência do solo, obtidos a partir dos valores característicos ou valores característicos nominais minorados por seus respectivos coeficientes de segurança.

Estes métodos são conhecidos como Métodos das Resistências Fatoradas. Porém, uma das questões mais difíceis a ser solucionada na norma NBR 6122/1996, é a definição dos valores característicos dos parâmetros de resistência do solo com base nos ensaios in situ e de laboratório.

Esta dificuldade deve-se sobretudo ao fato de que, enquanto na Engenharia Estrutural é relativamente fácil obter o número necessário de medições dos parâmetros (pesos específicos, resistências, etc.) dos materiais construtivos, e logo obter os respectivos valores médios, desvios padrões e valores característicos; na Engenharia Geotécnica, na melhor das hipóteses, dispõe-se de um resultado estatístico de poucas amostras geotécnicas colhidas, durante a fase de prospecção do solo. Há, portanto, uma 
dificuldade em selecionar parâmetros de resistência que sejam representativos das condições do solo in situ (MAGNAN, 1989).

No entanto, a maioria dos projetos de fundações profundas executados no Brasil, baseia-se em fórmulas empíricas e semi-empíricas para a determinação da carga de ruptura do solo, sendo que as correlações mais comuns utilizam os ensaios SPT e CPT. Como essas fórmulas não empregam os parâmetros coesão e atrito no cálculo da resistência do solo, outro procedimento deve ser empregado para obter a capacidade de carga de cálculo (MASCHWITZ \& CUNZE, 1989).

Uma alternativa consiste em aplicar coeficientes de minoração diretamente aos valores de capacidade de carga característica ou característica nominal obtidos através dos métodos empíricos ou semi-empíricos. Este procedimento é equivalente ao Método das Resistências não Fatoradas, ou seja, combina todas as incertezas associadas à resistência em um único coeficiente de segurança.

O critério geral de segurança é comparar os valores de cálculo da capacidade de carga com os valores de cálculo das solicitações, verificando todos os possíveis estados limites. Estes valores são obtidos a partir dos valores médios ou característicos correspondentes, pela divisão por coeficientes de ponderação adequados. O coeficiente de minoração da capacidade de carga geralmente modifica toda a expressão de cálculo, mas em algumas normas, estes coeficientes podem atuar nas parcelas individuais da expressão (ponta e/ou atrito lateral). Esta divisão tem como objetivo reduzir, a probabilidade de ocorrência de valores desfavoráveis, a níveis aceitáveis.

Admitindo que se dispõe de um número adequado de ensaios in situ para realização de um estudo estatístico, e que a distribuição de probabilidade da capacidade de carga é normal, aceita-se geralmente a probabilidade de obter até $5 \%$ dos resultados experimentais abaixo do valor representativo. Quando não se dispõe de ensaios em quantidade suficiente para efetuar um estudo estatístico, o valor da capacidade de carga estabelecido é denominado de capacidade de carga característica nominal (LACASSE \& NADIM, 1997).

Deve-se destacar, que os modelos analíticos de base empírica e semi-empírica são apenas aplicáveis dentro de uma faixa de condições específicas incluídas em seu processo de calibração, a extrapolação além dessas condições pode, potencialmente resultar em previsões errôneas do desempenho da fundação.

Segundo Velloso \& Lopes (1996), na fase de projeto, geralmente existe uma certa "timidez" por parte dos projetistas em solicitar ensaios para bem caracterizar os 
parâmetros, o que resulta em informações limitadas e escassas para efeito de amostragem., ficando o conhecimento do solo, quase sempre, restrito ao que fornecem, algumas poucas sondagens à percussão de simples reconhecimento.

Bilfinger (2002) comenta que na realização de um projeto de fundações, há uma grande dificuldade em avaliar qual deve ser a sondagem representativa do subsolo local. Diversas são as formas de consideração de investigações:

- Divisão da área da obra em sub-áreas de influência para cada sondagem;

- Escolha de uma sondagem "média" como representativa;

- Escolha de uma sondagem "ruim" como representativa;

- Montagem de uma sondagem fictícia, baseada em valores médios para cada profundidade (calculados a partir de todas as sondagens);

- Montagem de uma sondagem fictícia, baseada em valores mínimos para cada profundidade (calculados a partir de todas as sondagens); etc.

Logicamente que cada uma das possibilidades tem os seus defensores e que cada uma resulta em uma previsão diferente. Pois, não existe nenhuma metodologia indicada pela Norma Brasileira, o que dá ao engenheiro de fundações uma grande liberdade de elaborar o "seu" procedimento de projeto, padronizado ou adaptável a cada tipo de obra que enfrenta (BILFINGER, 2002).

Um ponto a ser ressaltado, é que a execução de obras de fundações em estacas cravadas, com raras exceções, está sempre vinculada aos chamados controles de campo: nega, repique, comprimento cravado e diagrama de cravação. Segundo Bilfinger (2002), o controle de execução de uma obra pode conduzir ao aumento da segurança desta. Pois, a medida de dados como nega, repique e registro de comprimento cravado para cada estaca da obra tem-se demonstrado bastante útil como critério de uniformidade da capacidade de carga de um estaqueamento.

Sabe-se que em uma obra na qual existe um controle efetivo de cravação pode apresentar menor dispersão da capacidade de carga, e assim, apresentar mais segurança em relação à mesma obra sem controle ou com um controle expedito. Logo, a realização ou não de um controle durante o processo de execução de uma fundação influi na segurança da mesma. Sendo assim, a existência ou não de um controle executivo deveria ser levado em consideração pela norma, por este influenciar na segurança de uma fundação (BILFINGER, 2002; PAIKOWSKY \& STENERSEN, 2000). 


\subsubsection{As deficiências do Coeficiente de Segurança Global}

Para assegurar uma racional segurança na Engenharia de Fundações, os projetos são usualmente realizados introduzindo nas análises um coeficiente de segurança que pode ser definido como a razão entre a resistência e a solicitações atuantes (MEYERHOF, 1969).

No Método das Cargas Admissíveis, os coeficientes de segurança globais introduzem uma conveniente distância entre a situação de utilização da fundação e àquela que corresponderia a uma ruína. Geralmente a medida desta distância, é representada pela razão entre a resistência média e a solicitação média. Logo, as solicitações e as resistências são consideradas determinísticas, ou seja, representadas por valores únicos. Quando o coeficiente de segurança global se iguala a um, teoricamente, atingi-se uma condição limite, pois as resistências se igualam às solicitações, ou seja, tem se a ruptura do sistema. Entretanto, na realidade existem inúmeras variabilidades e incertezas na determinação dos reais valores de solicitações e resistências, o que implica na existência de distribuições de freqüência para ambos.

Segundo DUNCAN (2000), a seleção do valor do coeficiente de segurança deveria considerar:

- As incertezas implícitas nos parâmetros utilizados no cálculo.

- As conseqüências de uma falha ou de um comportamento insatisfatório.

Os coeficientes de segurança usados na prática geotécnica convencional são, em geral, baseados na experiência. Entretanto, é comum o uso do mesmo valor de coeficiente de segurança independente do grau de incerteza envolvido no cálculo (DUNCAN, 2000).

Segundo Basma (1994), o procedimento comum de projeto é assegurar um coeficiente de segurança adequado. Entretanto, há basicamente dois problemas nesse comportamento. O primeiro refere-se ao fato dos coeficientes de segurança serem igualmente aplicados aos casos em que o maciço de solos é composto por solos homogêneos ou quando este é composto por solos extremamente heterogêneos. $\mathrm{O}$ segundo problema, é que, em ambos os casos, os valores dos coeficientes de segurança selecionados podem ser elevados, resultando em projetos antieconômicos ou, podem ser baixos, o que pode conduzir a projetos inseguros. Neste último caso, em geral, o coeficiente de segurança é usualmente baseado na experiência e precisa ser assegurado por um especialista. 
Segundo Duncan (2000), o mesmo valor do coeficiente de segurança é aplicado às condições envolvendo diferentes graus de incerteza e isto não é lógico. Lacasse \& Nadim (1997) afirmam que o coeficiente de segurança não é um indicador suficiente do nível de segurança, porque as incertezas existentes nos valores dos parâmetros usados na análise, afetam a probabilidade de ruína e essas incertezas não são explícitas em um cálculo determinístico usando o coeficiente de segurança.

Observando as curvas de distribuição dos valores de solicitações e a curva de distribuição dos valores de resistências, nota-se uma região de sobreposição entre elas, que está diretamente relacionada com a probabilidade de ruína. Quando as duas curvas ficam graficamente mais afastadas, a probabilidade de ruína diminui; de modo contrário, a probabilidade de ruína aumenta à medida que as curvas ficam mais próximas (ANG \& TANG, 1984).

Assim, para se reduzir a probabilidade de ruína, deve-se diminuir a região de sobreposição entre as curvas e, para isso, pode-se:

(1) adotar um coeficiente de segurança global maior, diminuindo a região de sobreposição entre as curvas, o que depende da posição relativa de $f_{X}(x)$ e $f_{Y}(y)$, que pode ser "medida" pelo coeficiente de segurança global $\left(\mu_{\mathrm{x}} / \mu_{\mathrm{y}}\right)$ ou pela margem de segurança média $\left(\mu_{x}-\mu_{y}\right)$. Observe a Figura 2.1.

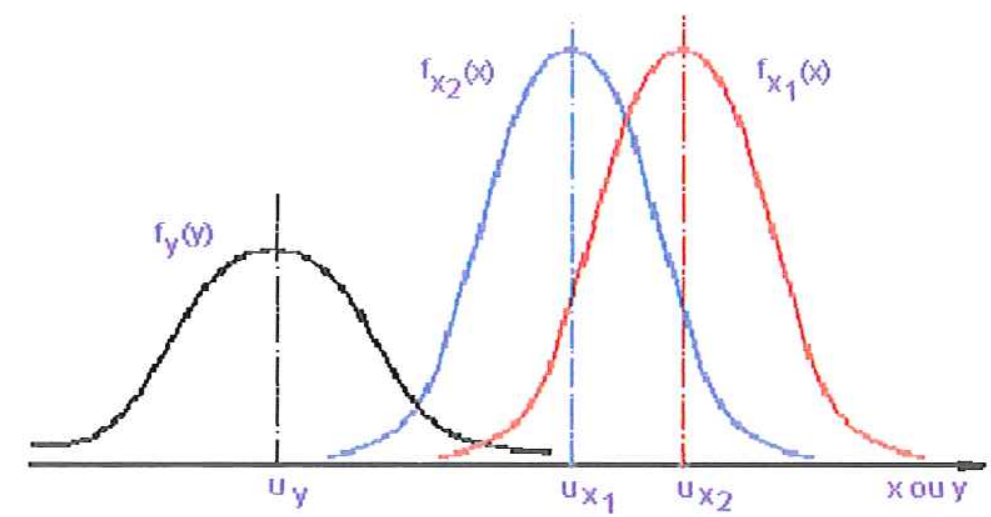

Figura 2.1. Efeito da posição relativa de $f_{X}(x)$ e $f_{Y}(y)$ na probabilidade de ruína (ANG \& TANG, 1984).

(2) ou manter as mesmas médias, e portanto, o mesmo coeficiente de segurança global e adotar um melhor controle, para se ter curvas com menor dispersão, pois a região sobreposta, também depende, do grau de dispersão de $f_{X}(x)$ e $f_{Y}(y)$. Logo, dispersões menores, expressas em termos de menores coeficientes de variação, resultam numa menor probabilidade de ruína, como pode ser observado na Figura 2.2. 


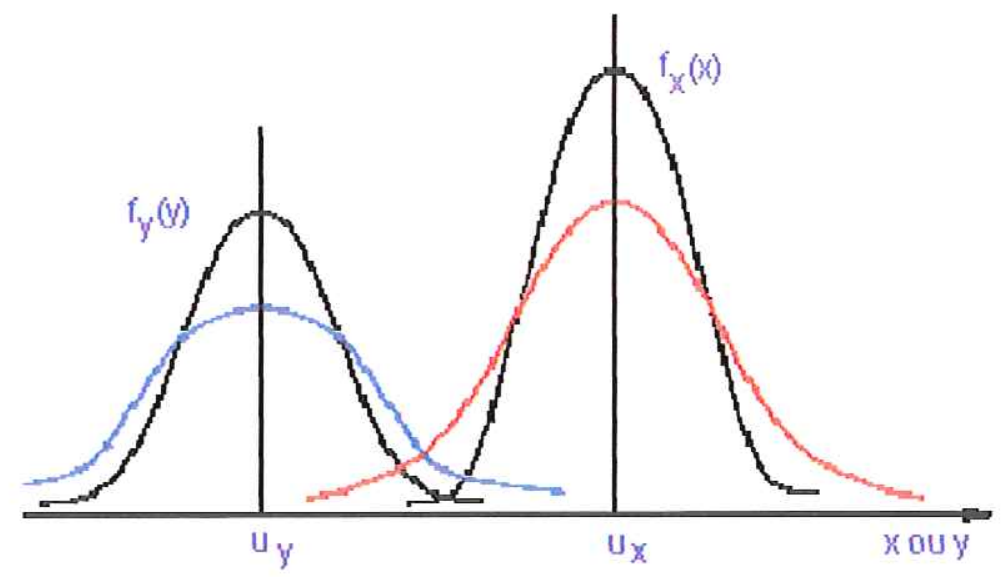

Figura 2.2. Efeito das dispersões de $f_{X}(x)$ e $f_{Y}(y)$ na probabilidade de ruína (ANG \& TANG, 1984).

Portanto, conclui-se que qualquer medida de segurança confiável deve ser função da posição relativa de $f_{X}(X)$ e $f_{Y}(Y)$, e do grau de dispersão dessas curvas. Logo, conclui-se que o coeficiente de segurança global é uma ferramenta deficiente para garantir a segurança de uma obra por não considerar a dispersão existente. Pois, ao não estar vinculado a probabilidade de ruína, não quantifica a segurança existente. Conseqüentemente, pode-se encontrar obras com o mesmo coeficiente e probabilidades de ruína diferentes, e obras com coeficientes de segurança diferentes e probabilidades de ruína iguais.

Como discutido por Li e Lumb (1987) e Nadim e Lacasse (1999), o coeficiente de segurança não é um bom indicador do nível de segurança. Pois, uma estrutura geotécnica com um elevado coeficiente de segurança pode ter um risco de falha maior que uma estrutura similar com um baixo coeficiente de segurança, dependendo da precisão do modelo usado na análise, e das incertezas existentes na determinação dos parâmetros envolvidos (LI \& LAM, 2001).

Sendo neste contexto, que se insere o estudo da Teoria da Confiabilidade, por se tratar da ferramenta mais adequada na tentativa de quantificar a segurança, a confiabilidade, as variabilidades e as incertezas da Engenharia de Fundações. 


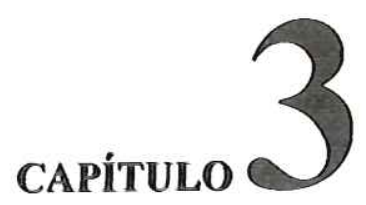

CONFIABILIDADE DE SISTEMAS DE ENGENHARIA

\subsection{Confiabilidade de Sistemas}

Um dos principais objetivos da engenharia é garantir a segurança e o desempenho satisfatório das estruturas com o máximo de economia possível. Atingir esse objetivo, entretanto, geralmente não é um problema simples, particularmente pelo grande número de sistemas estruturais existentes (ANG \& TANG, 1984).

Segundo Ang \& Tang (1984), os sistemas estruturais podem falhar ao desempenhar as funções para as quais foram projetados, pois o risco está sempre implícito nesses sistemas. Entretanto, a maioria dos projetos de sistemas de engenharia podem ser bem sucedidos sem o conhecimento completo das informações; assim, a garantia de desempenho raramente é perfeita. Além disso, muitas decisões requeridas durante o processo de projeto e cálculo são tomadas, invariavelmente, sob condições de incertezas. Portanto, há sempre alguma probabilidade de falha ou mau desempenho associado às suas conseqüências adversas; assim o risco será sempre inevitável. Sob tais condições, não é viável, prática e/ou economicamente, garantir segurança ou desempenho absolutos dos sistemas de engenharia.

No caso de uma estrutura, sua segurança é, claramente, uma função da máxima ação (ou combinação de ações) que lhe pode ser imposta durante seu tempo de vida útil e dependerá também da resistência ou capacidade dessa estrutura ou de seus componentes, de suportar essas ações. 
Como a máxima ação da vida útil de uma estrutura e sua capacidade real são dificeis de serem previstas exatamente e qualquer previsão está sujeita a incertezas, a garantia absoluta da segurança de uma estrutura é impossível. Na realidade, segurança ou desempenho somente podem ser garantidos em termos da probabilidade de que a resistência disponível (ou capacidade estrutural) será suficiente para resistir à máxima ação ou combinação de ações que poderá ocorrer durante a vida útil da estrutura. É dentro desse contexto que a Confiabilidade Estrutural encontra seu campo de atuação (ANG \& TANG, 1984).

Segundo Soares (2001), alguns dos principais interesses do uso da análise de confiabilidade são:

- Fornecer um bom conhecimento das incertezas existentes na previsão do comportamento estrutural;

- Proporcionar um tratamento realístico das incertezas e calibrar os coeficientes parciais de segurança;

- Oferecer uma real medida de segurança e, conseqüentemente, melhorar a estimativa do risco existente;

- O projeto pode ser mais bem dimensionado e, conseqüentemente, mais econômico, possibilitando uma distribuição ótima de materiais entre os elementos estruturais;

- Possibilitar a administração de um sistema existente com um custo ótimo para um dado nível de segurança.

\subsection{Análise e verificação da Confiabilidade}

\subsubsection{Problema básico}

Problemas de confiabilidade em engenharia podem ser definidos como a determinação da capacidade de um sistema para atender a determinadas condições (exigências). Na consideração da segurança de uma estrutura, a preocupação é assegurar que sua resistência seja suficiente para suportar a atuação da máxima ação ou combinação de ações durante toda a sua vida útil (ANG \& TANG, 1984).

Tradicionalmente, a segurança de sistemas estruturais é alcançada através da utilização de coeficientes ou margens de segurança e adoção de suposições conservadoras nos métodos de cálculo, visando assegurar uma mínima condição de resistência para suportar a atuação das máximas solicitações previstas (ANG \& TANG, 1984). 
Freqüentemente, a segurança é definida com base em juízos subjetivos e a suficiência ou insuficiência das "margens" aplicadas podem ser avaliadas ou calibradas somente em termos de experiências passadas com sistemas estruturais semelhantes (ANG \& TANG, 1984).

É dificil quantificar a eficiência da aproximação tradicional e há carência de bases lógicas para o estudo das incertezas, conseqüentemente, os níveis reais de segurança e confiabilidade não podem ser calculados quantitativamente. Além disso, para novos sistemas em que não há ainda bases anteriores para calibração, o problema de assegurar o bom desempenho estrutural se torna extremamente dificil (ANG \& TANG, 1984).

Na realidade, a determinação da resistência disponível bem como da máxima solicitação que pode atuar na estrutura não são problemas simples. Estimativas e previsões são sempre necessárias para esses tipos de problemas, incertezas são inevitáveis pela simples razão de que as informações relativas aos problemas de engenharia serem invariavelmente incompletas. Diante de tais incertezas, a resistência disponível e a solicitação real não podem ser determinadas precisamente; mas podem ser descritas como pertencentes a determinados intervalos, podendo ser modeladas como variáveis aleatórias (ANG \& TANG, 1984).

Variáveis aleatórias são grandezas que possuem uma probabilidade de ocorrência associada a cada valor do seu campo de variação. Assim, a Teoria da Confiabilidade é considerada como um método probabilístico de verificação da segurança por considerar as variáveis estruturais como grandezas aleatórias (SOARES, 2001).

Neste contexto, dá início o estudo da Teoria da Confiabilidade. Primeiramente, inicia-se o estudo da confiabilidade de sistemas pelo problema mais simples, para só posteriormente abordar os problemas mais gerais, que são mais complexos. Destaca-se que este capítulo teve por base os trabalhos de Ang \& Tang (1884) e Melchers (1987).

O Anexo A apresenta os principais conceitos de Estatística e Probabilidade necessários ao desenvolvimento e compreensão do trabalho. Este anexo foi elaborado com base nos trabalhos de Magalhães \& Lima (2002), Meyer (1972), Spiegel (1978) e Costa Neto \& Cymbalista (1974).

Nesses termos, portanto, a segurança de um sistema pode ser mais realisticamente medida em termos de probabilidade. Dessa forma, com a intenção de apresentar os conceitos básicos de avaliação da confiabilidade definem-se as seguintes 
variáveis aleatórias contínuas (ANG \& TANG, 1984):

$X=$ resistência ou capacidade resistente do sistema.

$Y=$ solicitação atuante no sistema.

O problema básico da confiabilidade estrutural considera a atuação de somente uma solicitação $Y$ suportada pela resistência $X$. Sabendo que uma estrutura entra em colapso se a sua resistência inerente $X$ for menor do que a solicitação nela atuante $Y, o$ objetivo da análise de confiabilidade é assegurar que o evento $(X>Y)$ ocorra durante toda a vida útil da estrutura (MELCHERS, 1987; BERNARDO, 1999). Ou seja,

$$
(X>Y), \forall t \in[0, T]
$$

na qual $[0, T]$ é o intervalo de tempo previsto para vida útil da estrutura.

No entanto, essa garantia é somente possível em termos da probabilidade: $P(X>Y)$. Esta probabilidade, portanto, representa a medida realista da probabilidade de segurança ou confiabilidade de uma estrutura, $p_{S}$. Inversamente, a probabilidade do evento complementar, $P(X<Y)$, é a medida correspondente da não-confiabilidade ou da probabilidade de falha, $p_{F}$ (ANG \& TANG, 1984). Ou seja,

$$
p_{F}=P(X<Y)=1-P(X>Y)
$$

Tanto $X$ como $Y$ são descritas por suas distribuições de probabilidade. Supondo que as distribuições de probabilidade das duas variáveis aleatórias $X$ e $Y$ sejam conhecidas $\left(F_{X}(x)\right.$ ou $f_{X}(x)$ e $F_{Y}(y)$ ou $\left.f_{Y}(y)\right)$, a probabilidade de falha pode ser determinada por:

$$
p_{F}=P(X<Y)=\sum_{\text {todos }} P(X<Y / Y=y) \cdot P(Y=y)
$$

Considerando $X$ e $Y$ estatisticamente independentes:

$$
P(X<Y / Y=y)=P(X<y)
$$

Substituindo (3.2) em (3.1), tem-se:

$$
p_{F}=P(X<Y)=\sum_{\text {todos }} P(X<y) \cdot P(Y=y)
$$


Para $X$ e $Y$ contínuos, a probabilidade de falha pode ser determinada pela integração da função densidade de probabilidade conjunta $f_{X, Y}(x, y)$ das variáveis aleatórias $X$ e $Y$, sob o domínio de falha $D_{F}$, isto é, sob a condição de que $(X<Y)$. Assim a equação (3.1) será escrita como:

$$
p_{F}=\iint_{D_{F}} f_{X, Y}(x, y) d x d y=\iint_{X<Y} f_{X, Y}(x, y) d x d y
$$

ou melhor,

$$
p_{F}=\int_{-\infty}^{+\infty}\left[\int_{-\infty}^{y} f_{X, Y}(x, y) d x\right] d y
$$

conseqüentemente, a correspondente probabilidade de segurança ou confiabilidade consiste na integração da função densidade de probabilidade conjunta $f_{X, Y}(x, y)$, sob o domínio de segurança $D_{S}$, isto é, sob a condição de que $(X>Y)$, ou seja,

$$
p_{S}=\iint_{D_{S}} f_{X, Y}(x, y) d x d y=\iint_{X>Y} f_{X, Y}(x, y) d x d y=\int_{-\infty}^{+\infty}\left[\int_{-\infty}^{x} f_{X, Y}(x, y) d y\right] d x
$$

Se a solicitação e a resistência forem variáveis aleatórias contínuas e estatisticamente independentes (ANG \& TANG, 1984):

$$
f_{X, Y}(x, y)=f_{X}(x) \cdot f_{Y}(y)
$$

Dessa forma, a função de densidade conjunta $f_{X, Y}(x, y)$, das variáveis aleatórias $X$ e $Y$, presente nas expressões anteriores, pode ser substituída pelo produto de suas funções de densidade de probabilidade $f_{X}(x)$ e $f_{Y}(y)$. Assim, a expressão (3.4a) para $X$ e $Y$ estatisticamente independentes passa a ser escrita da seguinte forma: 


$$
p_{F}=\iint_{D_{F}} f_{X, Y}(x, y) d x d y=\iint_{D_{F}} f_{X}(x) \cdot f_{Y}(y) d x d y=\iint_{X<Y} f_{X}(x) \cdot f_{Y}(y) d x d y
$$

Esta expressão também pode ser escrita como:

$$
p_{F}=\int_{-\infty}^{+\infty} \int_{-\infty}^{y} f_{X}(x) \cdot f_{Y}(y) d x d y=\int_{-\infty}^{+\infty} f_{Y}(y)\left[\int_{-\infty}^{y} f_{X}(x) d x\right] d y
$$

Integrando a função densidade $f_{X}(x) d x$ de $-\infty$ a $y$, tem-se a função de distribuição acumulada de $X$ em $y, F_{X}(y)$, ou seja:

$$
F_{X}(y)=[P(X) \leq y]=\int_{-\infty}^{y} f_{X}(x) d x
$$

Logo a equação (3.7b) reduz-se a:

$$
p_{F}=\int_{-\infty}^{+\infty} F_{X}(y) \cdot f_{Y}(y) d y
$$

Entretanto, como as variáveis aleatórias $X$ e $Y$ são essencialmente não negativas, pode-se substituir o limite inferior das integrais anteriores de $-\infty$ por 0 . Assim, as expressões: (3.4b), (3.5a) e (3.7c) podem ser escritas, respectivamente, como:

$$
\begin{aligned}
& p_{F}=\int_{0}^{+\infty}\left[\int_{0}^{y} f_{X, Y}(x, y) d x\right] d y \\
& p_{S}=\int_{0}^{+\infty}\left[\int_{0}^{x} f_{X, Y}(x, y) d y\right] d x \\
& p_{F}=\int_{0}^{+\infty} F_{X}(y) \cdot f_{Y}(y) d y
\end{aligned}
$$


A equação $(3.7 \mathrm{~d})$ representa a probabilidade de falha calculada pela integração em relação à $y$, podendo ser representada pela Figura 3.1 na qual as funções $f_{X}(x)$ e $f_{Y}(y)$ estão plotadas no mesmo eixo. No entanto, a probabilidade de falha pode também ser formulada através da integração em relação a $x$, como se segue:

$$
p_{F}=\int_{0}^{+\infty}\left[1-F_{Y}(x)\right] \cdot f_{X}(x) \cdot d x
$$

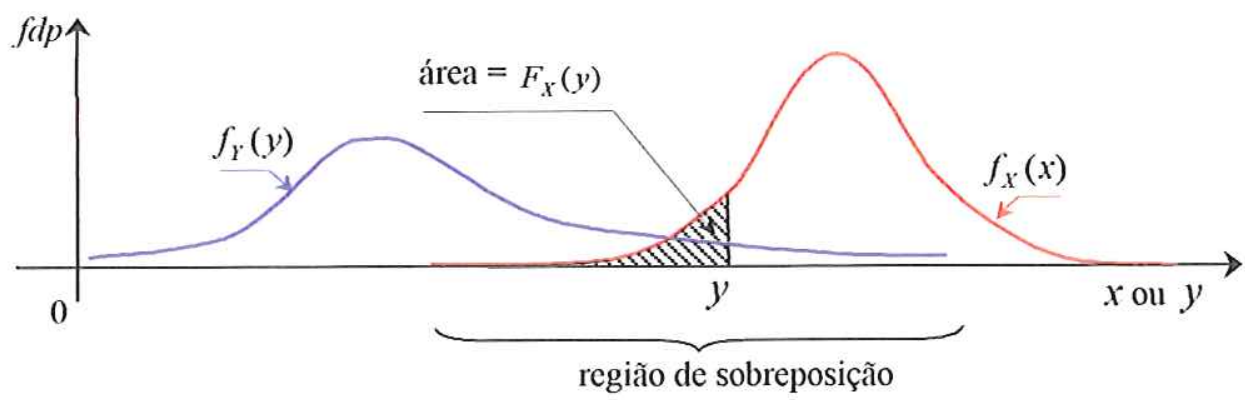

Figura 3.1. Funções densidade de probabilidade de $X$ e $Y$, $f_{X}(x)$ e $f_{Y}(y)$, respectivamente (ANG \& TANG, 1984).

Paralelamente, a correspondente probabilidade de segurança ou confiabilidade (não falha) também pode ser quantificada como o complemento da probabilidade de falha, ou seja, pode ser representada da seguinte forma:

$$
p_{S}=1-p_{F}
$$

Observando a Figura 3.1 e a integral (3.7d) pode-se notar que a falha é causada devido à ocorrência simultânea de dois eventos:

- $1^{\circ}$ evento: ocorrência de um valor de solicitação especifico, ou seja, $Y=y$. A probabilidade de $Y=y$ é dada por:

$$
P(y \leq Y \leq y+d y)=f_{Y}(y) d y
$$

- $2^{\circ}$ evento: ocorrência de valores de resistência inferiores a este valor de solicitação, ou seja, $X \leq y$, cuja probabilidade é dada por: 


$$
P(X \leq y)=\int_{-\infty}^{y} f_{X}(x) d x=F_{X}(y)
$$

Admitindo que os dois eventos são independentes, a probabilidade de que eles ocorram simultaneamente é igual ao produto de suas probabilidades individuais, ou seja:

$$
P(X \leq y \cap y \leq Y \leq y+d y)=f_{Y}(y) d y \cdot \int_{-\infty}^{y} f_{X}(x) d x
$$

Mas, como a falha pode ocorrer para qualquer valor de $y$, deve-se integrar $f_{Y}(y) d y$ ao longo de todos os valores de $y$, ou seja:

$$
P(X \leq y \cap y \leq Y \leq y+d y)=\int_{-\infty}^{+\infty} f_{Y}(y) \cdot \int_{-\infty}^{y} f_{X}(x) d x \cdot d y
$$

que corresponde a expressão (3.7b).

Em resumo, se $Y=y$ a probabilidade de falha será $F_{X}(y)$, mas como, $y \leq Y \leq y+d y$ está associado à probabilidade $f_{Y}(y) d y$, a integração ao longo de todos os valores de $Y$ conduz à probabilidade de falha.

Como mostrado graficamente na Figura 3.1 e discutido no capítulo anterior, sabe-se que a sobreposição das curvas $f_{X}(x)$ e $f_{Y}(y)$ representa uma medida qualitativa da probabilidade de falha, $p_{F}$.

A região de sobreposição depende da posição relativa e do grau de dispersão de $f_{X}(x)$ e $f_{Y}(y)$. Pois, quando as duas curvas ficam graficamente mais afastadas, a probabilidade de falha, $p_{F}$, diminui, enquanto que, de modo contrário, quando as curvas ficam mais próximas, a probabilidade de falha, $p_{F}$, aumenta.

Sabe-se que a posição relativa entre as duas curvas, $f_{X}(x)$ e $f_{Y}(y)$, pode ser medida pela relação entre as médias, $\left(\mu_{X} / \mu_{Y}\right)$, denominada de coeficiente de segurança central ou pela diferença entre as médias das variáveis aleatórias $X$ e $Y$, $\left(\mu_{X}-\mu_{Y}\right)$, denominada de margem de segurança média; enquanto que o grau de 
dispersão pode ser expresso em termos dos coeficientes de variação, $\delta_{X}$ e $\delta_{Y}$, ou pelos desvios padrões, $\sigma_{X}$ e $\sigma_{Y}$.

Sendo assim, conclui-se que a probabilidade de falha é função de $\mu_{X}, \mu_{Y}, \delta_{X}$ e $\delta_{Y}$, ou seja:

$$
p_{F} \sim g\left(\mu_{X}, \mu_{Y} ; \delta_{X}, \delta_{Y}\right)
$$

Logo, conclui-se que qualquer medida de segurança confiável deve ser função da posição relativa de $f_{X}(x)$ e $f_{Y}(y)$, bem como do grau de dispersão dessas curvas. Porém, teoricamente, a probabilidade de falha, $p_{F}$, também depende da forma de $f_{X}(x)$ e $f_{Y}(y)$.

\subsubsection{Formulação Geral}

No entanto, pode-se observar que toda a formulação anterior foi obtida considerando apenas duas variáveis aleatórias $(n=2)$, a resistência $X$ e solicitação $Y$. Contudo, para muitos problemas de engenharia, a formulação apresentada não é inteiramente adequada, já que pode não ser possível reduzir o problema da confiabilidade estrutural a uma simples formulação $X$ versus $Y$. Pois, a confiabilidade de um sistema de engenharia pode envolver variáveis múltiplas, ou seja, pode depender de mais de duas variáveis aleatórias $(n>2)$ (ANG \& TANG, 1984).

Em particular, as variáveis aleatórias resistência $X$ e solicitação $Y$ podem, respectivamente, ser funções de várias outras variáveis aleatórias. Como exemplo, a resistência $X$ é função das propriedades dos materiais, das dimensões, etc; enquanto que a solicitação $Y$ é função das cargas aplicadas, da interação solo-estrutura, etc; onde cada qual, pode ser uma variável aleatória.

As variáveis fundamentais, que definem e caracterizam o comportamento e a segurança de uma estrutura, são chamadas de variáveis básicas de cálculo ou de projeto. Elas são, geralmente, as variáveis empregadas na análise e no projeto estrutural convencional. Exemplos típicos de variáveis básicas são as dimensões, densidades, pesos próprios, materiais, cargas, resistências, etc. Como exemplo, a resistência à compressão do concreto é considerada uma variável básica, embora possa ser função de 
outras variáveis fundamentais, tais como a quantidade de cimento, a relação água/cimento, dimensões e resistência do agregado, etc. No entanto, essas últimas variáveis não são empregadas diretamente nos cálculos em um projeto estrutural, logo, não são consideradas variáveis básicas (ANG \& TANG, 1984).

As distribuições de probabilidade para as variáveis básicas podem ser obtidas por inferência direta dos dados observados, por avaliação subjetiva ou por alguma combinação dessas técnicas. No entanto, na prática, alguma influência subjetiva está sempre presente, já que, raramente, existem dados suficientes disponíveis para identificar, com certeza, apenas uma distribuição de probabilidade como apropriada. Tudo isso confirma que observações passadas e a experiência com estruturas similares devem ser usadas na avaliação da estrutura em consideração.

Com as variáveis básicas e suas distribuições de probabilidade estabelecidas o problema resistência versus solicitação pode ser generalizado. Assim, a forma simplificada da equação de cálculo da probabilidade de falha para apenas duas variáveis, resistência e solicitação, $n=2$, pode ser substituída por uma equação expressa diretamente em termos das $n$ variáveis básicas de cálculo ou de projeto. Esta generalização é freqüentemente necessária em engenharia, particularmente quando o problema deve ser formulado em termos das variáveis básicas de cálculo ou de projeto.

Num sentido mais amplo, a confiabilidade de um sistema de engenharia pode ser definida como probabilidade que o mesmo apresenta de desempenhar suas funções ou missões pretendidas. O nível de desempenho de um sistema, obviamente dependerá das propriedades deste sistema. Neste contexto, e para a proposta de uma formulação geral, define-se a função desempenho, $g(\bar{X})$, como uma função que envolve todas as variáveis básicas relevantes e determina o desempenho ou estado do sistema. Assim,

$$
g(\bar{X})=g\left(X_{1}, X_{2}, \ldots, X_{n}\right)
$$

onde $\bar{X}=\left(X_{1}, X_{2}, \ldots, X_{n}\right)$ é um vetor de variáveis aleatórias básicas de cálculo ou de projeto do sistema. Logo, a exigência de desempenho limitante pode ser definida como $g(\bar{X})=0$, que é a chamada equação de estado limite do sistema. Segue, portanto, que: $[g(\bar{X})>0]=$ representa o "estado seguro" do sistema.

e $[g(\bar{X})<0]=$ representa o "estado de falha" do sistema. 
Geometricamente, a função $g(\bar{X})$ é definida no espaço variável básico, que é um espaço n-dimensional no qual estão todos os possíveis valores de $\bar{X}$. Isto significa que sendo $\bar{x}$ um ponto de coordenadas $x_{1}, x_{2}, \ldots, x_{n}$, ou seja, $\bar{x}=\left(x_{1}, x_{2}, \ldots, x_{n}\right)$, representa a situação em que as variáveis básicas do vetor $\bar{X}=\left(X_{1}, X_{2}, \ldots, X_{n}\right)$ assumem os valores $x_{1}, x_{2}, \ldots, x_{n}$, respectivamente.

Neste contexto, a equação de estado limite, $g(\bar{X})=0$, é uma superfície ndimensional que pode ser chamada de "superficie de falha". De um lado da superficie de falha está o "estado seguro", $g(\bar{X})>0$, ao passo que do outro lado está o "estado de falha", $g(\bar{X})<0$.

Sendo assim, a probabilidade de falha é dada por:

$$
p_{F}=P[g(\bar{X})<0]
$$

Então, se a função densidade de probabilidade conjunta das variáveis básicas de projeto $X_{1}, X_{2}, \ldots, X_{n}$ é a função $f_{X_{1}, X_{2}, \ldots, X_{n}}\left(x_{1}, x_{2}, \ldots, x_{n}\right)$, a probabilidade de falha será dada, na forma escalar, por:

$$
p_{F}=\int_{g}(\bar{X})<0 \ldots \int f_{X_{1}, X_{2}, \ldots, X_{n}}\left(x_{1}, x_{2}, \ldots, x_{n}\right) d x_{1}, d x_{2}, \ldots, d x_{n}
$$

ou, de forma abreviada, em notação vetorial:

$$
p_{F}=\int_{g}(\bar{X})<0
$$

A equação anterior representa a solução analítica de um problema de confiabilidade e, nada mais é do que a integral de volume da função densidade de probabilidade conjunta das variáveis básicas de projeto $f_{\bar{X}}(\bar{x})$ sobre a região de falha, $g(\bar{X})<0$. Inversamente, a probabilidade de segurança ou confiabilidade será dada pela integral de volume de $f_{\bar{X}}(\bar{x})$ sobre a região de segurança, $g(\bar{X})>0$, ou seja: 


$$
p_{S}=\int_{g}(\bar{X})>0 f_{\bar{X}}(\bar{x}) d \bar{x}
$$

$\mathrm{Na}$ prática, entretanto, o desenvolvimento quantitativo (a quantificação) da verdadeira confiabilidade não é uma tarefa simples. As informações sobre as variáveis escolhidas para representar um determinado modelo são sempre limitadas, o que impede que se conheça, a rigor, as formas corretas de $f_{X}(x), f_{Y}(y)$ e $f_{X Y}(x, y)$. As informações disponíveis podem ser suficientes somente para calcular os principais parâmetros estatísticos (ou primeiros momentos) de $X$ e $Y$, tais como os valores médios $\mu_{X}$ e $\mu_{Y}$, e as correspondentes variâncias $\delta_{X}$ e $\delta_{Y}$.

Além do mais, o cálculo dessas integrais (solução analítica), principalmente quando se trata de integrais complexas é, em geral, uma operação extremamente trabalhosa. Assim, encontrar a probabilidade de falha ou a confiabilidade de um sistema, de uma maneira geral, não é fácil. Isto porque para tal se faz necessário à resolução de muitas expressões matemáticas que, muitas vezes, não tem solução analítica. Daí a necessidade de métodos alternativos que serão apresentados a seguir (SOARES, 2001).

Por exemplo, quando se têm integrais complexas a solução analítica das expressões anteriores não é possível, situação que acontece na maioria dos problemas de engenharia. Nestes casos, as expressões anteriores são usualmente resolvidas por dois caminhos:

integrações numéricas,

aproximações analíticas, que são métodos alternativos (aproximados), de solução do problema de confiabilidade, que serão examinados no próximo item.

\subsection{Formulação pelo Segundo Momento}

Em função do exposto anteriormente, pode-se concluir que, o cálculo da probabilidade de falha requer o conhecimento das distribuições de probabilidade ou da distribuição de probabilidade conjunta das variáveis aleatórias envolvidas. Na prática, nem sempre, essas distribuições são conhecidas pela falta de informações. Mas, mesmo quando as distribuições requeridas podem ser especificadas, ou seja, conhecidas, o cálculo exato da probabilidade de falha exige integrações que podem ser impraticáveis, 
por exigirem processos numéricos mais ou menos trabalhosos.

Por outro lado, em conseqüência da falta de informações, são conhecidos, em geral, apenas os primeiros e segundos momentos das variáveis aleatórias; isto é, freqüentemente as informações ou dados disponíveis são suficientes para estimar apenas os valores médios (momentos de $1^{\circ}$ ordem) e as variâncias (momentos de $2^{\circ}$ ordem) das respectivas variáveis aleatórias. Sob essas condições, a implementação dos conceitos de confiabilidade deve, necessariamente, ser limitada a uma formulação baseada nos primeiros e segundos momentos das variáveis aleatórias. Portanto, medidas práticas de segurança e confiabilidade devem exigir somente o conhecimento destes primeiros momentos (CORNELL, 1975; ANG \& TANG, 1984).

Neste contexto, usa-se a Formulação pelo Segundo Momento como um método alternativo de cálculo da confiabilidade baseado em aproximações analíticas que permite, mesmo quando não há informações das distribuições de probabilidade, estimar a confiabilidade usando somente os primeiros e segundos momentos (momento de $1^{\circ}$ ordem e de $2^{\circ}$ ordem) das variáveis de projeto.

Tabela 3.1. Fatores que influenciam o estudo da confiabilidade.

\begin{tabular}{|c|c|c|c|c|}
\hline $\begin{array}{l}\text { Tipo de Função } \\
\text { de desempenho }\end{array}$ & $\begin{array}{l}\text { Tipo de variável } \\
\text { aleatória }\end{array}$ & $\begin{array}{l}\text { Correlação entre as } \\
\text { variáveis aleatórias }\end{array}$ & $\begin{array}{l}\text { Número de } \\
\text { variáveis aleatórias }\end{array}$ & $\begin{array}{l}\text { Caso de } \\
\text { Estudo }\end{array}$ \\
\hline \multirow{8}{*}{ Linear } & \multirow{4}{*}{ Normal } & \multirow{2}{*}{ Não } & $\mathrm{n}=2$ & $1^{\circ}$ \\
\hline & & & $\mathrm{n}>2$ & $2^{\circ}$ \\
\hline & & \multirow{2}{*}{ Sim } & $\mathrm{n}=2$ & $3^{\circ}$ \\
\hline & & & $n>2$ & $4^{\circ}$ \\
\hline & \multirow{4}{*}{ Não Normal } & \multirow{2}{*}{ Não } & $n=2$ & $5^{\circ}$ \\
\hline & & & $\mathrm{n}>2$ & $6^{\circ}$ \\
\hline & & \multirow{2}{*}{ Sim } & $n=2$ & $7^{\circ}$ \\
\hline & & & $n>2$ & $8^{\circ}$ \\
\hline \multirow{8}{*}{ Não Linear } & \multirow{4}{*}{ Normal } & \multirow{2}{*}{ Não } & $\mathrm{n}=2$ & $9^{\circ}$ \\
\hline & & & $n>2$ & $10^{\circ}$ \\
\hline & & \multirow{2}{*}{ Sim } & $\mathrm{n}=2$ & $11^{\circ}$ \\
\hline & & & $n>2$ & $12^{\circ}$ \\
\hline & \multirow{4}{*}{ Não Normal } & \multirow{2}{*}{ Não } & $n=2$ & $13^{\circ}$ \\
\hline & & & $n>2$ & $14^{\circ}$ \\
\hline & & \multirow{2}{*}{ Sim } & $\mathrm{n}=2$ & $15^{\circ}$ \\
\hline & & & $\mathrm{n}>2$ & $16^{\circ}$ \\
\hline
\end{tabular}

Entretanto, o procedimento de cálculo da confiabilidade de um sistema depende de vários fatores: se a função desempenho $g(\bar{X})$ é ou não linear, se o estudo envolve duas (bi-dimensional) ou mais variáveis aleatórias (n-dimensional), se as variáveis 
aleatórias são ou não correlacionadas e, do tipo de distribuição de probabilidade dessas variáveis aleatórias (log-normal, normal, etc.); sendo que as combinações desses fatores dão origem aos 16 casos expostos na Tabela 3.1.

Dessa forma, o problema de cálculo da confiabilidade será dividido, didaticamente, nos 16 "casos de estudo" apresentados na Tabela 3.1. O estudo terá início pelos casos mais simples, ou seja, pelos casos nos quais a função de desempenho, $g(\bar{X})$, é linear, para só posteriormente dar início ao estudo dos casos nos quais as funções de desempenho são não lineares, por se tratarem dos casos mais complexos.

\subsubsection{Funções Lineares de Desempenho}

Considere uma classe especial de funções de desempenho, a das funções de desempenho lineares. Uma função de desempenho linear pode ser representada por:

$$
g(\bar{X})=a_{o}+\sum_{n} a_{n} X_{n}
$$

sendo, $a_{o}$ e $a_{i}$ constantes e o índice $n$ representa o número de variáveis.

O estudo da confiabilidade para a classe das funções de desempenho lineares foi subdivido em 8 casos que serão a seguir detalhados.

\section{$1^{\circ}$ caso:}

Este caso envolve apenas duas variáveis aleatórias, $n=2$, a resistência $X$ e a solicitação $Y$, e as considera como normalmente distribuídas (distribuição normal) e estatisticamente independentes; e uma função de desempenho linear definida no $\mathfrak{R}^{2}$ : $g(\bar{X})=g\left(X_{1}, X_{2}\right)=g(X, Y)$.

Suponha uma função de desempenho formulada em termos da margem de segurança. A margem de segurança $Z$ é definida pela diferença entre a resistência $X$ e a solicitação $Y$ :

$$
Z=X-Y
$$


sendo que $Z$ representa a função de desempenho correspondente ao modo de falha em consideração, ou seja, $g(\bar{X})=g\left(X_{1}, X_{2}\right)=g(X, Y)=X-Y=Z$. Assim, $Z$ na realidade é simplesmente uma função de desempenho linear bi-dimensional, com $a_{o}=0, a_{1}=1$, $a_{2}=-1, X_{1}=X$ e $X_{2}=Y$. Pois, sendo:

$$
g(\bar{X})=a_{o}+\sum_{n} a_{n} X_{n}
$$

para $(n=2)$,

$$
g(\bar{X})=g\left(X_{1}, X_{2}\right)=a_{0}+a_{1} X_{1}+a_{2} X_{2}
$$

$\operatorname{com} a_{o}=0, a_{1}=1, a_{2}=-1, X_{1}=X$ e $X_{2}=Y$, tem-se:

$$
g(\bar{X})=g\left(X_{1}, X_{2}\right)=g(X, Y)=0+1 . X-1 . Y=X-Y=Z
$$

ou seja,

$$
Z=g(X, Y)=X-Y
$$

Em termos da margem de segurança $Z=X-Y$, o estado seguro de um sistema pode ser definido por $Z>0$, e o estado de falha por $Z<0$. Assim, a fronteira que separa o estado seguro do estado de falha é o estado limite definido pela denominada equação de estado limite, $Z=0$.

Sabendo que $X$ e $Y$ são variáveis aleatórias, tem-se a função densidade de probabilidade conjunta e as suas funções marginais representadas na Figura 3.2. A fronteira de falha que delimita o estado seguro do estado de falha é representado pela reta (traço da superficie de falha) apresentada na figura; onde a equação de estado limite $Z=0$, nada mais é do que a equação dessa reta. Assim, a probabilidade de falha no espaço bi-dimensional, $(n=2)$, é representada pelo volume sombreado na Figura 3.2 ou pela área sombreada na Figura 3.3. Tudo isso representado no que se denomina de 
espaço físico, que por definição é o espaço n-dimensional formado pelas variáveis aleatórias de definição do modelo.

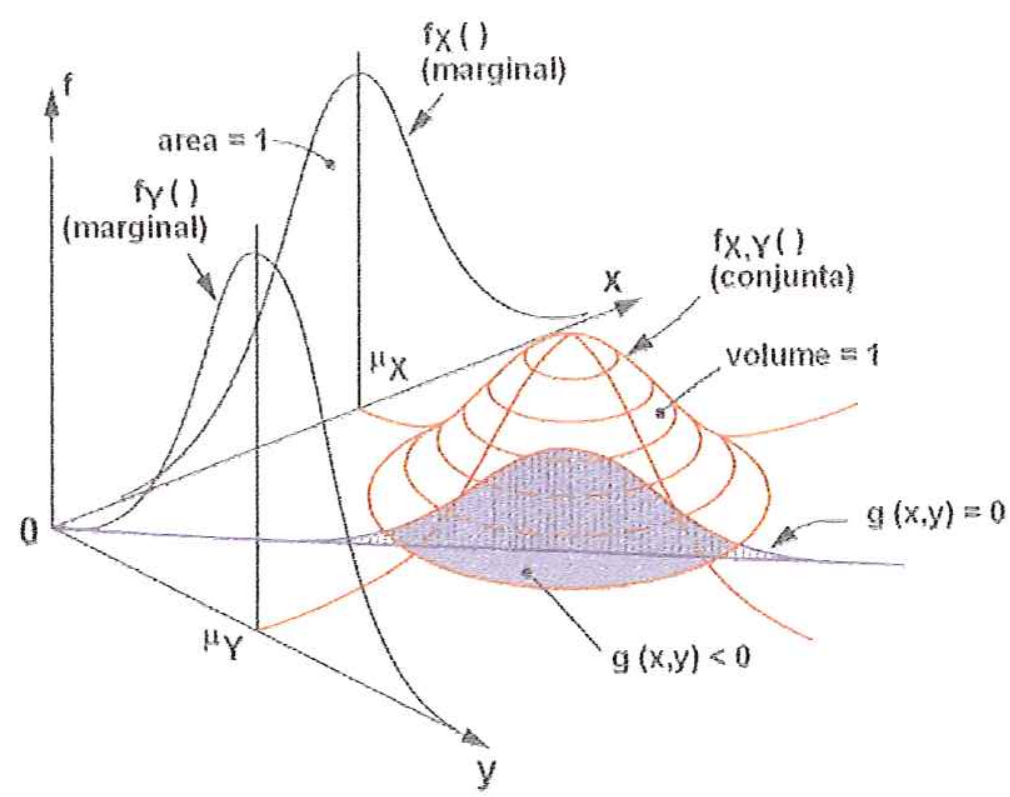

Figura 3.2. Espaço Físico bi-dimensional (MELCHERS, 1987).

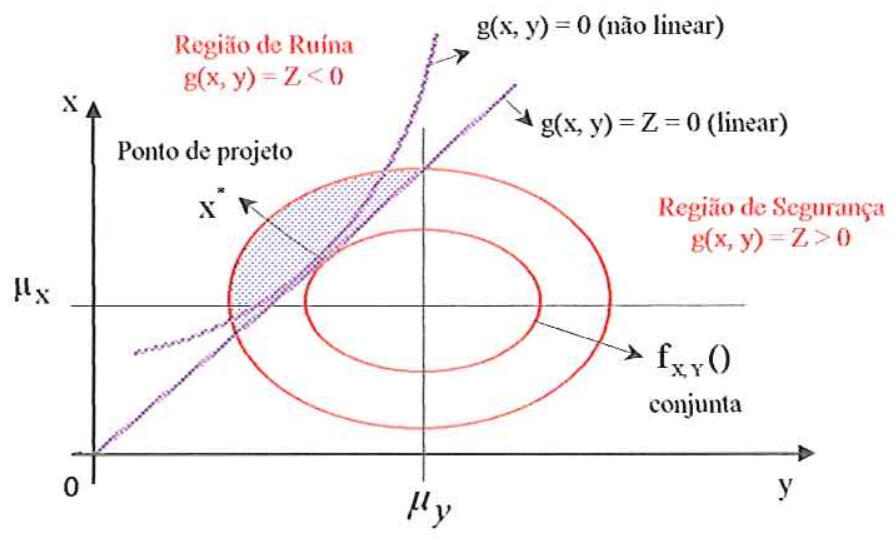

Figura 3.3. Projeção do Espaço Físico bi-dimensional no plano (MELCHERS, 1987).

A Figura 3.2 mostra as funções de densidade (marginal) para $X$ e $Y$ respectivamente, assim como a função densidade conjunta (bivariável).

No entanto, verifica-se ser mais adequado e prático calcular a confiabilidade de um sistema em termos de variáveis reduzidas. Uma variável reduzida é uma variável aleatória que tem média igual a zero e desvio padrão unitário.

O espaço das variáveis reduzidas é denominado de espaço reduzido, podendo também ser denominado de espaço normalizado ou ainda espaço normal padrão. Para passar do espaço físico para o espaço normal padrão e vice-versa, utiliza-se uma transformação isoprobabilística $(\mathrm{T})$, na qual: 


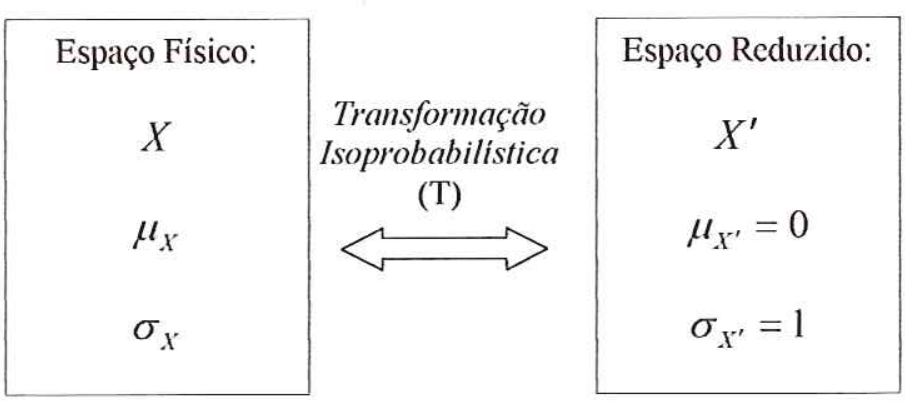

Figura 3.4. Transformação isoprobabilística.

Em geral, a equação de transformação de uma variável aleatória $X$ que possui média igual a $\mu_{X}$ e desvio padrão igual a $\sigma_{X}$, em uma variável aleatória reduzida $X^{\prime}$ é dada por:

$$
X^{\prime}=\frac{X-\mu_{X}}{\sigma_{X}} \Leftrightarrow X=X^{\prime} \sigma_{X}+\mu_{X}
$$

Assim, se $x$ for um valor particular da variável aleatória $X$, a variável reduzida $x^{\prime}$ correspondente a $x$ será:

$$
x^{\prime}=\frac{x-\mu_{X}}{\sigma_{X}}
$$

Transformando as variáveis aleatórias originais: resistência $X$ e solicitação $Y$, nas variáveis aleatórias reduzidas: $X^{\prime}$ e $Y^{\prime}$,

$$
X^{\prime}=\frac{X-\mu_{X}}{\sigma_{X}}
$$

$\mathrm{e}$

$$
Y^{\prime}=\frac{Y-\mu_{Y}}{\sigma_{Y}}
$$

tem-se a mudança do espaço original das variáveis $X$ e $Y$ (espaço físico) para o espaço das variáveis aleatórias reduzidas $X^{\prime}$ e $Y^{\prime}$ (espaço reduzido). Veja as Figuras 3.5 e 3.6. 


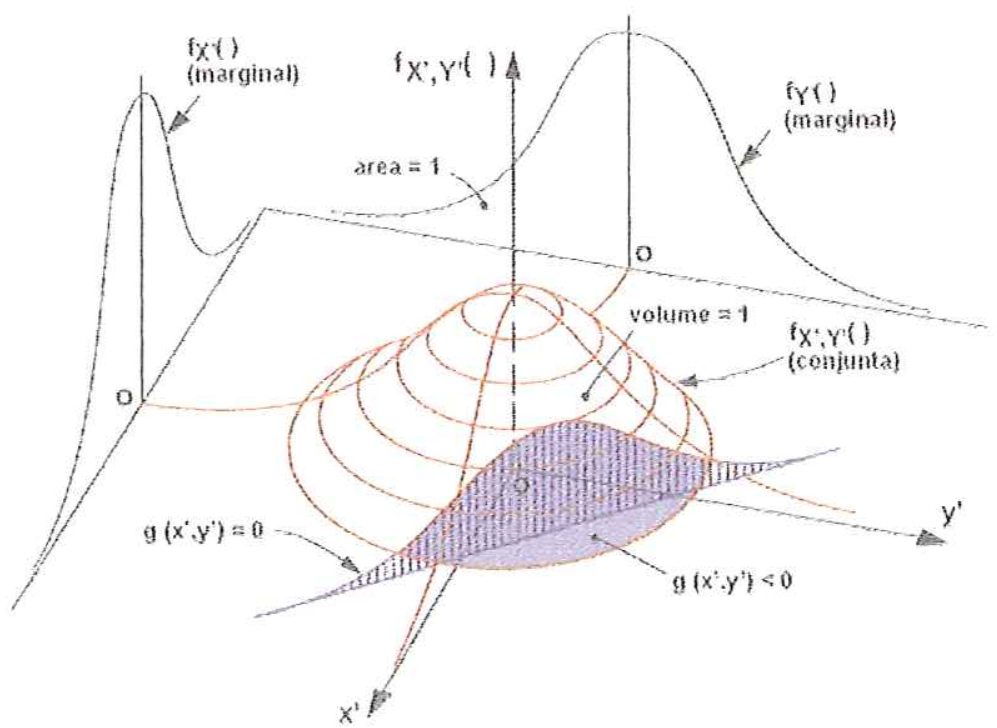

Figura 3.5. Espaço Reduzido bi-dimensional (MELCHERS, 1987).

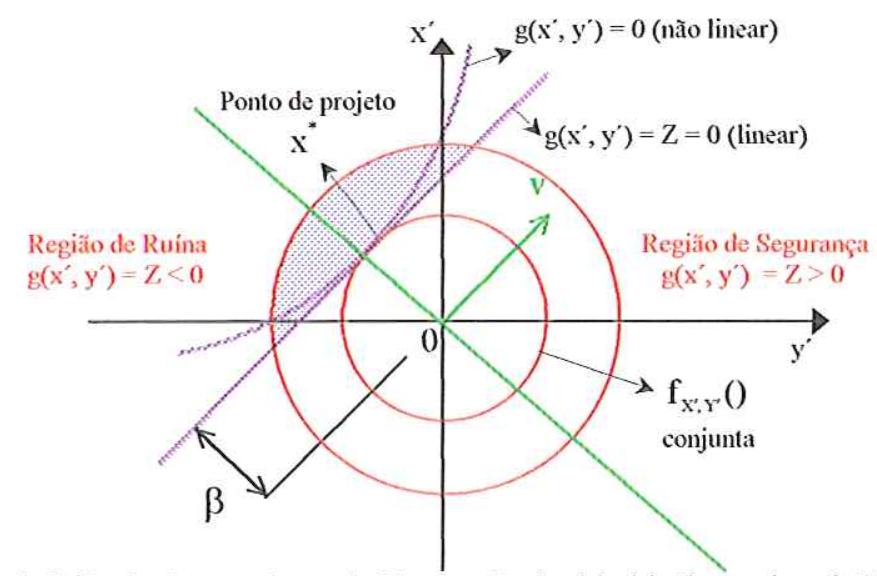

Figura 3.6. Projeção no plano do Espaço Reduzido bi-dimensional (MELCHERS, 1987).

Observa-se que no espaço reduzido a origem dos eixos é o ponto médio das variáveis reduzidas, pois $\mu_{X^{\prime}}=0$, e que a fronteira de falha que separa o estado seguro do estado de falha, antes representada pela reta que passa pela origem esboçada nas Figuras 3.2 e 3.3 , é agora representada pela reta das Figuras 3.5 e 3.6. Isso ocorre, porque em termos das variáveis reduzidas a equação de estado limite,

$$
Z=g(X, Y)=X-Y=0
$$

com $X=X^{\prime} \sigma_{X}+\mu_{X}$ e $Y=Y^{\prime} \sigma_{Y}+\mu_{Y}$, passa a ser escrita como: 


$$
\begin{aligned}
& X-Y=0 \\
& \left(X^{\prime} \sigma_{X}+\mu_{X}\right)-\left(Y^{\prime} \sigma_{Y}+\mu_{Y}\right)=0 \\
& \sigma_{X} X^{\prime}-\sigma_{Y} Y^{\prime}+\mu_{X}-\mu_{Y}=0
\end{aligned}
$$

que é a equação da reta mostrada nas Figuras 3.5 e 3.6 (translação da origem dos eixos).

Se a resistência $X$ e a solicitação $Y$ forem variáveis aleatórias, a margem de segurança, $Z=g(X, Y)=X-Y$, também será uma variável aleatória com a correspondente função densidade de probabilidade $f_{Z}(z)$.

No entanto, da Teoria da Probabilidade, sabe-se que, se a resistência $X$ e a solicitação $Y$ forem variáveis aleatórias normais com médias $\mu_{X}$ e $\mu_{Y}$, e variâncias $\delta_{X}\left(\sigma_{X}=\sqrt{\delta_{X}^{2}}\right)$ e $\delta_{Y}\left(\sigma_{Y}=\sqrt{\delta_{Y}^{2}}\right)$, ou seja: $N\left(\mu_{X}, \sigma_{X}\right)$ e $N\left(\mu_{Y}, \sigma_{Y}\right)$, respectivamente; a distribuição de probabilidade da margem de segurança, $Z=X-Y$, também será normal, $N\left(\mu_{z}, \sigma_{z}\right)$, tal que:

$$
\mu_{Z}=\mu_{X}-\mu_{Y}
$$

e, para $X$ e $Y$ estatisticamente independentes:

$$
\sigma_{Z}^{2}=\sigma_{X}^{2}+\sigma_{Y}^{2}
$$

sendo, $\sigma_{Z}, \sigma_{X}$ e $\sigma_{Y}$, o desvio padrão da margem de segurança, da resistência e da solicitação, respectivamente.

Assim, em função da margem de segurança, $Z=X-Y$, a falha é o evento $Z<0$ e a probabilidade de falha, $p_{F}$, é dada por:

$$
p_{F}=P(Z<0)=F_{Z}(0)=\int_{-\infty}^{0} f_{Z}(z) d z
$$

sendo, $F_{Z}(z)$ a função densidade de probabilidade acumulada da margem de segurança.

A variável aleatória $Z$ é mostrada na Figura 3.7, onde graficamente, a probabilidade de falha é representada pela área sombreada sob $f_{Z}(z)$ e $Z<0$. 


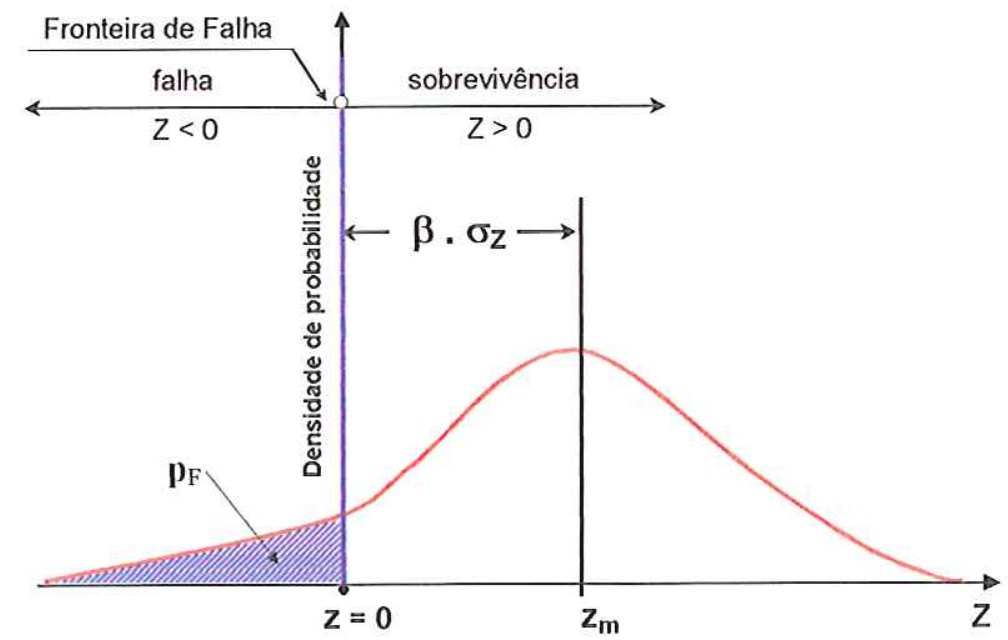

Figura 3.7. Função densidade de probabilidade da Margem de Segurança no espaço físico.

Observando a Figura 3.7, pode-se notar que a distância que separa a margem de segurança média, $\mu_{z}$, à origem do sistema, $z=0$ (estado limite) é múltipla do desvio padrão, ou seja,

$$
\mu_{Z}-i . \sigma_{Z}=0
$$

onde $i$ é um número real positivo. Esse número $i$ é representado por $\beta$ e denominado de "indice de confiabilidade". Assim, $\beta$ é expresso pela seguinte equação:

$$
\mu_{Z}-i . \sigma_{Z}=0 \Leftrightarrow \mu_{Z}=i . \sigma_{Z}
$$

com $i=\beta$, tem-se:

$$
\mu_{Z}=\beta . \sigma_{Z} \Leftrightarrow \beta=\frac{\mu_{Z}}{\sigma_{Z}} \Leftrightarrow \beta=\frac{\mu_{Z}}{\sigma_{Z}}=\frac{\mu_{X}-\mu_{Y}}{\sqrt{\sigma_{X}^{2}+\sigma_{Y}^{2}}}
$$

No espaço normal reduzido, a Figura 3.7 passa a ser representada pela Figura 3.8 , de onde pode-se notar que a distância que separa a margem de segurança média $\mu_{Z^{\prime}}$ (origem do sistema, pois $\mu_{Z^{\prime}}=0$ ) ao estado limite, é o próprio índice de confiabilidade, $\beta$, pois o desvio padrão no espaço reduzido é unitário, $\sigma_{Z^{\prime}}=1$. Veja a Figura 3.8: 


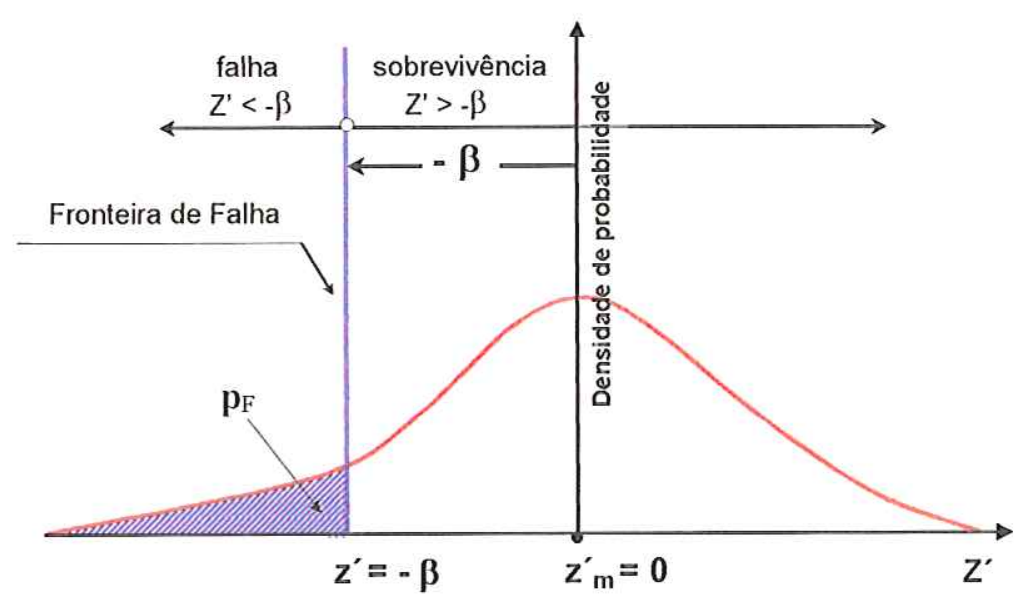

Figura 3.8. Função densidade de probabilidade da Margem de segurança no espaço reduzido.

Logo, ao transformar $Z$ em uma variável aleatória reduzida, $Z^{\prime}$, a probabilidade de falha é dada por:

$$
p_{F}=P\left(Z^{\prime}<-\beta\right)=\int_{-\infty}^{-\beta} f_{Z^{\prime}}\left(z^{\prime}\right) d z^{\prime}=F_{Z^{\prime}}(-\beta)
$$

mas como,

$$
F_{Z^{\prime}}\left(z^{\prime}\right)=\Phi\left(z^{\prime}\right)=\Phi\left(\frac{z-\mu_{Z}}{\sigma_{Z}}\right)
$$

tem-se:

$$
p_{F}=F_{Z}(0)=\Phi\left(\frac{0-\mu_{Z}}{\sigma_{Z}}\right)=\Phi\left(\frac{-\mu_{Z}}{\sigma_{Z}}\right)=1-\Phi\left(\frac{\mu_{Z}}{\sigma_{Z}}\right)
$$

e conseqüentemente, a probabilidade de segurança será:

$$
p_{S}=1-p_{F}=\Phi\left(\frac{\mu_{Z}}{\sigma_{Z}}\right)
$$

sendo, $\Phi()$ a função de distribuição normal padrão amplamente tabelada nos livros de estatística. 
Como se pode observar pela Figura 3.8, a probabilidade de falha em função do índice de confiabilidade é dada por:

$$
p_{F}=\Phi(-\beta)=1-\Phi(\beta)
$$

e a correspondente probabilidade de segurança por:

$$
p_{s}=\Phi(\beta)
$$

No entanto a função de densidade da Figura 3.8 nada mais é do que a projeção da integração da função densidade de probabilidade conjunta na direção $v$, de $-\infty$ à $+\infty$, veja Figura 3.5 .

Assim, pode-se notar claramente o significado "físico" do índice de confiabilidade, ou seja, o índice de confiabilidade nada mais é do que a menor distância entre a origem do espaço reduzido à superfície de falha. Pois, da geometria analítica plana, sabe-se que a distância de uma reta $r$ qualquer, cuja equação geral é $a_{0}+a_{1} X_{1}+a_{2} X_{2}=0$, à um ponto $P$ qualquer, $P(x, y)$, é dada pela equação:

$$
d(P, r)=\frac{\left|a_{0}+a_{1} x+a_{2} y\right|}{\sqrt{a_{1}^{2}+a_{2}^{2}}}
$$

No caso em questão, a equação da reta é $\sigma_{X} X^{\prime}-\sigma_{Y} Y^{\prime}+\mu_{X}-\mu_{Y}=0$, com $a_{1}=\sigma_{X}, a_{2}=-\sigma_{Y}$, e $a_{0}=\mu_{X}-\mu_{Y}$; e o ponto $P(x, y)$ é a origem do sistema dado por $P(x, y)=(0,0)$, logo tem-se:

$$
d(P, r)=\frac{\left|a_{0}+a_{1} \cdot 0+a_{2} \cdot 0\right|}{\sqrt{a_{1}^{2}+a_{2}^{2}}}=\frac{\left|a_{0}\right|}{\sqrt{a_{1}^{2}+a_{2}^{2}}}
$$

Assim, a distância da reta (estado limite) à origem do sistema de coordenadas reduzidas é dada por (HASOFER \& LIND, 1974): 


$$
\begin{aligned}
& d(P, r)=\frac{\left|a_{0}\right|}{\sqrt{a_{1}^{2}+a_{2}^{2}}}=\frac{\mu_{X}-\mu_{Y}}{\sqrt{\sigma_{X}^{2}+\sigma_{Y}^{2}}} \\
& d=\frac{\mu_{X}-\mu_{Y}}{\sqrt{\sigma_{X}^{2}+\sigma_{Y}^{2}}}=\frac{\mu_{Z}}{\sigma_{Z}}=\beta
\end{aligned}
$$

ou seja, é o índice de confiabilidade.

Logo, quanto maior $\beta$, maior será a distância entre a origem e o estado limite, conseqüentemente, maior será a região de segurança e menor a probabilidade de falha. É fazendo uso deste raciocínio, que o índice de confiabilidade é usado para estimar a confiabilidade de um sistema (CORNELL, 1975).

Assim, com a Formulação pelo Segundo Momento, a confiabilidade será invariavelmente medida (ficará completamente definida) por uma função dos primeiros e segundos momentos (momento de $1^{\circ}$ ordem e de $2^{\circ}$ ordem) das variáveis aleatórias de projeto, isto é, com o denominado índice de confiabilidade ( $\beta$ ), quando não há informações das distribuições de probabilidade (TANG, 1971, 1981).

Deve-se recordar, entretanto, que o nível de confiabilidade de um sistema depende da posição relativa de $f_{X}(x)$ e $f_{Y}(y)$ e do grau de dispersão dessas curvas; logo, o índice de confiabilidade, $\beta$, deve incluir o efeito desses dois fatores. No entanto, esses fatores são representados em termos da média da margem de segurança, $\mu_{\mathrm{Z}}=\mu_{\mathrm{X}}-\mu_{\mathrm{Y}}$, e do desvio padrão da margem de segurança, $\sigma_{Z}=\left(\sigma_{X}{ }^{2}+\sigma_{Y}{ }^{2}\right)^{1 / 2}$, respectivamente.

A primeira definição de índice de confiabilidade é atribuída a Rzhanitzyn, mas quem o popularizou foi Cornell em 1969. Porém, as primeiras definições do índice de confiabilidade dependiam da forma da equação de estado limite. Somente após algum tempo, é que $\beta$ foi corretamente definido por Hasofer \& Lind, que em 1974, propuseram utilizar o espaço reduzido para calcular $\beta$ independente da representação no espaço físico, ou seja, independente da forma de expressar a função de desempenho do sistema.

\section{$2^{\circ}$ caso:}

Este $2^{\circ}$ caso trabalha com o espaço n-dimensional, sendo portanto, uma generalização do $1^{\circ}$ caso que envolve apenas duas variáveis aleatórias, $n=2$. 
Continua-se considerando, as variáveis aleatórias como normalmente distribuídas (distribuição normal) e estatisticamente independentes e, a função de desempenho como linear (vide Tabela 3.1).

Com base na utilização da equação (3.18), tem-se definida a equação do estado limite correspondente:

$$
g(\bar{X})=0 \Rightarrow a_{o}+\sum_{n} a_{n} X_{n}=0
$$

ou, em termos de variáveis reduzidas:

$$
a_{o}+\sum_{n} a_{n}\left(\sigma_{X_{n}} X_{n}^{\prime}+\mu_{X n}\right)=0
$$

Como exemplo, em três dimensões, tem-se:

$$
a_{o}+a_{1}\left(\sigma_{X_{1}} X_{1}^{\prime}+\mu_{X_{1}}\right)+a_{2}\left(\sigma_{X_{2}} X_{2}^{\prime}+\mu_{X_{2}}\right)+a_{3}\left(\sigma_{X_{3}} X_{3}^{\prime}+\mu_{X_{3}}\right)=0
$$

que é a equação da superficie plana no espaço $x_{1}^{\prime}, x_{2}^{\prime}, x_{3}^{\prime}$.

A distância do plano de falha à origem das variáveis reduzidas $\bar{X}^{\prime}$ é:

$$
\beta=\frac{a_{o}+\sum_{n} a_{n} \mu_{X_{n}}}{\sqrt{\sum_{n}\left(a_{n} \sigma_{X_{n}}\right)^{2}}}
$$

A probabilidade de segurança, no presente caso, será:

$$
\begin{aligned}
& p_{S}=P\left(a_{o}+\sum_{n} a_{n} X_{n}>0\right)=1-\Phi\left[\frac{-\left(a_{o}+\sum a_{n} \mu_{X_{n}}\right)}{\sqrt{\sum\left(a_{n} \sigma_{X_{n}}\right)^{2}}}\right] \\
& p_{S}=\Phi\left[\frac{a_{o}+\sum a_{n} \mu_{X_{n}}}{\sqrt{\sum\left(a_{n} \sigma_{X_{n}}\right)^{2}}}\right]
\end{aligned}
$$


Pode-se perceber que o argumento inserido entre parênteses é a distância $\beta$. Assim, a probabilidade de segurança será:

$$
p_{s}=\Phi(\beta)
$$

que é a equação (3.32) já apresentada anteriormente.

$3^{\circ}$ e $4^{\circ}$ caso:

O $3^{\circ}$ e $4^{\circ}$ caso são semelhantes ao $1^{\circ}$ caso e $2^{\circ}$ caso, respectivamente; diferenciando destes últimos somente com relação ao fato de que as variáveis aleatórias que serão utilizadas nas análises de confiabilidade, serem variáveis aleatórias correlacionadas.

Quando se tem um conjunto de variáveis aleatórias correlacionadas, deve-se, inicialmente, transforma-las em um conjunto de variáveis não-correlacionadas e a este novo conjunto de variáveis aleatórias (não-correlacionadas), pode-se aplicar os procedimentos descritos nos $1^{\circ}$ e $2^{\circ}$ caso.

O procedimento que deve ser realizado para transformar um conjunto de variáveis aleatórias correlacionadas em um conjunto de variáveis aleatórias nãocorrelacionadas não será descrito aqui, o leitor interessado pode encontrar este procedimento em Ang \& Tang (1984).

$5^{\circ}$ e $6^{\circ}$ caso:

$05^{\circ}$ e $6^{\circ}$ caso são semelhantes ao $1^{\circ}$ caso e $2^{\circ}$ caso, respectivamente; sendo que a única diferença reside no fato de que as variáveis aleatórias do $5^{\circ}$ e $6^{\circ}$ caso não possuem distribuição normal.

Se as distribuições de probabilidade das variáveis aleatórias $X_{1}, X_{2}, \ldots, X_{n}$ não forem normais, a probabilidade de falha pode ser avaliada pela equação (3.16b), no entanto, uma integração numérica será necessária. No caso de função de desempenho linear, a função desempenho da equação (3.16b) é representada por $g(\bar{X})=a_{o}+\sum_{n} a_{n} X_{n}$ 
Porém, a probabilidade de falha é mais facilmente avaliada usando as distribuições normais equivalentes. Teoricamente, as distribuições normais equivalentes podem ser obtidas pela Transformação de Rosenblatt. Com o uso das distribuições normais equivalentes, o cálculo da probabilidade de falha, segue o mesmo procedimento descrito para variáveis normais no $1^{\circ}$ caso e $2^{\circ}$ caso (para funções de desempenho lineares). Ou seja,

$$
\beta=\frac{a_{o}+\sum a_{n} \mu_{X_{n}}^{N}}{\sqrt{\sum_{n}\left(a_{n} \sigma_{X_{n}}^{N}\right)^{2}}}
$$

sendo que o sobrescrito $N$ denota as estatísticas para a distribuição normal equivalente.

A substituição da distribuição original por uma distribuição normal equivalente requer a substituição do desvio padrão e da média da variável aleatória original pelos da distribuição normal equivalente, para se obter o índice de confiabilidade, $\beta$, e a correspondente probabilidade de falha. Sobre esta transformação consultar Ang \& Tang (1984).

$7^{\circ}$ e $8^{\circ}$ caso:

$07^{\circ}$ e $8^{\circ}$ caso envolve variáveis aleatórias correlacionadas e com distribuição de probabilidade não normal. Assim, as observações feitas no $3^{\circ}$ e $4^{\circ}$ caso para variáveis aleatórias correlacionadas, e no $5^{\circ}$ e $6^{\circ}$ caso para variáveis aleatórias não normais, são válidas, ou seja, deve-se transformar as variáveis aleatórias originais em variáveis aleatórias não correlacionadas com distribuição normal equivalente e só posteriormente usar as formulações apresentadas para os $1^{\circ}$ e $2^{\circ}$ casos.

\subsubsection{Funções de Desempenho não Lineares}

Quando a função de desempenho, $g(\bar{X})$, é não linear, a equação do estado limite, $g(\bar{X})=0$, também não o será; e ao contrário do caso linear, não há uma distância única entre a superfície de falha à origem das variáveis reduzidas.

Como indicado anteriormente, a avaliação exata da probabilidade de segurança requer a integração da função de densidade de probabilidade conjunta sobre a região 
$g(\bar{X})>0$, o que, em geral, implica numa integração numérica n-dimensional. Para propósitos práticos, pode-se, como alternativa, adotar uma solução aproximada para o cálculo da probabilidade de falha, ao invés de se calcular a probabilidade de falha exata.

Assim, no caso de uma função de desempenho não linear, usa-se um plano tangente à superficie de falha no lugar da superficie de falha original, o que permite calcular o índice de confiabilidade e a probabilidade de falha como no caso linear. Dependendo se a superficie de falha não linear, $g(\bar{X})=0$, é convexa ou côncava com relação à origem das coordenadas, essa aproximação estará no lado seguro ou no lado inseguro, ou seja, será a favor ou contra a segurança, respectivamente.

Com a aproximação da superfície de falha original por um hiper-plano tangente, a mínima distância deste plano à origem das variáveis reduzidas é o índice de confiabilidade, $\beta$, usado para estimar a segurança do sistema.

No presente caso, na qual a função de desempenho é não linear, o ponto de tangência na superficie de falha que fornece a mínima distância deste à origem não é conhecido a priori. Conseqüentemente, a determinação do índice de confiabilidade não é tão simples quanto no caso de uma função de desempenho linear, mesmo em se admitindo a aproximação linear.

$\mathrm{O}$ ponto de tangência na superficie de falha que fornece a distância mínima à origem das variáveis reduzidas é o ponto de falha mais provável, e é denominado ponto de projeto, $\bar{x}^{*}=\left(x_{1}^{*}, x_{2}^{*}, \ldots, x_{n}^{*}\right)$. Este ponto pode ser determinado pelo Método dos Multiplicadores de Lagrange como descrito a seguir.

Todos esses conceitos fazem parte do denominado Método de Confiabilidade de Primeira Ordem (First Order Reliability Method - FORM), que é um procedimento aproximado para o cálculo da probabilidade de falha em problemas não lineares com variáveis que seguem ou não uma distribuição normal.

O método consiste em obter uma estimativa da probabilidade de falha linearizando a superficie de falha (ou superfície de estado limite) no ponto de projeto no espaço reduzido. Para isso, inicialmente deve-se calcular as coordenadas do ponto de projeto e depois linearizar a superficie de estado limite neste ponto.

Com a função de desempenho linearizada, o procedimento para o cálculo da probabilidade de falha é o mesmo utilizado para as funções de desempenho lineares. A união dessas duas teorias é o denominado Método de Segundo Momento de Primeira Ordem (Second Moment First Order - FOSM). 
A seguir, será apresentado o procedimento usado para a determinação do ponto de projeto e, na seqüência, será apresentado o procedimento usado para realizar a linearização da função de desempenho de um sistema.

\section{Determinação do ponto de projeto:}

Introduzindo o conjunto de variáveis não correlacionadas reduzidas:

$$
X_{i}^{\prime}=\frac{X_{i}-\mu_{X_{i}}}{\sigma_{X_{i}}} \quad \text { com } \mathrm{i}=1,2, \ldots, \mathrm{n}
$$

Em termos dessas variáveis reduzidas, $X_{i}^{\prime}$, a equação do estado limite do sistema é escrita como:

$$
g\left(\sigma_{X_{1}} X_{1}^{\prime}+\mu_{X_{1}}, \ldots, \sigma_{X_{n}} X_{n}^{\prime}+\mu_{X_{n}}\right)=0
$$

Quando a superfície do estado limite (ou superficie de falha) se aproxima ou se afasta da origem, a região de segurança, $g(\bar{X})>0$, diminui ou aumenta. Conseqüentemente, a posição da superfície de falha em relação à origem das variáveis reduzidas determina a segurança ou confiabilidade do sistema. Pode-se demonstrar que o ponto da superficie de falha mais próximo da origem é o ponto de falha mais provável. Assim, dentro de alguma aproximação, essa distância mínima, pode ser usada como uma medida da confiabilidade do sistema.

A distância de um ponto $\bar{X}^{\prime}=\left(X_{1}^{\prime}, X_{2}^{\prime}, \ldots, X_{n}^{\prime}\right)$ na superficie de falha, $g\left(\bar{X}^{\prime}\right)$, à origem de $\overline{X^{\prime}}$ será dada por:

$$
D=\sqrt{X_{1}^{\prime 2}+X_{2}^{\prime 2}+\ldots+X_{n}^{\prime 2}}=\left(\bar{X}^{\prime} t \bar{X}^{\prime}\right)^{1 / 2}
$$

O ponto da superficie de falha $\left(x_{1}^{\prime *}, x_{2}^{\prime *}, \ldots, x_{n}^{\prime *}\right)$ cuja distância à origem é mínima pode ser determinado minimizando a função D sob a condição de $g(\bar{X})=0$; isto é: 


$$
\left\{\begin{array}{l}
\text { Minimizar D } \\
\operatorname{com} g(\bar{X})=0
\end{array}\right.
$$

Para isso, pode-se utilizar o Método dos Multiplicadores de Lagrange (para maiores detalhes sobre o método vide Anexo B):

$$
L=D+\lambda \cdot g(\bar{X})
$$

ou

$$
L=\left(\bar{X}^{\prime \prime} \bar{X}^{\prime}\right)^{1 / 2}+\lambda \cdot g(\bar{X})
$$

Em notação escalar:

$$
L=\sqrt{X_{1}^{\prime 2}+X_{2}^{\prime 2}+\ldots+X_{n}^{\prime 2}}+\lambda \cdot g\left(X_{1}, X_{2}, \ldots, X_{n}\right)
$$

$\operatorname{com} X_{i}=\sigma_{X_{i}} X_{i}^{\prime}+\mu_{X_{i}}$.

Minimizando L obtêm-se um sistema de $n+1$ equações e $n+1$ incógnitas:

$$
\frac{\partial L}{\partial X_{i}^{\prime}}=\frac{X_{i}^{\prime}}{\sqrt{X_{1}^{\prime 2}+X_{2}^{\prime 2}+\ldots+X_{n}^{\prime 2}}}+\lambda \frac{\partial g}{\partial X_{i}^{\prime}}=0, \text { com i }=1,2, \ldots, \mathrm{n}
$$

e

$$
\frac{\partial L}{\partial \lambda}=0+1 . g\left(X_{1}, X_{2}, \ldots X_{n}\right)=0
$$

A solução desse sistema de equações conduz ao ponto de falha mais provável: $\left(x_{1}^{\prime *}, x_{2}^{\prime *}, \ldots, x_{n}^{\prime *}\right)$.

Introduzindo o vetor gradiente:

$$
\bar{G}=\left(\frac{\partial g}{\partial X_{1}^{\prime}}, \frac{\partial g}{\partial X_{2}^{\prime}}, \ldots, \frac{\partial g}{\partial X_{n}^{\prime}}\right)
$$


sendo,

$$
\frac{\partial g}{\partial X_{i}^{\prime}}=\frac{\partial g}{\partial X_{i}} \cdot \frac{d X_{i}}{d X_{i}^{\prime}}=\frac{\partial g}{\partial X_{i}} \cdot \sigma_{X_{i}}
$$

pois se $X_{i}=\sigma_{X_{i}} X_{i}^{\prime}+\mu_{X_{i}}$, tem-se: $\frac{\partial X_{i}}{\partial X_{i}^{\prime}}=\sigma_{X_{i}} \cdot 1+0=\sigma_{X_{i}}$.

O sistema de equações poderá, então ser escrito na forma matricial:

$$
\frac{\overline{X^{\prime}}}{\left(\bar{X}^{\prime T} \cdot \bar{X}^{\prime}\right)^{\frac{1}{2}}}+\lambda \cdot \bar{G}=0
$$

com,

$$
\bar{X}^{\prime}=-\lambda \cdot D \cdot \bar{G}
$$

Conseqüentemente:

$$
D=\left(\bar{X}^{\prime \prime} \bar{X}^{\prime}\right)^{1 / 2}=\left[\left(\lambda D \bar{G}^{t}\right) \cdot(\lambda D \bar{G})\right]^{1 / 2}=\lambda D\left(\bar{G}^{t} \cdot \bar{G}\right)^{1 / 2}
$$

e, portanto:

$$
\lambda=\left(\bar{G}^{t} \cdot \bar{G}\right)^{-1 / 2}
$$

Levando essa relação em $\bar{X}^{\prime}=-\lambda \cdot D \cdot \bar{G}$, tem-se:

$$
\bar{X}^{\prime}=\frac{-D \cdot \bar{G}}{\left(\bar{G}^{t} \cdot \bar{G}\right)^{1 / 2}}
$$

Inversamente, pré-multiplicando a equação acima por $\bar{G}^{t}$ :

$$
D=\frac{-\bar{G}^{t} \cdot \bar{X}^{\prime}}{\left(\bar{G}^{t} \cdot \bar{G}\right)^{1 / 2}}
$$


Substituindo $\bar{X}^{\prime}=\frac{-D \cdot \bar{G}}{\left(\bar{G}^{\prime} \cdot \bar{G}\right)^{1 / 2}}$ em $\frac{\partial L}{\partial \lambda}=0+1 \cdot g\left(X_{1}, X_{2}, \ldots X_{n}\right)=0$, tem-se uma equação com a incógnita $D$, cuja solução é a distância mínima $d_{\min }=\beta$ :

$$
\beta=\frac{-\bar{G}^{* t} \cdot \bar{X}^{\prime *}}{\left(\bar{G}^{* t} \bar{G}^{*}\right)^{l / 2}}
$$

onde $\bar{G}^{*}$ é o vetor gradiente no ponto de falha mais provável $\left(x_{1}^{\prime *}, x_{2}^{\prime *}, \ldots, x_{n}^{\prime *}\right)$.

$\mathrm{Na}$ forma escalar, a equação anterior pode ser escrita como:

$$
\beta=\frac{-\sum_{i} x_{i}^{\prime *}\left(\frac{\partial g}{\partial X_{i}^{\prime}}\right)_{*}}{\sqrt{\sum_{i}\left(\frac{\partial g}{\partial X_{i}^{\prime}}\right)_{*}^{2}}}
$$

onde as derivadas $\left(\frac{\partial g}{\partial X_{i}^{\prime}}\right)_{*}$ são avaliadas em $\left(x_{1}^{\prime *}, x_{2}^{\prime *}, \ldots, x_{n}^{\prime *}\right)$.

Levando o valor de $\beta$ à equação (3.57) chega-se ao ponto de falha mais provável na superficie de falha:

$$
\bar{X}^{\prime}=\frac{-\beta \cdot \bar{G}^{*}}{\left(\bar{G}^{*} \cdot \bar{G}^{*}\right)^{1 / 2}}
$$

Em forma escalar, as componente de $\bar{X}^{\prime *}$ dadas pela equação anterior são escritas como:

$$
x_{i}^{\prime *}=-\alpha_{i}^{*} \cdot \beta \quad \text { com } \mathrm{i}=1,2, \ldots, \mathrm{n} .
$$

sendo: 


$$
\alpha_{i}^{*}=\frac{\left(\frac{\partial g}{\partial X_{i}^{\prime}}\right)_{*}}{\sqrt{\sum_{i}\left(\frac{\partial g}{\partial X_{i}^{\prime}}\right)_{*}^{2}}}
$$

os cossenos diretores em relação aos eixos $\bar{X}_{i}^{\prime}$, cujas derivadas são desenvolvidas em $\left(x_{1}^{\prime *}, x_{2}^{\prime *}, \ldots, x_{n}^{\prime *}\right)$. Então, o ponto de falha mais provável será:

$$
x_{i}^{*}=\sigma_{X_{i}} x_{i}^{*}+\mu_{X_{i}}=\mu_{X_{i}}-\alpha_{i}^{*} \sigma_{X_{i}} \beta
$$

que é a solução da equação de estado limite, $g\left(x_{1}^{*}, x_{2}^{*}, \ldots, x_{3}^{*}\right)=0$.

\section{Interpretação de primeira ordem (linearização)}

Desenvolvendo a função desempenho, $g(\bar{X})$, em uma Série de Taylor (maiores informações vide Anexo C) no ponto $\bar{x}^{*}$, que está na superficie de falha $g\left(\bar{x}^{*}\right)=0$, tem-se:

$$
\begin{aligned}
& g(\bar{X})=g\left(X_{1}, X_{2}, \ldots, X_{n}\right)=g\left(x_{1}^{*}, x_{2}^{*}, \ldots, x_{3}^{*}\right)+\sum_{i=1}^{n}\left(X_{i}-x_{i}^{*}\right)\left(\frac{\partial g}{\partial X_{i}}\right)_{*}+ \\
& +\sum_{j=1}^{n} \sum_{i=1}^{n}\left(X_{i}-x_{i}^{*}\right)\left(X_{j}-x_{j}^{*}\right) /\left(\frac{\partial^{2} g}{\partial X_{i} \partial X_{j}}\right)_{*}+\ldots
\end{aligned}
$$

onde as derivadas da expressão acima $\left(\frac{\partial g}{\partial X_{i}^{\prime}}\right)_{*}$ e $\left(\frac{\partial^{2} g}{\partial X_{i} \partial X_{j}}\right)_{*}$ são avaliadas em $\left(x_{1}^{*}, x_{2}^{*}, \ldots, x_{n}^{*}\right)$. Porém, $g\left(x_{1}^{*}, x_{2}^{*}, \ldots, x_{3}^{*}\right)=0$ na superficie de falha. Logo:

$$
\begin{aligned}
& g(\bar{X})=g\left(X_{1}, X_{2}, \ldots, X_{n}\right)=\sum_{i=1}^{n}\left(X_{i}-x_{i}^{*}\right)\left(\frac{\partial g}{\partial X_{i}}\right)_{*}+ \\
& +\sum_{j=1}^{n} \sum_{i=1}^{n}\left(X_{i}-x_{i}^{*}\right)\left(X_{j}-x_{j}^{*}\right) /\left(\frac{\partial^{2} g}{\partial X_{i} \partial X_{j}}\right)_{*}+\ldots
\end{aligned}
$$


Recordando que:

$$
X_{i}-x_{i}^{*}=\left(\sigma_{X_{i}} \cdot X_{I}^{\prime}+\mu_{X_{i}}\right)-\left(\sigma_{X_{i}} \cdot x_{i}^{\prime *}+\mu_{X_{i}}\right)=\sigma_{X_{i}} \cdot\left(X_{i}^{\prime}-x_{i}^{\prime *}\right)
$$

e

$$
\frac{\partial g}{\partial X_{i}}=\frac{\partial g}{\partial X_{i}^{\prime}} \cdot \frac{d X_{i}^{\prime}}{d X_{i}}=\frac{\partial g}{\partial X_{i}^{\prime}} \cdot \frac{1}{\sigma_{X_{i}}}
$$

pois, se $X_{i}=\sigma_{X_{i}} X_{i}^{\prime}+\mu_{X_{i}}$, tem-se: $\frac{\partial X_{i}}{\partial X_{i}^{\prime}}=\sigma_{X_{i}} \cdot 1+0=\sigma_{X_{i}}$, e logo, $\frac{\partial X_{i}^{\prime}}{\partial X_{i}}=\frac{1}{\sigma_{X_{i}}}$. Então:

$$
g(\bar{X})=g\left(X_{1}, X_{2}, \ldots, X_{n}\right)=\sum_{i=1}^{n}\left(X_{i}^{\prime}-x_{i}^{\prime}\right)\left(\frac{\partial g}{\partial X_{i}^{\prime}}\right)_{*}+\ldots
$$

Assim, a equação do hiper-plano tangente em $\bar{x}^{\prime *}=\left(x_{1}^{\prime *}, x_{2}^{\prime *}, \ldots, x_{n}^{\prime *}\right)$ será:

$$
\sum_{i=1}^{n}\left(X_{i}^{\prime}-x_{i}^{\prime *}\right)\left(\frac{\partial g}{\partial X_{i}^{\prime}}\right)_{*}=0
$$

onde as derivadas parciais $\left(\frac{\partial g}{\partial X_{i}^{\prime}}\right)$ são avaliadas em $\left(x_{1}^{\prime *}, x_{2}^{\prime *}, \ldots, x_{n}^{\prime *}\right)$.

Na aproximação de primeira ordem, isto é, desprezando os termos além da derivada de primeira ordem, o valor médio da função $g(\bar{X})$ será:

$$
\mu_{g} \approx-\sum_{i=1}^{n} x^{\prime}{ }_{i}\left(\frac{\partial g}{\partial X_{i}^{\prime}}\right)
$$

Dentro da aproximação de primeira ordem, a variância para variáveis nãocorrelacionadas será:

$$
\sigma_{g}^{2} \approx \sum_{i=1}^{n} \sigma_{X_{i}}^{2}\left(\frac{\partial g}{\partial X_{i}^{\prime}}\right)_{*}^{2}=\sum_{i=1}^{n}\left(\frac{\partial g}{\partial X_{i}^{\prime}}\right)_{*}^{2}
$$

Com as duas equações anteriores tem-se: 


$$
\frac{\mu_{g}}{\sigma_{g}}=\frac{-\sum_{i=1}^{n} x_{i}^{\prime *}\left(\frac{\partial g}{\partial X_{i}^{\prime}}\right)_{*}}{\sqrt{\sum_{i=1}^{n}\left(\frac{\partial g}{\partial X_{i}^{\prime}}\right)_{*}^{2}}}
$$

Comparando (3.73) com (3.60) verifica-se que:

$$
\beta=\frac{\mu_{g}}{\sigma_{g}}
$$

\subsection{Comentários Finais}

Ao término deste capítulo, é possível perceber que, independente das condições apresentadas por um problema de confiabilidade é possível reduzi-lo aos casos mais simples através dos recursos apresentados. Observando a Tabela 3.1, apresentada anteriormente, nota-se que todos os 16 casos apresentados podem ser reduzidos aos 2 casos mais simples ( $1^{\circ}$ e $2^{\circ}$ caso), cujas células estão sombreadas.

Para finalizar, recomenda-se a leitura do Anexo D, no qual é apresentado um exemplo numérico que possibilita uma maior compreensão do que seja a probabilidade de falha de um sistema. 


\section{contruos 4}

OBJETO DE ANÁLISE

\subsection{A Necessidade de rever conceitos na Engenharia de Fundações}

\subsubsection{O conceito de Fundação}

Ao realizar uma dissertação no âmbito da Engenharia de Fundações intitulada "Análise de Segurança e Confiabilidade de Fundações Profundas em Estacas", é de suma importância elucidar o que para esta dissertação o termo "fundação" representa.

Toda obra de engenharia civil possui elementos responsáveis pelo suporte e transferência das cargas nela atuantes, e que, interligados, compõem o que se denomina de estrutura de uma obra. Porém, didaticamente, a estrutura costuma ser dividida em superestrutura e subestrutura. A superestrutura é o sistema formado pela integração dos vários elementos estruturais discretos (viga, escada, pilar, lajes, paredes, tirante, etc.) que se encontram acima da superfície do terreno e sobre os quais agem as cargas. A subestrutura é o sistema formado pelos elementos estruturais que se encontram abaixo da superfície do terreno e estão em contato com o maciço de solos (sapata, bloco, viga de fundação, estaca, tubulão, baldrame, paredes do subsolo, radier, etc.) (AOKI, 2001). O motivo dessa divisão é que para executar o projeto estrutural de uma obra é comum a atuação de duas especialidades da Engenharia Civil: a Engenharia de Estruturas, responsável pelo projeto da superestrutura e, a Engenharia de Fundações responsável pelo projeto da subestrutura. 
Nesta visão tradicional, fortemente influenciada por conceitos da área da engenharia de estruturas, a fundação de uma obra é a própria subestrutura (AOKI, 2001). Esse pensamento é nitidamente exposto por Tschebotarioff (1973) ao definir que o termo fundação é usado para designar a parte de uma estrutura que transmite ao terreno subjacente seu próprio peso, o peso da superestrutura e qualquer outra força que atue sobre ela. A fundação é, portanto, o elemento de ligação entre a superestrutura e o solo.

Sendo assim, ainda segundo Tschebotarioff (1973), a função de uma fundação corretamente projetada é suportar as cargas que atuam sobre ela e distribui-las de maneira satisfatória sobre as superficies de contato com o solo sobre o qual ela se apóia. Logo, fica claro que aqui, o termo fundação, é usado para designar apenas o elemento estrutural de fundação (estaca, tubulão, etc.), da qual o solo não faz parte.

Porém, analisando uma estrutura como um sistema em equilíbrio estático, têm-se as reações de apoio equilibrando as forças ativas que nele atuam. As forças ativas são as forças externas ao sistema que atuam direta ou indiretamente sobre as peças estruturais que compõem a superestrutura (como, por exemplo, a força da gravidade, do vento, etc.), as peças estruturais que compõem a fundação (como os empuxos de água ou de terra), as camadas que compõem o maciço de solos (força da gravidade, sobrecarga vertical, atrito negativo, etc.). As reações de apoio são forças reativas que atuam em resposta às forças ativas atuantes, e se diferenciam das forças reativas convencionais pelo fato de serem externas ao sistema (AOKI, 2000c).

Supõe-se que a função da fundação de uma obra é atuar como o elemento responsável pelo seu apoio. Logo, é razoável imaginar, que o maciço de solos faz parte da fundação, uma vez que, sem a sua presença, a subestrutura não consegue desempenhar a função de apoio, conforme indica a Figura 4.1.

É com este raciocínio que, na visão geotécnica, a fundação de uma obra é definida como o sistema formado pela subestrutura e o maciço de solos que a envolve (AOKI, 2001). Pois, qualquer carregamento atuante no maciço de solos, como por exemplo, uma estrutura, gera tensões que se propagam no seu interior e cuja distribuição pode ser obtida, com razoável precisão, pela Teoria da Elasticidade. A tensão é máxima na região do carregamento e diminui gradativamente à medida que deste se distancia tanto horizontalmente como em profundidade. Esta região sob influência do carregamento é teoricamente delimitada por um conjunto de isóbaras, 
denominado de bulbo de pressões, onde seu limite máximo para fins práticos, é representado pela isóbara de $10 \%$ da tensão média atuante (ORTIGÃO, 1995).

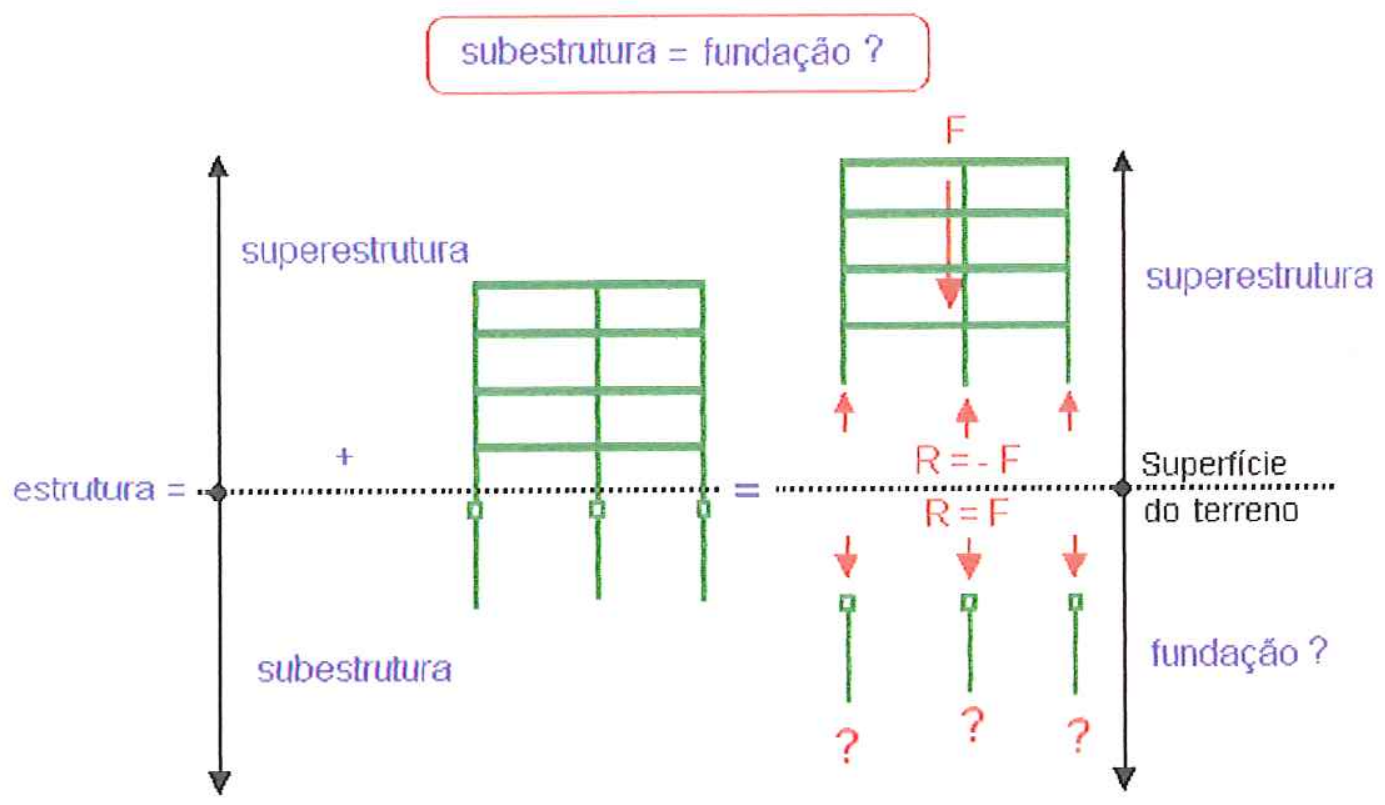

Figura 4.1. Análise do equilíbrio estático de uma estrutura.

Pode-se supor que existe uma região no interior do maciço de solos que pode ser considerada indeslocável por não sofrer deformações e/ou deslocamentos, seja por estar abaixo do bulbo de pressões e sendo assim estar isenta de solicitações ou porque as solicitações que nela atuam não são suficientes para the provocar deformações e/ou deslocamentos dada a sua maior rigidez. A superfície superior desta região é denominada superfície do indeslocável e sua posição no interior do maciço de solos é função da intensidade do carregamento nele atuante e da formação geológica-geotécnica (AOKI \& CINTRA, 1996).

O maciço de solos é uma estrutura natural composta por diversas camadas contínuas de formas indefinidas formando um meio natural contínuo. Entretanto, na ocasião de implantação de uma estrutura, o maciço de solos que com esta irá interagir, vindo a fazer parte da fundação, fica restrito a um volume especifico. Este volume é limitado pela superfície do terreno, a superfície do indeslocável e, juridicamente, pela projeção dos limites da obra em planta, na realidade, pelo limite do bulbo de pressões (AOKI, 2001).

Na norma brasileira de fundações, NBR 6122/1996: "Projeto e Execução de Fundações", fica implícita a definição de elemento de fundação como o elemento estrutural (estaca, sapata, bloco, etc.) que se acha em contato com o solo. Mas, como o 
maciço de solos faz parte da fundação, é imprescindível uma mudança na definição do que é fundação. Devido a este contexto, a definição de fundação que será adotada nas futuras análises dessa dissertação será a seguinte: a fundação de uma obra é o sistema formado pela subestrutura e o maciço de solos que a envolve e, ao subsistema formado pelo elemento isolado da subestrutura e o maciço de solos que o envolve denomina-se elemento isolado de fundação (CINTRA \& AOKI, 1999). Assim, fundação pode ser definida como o sistema formado pelo conjunto de elementos isolados de fundação da obra ou pelo sistema formado pela subestrutura e o maciço de solos (AOKI, 2001). Neste caso, pode-se considerar que a obra encontra-se em equilíbrio ao longo da interface superestrutura-fundação como ilustra a Figura 4.2.

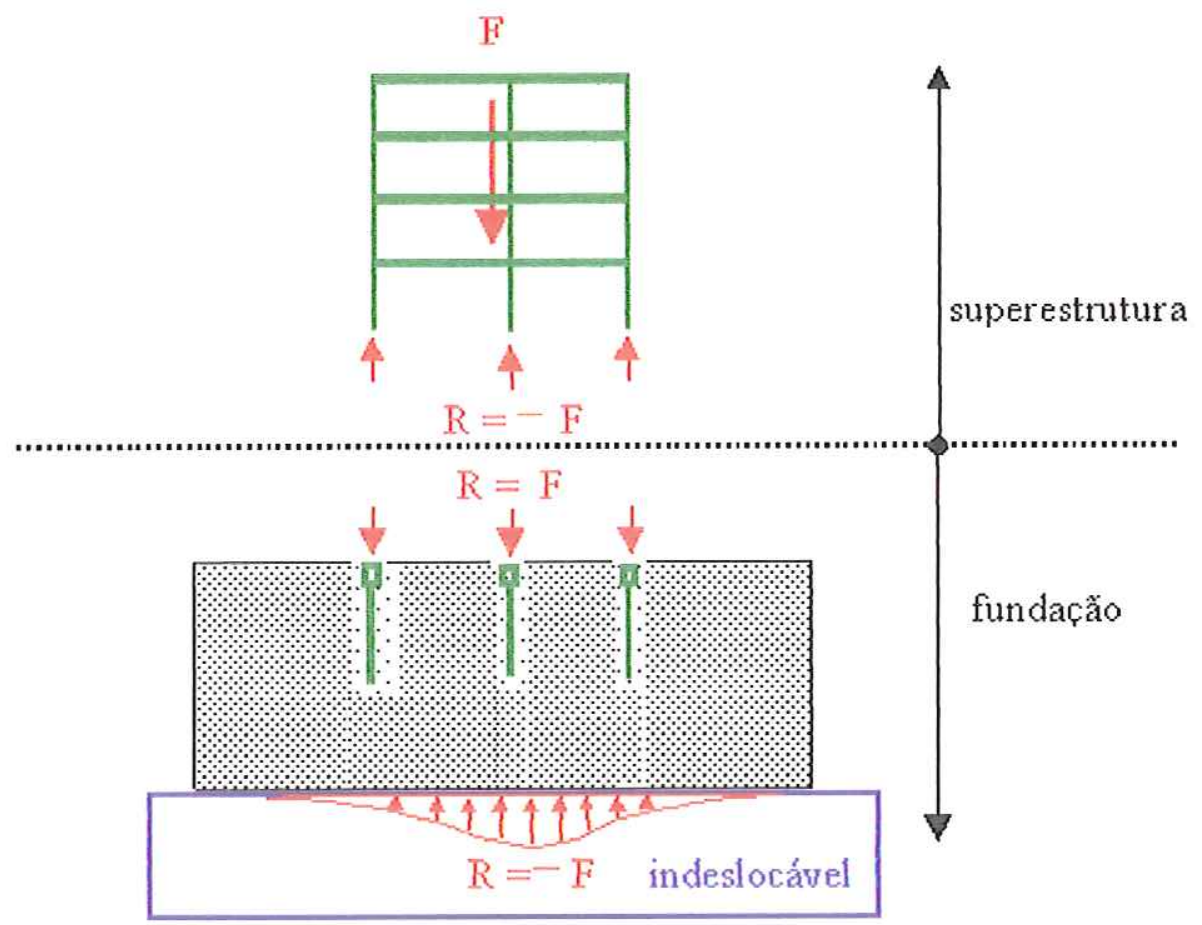

Figura 4.2. Equilíbrio na interface superestrutura-fundação (AOKI, 2000c).

Ao analisar o equilibrio estático do sistema observa-se a existência das denominadas "forças" reativas, que são esforços internos ao sistema, que podem ser caracterizadas por esforços solicitantes, numa seção qualquer, quando se trata de um elemento discreto (como, por exemplo, um elemento estrutural da superestrutura ou da fundação), ou por um tensor de tensões ou de deformações num ponto, quando se trata de um meio contínuo (como, por exemplo, o maciço de solos). Logo, as "cargas nos pilares" fornecidas pelo engenheiro estrutural ao engenheiro de fundações não são ações atuantes no sistema, mas sim forças reativas, pois as "cargas nos pilares" são 
esforços solicitantes na superfície de contato da superestrutura com a fundação, ou melhor, nos pontos da seção estrutural que liga a base do pilar da superestrutura com a fundação. Portanto, as forças reativas ou reações internas que solicitam a seção de interligação das duas partes do sistema, que são seções deslocáveis, não podem ser confundidas com as reações de apoio que se encontram ao longo da superfície indeslocável (AOKI, 2000c).

Porém, a terminologia diferenciando subestrutura, fundações e superestrutura tem apenas a função de facilitar o estudo da "realidade". Pois, estas não subsistem isoladas mas são intimamente interligadas. O que existe realmente, é a obra composta pela estrutura construída pelo homem e o maciço de solos natural perturbado pela execução da estrutura, sendo esta a realidade que não se deve esquecer em meio às nossas idealizações (ANTUNES \& IWAMOTO, 2000). A Figura 4.3, ilustra a idéia exposta acima.

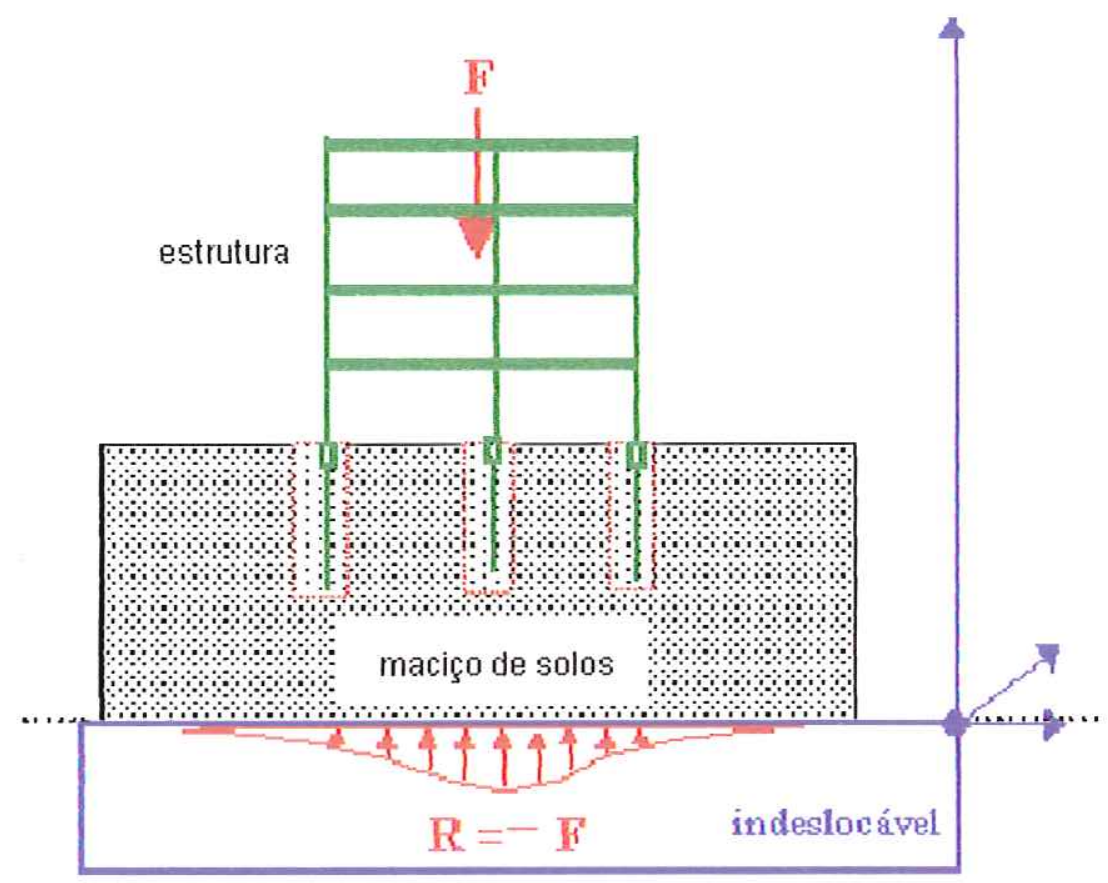

Figura 4.3. Equilíbrio na interface entre o maciço de solos e o indeslocável. (AOKI, 2000c).

Entretanto, ao analisar a "realidade" deve-se considerar a interação estruturasolo, onde a estrutura (superestrutura + subestrutura) interage com o maciço de solos, e sendo assim, a análise do equilíbrio das forças deverá ser feita ao longo da interface entre a estrutura e o maciço de solos, como ilustra a Figura 4.4. 


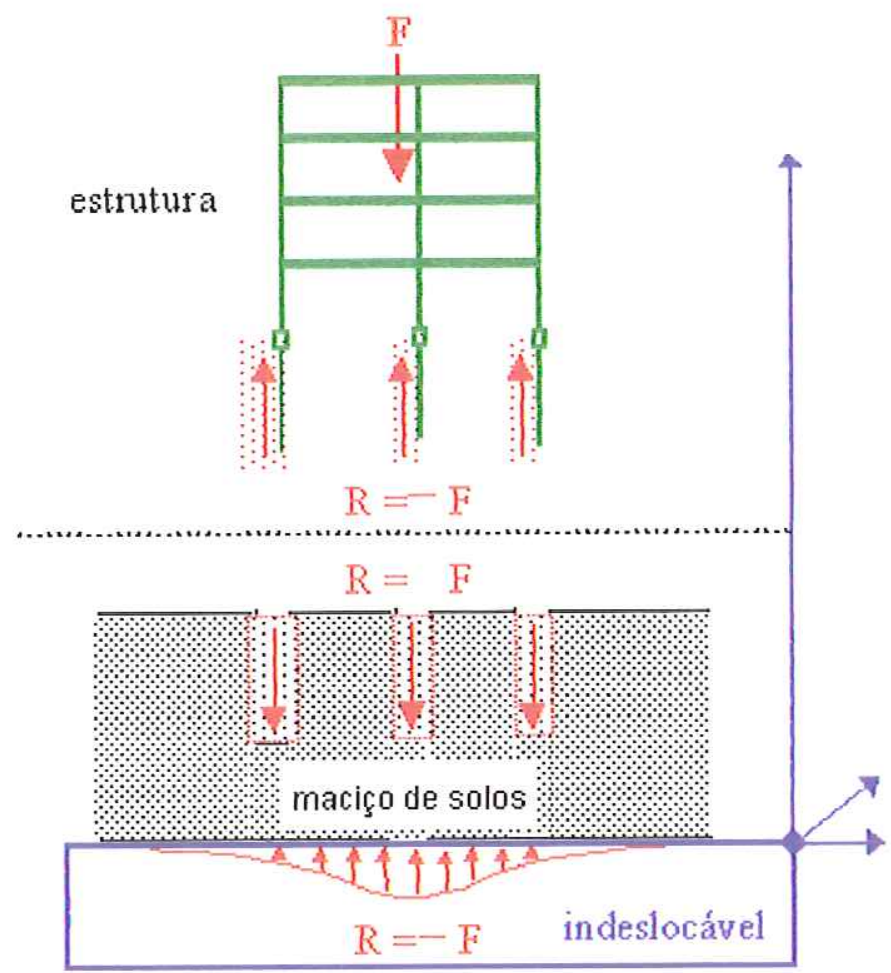

Figura 4.4. Equilíbrio na interface entre a estrutura e o maciço de solos (AOKI, 2000c).

Segundo Aoki (2000c), as principais divergências entre os engenheiros estruturais e os geotécnicos começa na escolha do sistema de referência (chama-se a atenção para a posição do sistema de referência nas três figuras anteriores: Figura 4.2, 4.3 e 4.4). Ambos consideram o nível do terreno como sendo a origem do sistema, no entanto, para os engenheiros estruturais, o sentido do eixo é para cima, enquanto que para os geotécnicos, o sentido do eixo é para baixo (Figura 4.2). No entanto, ambas as convenções não fazem sentido, pois esse ponto de referência é deslocável. A escolha certa seria um ponto abaixo da superfície do terreno na profundidade onde pode-se considerar a camada indeslocável (Figura 4.3 e Figura 4.4).

Porém, como já exposto anteriormente, nessa dissertação considera-se, por efeito de simplificação, a visão superestrutura-fundação (Figura 4.2). Mas, faz-se necessário deixar claro que se trata apenas de uma idealização para efeito de estudo, pois a realidade é composta por uma estrutura e por um maciço de solos que com ela irá interagir, compondo o que conhecemos como uma obra de engenharia civil. 


\subsubsection{Equilíbrio estático de um Elemento Isolado de Fundação}

A NBR 6122/1996: "Projeto e Execução de Fundações", separa as fundações (ou melhor, os elementos estruturais de fundação), em fundações superficiais e fundações profundas com base na forma de transferência de carga desses elementos. Fazendo uma analogia, é exposto o que se entende por elemento isolado de fundação e como é a sua transferência de carga com base no seu equilíbrio estático.

Segundo a NBR 6122/1996, fundação profunda é elemento de fundação (sic) que transmite a carga ao terreno pela base (resistência de ponta), por sua superfície lateral (resistência de fuste) ou por uma combinação das duas, e que está assente em profundidade superior ao dobro de sua menor dimensão em planta, e no mínimo $3 \mathrm{~m}$, salvo justificativa. Neste tipo de fundação incluem-se as estacas, os tubulões e os caixões.

Considere, como exemplo, um elemento isolado de fundação em estaca, formado pelo elemento estrutural estaca de dimensão B e L e pelo maciço de solos de espessura $\mathrm{H}$ que o envolve. O esquema de equilíbrio deste sistema sob ação de uma força vertical de compressão axial $\mathrm{P}$, encontra-se ilustrado na Figura 4.5a onde, a força externa P é equilibrada pelas reações de apoio $\mathrm{R}$ distribuídas ao longo da interface com a superfície indeslocável, que se encontra no interior do maciço de solos a uma certa profundidade (H - L) abaixo da base da estaca (AOKI, 2000a).

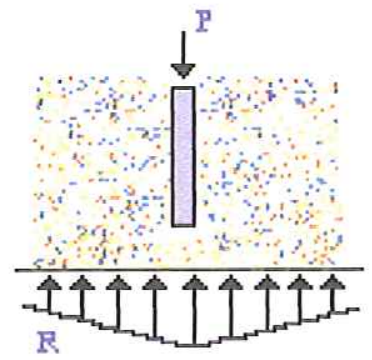

Figura 4.5a. Equilíbrio do elemento isolado de fundação (AOKI, 2000a).

Este equilíbrio é resultante do equilíbrio do elemento estrutural estaca sob ação da carga $\mathrm{P}$ e das forças reativas verticais distribuídas ao longo da superficie de interface com o maciço de solos, $R_{b}$ ao longo da base e $R_{l}$ ao longo do fuste, representados na Figura 4.5b, associado ao equilíbrio do maciço de solos sob a ação das forças reativas internas $R_{b}$ e $R_{l}$ e das reações de apoio $R$ distribuídas ao longo da superfície indeslocável, Figura 4.5c (AOKI, 2000a). 


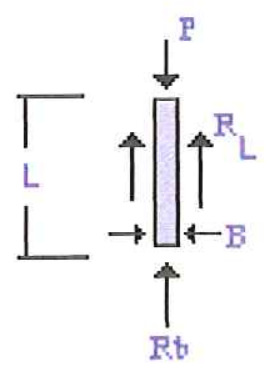

Figura 4.5b. Equilíbrio do elemento estrutural estaca (AOKI, 2000a).

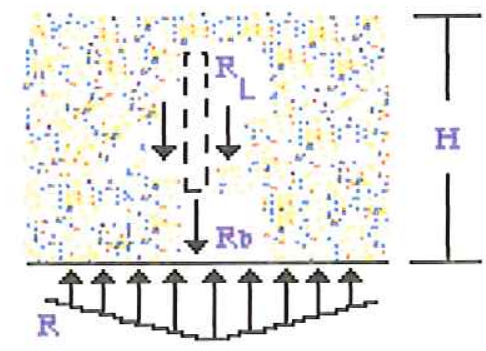

Figura 4.5c. Equilíbrio do maciço de solos (AOKI, 2000a).

Em resumo, o esquema de equilíbrio de um elemento isolado de fundação em estaca encontra-se ilustrado na Figura 4.5 (AOKI, 2000a).
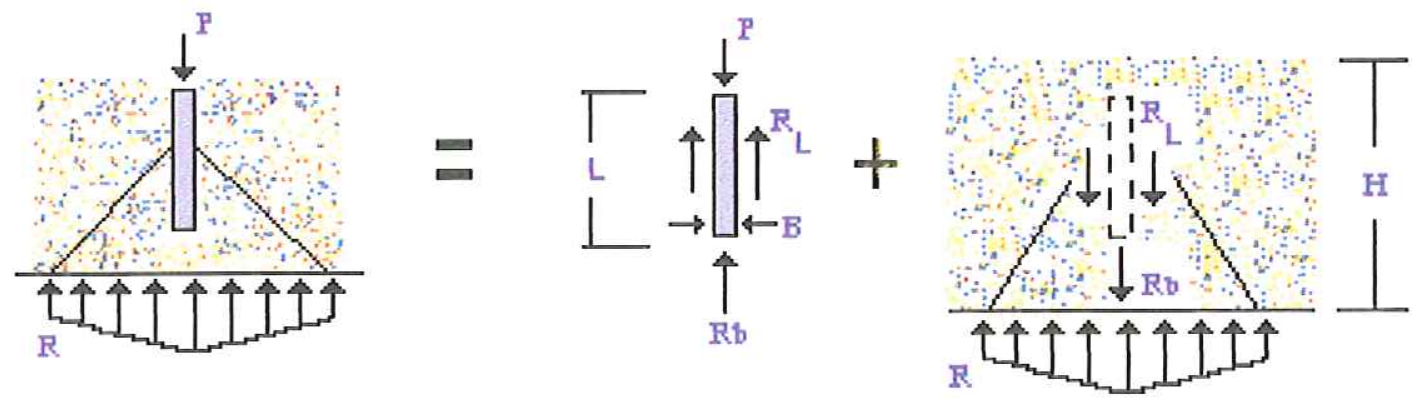

Figura 4.5. Equilíbrio do elemento isolado de fundação em estaca (AOKI, 2000a).

Quanto à fundação superficial (ou rasa ou direta), segundo a NBR 6122/1996, é elemento de fundação (sic) em que a carga é transmitida ao terreno, predominantemente pelas pressões distribuídas sob a base da fundação, e em que a profundidade de assentamento em relação ao terreno adjacente é inferior a duas vezes a menor dimensão da fundação. Incluem-se neste tipo de fundação as sapatas, os blocos, os radier, as sapatas associadas, as vigas de fundação e as sapatas corridas.

Adotando como exemplo uma sapata, ou seja, um elemento isolado de fundação em sapata, formado pelo elemento estrutural sapata de dimensão B e pelo maciço de solos de espessura $\mathrm{H}$ que o envolve, sob ação de uma carga $\mathrm{P}$, tem-se a Figura 4.6a, em 
que a carga externa $\mathrm{P}$ é equilibrada pelas reações de apoio $\mathrm{R}$ distribuídas ao longo da interface com a superfície indeslocável, que se encontra no interior do maciço de solos a uma certa profundidade abaixo da base da sapata (AOKI, 2000a).

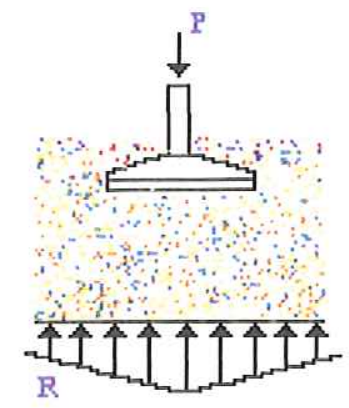

Figura 4.6a. Equilíbrio do elemento isolado de fundação (AOKI, 2000a).

Este equilíbrio é resultante do equilíbrio do elemento estrutural sapata sob ação da carga $P$ e das reações verticais $R_{b}$ na interface da base da sapata com o maciço de solos, representado na Figura 4.6b, associado ao equilíbrio do maciço de solos sob a ação da pressão $R_{b}$ e das reações de apoio $R$ distribuídas ao longo da superfície indeslocável, Figura 4.6c (AOKI, 2000a).

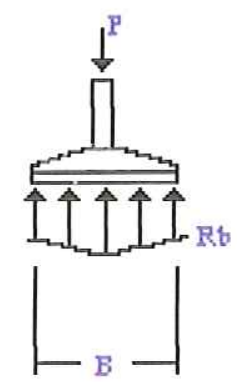

Figura 4.6b. Equilíbrio do elemento estrutural sapata (AOKI, 2000a).

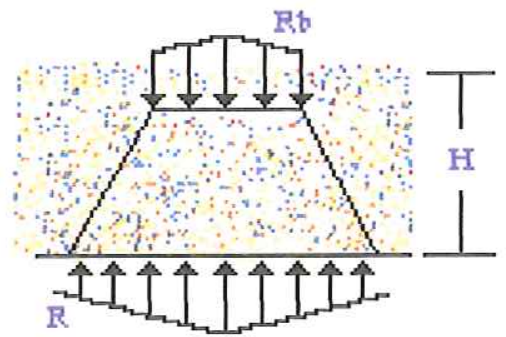

Figura 4.6c. Equilíbrio do maciço de solos (AOKI, 2000a).

Em resumo, o esquema de equilíbrio de um elemento isolado de fundação em sapata encontra-se ilustrado na Figura 4.6 (AOKI, 2000a). 

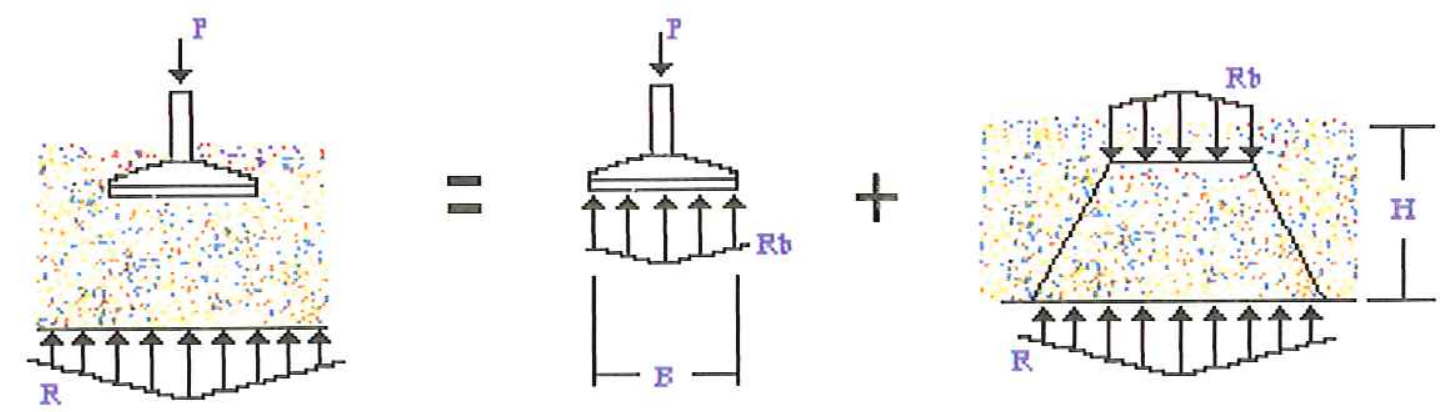

Figura 4.6. Equilíbrio do elemento isolado de fundação em sapata (AOKI, 2000a).

Pode-se então concluir que o elemento isolado de fundação é o sistema formado pelo elemento estrutural (estaca, sapata, etc.) e o maciço de solos ao longo do seu comprimento e sob a sua base, e que seu comportamento sob ação de carga estática ou dinâmica é único, e é condicionado pela geometria das camadas de solos do local da obra, pela geometria dos elementos estruturais de fundação, pelas características finais do solo e dos elementos estruturais após a sua execução ou instalação dentro do maciço de solos, pelo efeito de escala e pelo nível de tensões induzido pela carga aplicada (AOKI, 2000b).

\subsection{Superfície Resistente - Objeto de Análise}

Nas últimas décadas, muitos foram os esforços realizados para a incorporação de propriedades realistas dos solos em suas análises. Os dados experimentais comprovam a alta complexidade desse material e a sua constituição altamente heterogênea. Anteriormente porém, não se pensava em poder tratá-los de maneira precisa por apresentarem dificil modelagem. No entanto, houve uma intensa ampliação das pesquisas em busca da compreensão do real comportamento dos solos, porém, a maioria dos avanços, não considera a natureza aleatória das variáveis envolvidas nos projetos, ou melhor, não considera as incertezas e as variabilidades presentes nos parâmetros de projeto (BUENO \& VILAR, 1984).

A quantificação da segurança através da Teoria da Probabilidade possui, entre outras vantagens, a de assegurar um nível de segurança mais realístico, racional e consistente, entretanto, necessita de uma vasta gama de dados para ser implementada.

Para determinar a real probabilidade de ruína, de forma adequada, deve-se considerar as funções probabilísticas de distribuição das suas variáveis básicas. Isto geralmente é feito, expressando-se, independentemente, as variáveis aleatórias $\mathrm{R}$ e $\mathrm{S}$ 
como funções de suas variáveis básicas (propriedades dos materiais, dados geométricos, cargas, parâmetros do sistema, etc.) usando-se os parâmetros estocásticos das funções de distribuição. A margem de segurança, entre a capacidade resistente estrutural teórica e as cargas de projeto, deve ser determinada para cada sistema estrutural individualmente, considerando as suas variáveis básicas.

Mas, as incertezas na engenharia não estão limitadas somente à variabilidade das variáveis básicas. Pois, os valores estimados de uma dada variável, como a média, por exemplo, são baseados em dados experimentais e portanto não estão livres de erros (especialmente quando os dados são limitados). E os modelos matemáticos ou de simulação (como por exemplo, fórmulas, equações, algoritmos, programas de simulação computacional, etc.) e os de laboratório, usados na análise de engenharia, são representações idealizadas da realidade, algumas vezes, representações imperfeitas do universo real. Conseqüentemente, previsões e/ou cálculos feitos com base nesses modelos podem ser imprecisos e, portanto, também contêm incertezas.

A quantidade de variáveis geralmente envolvidas nos modelos é tamanha, que torna-se praticamente impossível prever, de forma precisa, o comportamento real de uma dada fundação. O que se pode fazer é estudar as variáveis mais importantes, obtendo assim avaliações e resultados de caráter apenas aproximado (BERNARDO, 1999). Assim, o nível de confiabilidade estimado será, portanto, apenas uma aproximação do nível real.

Os resultados obtidos a partir de uma análise ou de um modelo de projeto devem ser suficientemente realísticos, mas a formulação de um modelo matemática não é guiada somente pelo desejo de obtenção de uma descrição realística, mas também pela necessidade do modelo ser operacional. Logo, um aspecto importante do processo de formulação de um modelo é a arte de equilibrar realismo e operacionalidade.

Recordando o conceito de fundação de uma obra, anteriormente apresentado, percebe-se que quando se projeta uma fundação para um determinado nível de solicitação oriundo da sua interação com a superestrutura é necessário determinar em qual profundidade o maciço de solo poderá oferecer a resistência de que se necessita. Conhecida essa profundidade, para cada elemento isolado de fundação, tem-se a sua resistência e a sua solicitação.

Então, o que particulariza uma fundação, cuja geometria em planta já se encontra previamente definida, é a profundidade da base de cada elemento estrutural da subestrutura. Ao unirmos as áreas destas bases, é definimos uma superfície dentro do 
maciço de solos, que denominamos superfície resistente. Assim, pode-se afirmar que, em fundações, o objeto de estudo é a superfície resistente (AOKI, 2001). Pois, a análise de segurança e confiabilidade de uma fundação só pode ser realizada, através das curvas de distribuição estatística das solicitações e das resistências de uma dada superfície resistente analisada (AOKI, 2001).

Sendo assim, para esta dissertação, fixada uma superficie resistente, a fundação será considerada segura, se e somente se a probabilidade de ruína da fundação for considerada aceitável de forma a satisfazer aos estados limites da mesma.

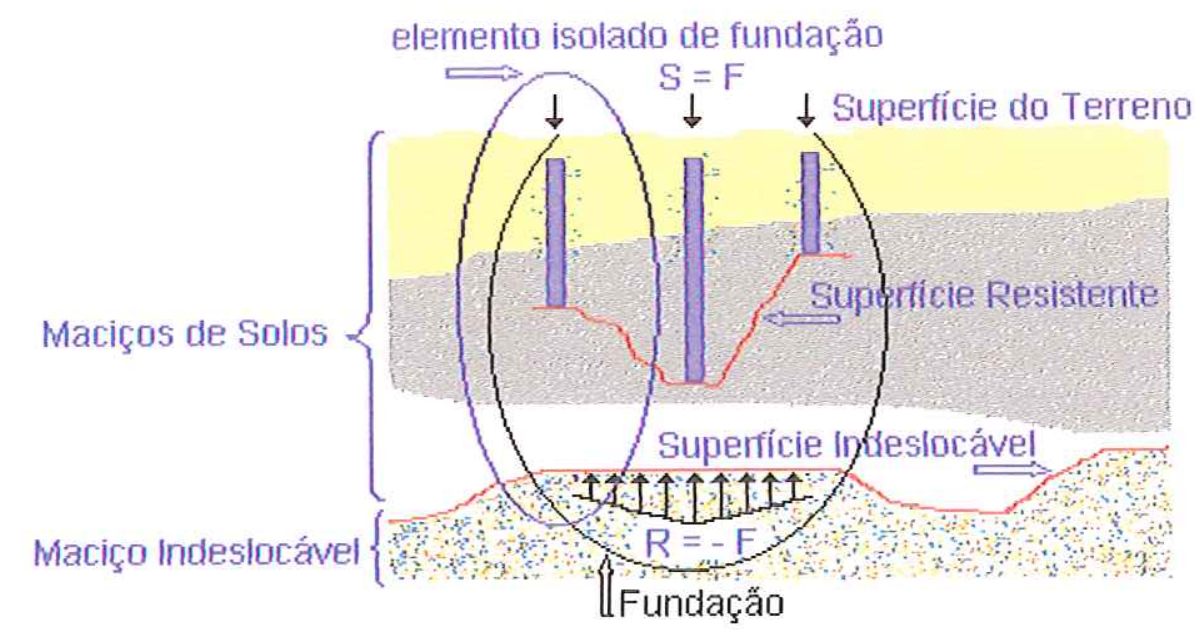

Figura 4.7. Equilíbrio estático da fundação (AOKI et al., 2001).

A Figura 4.7 apresenta o esquema de equilíbrio estático de uma fundação cuja distribuição em planta, dos elementos que compõem a subestrutura, encontram-se previamente definida (AOKI et al., 2001).

Para efeito de simplificação, supõe-se que $\mathrm{R}$ e $\mathrm{S}$ são variáveis aleatórias estatisticamente independentes, ou seja, não será considerada a correlação entre elas. Entretanto, as variáveis em análise são correlacionadas (i.e. dependentes) por estarem vinculadas a uma superfície resistente e devido aos inevitáveis recalques da fundação, que provocam redistribuição dos esforços na estrutura (hiperestática).

O escopo de toda essa explanação é ressaltar que ao se abordar o tema fundação de uma obra é de fundamental importância caracterizar qual é o objeto de análise (AOKI, 2001). Logo, para esta dissertação, ao efetuar análises baseadas em conceitos de confiabilidade e estatística, o seu principal objeto de análise será a superfície resistente de uma determinada fundação. Ou seja, o objetivo dessa dissertação é analisar a segurança e a confiabilidade associadas a uma superficie resistente previamente definida (i.e. fixada). 
AS INCERTEZAS NA ENGENHARIA DE FUNDAÇÕES

\subsection{A Complexidade de introduzir Segurança na Engenharia de Fundações}

Diferentes tipos de incertezas são inerentes ao projeto de fundações, essas incertezas podem ser agrupadas nas seguintes categorias (BECKER, 1996a):

- incertezas na determinação das solicitações;

- incertezas associadas à variabilidade do maciço de solos;

- incertezas na determinação dos parâmetros geotécnicos de projeto;

- incertezas associadas com o grau no qual o modelo analítico representa o comportamento real da fundação.

No entanto, as incertezas associadas com a variabilidade natural das condições do solo e com a avaliação dos parâmetros geotécnicos são geralmente as maiores, como conseqüência dos complexos processos envolvidos na deposição e formação dos solos e rochas (PHOON et al., 2000). Todas as incertezas enumeradas acima podem ser quantificadas, explicitamente ou implicitamente; são assim conhecidas como incertezas objetivas. Mas, ao contrário das incertezas objetivas, os erros grosseiros, incluindo erros humanos ou omissões que ocorrem na prática, raramente podem ser quantificadas no projeto, sendo assim chamadas de incertezas subjetivas. Essas incertezas, apesar de não quantificáveis, podem ser reduzidas a valores mínimos a partir do controle de qualidade (BECKER, 1996a; OLIVERA, 1998). 
Bolton (1989) afirma que a maioria das falhas ocorrem devido a erros grosseiros ou humanos, como por exemplo, cálculos de projeto inadequados para a situação prática, e que nenhum nível de segurança, economicamente aceitável, pode cobrir situações em que as condições do local ou as propriedades do solo foram mal avaliadas, onde uma carga foi esquecida ou onde um cálculo ou uma análise foram inapropriados.

Segundo Velloso \& Lopes (1996), em toda obra de engenharia, há um certo "risco", ou seja, uma probabilidade de insucesso. Nas obras de terra e fundações, como decorrência, sobretudo, da natureza do material com que se trabalha, o solo, esse risco é sensivelmente maior que nas demais especialidades da Engenharia Civil. Por isso, ele tem sido objeto de estudos por parte de inúmeros profissionais tais como Casagrande (1965), de Mello (1975, 1977) e Velloso (1985a, 1985b, 1987).

A respeito dos métodos mais tradicionais de mensuração de riscos, Casagrande (1964), em "Role of the 'Calculated Risk' in Earthwork and Foundation Engineering" explica que a expressão "risco calculado" envolve dois diferentes aspectos:

- O uso de um conhecimento imperfeito, orientado pelo bom senso e experiência, para estimar as variações prováveis de todas as quantidades que entram na solução de um problema;

- A decisão com base em uma margem de segurança adequada ou grau de risco adequado, levando em conta fatores econômicos e a magnitude das perdas que resultariam de um colapso.

Segundo Casagrande (1964), os "riscos" podem ser classificados em:

1) Riscos de Engenharia:

1.a) Riscos desconhecidos: são aqueles desconhecidos até que se revelam em um acidente, através do qual podem, então, ser observados e investigados. Na opinião de Casagrande (1964), os atuais conhecimentos de Geotecnia permitem que se tenha, pelo menos, uma estimativa qualitativa da resposta da grande maioria de tipos de solos e rochas existentes quando estes são submetidos às atividades convencionais das obras de Engenharia. Em outras palavras, pode-se dizer que é muito pouco provável encontrarem-se riscos desconhecidos na atualidade.

1.b) Riscos calculados: correspondem aos fenômenos para os quais a Geotecnia ainda não apresentou uma solução quantitativa satisfatória. Casagrande (1964) enumera os seguintes riscos calculados: 
- deslizamentos por liquefação em solos granulares;

- deslizamentos por liquefação em argilas extremamente sensíveis;

- características tensão $\mathrm{x}$ deformação $\mathrm{x}$ resistência em materiais granulares grossos, incluindo enrocamentos, sob elevadas pressões confinantes;

- características tensão x deformação x resistência, a longo prazo, de argilas não drenadas;

- características de estabilidade de argilas rijas e argilas siltosas muito plásticas;

- controle de fissuras transversais e longitudinais no núcleo de barragens de enrocamento de grande altura;

- efeitos de terremotos em barragens de terra ou enrocamento de grande altura.

2) Riscos humanos:

A maioria dos riscos humanos, tanto desconhecidos como calculados, podem ser agrupados em três categorias, sendo que, freqüentemente, não há uma demarcação nítida entre eles:

2.a) organização insatisfatória, incluindo divisão de responsabilidade entre projeto e supervisão d construção;

2.b) uso insatisfatório do conhecimento disponível e do bom senso;

2.c) corrupção.

\subsection{Variabilidade da Resistência}

O solo cobre o substrato rochoso e provêm da desintegração e decomposição das rochas, mediante a ação dos intemperismos físico e químico. Assim, de maneira geral, por causa da sua heterogeneidade e das suas propriedades bastante complexas, não existe modelo matemático ou ensaio em modelo reduzido que caracterize, de forma satisfatória, seu comportamento. Como, de modo geral, as características do solo em seu estado natural devem ser aceitas e só em casos particulares, com o auxilio de técnicas especiais, devem ser melhoradas, verifica-se que, na Engenharia de Fundações ou, de forma mais ampla, na Geotecnia, o profissional terá que lidar com um material natural sobre o qual pouco pode atuar, isto é, tem que aceitá-lo tal como ele se apresenta, com suas propriedades e comportamento específicos (BUENO \& VILAR, 1989).

Sabe-se que a determinação da resistência última ou capacidade de carga da fundação é geralmente feita de forma teórica, empírica ou semi-empírica. 
Os métodos semi-empíricos amplamente utilizados no Brasil são baseados em investigações in situ tais como os ensaios de penetração estática (CPT) e os ensaios de penetração dinâmica (SPT). Quando não se dispõe de ensaios CPT, mas apenas ensaios SPT, algumas correlações podem ser aplicadas entre esses dois ensaios, entretanto, tais correlações necessitam ser aplicadas com cautela, pois envolvem grandes dispersões.

Cabe lembrar ainda que os métodos semi-empíricos só devem ser aplicados aos tipos de estacas e regiões geotécnicas para os quais foram estabelecidos, todavia, apesar dessas ressalvas esses métodos são usados indiscriminadamente na prática de projeto de fundações na Brasil (VARGAS, 1990).

O projeto de fundações, ou mais precisamente seu dimensionamento, está calcado na utilização de correlações que são estabelecidas para determinadas regiões e são extrapoladas para outras condições, às vezes, de maneira inescrupulosa. Tem-se que reconhecer que essas correlações são, pelo menos no presente, "um mal necessário". O que se impõe é que seus autores sejam mais explícitos e precisos na caracterização das condições em que foram estabelecidas e que, por outro lado, aqueles que vão utilizá-las o façam com critério, comparando aquelas condições com as que se tem diante de si (VELLOSO \& LOPES, 1996).

A resistência de um elemento de fundação isolado é constituída da resistência oferecida pelo elemento estrutural de fundação e a resistência oferecida pelo maciço de solo de fundação. Assim, a resistência das fundações decorre de uma dupla variabilidade, entretanto, esta última, na maioria das vezes, condiciona o limite inferior para a resistência do sistema sendo, portanto, o principal objeto de estudo da Engenharia de Fundações (OLIVEIRA, 1998).

Como exemplo, a capacidade de carga de uma estaca é função das características do elemento estrutural e da resistência do solo e a sua verificação de segurança à ruptura, é feita através do cálculo de sua capacidade de carga última, que sob ponto de vista geotécnico, é a carga que aplicada à estaca mobiliza toda a resistência disponível do solo (OLIVEIRA, 1998).

A complexidade dos maciços de solos torna dificil a fixação de valores normativos, como valores médios e coeficientes de variação para a resistência do solo. No caso específico de estacas cravadas pode-se determinar os valores médios, coeficientes de variação e ajustar distribuições de probabilidade para a capacidade de carga mobilizada durante a sua cravação (resistência mobilizada do solo) através de ensaios de carregamento dinâmico. Pois, quando a energia transferida a estaca é 
suficiente para mobilizar toda a resistência do solo, a carga mobilizada pelo ensaio de carregamento dinâmico corresponde à capacidade de carga última da estaca (OLIVEIRA, 1998; VANMARCKE, 1977).

A principal fonte de incertezas e erros na determinação da resistência do solo a partir de ensaios de laboratório é o amolgamento devido às operações de extração, manipulação e talhagem dos corpos de prova. No entanto, muito esforço vem sendo investido na pesquisa dos desvios introduzidos pelos métodos de avaliação da resistência e à medida que novas influências são quantificadas, verifica se que alguns desvios aparentemente aleatórios são, na realidade, provenientes do efeito conjunto de diversos desvios sistemáticos passíveis de correção. As incertezas reduzem-se assim gradualmente àquelas inerentes a qualquer método experimental.

É neste contexto que, em 1964, Casagrande comentou: "É insuficiente o conhecimento sobre solos, rochas e sobre seu comportamento in situ, para fazer uma avaliação do risco. Logo, seremos criticados, não importa como façamos esta análise. Porém, devemos prosseguir e realizar tais estudos, pois aprender a fazer esta análise de maneira significativa e responsável é um importante desafio para a profissão."

Na estimativa das propriedades do solo, depara-se com uma série de incertezas, mas mesmo assim, a variabilidade inerente das propriedades do solo in situ deve ser determinada, pois é a realidade com que se lida (GIMENES \& HACHICH, 1992).

Um importante fator de incerteza geotécnica é a incerteza de medição e a incerteza estatística. A dispersão dos dados é, em geral, função da variabilidade inerente do solo, dos erros de medida provenientes do procedimento adotado ou mesmo do operador (em geral, testes que são altamente dependentes do operador e que têm procedimentos complicados apresentam maior variabilidade do que aqueles com simples procedimentos e pouco dependentes do operador), dos erros advindos do equipamento (resultantes de imperícias e variações da geometria do equipamento), e dos sistemas empregados nos ensaios geotécnicos de rotina (PACHECO, 1990).

As medidas in situ também são influenciadas pela incerteza estatística ou por erros de amostragem, advindos de quantidades limitadas de informação. Outro fator importante de incerteza é introduzido quando medidas de campo ou laboratório são transformadas em parâmetros de propriedades de solo para projetos usando modelos de correlação empíricos ou outros. Sendo que, a contribuição relativa dessas incertezas na estimativa das propriedades do solo depende das condições in situ, do grau de controle do procedimento e equipamento, e da qualidade do modelo de correlação . 


\subsection{Variabilidade da Solicitação}

\subsubsection{Ações e Solicitações}

Tanto quanto possível, as estatísticas das ações são baseadas em pesquisas in loco. Além da variabilidade básica da ação, incertezas surgem do modelo que transforma a ação real, variável tanto no tempo quanto no espaço, em uma ação estática equivalente para ser usada no cálculo. Incertezas também surgem na análise que transforma a ação equivalente em efeito desta ação (GALAMBOS et al., 1982).

As solicitações dependem fundamentalmente do maciço de solos. Para um mesmo projeto estrutural, têm-se diferentes solicitações nos elementos isolados de fundação em função da geologia local. Observe a Figuras 5.1.
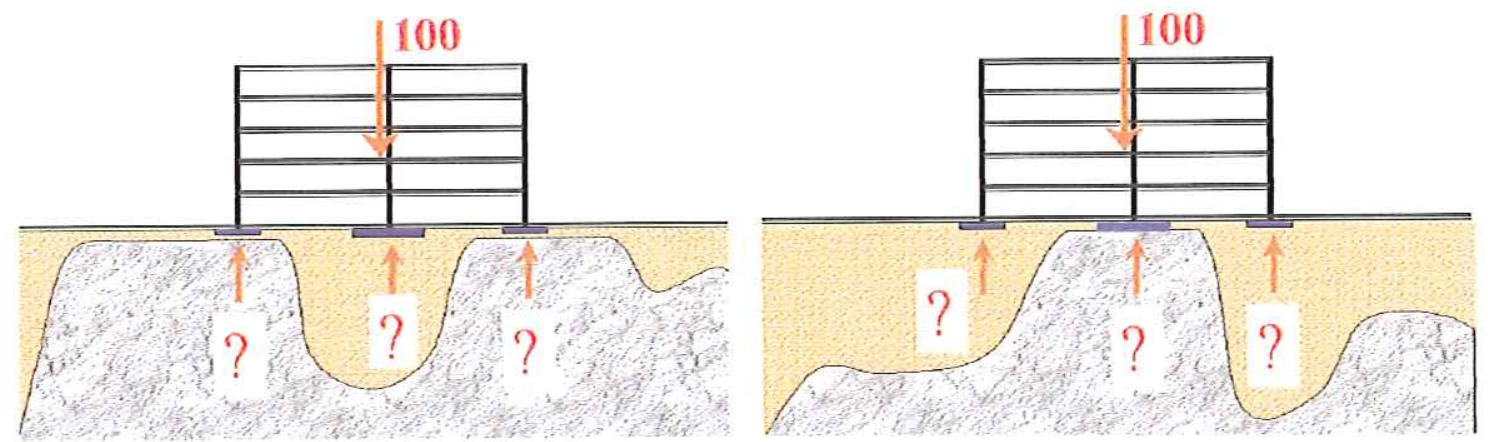

Figura 5.1. Análise do equilíbrio da estrutura em função da geologia local.

\subsubsection{Interação Solo-Estrutura}

A interação solo-estrutura (ISE) é uma linha de pesquisa que tem alcançado significativa importância nos últimos anos. A consideração da interação entre a superestrutura e a fundação tem demonstrado que o comportamento obtido na análise é mais próximo do observado na medição de recalques de edifícios monitorados do que os obtidos pela análise convencional que considera os apoios indeslocáveis (MENDONÇA \& AOKI, 2000).

Como exemplo, considere o caso simples de um edifício em terreno sem vizinhos. Em geral, a estrutura é calculada por um engenheiro estrutural supondo os apoios indeslocáveis, o que resulta um conjunto de esforços (reações verticais, horizontais e momentos fletores) que é passado ao engenheiro de fundações que dimensiona as fundações e calcula os recalques, comparando-os com os recalques 
admissíveis (ANTUNES \& IWAMOTO, 2000).

Toda obra introduz no maciço de solos um estado de tensões que provoca no mesmo deformações e deslocamentos que resultam em deslocamentos verticais (recalques), horizontais e rotações nas fundações (REIS \& AOKI, 2000). No entanto, estas fundações, devido à deformação do solo, aplicam à estrutura, geralmente hiperestática, um fluxo de carregamento diferente da hipótese de apoios indeslocáveis, modificando assim os esforços atuantes na estrutura e conseqüentemente as cargas no solo (ANTUNES \& IWAMOTO, 2000). A esse mecanismo dá-se o nome de interação solo-estrutura (ISE), onde a superestrutura e a fundação formam um sistema onde o fator determinante para o desempenho da obra é a rigidez relativa (REIS \& AOKI, 2000). Observe a Figura 5.2.

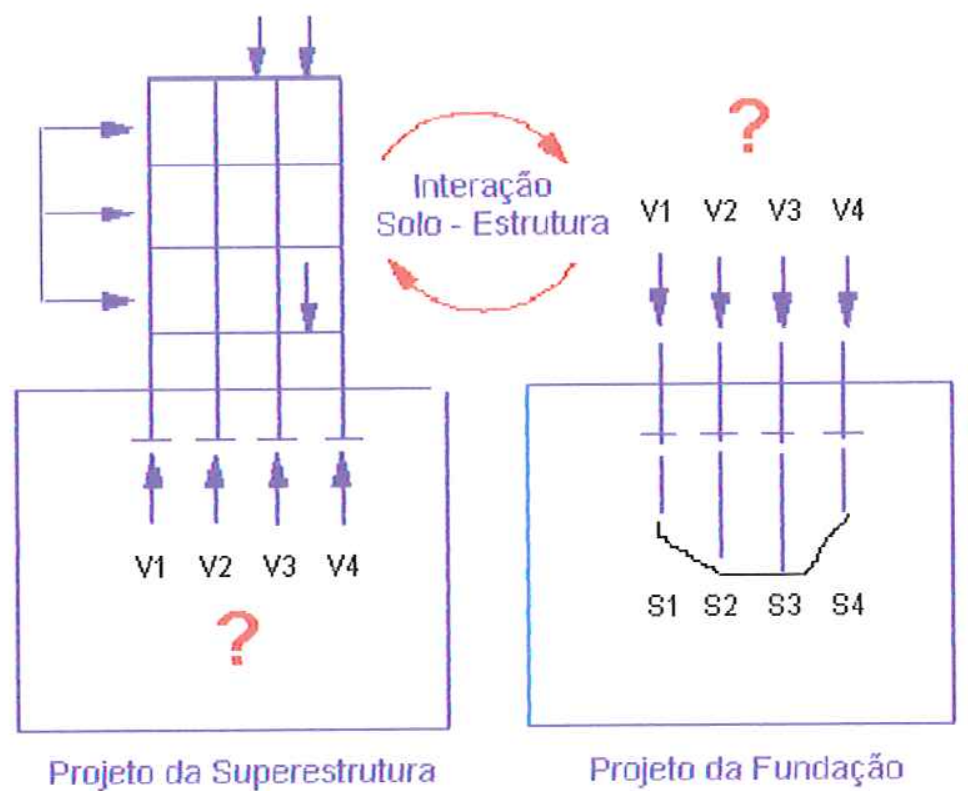

Figura 5.2. Mecanismo de interação solo-estrutura em edificações (GUSMÃO et al., 2000).

Segundo Gusmão et al. (2000), Brown em 1977 utilizando um modelo viscoelástico linear para o solo e elástico linear para a superestrutura percebeu que quanto maior a rigidez da estrutura, em relação à rigidez do solo, menores são os recalques diferenciais e que para grandes relações entre a rigidez da estrutura e do solo a influência do tempo passa a ser menor. No entanto, o projeto de fundações convencional considera apenas as cargas nos apoios obtidas pelo projeto estrutural convencional, e as propriedades geotécnicas do terreno, desprezando o efeito da rigidez da estrutura.

É importante destacar que, a compressibilidade dos solos em função do tempo, aparece no fenômeno de interação solo-estrutura como principal agente, uma vez que a 
maneira como os recalques evoluem e se estabilizam, é que determina a importância ou a gravidade dos danos causados por estes recalques à superestrutura.

Há uma tendência dos recalques máximos e mínimos se aproximarem da média, à medida que a rigidez da edificação vai aumentando, no entanto, a influência dos primeiros pavimentos nesta tendência de uniformização dos recalques é maior (GUSMÃO et al, 2000).

Gusmão et al. (2000) demonstra que o sistema solo-estrutura ao ser solicitado promove uma redistribuição de esforços que, em geral, aumenta a carga dos pilares periféricos e diminui a carga dos pilares centrais mais carregados. Esta redistribuição de esforços promove maiores recalques em pilares menos carregados e menores recalques em pilares mais carregados, suavizando a deformada de recalques. Logo, a interação solo-estrutura influencia a deformada de recalques da edificação, fazendo com que este fique mais suave, embora o recalque absoluto médio seja independente. Com isto, podese admitir que o recalque absoluto médio seja função apenas do carregamento total da estrutura e das propriedades de deformação do terreno. 
CARGA ADMISSÍVEL - PROPOSTA

\subsection{Carga admissível baseada na Probabilidade de Ruína}

Segundo Bilfinger (2002), a função fim de uma determinada fundação é suportar as cargas que nela atuam de acordo com os requisitos de projeto (deformabilidade, durabilidade, etc.).

Existe atualmente uma série de critérios de segurança que se diferenciam pela sistemática de introdução da segurança e pela escolha do(s) indicador(es) de segurança. Estes critérios de segurança se subdividem em dois grandes grupos: determinísticos e probabilísticos.

Os métodos determinísticos se caracterizam pela não consideração explícita das incertezas. No uso do coeficiente de segurança global embutem-se, implicitamente, todas as incertezas e erros, sendo o seu valor ajustado empiricamente. Logo, o coeficiente de segurança global é um valor único que incorpora a variabilidade das ações, das resistências dos materiais envolvidos, incertezas e erros inerentes às simplificações de cálculo. Quanto aos métodos probabilísticos, estes se caracterizam pelo tratamento probabilístico das grandezas envolvidas e pela tentativa de se determinar à probabilidade de ruína existente.

Sabe-se que quanto maior o índice de confiabilidade, $\beta$, maior será a distância entre a origem e o estado limite, conseqüentemente, maior será a região de segurança e menor a probabilidade de ruína. 
É fazendo uso deste raciocínio, que o índice de confiabilidade é usado para quantificar a confiabilidade de um sistema. Pois, deve-se recordar que a segurança de um sistema depende da posição relativa e do grau de dispersão das curvas de distribuição de probabilidade da resistência e da solicitação; logo, o índice de confiabilidade, $\beta$, por incluir esses dois fatores ao usar a média e o desvio padrão da margem de segurança, está diretamente vinculado à probabilidade de ruína, sendo, portanto, um índice eficiente para quantificar a confiabilidade e a segurança de uma fundação. É fazendo uso deste raciocínio que se propõe, nesta dissertação, uma nova metodologia de cálculo da carga admissível de um estaqueamento.

Conceitualmente, a carga admissível é a máxima solicitação que pode ser aplicada com segurança a uma fundação. Segundo a NBR 6122/1996, com relação à ruptura, a carga admissível de um estaqueamento, é dada por:

$$
P_{a d m}=\frac{R_{m}}{C S}
$$

Porém, de acordo com o Método da Carga Admissível, o coeficiente de segurança global relaciona a resistência média com a solicitação média dos $n$ elementos isolados de uma fundação, ou seja:

$$
C S=\frac{R_{m}}{S_{m}} \rightarrow S_{m}=\frac{R_{m}}{C S}
$$

Assim, ao observar (6.1) e (6.2), conclui-se que:

$$
P_{a d m}=S_{m}
$$

Logo, usando o conceito de índice de confiabilidade, a carga admissível de um estaqueamento pode ser estimada por:

$$
\beta=\frac{\mu_{X}-\mu_{Y}}{\sigma_{z}}=\frac{R_{m}-S_{m}}{\sigma_{Z}} \rightarrow P_{a d m}=S_{m}=R_{m}-\beta \cdot \sigma_{Z}
$$

sendo,

$P_{a d m}=$ carga admissível correspondente a uma probabilidade de ruína, $p_{R}$;

$\mu_{X}=R_{m}=$ resistência média; 
$\mu_{Y}=S_{m}=$ solicitação média;

$\beta$ = índice de confiabilidade correspondente a uma determinada probabilidade de ruína;

$\sigma_{Z}=$ desvio padrão da função margem de segurança, $Z$.

No caso particular de uma abordagem semi-probabilística, muito comum na prática, o desvio padrão da solicitação é igual a zero, o que resulta na expressão simplificada:

$$
P_{a d m}=S_{m}=R_{m}-\beta . \sigma_{R}
$$

sendo,

$\sigma_{R}=$ desvio padrão da função resistência.

Ao calcular a carga admissível de um estaqueamento usando o coeficiente de segurança global não se sabe qual é a probabilidade de ruína deste sistema. Porém, com o uso da formulação proposta acima, é possível projetar uma fundação com uma determinada probabilidade de ruína desejada. Em função de se desejar uma maior ou menor probabilidade de ruína, usa-se um índice de confiabilidade menor ou maior, respectivamente.

A seguir são apresentadas algumas observações importantes, que devem ser destacadas, a respeito da formulação proposta.

\subsection{Algumas considerações sobre a metodologia proposta}

Este item tem como objetivo discutir e apresentar as premissas adotadas na formulação da carga admissível proposta, bem como as conseqüências que delas advém.

Inicialmente, discute-se a utilização das palavras "falha" e "ruína" no contexto desta dissertação, assim como os valores de probabilidade de ruína que são considerados aceitáveis no meio geotécnico. A seguir, é apresentada uma discussão com relação à probabilidade de ruína que está sendo considerada adequada neste trabalho. $\mathrm{E}$ finalmente, apresentam-se as simplificações implícitas quando da utilização da formulação proposta na estimativa da carga admissível de uma fundação. 


\subsubsection{Probabilidade de Ruína aceitável}

Deve-se destacar que na Teoria da Confiabilidade é utilizada a expressão "probabilidade de falha" (observe o Capítulo 3) enquanto que em Geotecnia é comum o uso da expressão "probabilidade de ruínc"; que será a terminologia adotada nesta dissertação. Entretanto, deve-se destacar que não há diferenças entre elas, pois entendese que os termos "falha" e "ruina" possuam o mesmo significado, e sendo assim, eles devem ser considerados idênticos no contexto desta dissertação.

A palavra "falha" usada no contexto da Teoria da Confiabilidade não implica necessariamente numa catástrofe. Algumas condições, como por exemplo, um recalque, poderá originar um comportamento insatisfatório, e ser considerado como falha (DUNCAN, 2000). Logo, percebe-se que o termo "falha" deve ser interpretado como a violação de um estado limite qualquer, devendo ser interpretado no sentido mais geral. Se o estado limite é relacionado a recalque, a falha é dita a ocorrência de um recalque excessivo (LI et al., 1993).

Sendo assim, é importante ter em mente as conseqüências reais do evento analisado e não esperar uma catástrofe quando o termo "probabilidade de falha ou ruína" é usado. Pois, a palavra "falha", assim como a palavra "ruína", simboliza um evento insatisfatório qualquer, um estado limite qualquer (DUNCAN, 2000).

As normas não especificam de forma clara qual é a probabilidade de ruína aceitável para uma fundação.

Meyerhof (1969), apresenta as probabilidades de ruína assumidas como aceitáveis para três tipos de obra:

Tabela 6.1. Probabilidades de ruína aceitáveis (MEYERHOF, 1969).

\begin{tabular}{|c|c|}
\hline Tipo de Estrutura & Probabilidade de Ruína \\
\hline Obra de Terra & 1. $10^{-3}=\frac{1}{1000}$ \\
\hline Fundações "Offshore" & 1. $10^{-2}$ \\
\hline Fundações Convencionais & 1. $10^{-4} \quad \frac{1}{10000}$ \\
\hline
\end{tabular}

Whitman (2000) apresenta um gráfico relacionando a probabilidade de ruína anual de algumas obras com as conseqüências de ruína em termos de vidas perdidas e de custo. Pode-se observar pela figura apresentada em Whitman (2000) que a probabilidade de ruína associada a fundações varia de $10^{-2}$ a $10^{-3}$. 
No caso da resistência e da solicitação serem variáveis aleatórias com distribuição normal, a relação quantitativa entre a probabilidade de ruína e o índice de confiabilidade, é dada pela relação apresentada na Tabela 6.2 (ANG \& TANG, 1984).

Tabela 6.2. Relação quantitativa entre probabilidade de ruína e índice de confiabilidade.

\begin{tabular}{|c|c|}
\hline$P_{R}$ & $\beta$ \\
\hline 0.50 & 0.00 \\
\hline 0.25 & 0.67 \\
\hline 0.16 & 1.00 \\
\hline 0.10 & 1.28 \\
\hline 0.05 & 1.65 \\
\hline 0.01 & 2.33 \\
\hline $10^{-3}$ & 3.09 \\
\hline $10^{-4}$ & 3.72 \\
\hline $10^{-5}$ & 4.25 \\
\hline $10^{-6}$ & 4.75 \\
\hline
\end{tabular}

Nesta dissertação, o valor de probabilidade de ruína que será considerado aceitável para fundações convencionais será de $1.10^{-3}$, que corresponde a um índice de confiabilidade de 3.09. Logo, para se projetar fundações com uma probabilidade de ruína aceitável, deve-se utilizar um índice de confiabilidade de no mínimo 3.09 na formulação proposta.

Segundo Duncan (2000), a Teoria da Confiabilidade não tem sido usado na prática geotécnica por duas razões. A primeira, é que a Teoria da Confiabilidade envolve termos e conceitos que não são familiares à maioria dos engenheiros geotécnicos. Segundo, é conhecido que o uso da Teoria da Confiabilidade requer mais dados, tempo e esforço que são necessários nas circunstâncias.

Entretanto, esta dissertação vem destacar que os conceitos de confiabilidade podem ser aplicados em situações simples, sem maiores dados, tempo e esforço que são usualmente necessários na Engenharia Geotécnica. Trabalhando com a mesma quantidade e tipos de dados, e mesmo tipo de juízos que são normalmente utilizados nas análises convencionais.

Deve-se destacar que não defende-se aqui, que as análises com o uso dos coeficientes de segurança sejam abandonadas em favor do uso das análises de confiabilidade. Mas, sugere-se que o coeficiente de segurança e a confiabilidade sejam usados em conjunto, para possibilitar a realização de projetos seguros e de forma 
consciente dos riscos envolvidos. Mesmo porque, qualquer transição deve ser realizada de forma gradual, para que possa se tornar clara às diferenças e às vantagens que a nova metodologia venha a oferecer.

\subsubsection{Probabilidade de Rúna de um Elemento Isolado de Fundação}

Deve-se destacar que a carga admissível proposta é baseada na probabilidade de ruína de uma estaca isolada, ou melhor, de um elemento isolado de fundação.

Entretanto, as fundações por estacas são geralmente constituídas de grupos de estacas. Ou seja, as estacas são agrupadas de forma a constituírem grupos com um número determinado de estacas unidas por meio de um bloco de coroamento que deve ser dimensionado de forma a distribuir uniformemente as cargas (solicitações) para cada uma das estacas do grupo (VESIC, 1975).

Vesic (1975) comenta que a principal questão a ser resolvida no projeto de um estaqueamento é determinar qual a carga de ruptura do grupo $\left(P_{\text {grupo }}\right)$ e fazer a previsão de recalque para o mesmo ( $\left.w_{\text {grupo }}\right)$.

Segundo Vesic (1975), ao se projetar um estaqueamento, as estacas devem ser espaçadas de forma que a capacidade de carga do grupo não seja menor que a soma das capacidades de carga individuais das estacas. Logo, em qualquer estaqueamento tem-se que a resistência apresentada por um grupo de estacas é sempre superior à apresentada pela soma das resistências dos elementos isolados de fundação.

Sabe-se que a carga de ruptura do grupo é, geralmente, diferente da soma das cargas de ruptura individuais das estacas do grupo $\left(\sum P_{\text {estacas }}\right)$ e que elas se relacionam segundo o fator:

$$
n=\frac{P_{\text {grupo }}}{\sum P_{\text {estacas }}}
$$

que é denominado de eficiência de grupo e, depende dos seguintes parâmetros:

- tipo de solo;

- tamanho e forma do grupo;

- espaçamento e comprimento relativo das estacas;

- metodologia executiva. 
Sabe-se também que o recalque do grupo ( $w_{\text {grupo }}$ ) é normalmente maior que o recalque de uma estaca isolada. Em geral,

$$
w_{\text {grupo }}=\xi \cdot w_{\text {estaca }}
$$

sendo $\xi$ o denominado fator de recalque do grupo e este fator também depende dos parâmetros citados acima.

Não existe atualmente uma teoria racional de cálculo da capacidade de carga de um grupo de estacas. No entanto, com base nos dados disponíveis, Vesic (1975) conclui que:

a) A resistência de ponta na ruptura de um grupo de estacas pode ser considerada igual a soma das resistências de ponta na ruptura individuais de cada estaca isolada.

$$
R_{\text {ponta grupo }}=\sum R_{\text {ponta estaca }}
$$

b.1) A resistência lateral na ruptura de um grupo de estacas em solos coesivos não é maior que a soma das resistências laterais na ruptura das estacas individuais multiplicada pela razão entre o perímetro externo do grupo e a soma dos perímetros individuais. Ou seja,

$$
R_{\text {lateral grupo }} \leq \frac{U_{\text {grupo }}}{\sum U_{\text {estaca }}} \cdot \sum R_{\text {lateral estaca }}
$$

Entretanto, se for especificado no projeto um espaçamento mínimo entre as estacas, igual a 2.5 o diâmetro das estacas do grupo (o espaçamento ótimo é usualmente em torno de 3.0 a 3.5 do diâmetro das estacas do grupo), a resistência lateral do grupo ficará:

$$
R_{\text {lateral grupo }} \geq \frac{U_{\text {grupo }}}{\sum U_{\text {estaca }}} \cdot \sum R_{\text {lateral estaca }}
$$

b.2) A resistência lateral na ruptura de um grupo de estacas em solos não coesivos pode ser maior que a soma das resistências laterais na ruptura das estacas individuais. Ou seja, 


$$
R_{\text {lateral grupo }} \geq \sum R_{\text {lateral estaca }}
$$

Agora é possível responder à seguinte questão: “A probabilidade de ruína de uma estaca de um grupo de estacas isoladas é diferente da probabilidade de ruína de uma estaca de um grupo de estacas sob blocos com um número variado de estacas?" Sim, a carga de ruptura de uma estaca isolada é diferente da carga de ruptura de uma estaca de um grupo de estacas capeadas por um bloco:

$$
R_{\text {estaca }} \text { grupo } \neq R_{\text {estaca isolada }}
$$

pois, sabe-se que a resistência de uma estaca de um grupo é superior à resistência apresentada por essa mesma estaca quando isolada:

$$
R_{\text {estaca grupo }} \geq R_{\text {estaca isolada }}
$$

Sendo assim, pode-se observar que a metodologia proposta ao calcular a carga admissível do estaqueamento com base na probabilidade de ruína de um elemento isolado de fundação está trabalhando com uma probabilidade de ruína superior à real, estando, portanto, a favor da segurança

\subsubsection{Variáveis aleatórias: Resistência e Solicitação}

Sabe-se que são inúmeros os fatores que intervêm na segurança de uma fundação. Entretanto, devido à complexidade de se trabalhar com um número elevado de variáveis optou-se por analisar a segurança e a confiabilidade das fundações através da consideração de somente duas variáveis aleatórias: a resistência e a solicitação. Pois, para o desenvolvimento dos critérios de cálculo baseados em probabilidade são requeridos, no mínimo, dados dessas duas variáveis. Sendo que a informação básica requerida é a distribuição de probabilidade dessas variáveis, ou pelo menos, a estimativa de suas médias e desvios padrão.

Apesar de ser considerada nas análises somente essas duas variáveis aleatórias, sabe-se que a variabilidade apresentada por elas, se deve a todas as demais variáveis que influem no sistema, as denominadas variáveis básicas. Sendo assim, ao se determinar à segurança de uma fundação com base nestas duas variáveis, deve-se ter como 
preocupação primordial, garantir que os valores médios e de coeficiente de variação determinados, sejam realmente representativos dos valores reais presentes na fundação analisada. Sendo por este motivo, que nesta dissertação, optou-se por trabalhar com resultados de provas de carga, por serem resultados que permitem conhecer a real variabilidade do sistema, por envolverem toda as incertezas presentes.

Entretanto, de nada adianta ter um modelo matemático bem definido se a aplicação do mesmo for feita de forma inadequada. Sendo este, infelizmente, um dos principais problemas, que tem contribuído para limitar o desenvolvimento da Teoria da Confiabilidade no meio geotécnico. Pois, as referências bibliográficas sobre o tema Segurança em Fundações nem sempre se preocupam em bem definir qual o seu objeto de estudo de segurança e confiabilidade. Foi pensando nisso que no Capítulo 4 desta dissertação foi destacado o que, para esta dissertação, se entende por fundação de uma obra e qual será o objeto de análise deste trabalho.

Ficou claro, naquele capítulo, que o objeto de estudo desta dissertação é a superficie resistente de uma fundação, e que esta superfície é uma superfície tridimensional que cada um dos elementos estruturais da fundação deve alcançar em profundidade para atender o valor da carga admissível de projeto. Sendo assim, conhecida a superficie resistente tem-se definida a resistência e a solicitação da fundação em análise. Logo, é possível perceber que as variáveis aleatórias resistência e solicitação estão interligadas pela superfície resistente da fundação analisada. Entretanto, por efeito de simplificação, estas foram consideradas como variáveis aleatórias independentes nas análises desenvolvidas nesta dissertação. Pois, entende-se que para a prática da engenharia, o uso de conceitos muito complexos e de difícil aplicação deve ser evitado, pois caso contrário, o engenheiro no seu dia a dia irá evitar o seu uso.

Com o mesmo raciocínio, em virtude do Teorema do Limite Central, a distribuição de probabilidade da resistência e da solicitação foi aproximada pela distribuição Normal ou Gaussiana (VANMARCKE, 1977). Entretanto, sabe-se que a imposição de um modelo do tipo normal, ou de qualquer outro modelo, sempre esbarra nas limitações associadas a este modelo. Mas, esse é ainda, infelizmente, "um mal necessário" até que seja possível se ter dados suficientes e com uma qualidade mínima que permita determinar a real distribuição de probabilidade das variáveis aleatórias resistência e solicitação (BILFINGER, 2002). 
Logo, pode-se perceber que, neste modelo, várias simplificações foram feitas, e conseqüentemente, as avaliações e os resultados obtidos serão de caráter apenas aproximado. Assim, o nivel de confiabilidade estimado nesta dissertação será uma aproximação do nível real.

Sabe-se que os resultados obtidos a partir de uma análise ou de um modelo de projeto devem ser suficientemente realísticos, mas a formulação de um modelo matemático não deve ser guiada somente pelo desejo de obtenção de uma descrição realista, mas também pela necessidade do modelo ser funcional. Logo, como já exposto anteriormente, um aspecto importante do processo de formulação de um modelo é a arte de equilibrar realismo e operacionalidade.

Foi pensando nas aplicações práticas, que nessa metodologia de projeto de fundações renuncia-se calcular a probabilidade de ruína exata da fundação, contentando-se em calcular uma probabilidade de ruína dita "nominal" na tentativa de garantir níveis aceitáveis de segurança através da consideração de alguns, dos diversos fatores que intervêm na avaliação da segurança de uma fundação.

Mesmo assim, o uso desta nova metodologia, apresenta grandes vantagens em relação às atuais. Pois, ao se estimar a probabilidade de ruína nominal com o método proposto, tem-se o conhecimento, ao menos aproximado, do nível de segurança com o qual se está trabalhando no projeto, possibilitando a execução de fundações mais seguras, confiáveis e economicamente mais viáveis. 


\section{Capítulo}

MATERIAIS E MÉTODOS

A metodologia adotada para a realização da pesquisa, consiste em obter as informações necessárias para o seu adequado desenvolvimento através da literatura existente sobre fundações, que possua dados de instrumentação e controle de obras durante o seu processo construtivo e dados obtidos para a realização do projeto, tais como, dados laboratoriais e de investigações geológico-geotécnicas.

Todo o desenvolvimento desta pesquisa está vinculado à análise de dados reais de obras. Esses dados consistem, essencialmente, de:

1) Características geométricas dos elementos estruturais de fundação: comprimento, diâmetro, etc.;

2) Características do maciço de solos: tipos de solos, $\mathrm{N}_{\mathrm{SPT}}$, etc.;

3) Resultados de provas de cargas estáticas e dinâmicas (energia constante e energia crescente).

4) Previsões de capacidade de carga baseadas na avaliação do perfil do subsolo.

A segurança de um determinado elemento de fundação é determinada pela sua probabilidade de ruína, que pode ser definida como a probabilidade de sua resistência ser menor que a solicitação atuante. Sabe-se que a capacidade de carga ou resistência de uma estaca é o menor dos dois valores: resistência estrutural do elemento que a constitui ou resistência geotécnica do sistema estaca-solo.

A capacidade de carga ou resistência de um elemento isolado de fundação é uma de suas características mais importante. A determinação de sua capacidade de carga 
pode ser feita diretamente, através de provas de carga, ou indiretamente, através de algum método de estimativa desse valor. Sendo assim, qualquer estudo sobre capacidade de carga de fundações profundas pode ser dividido em dois grupos:

- Análises prévias: baseadas em dados indiretos, tais como ensaios de laboratório e ensaios de campo (sondagens SPT, CPT, etc.).

- Análises do próprio elemento de fundação: desde a sua nega, até a realização de provas de carga estáticas, passando por medidas de repique e provas de carga dinâmicas.

O objetivo de uma prova de carga é, de forma simplificada, antecipar os potencias carregamentos em determinado elemento de fundação, visando avaliar a sua real capacidade de carga, seu comportamento tensão x deformação e/ou determinar as características do maciço de solos. Esta antecipação busca reproduzir a seqüência de carregamentos reais de uma construção, geralmente crescentes. Obviamente, esta reprodução depende de uma série de fatores, pois dificilmente as condições reais de carregamento serão seguidas (BILFINGER, 2002).

Mesmo assim, a realização de uma prova de carga estática é o processo mais eficiente, embora apresente como inconvenientes o tempo de execução e o custo elevado para a determinação da resistência de um elemento isolado de fundação. Este processo consiste em aplicar uma carga na estaca e medir os recalques correspondentes.

Logo, a realização de ensaios de carregamento estático ou dinâmico por amostragem representa uma boa solução para avaliar a qualidade de um estaqueamento, e para identificar a variabilidade do maciço de solos. Entretanto, o número de estacas ensaiadas deve ser insuficiente para representar a fundação em análise.

Nesta dissertação foi adotado um número mínimo de cinco provas de carga como ideal para a avaliação da fundação. Entretanto, com o intuito de analisar algumas fundações especificas, foram realizadas algumas análises (item 8.1 e 8.3 do Capítulo 8) utilizando-se apenas três e/ou quatro resultados de provas de carga, apesar de se ter consciência, que do ponto de vista estatístico, estas podem não estar sendo representativas da fundação em análise.

Entretanto, deve ser lembrado que a capacidade de carga obtida através de uma prova de carga estática não é sempre bem definida. Provas de carga estáticas não levadas à ruptura, podem ser tratadas de diversas formas para a determinação da carga de ruptura. Nesta dissertação será utilizado o Método de Van der Veen (1953) para a 
extrapolação da curva carga x recalque e determinação da capacidade de carga do elemento isolado de fundação.

A partir dos resultados das provas de carga analisadas será determinada a distribuição de probabilidades das variáveis aleatórias resistência e solicitação com o objetivo de permitir uma previsão, com segurança adequada, da carga admissível a ser adotada no projeto da fundação em análise.

Durante o desenvolvimento do trabalho, foi necessário, devido às análises a serem realizadas, desenvolver um programa para a obtenção das funções densidade de probabilidade das variáveis aleatórias resistência e solicitação, para a determinação do índice de confiabilidade e da probabilidade de ruína. A Figura 7.1 apresenta o layout deste programa.

\begin{tabular}{|c|c|c|c|c|c|c|c|c|c|}
\hline \multicolumn{4}{|c|}{ PROVAS DE CARGA DINÂMICAS } & \multicolumn{6}{|c|}{ RESULTADOS DA ANÁLISE DA FUNDAÇĀO } \\
\hline Dados $(\mathrm{kPa})$ & \multicolumn{2}{|c|}{$\mathrm{S}$} & $\mathrm{R}$ & \multicolumn{4}{|c|}{ Coeficiente de Segurança Global } & $\mathrm{C}_{\mathrm{S}}$ & 2.34 \\
\hline Média & \multicolumn{2}{|c|}{12188.1} & 28542.3 & \multicolumn{4}{|c|}{ Indice de confiabilidade } & $\beta$ & 2.91 \\
\hline Desvio & \multicolumn{2}{|c|}{467.9} & 5594.0 & \multicolumn{4}{|c|}{ Carga Admissivel - NBR 6122 (kPa) } & $P_{\text {adm }}$ & 12188.1 \\
\hline $\mathrm{CV}$ & \multicolumn{2}{|c|}{$3.8 \%$} & $19.6 \%$ & \multicolumn{4}{|c|}{ Probabilidade de Ruina } & $p_{r}$ & $1.8 \mathrm{E}-03$ \\
\hline \multirow{2}{*}{\multicolumn{3}{|c|}{$\frac{\sigma_{Z}}{\text { Escala do gráfico }}$}} & & \multicolumn{4}{|c|}{ Inverso da prob. Ruína } & $1 / \mathrm{N}$ & 559 \\
\hline & & & 50000 & \multicolumn{5}{|c|}{ Intercepto das curvas Re $\mathrm{S}$} & 13803 \\
\hline \multicolumn{10}{|c|}{ PRÉ MOLDADA - DUQUE DE CAXIAS / RJ } \\
\hline \multirow{9}{*}{ 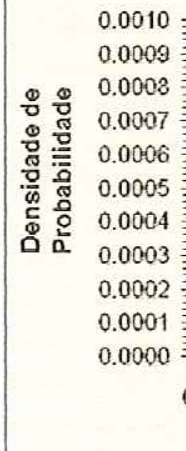 } & & & & & & & & & \\
\hline & & & A & & & & & & $-s$ \\
\hline & & & & & & & & & $-\mathrm{R}$ \\
\hline & & & & & & & & & 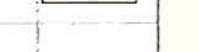 \\
\hline & & & & & & & & & \\
\hline & & & & & & & & & \\
\hline & & & & & & & & & \\
\hline & & & f & & 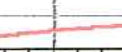 & & 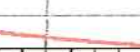 & & \\
\hline & & 0000 & 10000 & 20000 & 25000 & 30000 & 35000 & 40000 & $\begin{array}{r}45000 \quad 50000 \\
\text { S\& R (KPa) }\end{array}$ \\
\hline
\end{tabular}

Figura 7.1. Layout do programa utilizado nas análises.

As células com texto em cor azul, são as células de entrada de dados, enquanto que as demais células apresentam os valores que resultaram dos cálculos realizados pelo programa. Trata-se de um programa simples, mas cuja aplicação se mostrou de fundamental importância para o desenvolvimento deste trabalho.

Para cada fundação analisada serão realizados três tipos de análises:

- Análise 1: a partir da média e do coeficiente de variação da resistência calculado usando os resultados das provas de carga, calculou-se o coeficiente de segurança, o índice de confiabilidade e a correspondente probabilidade de ruína da fundação, 
considerando a solicitação atuante igual à carga admissível estrutural apresentada em catálogo.

- Análise 2: adotando um coeficiente de segurança igual a dois, é calculada a solicitação média e o desvio padrão da fundação considerando que o coeficiente de variação da solicitação seja igual ao calculado na Análise 1. Com o valor de resistência e de solicitação é calculado o índice de confiabilidade e a probabilidade de falha da fundação.

- Análise 3: nesta análise, partindo de um índice de confiabilidade igual a 3.09 correspondente a uma probabilidade de ruína de 1/1000 (considerada aceitável em fundações), obtém-se a carga admissível da fundação e o seu correspondente coeficientes de segurança.

A Análise 1 tem como objetivo determinar qual será a probabilidade de ruína e o coeficiente de segurança caso o projetista pretenda adotar a carga admissível estrutural como carga admissível para o dimensionamento do estaqueamento. A Análise 2 apresenta qual será a probabilidade de ruína da fundação caso esta seja projetada utilizando a formulação da norma com um coeficiente de segurança igual a dois. Enquanto que, a Análise 3, tem como objetivo determinar qual o valor de carga admissível que deve ser adotado para que a fundação tenha uma probabilidade de ruína adequada, sendo que, a Análise 3 também permite conhecer qual deve ser o valor do coeficiente de segurança para que fundação seja projetada com segurança.

Deve-se ressaltar que, nesta dissertação, optou-se por utilizar a expressão "carga admissível" mesmo quando se tratar de tensões, ao invés de utilizar a expressão "tensão admissível”. Logo, o termo "carga admissível” se apresentará nas unidades kN e kPa.

No Capítulo 8 serão apresentadas todas as análises efetuadas para esta dissertação. Os dados que serviram de base para estas análises foram extraídos de artigos e publicações técnicas. Estes dados incluem resultados de provas de carga dinâmicas e resultados de provas de carga estáticas. Em resumo, esses dados foram obtidos: catálogo de empresa (SCAC, vol. 2), dados reais de obra (Paulínia/SP), dissertações de mestrado (Balech, 2000; Vianna, 2000; Ávila, 2001) e artigos publicados (Santa Maria \& Siqueira, 2002; Alonso, 2000, 2002).

Foi estudada a possibilidade de utilização de outros bancos de dados, como por exemplo, o banco de dados da COPPE/RJ, entretanto, houve algumas limitações que impediram a sua inclusão nas análises. Todos os dados utilizados nesta dissertação se encontram tabelados e apresentados de forma gráfica nos apêndices 


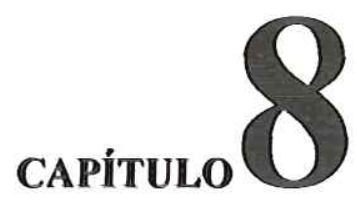

SEGURANÇA E CONFIABILIDADE DE FUNDAÇÕES

Neste item, encontram-se os resultados das diversas análises realizadas com alguns tipos de fundações:

- Item 8.1: este item apresenta a análise de 13 fundações em estacas moldadas in situ tipo hélice contínua executadas em diversas regiões do país. Neste item, será mostrado que o coeficiente de variação da resistência depende da formação geológica na qual as estacas hélice contínua foram executadas. As análises demonstram, claramente, a influência da Formação Geológica-Geotécnica na resistência de uma fundação.

- Item 8.2: este item apresenta a análise de 34 estacas pré-moldadas de concreto, cravadas em solos problemáticos da Formação Guabirotuba em Curitiba, Paraná. Nesta obra, foram realizadas 34 provas de carga estáticas e 34 sondagens à percussão tipo SPT, o que permitiu demonstrar claramente a interferência da variável processo executivo na resistência de uma fundação.

- Item 8.3: este item apresenta algumas análises realizadas com 7 fundações executadas em estacas de concreto armado com seção circular vazada. As análises foram realizadas com base nos resultados de diversas provas de carga estáticas à compressão realizadas em diferentes regiões do Brasil.

- Item 8.4: este item tem por finalidade analisar a confiabilidade das fundações por estacas de concreto armado in situ tipo hélice ômega, executadas mecanicamente em Paulínia - São Paulo, considerando os resultados de 10 provas de carga estáticas à compressão e as respectivas solicitações atuantes de projeto. 
- Item 8.5: este item apresenta a análise da fundação de um complexo de prédios industriais para armazenamento de alimentos no município de Duque de Caxias, RJ. Nesta obra foram cravadas 2.522 estacas pré-moldadas de concreto de concreto protendido e realizadas 23 provas de carga dinâmicas, cujos resultados serão analisados.

- Item 8.6: este item apresenta a análise de uma fundação em estacas metálicas executada na Formação Tremembé. Foram utilizadas nesta análise, 14 provas de carga dinâmica de energia crescente, cujos resultados foram analisados através do programa CAPWAPC.

- Item 8.7: neste item, encontram-se as análises realizadas utilizando os resultados de 25 provas de carga de energia crescente executadas em estacas de concreto armado de seção circular vazada.

A Tabela 8.1 tem como objetivo apresentar um resumo geral das principais informações a respeito das análises que serão apresentadas. Observa-se que ao todo, foram analisadas 25 fundações com base em 201 provas de carga executadas, sendo destas, 145 estática, 23 dinâmica de energia constante e 39 dinâmica tipo DIET.

Tabela 8.1. Resumo das principais informações das análises realizadas.

\begin{tabular}{|c|c|c|c|c|c|}
\hline Análise & $\begin{array}{c}\text { Tipo de } \\
\text { Prova } \\
\text { de Carga }\end{array}$ & $\begin{array}{l}\text { Número de } \\
\text { Provas } \\
\text { de Carga }\end{array}$ & Tipo de Estaca & Local & Referência \\
\hline Item 8.1 & Estática & $\begin{array}{c}63 \\
\text { (13 fundações) }\end{array}$ & Hélice Contínua & Diversos & $\begin{array}{l}\text { Alonso (2000) } \\
\text { Alonso (2002) }\end{array}$ \\
\hline Item 8.2 & Estática & $\begin{array}{c}34 \\
\text { (1 fundação) }\end{array}$ & $\begin{array}{l}\text { Pré-moldada de concreto } \\
\text { armado circular }\end{array}$ & Curitiba/PR & Vianna (2000) \\
\hline Item 8.3 & Estática & $\begin{array}{c}32 \\
\text { (7 fundações) }\end{array}$ & $\begin{array}{c}\text { Pré-moldada centrifugada } \\
\text { de concreto armado } \\
\text { circular }\end{array}$ & Diversos & SCAC (vol. 2) \\
\hline Item 8.4 & Estática & $\begin{array}{c}10 \\
\text { (1 fundação) }\end{array}$ & Hélice Tipo Ômega & Paulínia/SP & $\begin{array}{l}\text { Relatório } \\
\text { (2003) }\end{array}$ \\
\hline Item 8.5 & Dinâmica & $\begin{array}{c}23 \\
\text { (1 fundação) }\end{array}$ & $\begin{array}{l}\text { Pré-moldada de concreto } \\
\text { protendido quadrada }\end{array}$ & $\begin{array}{l}\text { Duque de } \\
\text { Caxias/RJ }\end{array}$ & $\begin{array}{l}\text { Santa Maria \& } \\
\text { Siqueira (2002) }\end{array}$ \\
\hline Item 8.6 & $\begin{array}{l}\text { Dinâmica } \\
\text { (DIET) }\end{array}$ & $\begin{array}{c}14 \\
\text { (1 fundação) }\end{array}$ & $\begin{array}{c}\text { Estacas metálicas do tipo } \\
\text { perfil soldado }\end{array}$ & Taubaté, SP & Ávila (2001) \\
\hline Item 8.7 & $\begin{array}{l}\text { Dinâmica } \\
\text { (DIET) }\end{array}$ & $\begin{array}{c}25 \\
\text { (1 fundação) }\end{array}$ & $\begin{array}{c}\text { Pré-moldada centrifugada } \\
\text { de concreto armado } \\
\text { circular }\end{array}$ & $\begin{array}{c}\text { Rio de } \\
\text { Janeiro/RJ }\end{array}$ & Balech (2000) \\
\hline
\end{tabular}




\subsection{Provas de carga estática executadas em estacas tipo hélice contínua}

Neste item, encontram-se os resultados das diversas análises realizadas com algumas fundações em estacas moldadas in sitı do tipo hélice contínua executadas em diversas localidades do país.

Mostra-se que o coeficiente de variação da resistência depende da formação

geológica-geotécnica na qual as estacas foram executadas e, a aplicação da carga admissível proposta com base na probabilidade de ruína para as diversas fundações, executadas em diferentes formações geológica-geotécnica.

Os dados utilizados nestas análises foram publicados por Alonso $(2000,2002)$ onde se encontram publicadas diversas provas de carga à compressão realizadas em diferentes regiões do Brasil.

\subsubsection{Variabilidade da resistência}

Destaca-se, neste item, a importância de se considerar a formação geológicageotécnica no estudo da variabilidade da resistência de uma fundação. Pois, verifica-se que a resistência do sistema estaca-solo é fortemente influenciada pela variabilidade das camadas de solo atravessadas pelo elemento estrutural de fundação em que estes são instalados. Logo, no estudo do comportamento dos elementos isolados de fundação, é preciso levar em consideração a formação geológica-geotécnica.

Entende-se por carga de ruptura ou resistência última, a máxima resistência oferecida pelo elemento isolado de fundação. Essa resistência máxima é limitada pela menor resistência do sistema, que pode tanto ser devida ao elemento estrutural de fundação, como ao maciço de solos que o envolve.

A forma mais precisa de se determinar à resistência última de um elemento isolado de fundação é realizando uma prova de carga. Através de uma prova de carga é possível conhecer o comportamento do elemento de fundação sob a ação de uma determinada solicitação (VARGAS, 1990). A forma da curva carga $\mathrm{x}$ recalque representa esse comportamento. No entanto, o principal objetivo de uma prova carga é a determinação da carga de ruptura ou resistência última do sistema.

Considerando que a prova de carga estática é o ensaio que melhor reproduz as condições de trabalho de uma estaca, foram analisados os resultados relativos a 63 
provas de carga estática à compressão constantes do banco de dados de Alonso (2000, 2002).

Tabela 8.1.1. Provas de Carga - Alonso (2000).

\begin{tabular}{|c|c|}
\hline Estado & Número de provas de carga \\
\hline $\mathrm{SP}$ & 36 \\
\hline $\mathrm{PR}$ & 19 \\
\hline $\mathrm{MG}$ & 13 \\
\hline $\mathrm{RS}$ & 9 \\
\hline $\mathrm{RJ}$ & 8 \\
\hline $\mathrm{BA}$ & 4 \\
\hline $\mathrm{ES}$ & 4 \\
\hline $\mathrm{SC}$ & 3 \\
\hline $\mathrm{PE}$ & 2 \\
\hline AM & 1 \\
\hline Total & 99 \\
\hline
\end{tabular}

Tabela 8.1.3. Provas de Carga - Alonso (2000, 2002).

\begin{tabular}{|c|c|}
\hline Estado & Número de provas de carga \\
\hline SP & 52 \\
\hline PR & 21 \\
\hline MG & 20 \\
\hline RS & 11 \\
\hline RJ & 10 \\
\hline BA & 9 \\
\hline ES & 9 \\
\hline SC & 8 \\
\hline MA & 2 \\
\hline AL & 2 \\
\hline DF & 1 \\
\hline PE & 2 \\
\hline AM & 1 \\
\hline Total & 148 \\
\hline
\end{tabular}

Tabela 8.1.2. Provas de Carga - Alonso (2002).

\begin{tabular}{|c|c|}
\hline Estado & Número de provas de carga \\
\hline SP & 16 \\
\hline PR & 2 \\
\hline MG & 7 \\
\hline RS & 2 \\
\hline RJ & 2 \\
\hline BA & 5 \\
\hline ES & 5 \\
\hline SC & 5 \\
\hline MA & 2 \\
\hline AL & 2 \\
\hline DF & 1 \\
\hline Total & 49 \\
\hline
\end{tabular}

Tabela 8.1.4. Provas de Carga analisadas.

\begin{tabular}{|c|c|}
\hline Estado & Número de provas de carga \\
\hline SP & 17 \\
\hline PR & 5 \\
\hline MG & 12 \\
\hline RS & 7 \\
\hline RJ & 6 \\
\hline BA & 7 \\
\hline ES & 5 \\
\hline SC & 4 \\
\hline Total & 63 \\
\hline
\end{tabular}

A Tabela 8.1.1 apresenta o número de provas de carga publicadas por estado em Alonso (2000), enquanto que a Tabela 8.1.2 apresenta o número de provas de carga publicadas por estado em Alonso (2002).

Da reunião de todas as provas de carga publicadas, tem-se a Tabela 8.1.3, entretanto destas, somente 63 provas de carga foram utilizadas nas análises, como se pode observar pela Tabela 8.1.4. 
Para a obtenção das resistências das estacas cujas provas de carga foram utilizadas nestas análises foi necessário qu utilizar o Método de extrapolação de Van Der Veen (1953). Os resultados das provas de carga foram agrupados por formação geológica-geotécnica e feita análise estatística das resistências em termos da tensão média de ruptura devido à diversidade de diâmetros das estacas nas quais foram realizadas as provas de carga. A tensão média de ruptura foi obtida pela média das cargas de ruptura dividida pela área da seção transversal fuste das estacas ensaiadas.

Os resultados das provas de carga analisadas estão apresentados na Tabela 8.15. Nesta tabela estão apresentadas as 63 estacas analisadas em função da fundação a que pertencem. Para cada uma das 13 fundações em análise foram calculados o valor médio, o desvio padrão e o correspondente coeficiente de variação dos valores de tensão resistente e solicitante das estacas.

Observando essa tabela, percebe-se que os valores médios de resistências oscilaram entre $6300.1 \mathrm{kPa}$ em Belo Horizonte/MG e $14992.1 \mathrm{kPa}$ em Porto Alegre/RS. Com relação ao coeficiente de variação, as estacas executadas em Jacarepaguá/RJ foram as que apresentaram comportamento mais homogêneo. $\mathrm{O}$ coeficiente de variação obtido dos resultados das 6 provas de carga executadas neste local foi o menor de todos os calculados, $13.2 \%$. Por outro lado, o maior coeficiente de variação obtido foi de $48.5 \%$ referente as 6 provas de carga realizadas em Contagem/MG.

A variabilidade encontrada nos valores obtidos deve-se às diversas formações em que os elementos estruturais de fundação foram instalados, demonstrando a relevância de se considerar, em todos os estudos, o comportamento do sistema estacasolo. Assim, a definição de fundação que consta na norma, considerando como fundação apenas o elemento estrutural, perde significado diante dessas análises. Pois, nota-se a importância que a formação geológica-geotécnica exerce sobre o comportamento da mesma. 
Tabela 8.1.5. Variabilidade dos valores de tensões resistentes e solicitantes das fundações analisadas.

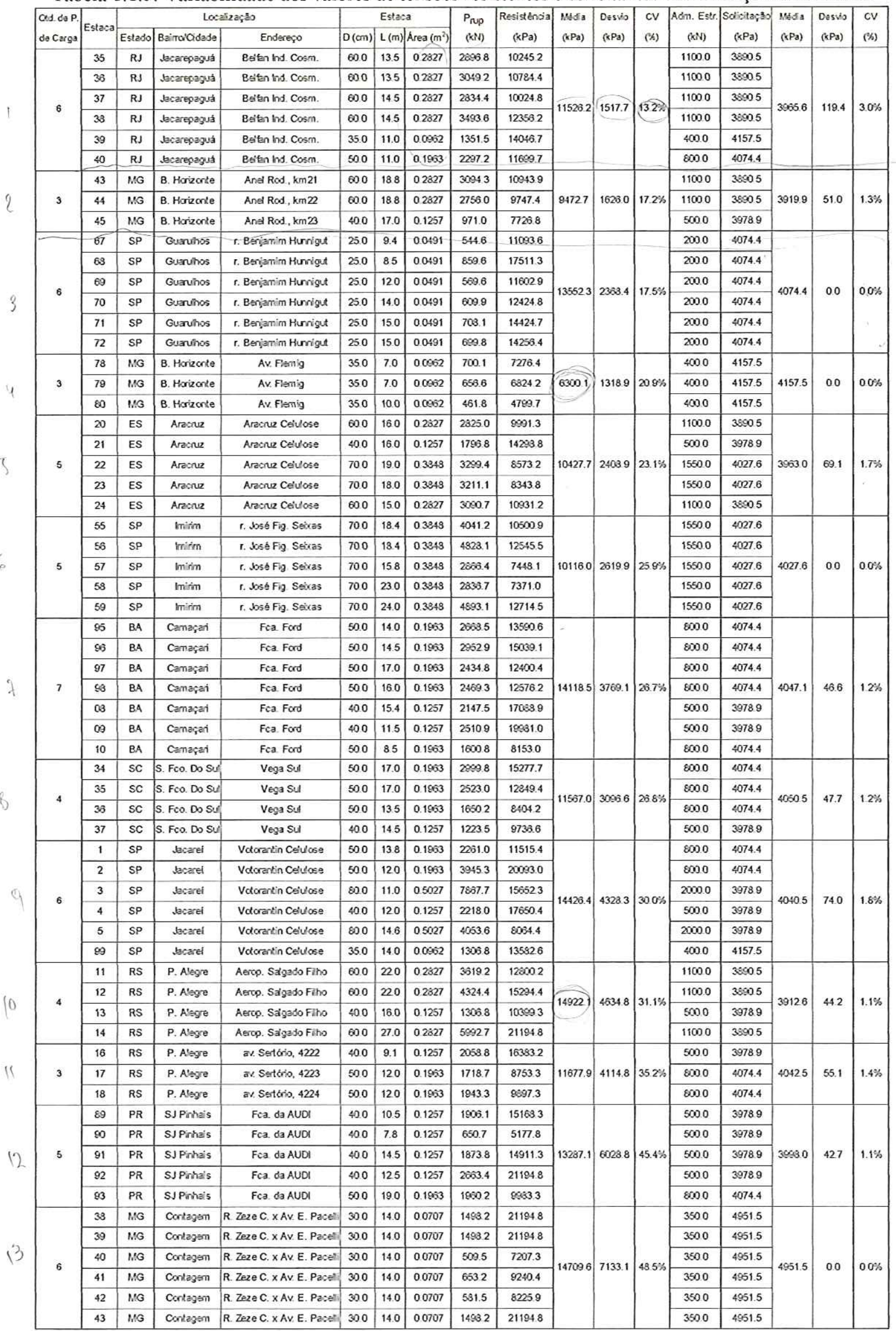




\subsubsection{Análise de Segurança e Confiabilidade}

Neste item será feita a estimativa da carga admissível dos 13 estaqueamentos analisados usando a formulação da norma e a formulação proposta nesta dissertação.

As provas de carga utilizadas nesta análise encontram-se resumidas na Tabela 8.1.5. Apesar de se tratar de um estudo de carga admissível optou-se por trabalhar com tensões admissíveis devido à diversidade de diâmetros das provas de carga. Recordando que para se obter a carga admissível deve-se multiplicar a tensão admissível estimada pela área da seção transversal do fuste da estaca.

Na prática, geralmente, o projeto de uma fundação é realizado com base na estimativa das resistências dos $n$ elementos isolados de fundação através de um determinado método de previsão de capacidade de carga. Essa previsão conduz a um valor de resistência média para o estaqueamento, $R_{m}$. Usando o coeficiente de segurança prescrito em norma, em geral, adota-se o valor dois, calcula-se a carga admissível do estaqueamento, $P_{a d m}$, utilizando a fórmula da norma, ou seja:

$$
P_{a d m}=S_{m}=\frac{R_{m}}{C S}=\frac{R_{m}}{2}
$$

Atualmente, considera-se que se a fundação for projetada dessa forma, esta apresentará segurança com relação à ruptura. No entanto, as análises realizadas demonstram que, apesar de ter sido fixado um coeficiente de segurança igual a dois $(C S=2.0)$, pode-se encontrar fundações com elevadas probabilidades de ruína. Logo, fundações projetadas com base na carga admissível expressa em norma, podem não ser seguras, pois, ao não considerar a dispersão existente, o coeficiente de segurança não é capaz de garantir uma probabilidade de ruína aceitável.

A experiência demonstra que, na Engenharia de Fundações, uma probabilidade de ruína em mil, ou seja, 1/1000, é uma probabilidade de ruína aceitável (WHITMAN, 1984). Essa probabilidade de ruína corresponde a utilizar um índice de confiabilidade de no mínimo 3.09 na formulação proposta.

Sendo assim, foram analisadas as 13 fundações cujas provas de carga estão apresentadas na Tabela 8.1.5. Com os valores de resistência e de solicitação expostos nesta tabela foram realizadas as Análises 1. Usando esses valores de resistência na formulação da norma com um CS $=2.0$, têm-se as Análises 2 e, usando um $\beta=3.09$, têm-se as Análises 3. Na seqüência, estão apresentadas todas as análises realizadas. 
Tabela 8.1.6. Estatísticas das Provas de Carga analisadas - Bahia.

\begin{tabular}{|c|c|c|c|c|c|c|c|c|c|c|c|}
\hline \multirow{2}{*}{ Número } & \multicolumn{3}{|c|}{ Localização } & \multicolumn{3}{|c|}{ Estaca } & \multirow{2}{*}{$\begin{array}{l}2 \mathrm{P} \\
(\mathrm{kN})\end{array}$} & \multirow{2}{*}{$\begin{array}{l}P_{\text {rup }} \\
(\mathrm{kN})\end{array}$} & \multirow{2}{*}{$\begin{array}{c}\text { Resistência } \\
(\mathrm{kPa})\end{array}$} & \multirow{2}{*}{$\begin{array}{c}\text { Carga Adm. } \\
(\mathrm{kN})\end{array}$} & \multirow{2}{*}{$\begin{array}{c}\text { Solicitação } \\
(\mathrm{kPa})\end{array}$} \\
\hline & Estado & Bairro/Cidade & Endereço & $D(\mathrm{~cm})$ & $L(m)$ & Área $\left(\mathrm{m}^{2}\right)$ & & & & & \\
\hline 95 & $\mathrm{BA}$ & Camaçari & Fca. Ford & 50.0 & 14.0 & 0.1963 & 2030.0 & 2668.5 & 13590.6 & 800.0 & 4074.4 \\
\hline 96 & BA & Camaçari & Fca. Ford & 50.0 & 14.5 & 0.1953 & 2030.0 & 2952.9 & 15039.1 & 800.0 & 4074.4 \\
\hline 97 & $B A$ & Camaçari & Fca. Ford & 50.0 & 17.0 & 0.1963 & 2030.0 & 2434.8 & 12400.4 & 800.0 & 4074.4 \\
\hline 98 & $B A$ & Camaçari & Fca. Ford & 50.0 & 16.0 & 0.1953 & 2030.0 & 2469.3 & 12576.2 & 800.0 & 4074.4 \\
\hline 08 & $\mathrm{BA}$ & Camaçari & Fca. Ford & 40.0 & 15.4 & 0.1257 & 1200.0 & 2147.5 & 17088.9 & 500.0 & 3978.9 \\
\hline$\infty$ & $\mathrm{BA}$ & Camaçari & Fca. Ford & 40.0 & 11.5 & 0.1257 & 3320.0 & 2510.9 & 19981.0 & 500.0 & 3978.9 \\
\hline 10 & BA & Camaçari & Fca. Ford & 50.0 & 8.5 & 0.1903 & 3600.0 & 1600.8 & 8153.0 & 800.0 & 4074.4 \\
\hline \multicolumn{4}{|l|}{ Média } & 47.1 & 13.8 & 0.1762 & 2320.0 & & 14118.5 & & 4047.1 \\
\hline \multicolumn{4}{|c|}{ Desvio Padrão } & 4.9 & 2.9 & 0.0345 & 839.6 & & 3769.1 & & 46.6 \\
\hline \multicolumn{4}{|c|}{ Coeficiente de Variação } & $10.4 \%$ & $21.2 \%$ & $19.6 \%$ & $36.2 \%$ & & $26.7 \%$ & & $1.2 \%$ \\
\hline
\end{tabular}

A Tabela 1 do Apêndice A apresenta a quantidade de provas de cargas que foram realizadas no estado da Bahia. A Tabela 2 do Apêndice A apresenta as provas de carga publicadas por Alonso (2000) e a Tabela 3 do Apêndice A apresenta as provas de carga publicadas por Alonso (2002). A Tabela 4 do Apêndice A apresenta todas as provas de carga publicadas, enquanto que a Tabela 5 do Apêndice A apresenta as provas de carga que serão analisadas.

A Tabela 6 do Apêndice A apresenta as curva carga $x$ recalque das estacas analisadas e a Tabela 7 do Apêndice A apresenta os parâmetros A e B e as cargas de ruptura determinadas com o uso do Critério de Van der Veen. As provas de carga das estacas analisadas estão apresentadas nas Figuras 1 a 7 do Apêndice A.

Com base nas estatísticas apresentadas na Tabela 8.1.6 acima, foram realizadas as análises apresentadas nas Figuras 8 a 10 do Apêndice A. O resumo dos resultados obtidos dessas análises se encontra na Tabela 8.1.7.

Tabela 8.1.7. Resultados das análises realizadas - Bahia.

\begin{tabular}{|c|c|c|c|c|c|c|c|c|c|c|c|}
\hline \multirow{2}{*}{ Análises } & \multicolumn{3}{|c|}{ Resistência } & \multicolumn{3}{|c|}{ Solicitaçāo } & \multirow{2}{*}{ CS } & \multirow{2}{*}{$\beta$} & \multirow{2}{*}{ Pr } & \multirow{2}{*}{$1 / \mathrm{Pr}$} & \multirow{2}{*}{$\begin{array}{l}P_{\text {adm }} \\
\text { (kPa) }\end{array}$} \\
\hline & Média (kPa) & Desvio $(\mathrm{kPa})$ & CV (\%) & Média (kPa) & Desvio (kPa) & CV (\%) & & & & & \\
\hline Análise 1 & 14118.5 & 3769.1 & $26.7 \%$ & 4047.1 & 46.6 & $1.2 \%$ & 3.5 & 2.67 & 0.00377 & 265 & 4047.1 \\
\hline Análise 2 & 14118.5 & 3769.1 & $26.7 \%$ & 7059.3 & 81.3 & $1.2 \%$ & 2.0 & 1.87 & 0.03057 & 33 & 7059.3 \\
\hline Análise 3 & 14118.5 & 3769.1 & $26.7 \%$ & 2470.1 & 28.4 & $1.2 \%$ & 5.7 & 3.09 & 0.00100 & 1000 & 2470.1 \\
\hline
\end{tabular}

Observa-se que se a fundação for projetada usando a formulação da norma (Análise 2) esta apresentará uma probabilidade de ruína de $1 / 33$. Sendo que, caso se opte em projetá-la com uma probabilidade de ruína adequada (1/1000), deve ser utilizado um CS = 5.7 (Análise 3).

A Tabela 8 do Apêndice A apresenta a relação existente entre os valores de 
índice de confiabilidade e de coeficiente de segurança. Enquanto que a Figura 11 do Apêndice A apresenta o gráfico de carga admissível proposta.

Tabela 8.1.8. Estatísticas das Provas de Carga analisadas - Rio de Janeiro.

\begin{tabular}{|c|c|c|c|c|c|c|c|c|c|c|c|}
\hline \multirow{2}{*}{ Número } & \multicolumn{3}{|c|}{ Localização } & \multicolumn{3}{|c|}{ Estaca } & \multirow{2}{*}{\begin{tabular}{l|}
$2 \mathrm{P}$ \\
$(\mathrm{kN})$
\end{tabular}} & \multirow{2}{*}{$\begin{array}{l}P_{\text {rup }} \\
(\mathrm{kN}) \\
\end{array}$} & \multirow{2}{*}{$\begin{array}{c}\text { Resistência } \\
(\mathrm{kPa})\end{array}$} & \multirow{2}{*}{$\begin{array}{c}\text { Carga Adm. } \\
(\mathrm{kN})\end{array}$} & \multirow{2}{*}{$\begin{array}{c}\text { Solicitação } \\
(\mathrm{kPa})\end{array}$} \\
\hline & Estado & Bairro/Cidade & Endereço & $D(\mathrm{~cm})$ & $\mathrm{L}(\mathrm{m})$ & Área $\left(\mathrm{m}^{2}\right)$ & & & & & \\
\hline 35 & RJ & Jacarepaguá & Belfan Ind. Cosm. & 60.0 & 13.5 & 0.2827 & 2660.0 & 2896.8 & 10245.2 & 1100.0 & 3890.5 \\
\hline 36 & RJ & Jacarepaguá & Belfan Ind. Cosm. & 60.0 & 13.5 & 0.2827 & 2800.0 & 3049.2 & 10784.4 & 1100.0 & 3890.5 \\
\hline 37 & RJ & Jacarepaguá & Belfan Ind. Cosm. & 60.0 & 14.5 & 0.2827 & 2800.0 & 2834.4 & 10024.8 & 1100.0 & 3890.5 \\
\hline 38 & RJ & Jacarepaguá & Belfan Ind. Cosm. & 60.0 & 14.5 & 0.2827 & 2800.0 & 3493.6 & 12356.2 & 1100.0 & 3890.5 \\
\hline 39 & RJ & Jacarepaguá & Belfan Ind. Cosm. & 35.0 & 11.0 & 0.0962 & 1200.0 & 1351.5 & 14046.7 & 400.0 & 4157.5 \\
\hline 40 & RJ & Jacarepaguá & Belfan Ind. Cosm. & 50.0 & 11.0 & 0.1963 & 2000.0 & 2297.2 & 11699.7 & 800.0 & 4074.4 \\
\hline \multicolumn{4}{|l|}{ Média } & 54.2 & 13.0 & 0.2373 & 2376.7 & & 11526.2 & & 3965.6 \\
\hline \multicolumn{4}{|c|}{ Desvio Padrão } & 10.2 & 1.6 & 0.0773 & 654.9 & & 1517.7 & & 119.4 \\
\hline \multicolumn{4}{|c|}{ Coeficiente de Variação } & $18.8 \%$ & $12.4 \%$ & $32.6 \%$ & $27.6 \%$ & & $13.2 \%$ & & $3.0 \%$ \\
\hline
\end{tabular}

A Tabela 9 do Apêndice A apresenta o número de provas de cargas realizadas no estado do Rio de Janeiro. A Tabela 10 e 11 do Apêndice A apresentam, respectivamente, as provas de carga publicadas por Alonso (2000) e por Alonso (2002), e a Tabela 12 do Apêndice $A$, apresenta a reunião de todas essas provas de carga. Quanto a Tabela 13 do Apêndice A, esta apresenta as provas de carga que serão analisadas.

A Tabela 14 do Apêndice A apresenta os pontos das curvas carga $\mathrm{x}$ recalque das estacas analisadas, enquanto que a Tabela 15 do Apêndice A apresenta os parâmetros A e B e as cargas de ruptura estimadas pelo Critério de Van der Veen. As Figuras 12 a 17 do Apêndice A apresentam as provas de carga das estacas analisadas.

Com base nos valores de resistência apresentados na Tabela 8.1.8 foram realizadas as análises das Figuras 18 a 20 do Apêndice A, cujos resultados se encontram resumidos na Tabela 8.1 .9 abaixo.

Tabela 8.1.9. Resultados das análises realizadas - Rio de Janeiro.

\begin{tabular}{|c|c|c|c|c|c|c|c|c|c|c|c|}
\hline \multirow{2}{*}{ Análises } & \multicolumn{3}{|c|}{ Resistência } & \multicolumn{3}{|c|}{ Solicitação } & \multirow{2}{*}{ CS } & \multirow{2}{*}{$\beta$} & \multirow{2}{*}{$\mathrm{Pr}$} & \multirow{2}{*}{$1 / \mathrm{Pr}$} & \multirow{2}{*}{$\begin{array}{l}\mathrm{P}_{\mathrm{adm}} \\
(\mathrm{kPa})\end{array}$} \\
\hline & Média (kPa) & Desvio $(\mathrm{kPa})$ & CV (\%) & Média (kPa) & Desvio $(\mathrm{kPa})$ & CV (\%) & & & & & \\
\hline Análise 1 & 115262 & 1517.7 & $132 \%$ & 3965.6 & 119.4 & $3.0 \%$ & 2.9 & 4.97 & 0.00000 & 2924093 & 3965.6 \\
\hline Análise 2 & 11526.2 & 1517.7 & $132 \%$ & 5763.1 & 173.5 & $3.0 \%$ & 2.0 & 3.77 & 0.00008 & 12376 & 5763.1 \\
\hline Análise 3 & 11526.2 & 1517.7 & $13.2 \%$ & 6793.4 & 204.5 & $3.0 \%$ & 1.7 & 3.09 & 0.00100 & 1000 & 6793.4 \\
\hline
\end{tabular}

A Tabela 16 do Apêndice A apresenta a relação entre o índice de confiabilidade e o coeficiente de segurança, e a Figura 21 do Apêndice A apresenta o gráfico de carga admissível proposta para Jacarepaguá/RJ. 
Na Tabela 17 do Apêndice A consta o número de provas de cargas realizadas no Espírito Santo. As provas de carga publicadas por Alonso (2000), estão apresentadas na Tabela 18 do Apêndice A, enquanto que provas de carga publicadas por Alonso (2002) se encontram na Tabela 19 do Apêndice A.

A reunião de todas as provas de carga realizadas na estado do Espírito Santo dá origem à Tabela 20 do Apêndice $\mathrm{A}$, sendo que destas, somente as provas de carga apresentadas na Tabela 21 do Apêndice A foram analisadas.

A Tabela 22 do Apêndice A traz as curva carga x recalque das estacas analisadas e a Tabela 23 do Apêndice A apresenta os parâmetros A e B e a carga de ruptura resultantes da aplicação do Critério de Van der Veen. Enquanto que as Figuras 22 a 26 do Apêndice A apresentam as provas de carga das estacas analisadas.

Tabela 8.1.10. Estatísticas das Provas de Carga analisadas - Espírito Santo.

\begin{tabular}{|c|c|c|c|c|c|c|c|c|c|c|c|}
\hline \multirow{2}{*}{ Número } & \multicolumn{3}{|c|}{ Localizaçăo } & \multicolumn{3}{|c|}{ Estaca } & \multirow{2}{*}{$\begin{array}{l}2 \mathrm{P} \\
(\mathrm{kN})\end{array}$} & \multirow{2}{*}{$\begin{array}{l}P_{\text {rup }} \\
(\mathrm{kN})\end{array}$} & \multirow{2}{*}{$\begin{array}{c}\text { Resistência } \\
(\mathrm{kPa})\end{array}$} & \multirow{2}{*}{$\begin{array}{c}\text { Carga Adm. } \\
\text { (kN) }\end{array}$} & \multirow{2}{*}{$\begin{array}{c}\text { Solicitação } \\
(\mathrm{kPa})\end{array}$} \\
\hline & Estado & Bairro/Cidade & Endereço & $\mathrm{D}(\mathrm{cm})$ & $L(m)$ & Área $\left(\mathrm{m}^{2}\right)$ & & & & & \\
\hline 20 & ES & Aracruz & Aracruz Celulose & 60.0 & 16.0 & 0.2827 & 2570.0 & 2825.0 & 9991.3 & 1100.0 & 3890.5 \\
\hline 21 & ES & Aracruz & Aracruz Celulose & 40.0 & 16.0 & 0.1257 & 1310.0 & 1796.8 & 14298.8 & 500.0 & 3978.9 \\
\hline 22 & ES & Aracruz & Aracruz Celulose & 70.0 & 19.0 & 0.3848 & 2400.0 & 3299.4 & 8573.2 & 1550.0 & 4027.6 \\
\hline 23 & ES & Aracruz & Aracruz Celulose & 70.0 & 18.0 & 0.3848 & 2600.0 & 3211.1 & 8343.8 & 1550.0 & 4027.6 \\
\hline 24 & ES & Aracruz & Aracruz Celulose & 60.0 & 15.0 & 0.2827 & 2570.0 & 3000.7 & 10931.2 & 1100.0 & 3690.5 \\
\hline \multicolumn{4}{|l|}{ Média } & 60.0 & 16.8 & 0.2922 & 2290.0 & & 10427.7 & & 3963.0 \\
\hline \multicolumn{4}{|c|}{ Desvio Padrão } & 12.2 & 1.6 & 0.1062 & 553.5 & & 2408.9 & & 6.1 \\
\hline \multicolumn{4}{|c|}{ Coeficiente de Variação } & $20.4 \%$ & $9.8 \%$ & $36.3 \%$ & $24.2 \%$ & & $23.1 \%$ & & $1.7 \%$ \\
\hline
\end{tabular}

Na Tabela 8.1.10 estão apresentadas as estatísticas dos valores de resistência utilizadas nas análises. Sendo que as Figuras 27, 28 e 29 do Apêndice A apresentam as análises realizadas e a Tabela 8.1.11 traz um resumo dos resultados das mesmas.

Tabela 8.1.11. Resultados das análises realizadas - Espírito Santo.

\begin{tabular}{|c|c|c|c|c|c|c|c|c|c|c|c|}
\hline \multirow{2}{*}{ Análises } & \multicolumn{3}{|c|}{ Resisténcia } & \multicolumn{3}{|c|}{ Solicitaçăo } & \multirow{2}{*}{ cs } & \multirow{2}{*}{$\beta$} & \multirow{2}{*}{$\mathrm{Pr}$} & \multirow{2}{*}{$1 / \mathrm{Pr}$} & \multirow{2}{*}{$\begin{array}{l}P_{\text {adim }} \\
(\mathrm{KPa})\end{array}$} \\
\hline & Média $(\mathrm{kPa})$ & Desvio $(\mathrm{kPa})$ & CV $(\%)$ & Média (kPa) & Desvio (kPa) & CV (\%) & & & & & \\
\hline Análise 1 & 10427.7 & 2408.9 & $23.1 \%$ & 3963.0 & 69.1 & $1.7 \%$ & 2.6 & 2.68 & 0.00365 & 274 & 3963.0 \\
\hline Análise 2 & 10427.7 & 2408.9 & $23.1 \%$ & 5213.8 & 91.0 & $1.7 \%$ & 2.0 & 2.16 & 0.01528 & 65 & 5213.8 \\
\hline Análise 3 & 10427.7 & 2408.9 & $23.1 \%$ & 2981.4 & 52.0 & $1.7 \%$ & 3.5 & 3.09 & 0.00100 & 1000 & 2981.4 \\
\hline
\end{tabular}

Nota-se que um coeficiente de segurança igual a 3.5 é recomendado, caso se opte por projetar essa fundação com uma probabilidade de ruína de 1/1000 (Análise 3).

A Tabela 24 do Apêndice A mostra a relação entre índice de confiabilidade e coeficiente de segurança para esta fundação, assim como a Figura 30 do Apêndice A apresenta a curva de carga admissível proposta para Aracruz/ES. 
Tabela 8.1.12. Estatísticas das Provas de Carga analisadas - Santa Catarina.

\begin{tabular}{|c|c|c|c|c|c|c|c|c|c|c|c|}
\hline \multirow{2}{*}{ Número } & \multicolumn{3}{|c|}{ Localização } & \multicolumn{3}{|c|}{ Estaca } & \multirow{2}{*}{$\begin{array}{l}2 \mathrm{P} \\
(\mathrm{kN})\end{array}$} & \multirow{2}{*}{$\begin{array}{r}P_{\text {rup }} \\
(\mathrm{kN})\end{array}$} & \multirow{2}{*}{$\begin{array}{c}\text { Resistência } \\
\text { (kPa) }\end{array}$} & \multirow{2}{*}{$\begin{array}{c}\text { Carga Adm } \\
(\mathrm{kN})\end{array}$} & \multirow{2}{*}{$\begin{array}{c}\text { Solicitação } \\
\text { (kPa) }\end{array}$} \\
\hline & Estado & Bairro/Cidade & Endereço & $D(\mathrm{~cm})$ & $L(m)$ & Área $\left(\mathrm{m}^{2}\right)$ & & & & & \\
\hline 34 & SC & S. Fo. Do Sul & Vega Sul & 50.0 & 17.0 & 0.1953 & 2260.0 & 2999.8 & 15277.7 & 800.0 & 4074.4 \\
\hline 35 & SC & S. Fco. Do Sul & Vega Sul & 50.0 & 17.0 & 0.1963 & 2110.0 & 2523.0 & 12849.4 & 800.0 & 4074.4 \\
\hline 36 & SC & S. Foo. Do Sul & Vega Sul & 50.0 & 13.5 & 0.1963 & 1650.0 & 1650.2 & 8404.2 & 800.0 & 4074.4 \\
\hline 37 & SC & S. Foo. Do Sul & Vega Sul & 40.0 & 14.5 & 0.1257 & 1220.0 & 1223.5 & 9736.6 & 500.0 & 3978.9 \\
\hline \multicolumn{4}{|l|}{ Média } & 47.5 & 15.5 & 0.1787 & 1810.0 & & 11567.0 & & 4050.5 \\
\hline \multicolumn{4}{|c|}{ Desvio Padrão } & 5.0 & 1.8 & 0.0353 & 471.2 & & 3006.6 & & 47.7 \\
\hline \multicolumn{4}{|c|}{ Coeficiente de Variacão } & $10.5 \%$ & $11.5 \%$ & $19.8 \%$ & $26.0 \%$ & & $26.8 \%$ & & $1.2 \%$ \\
\hline
\end{tabular}

Tabela 8.1.13. Resultados das análises realizadas - Santa Catarina.

\begin{tabular}{|c|c|c|c|c|c|c|c|c|c|c|c|}
\hline \multirow{2}{*}{ Análises } & \multicolumn{3}{|c|}{ Resistência } & \multicolumn{3}{|c|}{ Solicitaçâo } & \multirow{2}{*}{ cs } & \multirow{2}{*}{$\beta$} & \multirow{2}{*}{ Pr } & \multirow{2}{*}{$1 / \mathrm{Pr}$} & \multirow{2}{*}{$\begin{array}{l}P_{a d m} \\
(\mathrm{kPa})\end{array}$} \\
\hline & Média (kPa) & Desvio (kPa) & $\mathrm{CV}(\%)$ & Méda (KPa) & Desvio (kPa) & $\mathrm{CV}(\%)$ & & & & & \\
\hline Análise 1 & 11567.0 & 3096.6 & $26.8 \%$ & 4050.5 & 47.7 & $1.2 \%$ & 2.9 & 2.43 & 0.00761 & 131 & 4050.5 \\
\hline Análise 2 & 11567.0 & 3096.6 & $26.8 \%$ & 5783.5 & 68.2 & $1.2 \%$ & 2.0 & 1.87 & 0.03094 & 32 & 5783.5 \\
\hline Análise 3 & 11567.0 & 3096.6 & $26.8 \%$ & 1996.9 & 23.5 & $1.2 \%$ & 5.8 & 3.09 & 0.00100 & 1000 & 1996.9 \\
\hline
\end{tabular}

A Tabela 25 do Apêndice A esboça o número de provas de cargas realizadas em Santa Catarina. Destas, a Tabela 26 do Apêndice A apresenta as provas de carga publicadas por Alonso (2000) e a Tabela 27 do Apêndice A as provas de carga publicadas por Alonso (2002).

A reunião de todas as provas de carga publicadas dá origem a Tabela 28 do Apêndice A. Enquanto que a Tabela 29 do Apêndice A apresenta somente as provas de carga que foram utilizadas nas análises.

As curvas carga $\mathrm{x}$ recalque das estacas analisadas estão apresentadas na Tabela 30 do Apêndice A, sendo que na Tabela 31 do Apêndice A estão os parâmetros A e B e as cargas de ruptura obtidas pela aplicação do Critério de Van der Veen.

As Figuras 31 a 34 do Apêndice A apresentam as provas de carga das estacas analisadas. Enquanto que as Figuras 35, 36 e 37 do Apêndice A apresentam as análises realizadas com os valores de resistência apresentados na Tabela 8.1.12 acima. Os resultados dessas análises encontram-se resumidos na Tabela 8.1.13, também acima.

Percebe-se que se a fundação for projetada usando os valores de carga admissível estrutural, ela apresentará uma probabilidade de ruína de 1/131, apesar de possuir um coeficiente de segurança igual a 2.9 (Análise 1).

A Tabela 32 do Apêndice A apresenta a relação entre índice de confiabilidade e coeficiente de segurança para esta fundação e a Figura 38 do Apêndice A, a curva de carga admissível proposta. 
A Tabela 33 do Apêndice A apresenta o número total de provas de cargas realizadas em São Paulo. Destas, algumas foram publicadas por Alonso (2000) (Tabela 34 do Apêndice A), outras por Alonso (2002) (Tabela 35 do Apêndice A). Todas as provas de carga publicadas podem ser visualizadas na Tabela 36 do Apêndice A. Destas, três fundações serão analisadas: a fundação executada em Jacareí/SP (Tabela 37 do Apêndice A), em Guarulhos/SP (Tabela 38 do Apêndice A) e em Imirim/SP (Tabela 39 do Apêndice A).

A Tabela 40 do Apêndice A apresenta as curva carga x recalque das estacas ensaiadas em Jacareí/SP, enquanto que a Tabela 41 do Apêndice A apresenta os parâmetros A e B e as cargas de ruptura obtidas pelo Critério de Van der Veen para esta fundação. As Figuras 39 a 44 do Apêndice A apresentam as provas de carga realizadas em Jacareí/SP

Com as estatísticas apresentadas na Tabela 8.1.14, foram realizadas as análises que se encontram apresentadas nas Figuras 45 a 47 do Apêndice A, cujos resultados se encontram resumidos na Tabela 8.1 .15 abaixo.

Tabela 8.1.14. Estatísticas das Provas de Carga analisadas - Jacareí/SP.

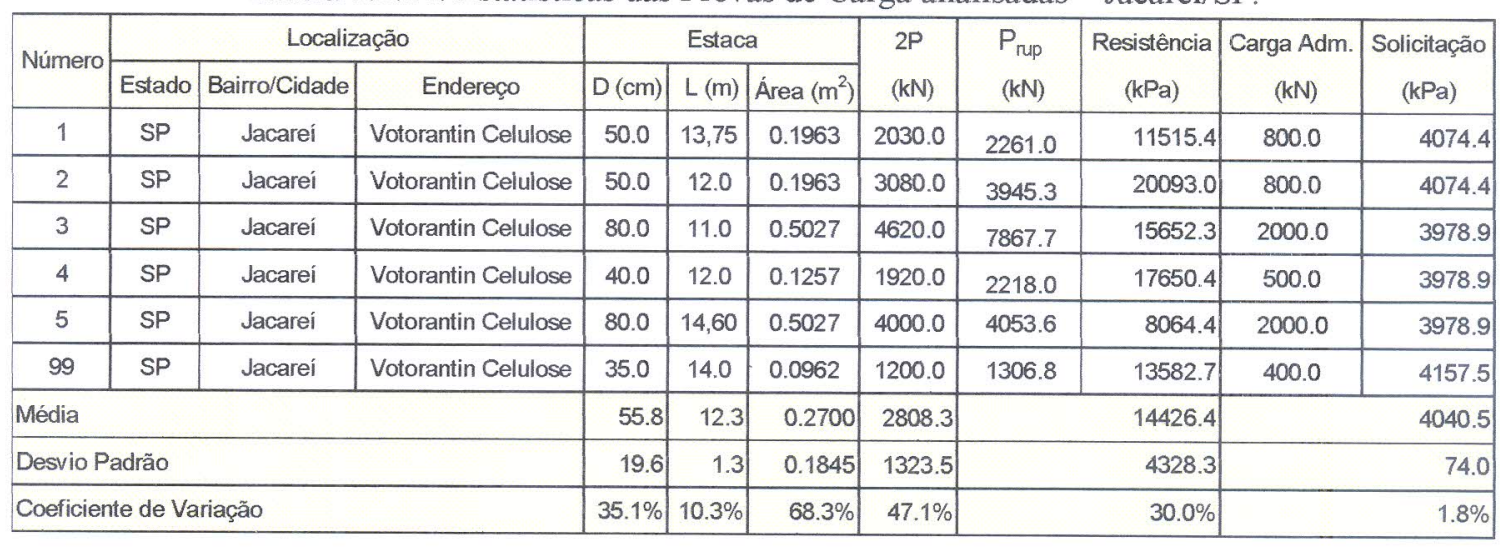

Tabela 8.1.15. Resultados das análises realizadas - Jacareí/SP

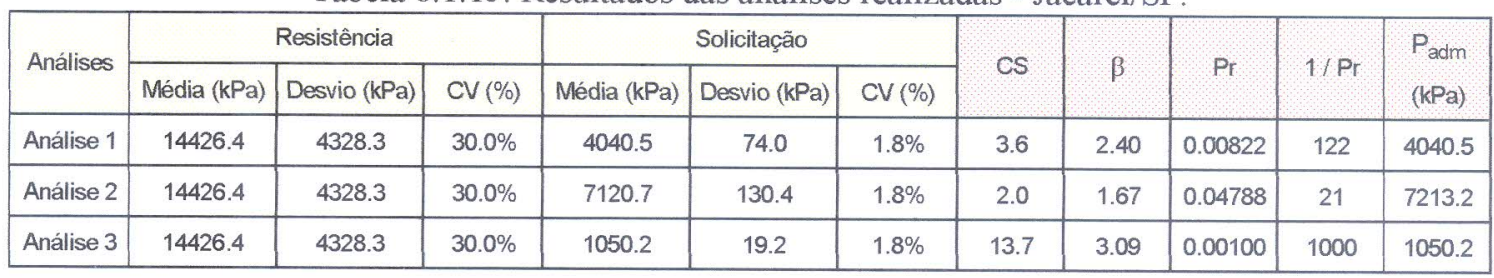

A Tabela 42 do Apêndice A mostra a relação existente entre os valores de índice de confiabilidade e coeficiente de segurança para esta fundação, e a Figura 48 do Apêndice A o gráfico de carga admissível proposta. 
Tabela 8.1.16. Estatísticas das Provas de Carga analisadas - Guarullos/SP.

\begin{tabular}{|c|c|c|c|c|c|c|c|c|c|c|c|}
\hline \multirow{2}{*}{ Número } & \multicolumn{3}{|c|}{ Localização } & \multicolumn{3}{|c|}{ Estaca } & \multirow{2}{*}{\begin{tabular}{c|}
$2 P$ \\
$(\mathrm{kN})$
\end{tabular}} & \multirow{2}{*}{$\begin{array}{l}P_{\text {rup }} \\
\text { (kN) }\end{array}$} & \multirow{2}{*}{$\begin{array}{c}\text { Resisténcia } \\
(\mathrm{kPa})\end{array}$} & \multirow{2}{*}{$\begin{array}{c}\text { Carga Adim } \\
(\mathrm{kN}) \\
\end{array}$} & \multirow{2}{*}{$\begin{array}{c}\text { Solicitaçăo } \\
\text { (kPa) }\end{array}$} \\
\hline & Estado & Bairro'Cidade & Endereşo & $\mathrm{D}(\mathrm{cm})$ & $\mathrm{L}(\mathrm{m})$ & Área $\left(\mathrm{m}^{2}\right)$ & & & & & \\
\hline 67 & $\mathrm{SP}$ & Guarulhos & r. Benjamim Hunnigut & 25.0 & 9.4 & 0.0491 & 500.0 & 5446 & 11093.6 & 200.0 & 4074.4 \\
\hline 68 & SP & Guarulhos & r. Benjamim Hunnigut & 25.0 & 8.5 & 0.0491 & 500.0 & 859.6 & 17511.3 & 200.0 & 4074.4 \\
\hline 69 & SP & Guarulhos & r. Benjamim Hunnigut & 25.0 & 12.0 & 0.0491 & 500.0 & 569.6 & 116029 & 200.0 & 4074.4 \\
\hline 70 & $\mathrm{SP}$ & Guarulhos & r. Benjamim Hunnigut & 25.0 & 14.0 & 0.0491 & 560.0 & 609.9 & 12424.8 & 200.0 & 4074.4 \\
\hline 71 & SP & Guarulhos & r. Benjamim Hunnigut & 25.0 & 15.0 & 0.0491 & 590.0 & 708.1 & 14424.7 & 2000 & 4074.4 \\
\hline 72 & $\mathrm{SP}$ & Guarulhos & r. Berjamim Hunrigut & 25.0 & 15.0 & 0.0491 & 590.0 & 699.8 & 14256.4 & 200.0 & 4074.4 \\
\hline \multicolumn{4}{|l|}{ Média } & 25.0 & 123 & 0.0491 & 540.0 & & 135523 & & 4074.4 \\
\hline \multicolumn{4}{|c|}{ Desvio Padrão } & 0.0 & 28 & 0.0000 & 45.2 & & 2368.4 & & 0.0 \\
\hline \multicolumn{4}{|c|}{ Coeficiente de Variação } & $0.0 \%$ & $23.0 \%$ & $0.0 \%$ & $8.4 \%$ & & $17.5 \%$ & & $0.0 \%$ \\
\hline
\end{tabular}

A Tabela 43 do Apêndice A apresenta as curvas carga $\mathrm{x}$ recalque das estacas ensaiadas em Guarulhos/SP (vide Tabela 38 do Apêndice A) e a Tabela 44 do Apêndice A apresenta os resultados da aplicação do Critério de Van der Veen. As provas de carga desta fundação estão apresentadas nas Figuras 49 a 54 do Apêndice A.

As Figuras 55, 56 e 57 do Apêndice A apresentam as análises realizadas com os valores de resistências apresentadas na Tabela 8.1.16 acima.

Os resultados dessas análises estão apresentados na Tabela 8.1.17. A observação desta tabela permite concluir que se esta fundação for projeta com o uso dos valores de carga admissível estrutural indicados (Análise 1), esta apresentará uma baixa probabilidade de ruína (1/31789). Entretanto, é possível perceber que é mais econômico, projetar essa fundação com a carga admissível apresentada na Análise 3, e ter mesmo assim, uma probabilidade de ruína adequada (1/1000).

Tabela 8.1.17. Resultados das análises realizadas - Guarulhos/SP.

\begin{tabular}{|c|c|c|c|c|c|c|c|c|c|c|c|}
\hline \multirow{2}{*}{ Análises } & \multicolumn{3}{|c|}{ Resistência } & \multicolumn{3}{|c|}{ Solicitação } & \multirow{2}{*}{ CS } & \multirow{2}{*}{$\beta$} & \multirow{2}{*}{ Pr } & \multirow{2}{*}{$1 / \mathrm{Pr}$} & \multirow{2}{*}{$\begin{array}{l}P_{\text {adm }} \\
(\mathrm{kPa})\end{array}$} \\
\hline & Média (kPa) & Desvio (kPa) & CV $(\%)$ & Média (kPa) & Desvio (kPa) & CV (\%) & & & & & \\
\hline Análise 1 & 13552.3 & 2368.4 & $17.5 \%$ & 4074.4 & 0.0 & $0.0 \%$ & 3.3 & 4.00 & 0.00003 & 31789 & 4074.4 \\
\hline Análise 2 & 13552.3 & 2368.4 & $17.5 \%$ & 6776.1 & 0.0 & $0.0 \%$ & 2.0 & 2.86 & 0.00211 & 473 & 6776.1 \\
\hline Análise 3 & 13552.3 & 2368.4 & $17.5 \%$ & 6232.8 & 0.0 & $0.0 \%$ & 2.2 & 3.09 & 0.00100 & 1000 & 6232.8 \\
\hline
\end{tabular}

A Tabela 45 do Apêndice A indica a relação existente entre os valores de índice de confiabilidade e coeficiente de segurança para esta fundação. Com o uso destes valores, tem-se o gráfico da Figura 58 do Apêndice A que apresenta a curva de carga admissível proposta para essa fundação que está localizada em Guarulhos/SP. 
Tabela 8.1.18. Estatísticas das Provas de Carga analisadas - Imirim/SP.

\begin{tabular}{|c|c|c|c|c|c|c|c|c|c|c|c|}
\hline \multirow{2}{*}{ Número } & \multicolumn{3}{|c|}{ Localização } & \multicolumn{3}{|c|}{ Estaca } & \multirow{2}{*}{$\begin{array}{l}2 \mathrm{P} \\
(\mathrm{kN})\end{array}$} & \multirow{2}{*}{$\begin{array}{l}P_{\text {rup }} \\
\text { (kN) }\end{array}$} & \multirow{2}{*}{$\begin{array}{c}\text { Resistência } \\
(\mathrm{kPa})\end{array}$} & \multirow{2}{*}{$\begin{array}{c}\text { Carga Adm. } \\
\text { (kN) }\end{array}$} & \multirow{2}{*}{$\begin{array}{c}\text { Solicitação } \\
(\mathrm{kPa})\end{array}$} \\
\hline & Estado & Bairro/Cidade & Endereço & $\mathrm{D}(\mathrm{cm})$ & $L(m)$ & Área $\left(\mathrm{m}^{2}\right)$ & & & & & \\
\hline 55 & SP & Iminim & I. José Fig. Seixas & 70.0 & 18.4 & 0.3848 & 4000.0 & 4041.2 & 10500.9 & 1550.0 & 4027.6 \\
\hline 56 & SP & Imirim & r. José Fig. Seixas & 70.0 & 18.4 & 0.3848 & 4000.0 & 4828.1 & 12545.5 & 1550.0 & 4027.6 \\
\hline 57 & SP & Imirim & r. José Fig. Seixas & 70.0 & 15.8 & 0.3848 & 2800.0 & 2866.4 & 7448.1 & 1550.0 & 4027.6 \\
\hline 58 & SP & Imirim & r. José Fig. Seixas & 70.0 & 23.0 & 0.3848 & 2800.0 & 2836.7 & 7371.0 & 1550.0 & 4027.6 \\
\hline 59 & $\mathrm{SP}$ & Imirim & r. Josê Fig. Seixas & 70.0 & 24.0 & 0.3848 & 4800.0 & 4893.1 & 12714.5 & 1550.0 & 4027.6 \\
\hline \multicolumn{4}{|l|}{ Média } & 70.0 & 19.9 & 0.3848 & 3680.0 & & 10116.0 & & 4027.6 \\
\hline \multicolumn{4}{|c|}{ Desvio Padrão } & 0.0 & 3.5 & 0.0000 & 867.2 & & 2619.9 & & 0.0 \\
\hline \multicolumn{4}{|c|}{ Coeficiente de Variaçăo } & $0.0 \%$ & $17.3 \%$ & $0.0 \%$ & $23.6 \%$ & & $25.9 \%$ & & $0.0 \%$ \\
\hline
\end{tabular}

Na Tabela 46 do Apêndice A consta as curva carga $\mathrm{x}$ recalque das estacas ensaiadas em Imirim/SP. E na Tabela 47 do Apêndice A têm-se os parâmetros A e B e os valores de carga de ruptura resultantes da aplicação do Critério de Van der Veen.

As Figuras 59 a 63 do Apêndice A apresentam as prova de carga da estaca ensaiadas em Imirim/SP. Enquanto que as Figuras 64, 65 e 66 do Apêndice A e a Tabela 8.1.19 abaixo apresentam os resultados das análises realizadas para esta fundação com base nas estatísticas apresentadas na Tabela 8.1 .18 acima.

Tabela 8.1.19. Resultados das análises realizadas - Imirim/SP.

\begin{tabular}{|c|c|c|c|c|c|c|c|c|c|c|c|}
\hline \multirow{2}{*}{ Análises } & \multicolumn{3}{|c|}{ Resistência } & \multicolumn{3}{|c|}{ Solicitação } & \multirow{2}{*}{ CS } & \multirow{2}{*}{$\beta$} & \multirow{2}{*}{ Pr } & \multirow{2}{*}{$1 / \mathrm{Pr}$} & \multirow{2}{*}{$\begin{array}{l}P_{\text {adm }} \\
(\mathrm{kPa})\end{array}$} \\
\hline & Média (kPa) & Desvio (kPa) & CV (\%) & Média $(\mathrm{kPa})$ & Desvio (kPa) & CV $(\%)$ & & & & & \\
\hline Análise 1 & 10116.0 & 2619.9 & $25.9 \%$ & 4027.6 & 0.0 & $0.0 \%$ & 2.5 & 2.32 & 0.01007 & 99 & 4027.6 \\
\hline Análise 2 & 10116.0 & 2619.9 & $25.9 \%$ & 5058.0 & 0.0 & $0.0 \%$ & 2.0 & 1.93 & 0.02677 & 37 & 5058.0 \\
\hline Análise 3 & 10116.0 & 2619.9 & $25.9 \%$ & 2019.4 & 0.0 & $0.0 \%$ & 5.0 & 3.09 & 0.00100 & 1000 & 2019.4 \\
\hline
\end{tabular}

A Tabela 48 do Apêndice A mostra a relação: índice de confiabilidade $\mathrm{x}$ coeficiente de segurança, enquanto que na Figura 67 do Apêndice A tem-se o gráfico de carga admissível proposta para a fundação localizada em Imirim/SP.

Tabela 8.1.20. Estatísticas das Provas de Carga analisadas - Contagem/MG.

\begin{tabular}{|c|c|c|c|c|c|c|c|c|c|c|c|}
\hline \multirow{2}{*}{ Número } & \multicolumn{3}{|r|}{ Localização } & \multicolumn{3}{|c|}{ Estaca } & \multirow{2}{*}{$\begin{array}{l}2 \mathrm{P} \\
(\mathrm{kN})\end{array}$} & \multirow{2}{*}{$\begin{array}{l}P_{\text {rup }} \\
(\mathrm{kN})\end{array}$} & \multirow{2}{*}{$\begin{array}{c}\text { Resisténcia } \\
(\mathrm{kPa})\end{array}$} & \multirow{2}{*}{$\begin{array}{c}\text { Carga Adm } \\
\text { (KN) }\end{array}$} & \multirow{2}{*}{$\begin{array}{l}\text { Solicitaçäo } \\
(\mathrm{KPa})\end{array}$} \\
\hline & Estado & BairrolCidade & Endereso & $D(\mathrm{~cm})$ & $L(m)$ & Área $\left(\mathrm{m}^{2}\right)$ & & & & & \\
\hline 38 & MG & Contagem & R Zeze Camargo $x$ Av. Eugenio Pacelli & 300 & 140 & 0.0707 & 500.0 & 14982 & 21194.8 & 350.0 & 4961.5 \\
\hline 39 & MG & Contagem & R Zeze Camargo x Av. Eugenio Pacelli & 300 & 140 & 0.0707 & 3000 & 14982 & 21194.8 & 3500 & 4961.5 \\
\hline 40 & MG & Contagem & R Zeze Camargo x Av. Eugenio Pacelli & 300 & 140 & 0.0707 & 3000 & 509.5 & 7207.3 & 350.0 & 4961.5 \\
\hline 41 & MG & Contagem & R Zeze Camargo x Av. Eugenio Pacelli & 300 & 140 & 0.0707 & 300.0 & 653.2 & 9240.4 & 350.0 & 4961.5 \\
\hline 42 & MG & Contagem & R Zeze Camargo x Av. Eugenio Pacelli & 300 & 140 & 0.0707 & 300.0 & 581.5 & 82259 & 350.0 & 4951.5 \\
\hline 43 & MG & Contagem & R Zeze Camargo x Av. Eugenio Pacelli & 300 & 140 & 0.0707 & 500.0 & 14982 & 21194.8 & 350.0 & 4951.5 \\
\hline \multicolumn{4}{|l|}{ Média } & 30.0 & 140 & 0.0707 & 305.7 & & 14709.6 & & 4961.5 \\
\hline \multicolumn{4}{|c|}{ Desvio Padrāo } & 0.0 & 0.0 & 0.0000 & 103.3 & & 7133.1 & & 0.0 \\
\hline \multicolumn{4}{|c|}{ Coeficiente de Variaçāo } & $00 \%$ & $0.0 \%$ & $0.0 \%$ & $282 \%$ & & $48.5 \%$ & & $0.0 \%$ \\
\hline
\end{tabular}


A Tabela 49 do Apêndice A apresenta o número de provas de cargas realizadas em Minas Gerais. A Tabela 50 do Apêndice A traz as provas de carga publicadas por Alonso (2000), e a Tabela 51 do Apêndice A as publicadas por Alonso (2002).

A Tabela 52 do Apêndice A apresenta a reunião de todas as provas de carga publicadas, enquanto que a Tabela 53 do Apêndice A apresenta as provas de carga que foram realizadas em Contagem/MG, a Tabela 54 do Apêndice A apresenta as provas de carga realizadas no Anel Rod em Belo Horizonte/MG, e a Tabela 55 do Apêndice A as provas de carga realizadas na Av. Flemig, também em Belo Horizonte /MG.

A Tabela 56 do Apêndice A apresenta as curvas carga $\mathrm{x}$ recalque das estacas ensaiadas em Contagem/MG e a Tabela 57 do Apêndice $A$, os parâmetros A e B e as cargas de ruptura estimadas pelo Critério de Van der Veen para essas provas de carga. As Figuras 68 a 73 do Apêndice A apresentam as provas de carga das estacas executadas em Contagem/MG.

Tabela 8.1.21. Resultados das análises realizadas - Contagem/MG.

\begin{tabular}{|c|c|c|c|c|c|c|c|c|c|c|c|}
\hline \multirow{2}{*}{ Análises } & \multicolumn{3}{|c|}{ Resisténcia } & \multicolumn{3}{|c|}{ Solicitação } & \multirow{2}{*}{ CS } & \multirow{2}{*}{$\beta$} & \multirow{2}{*}{ Pr } & \multirow{2}{*}{$1 / \mathrm{Pr}$} & \multirow{2}{*}{$\begin{array}{l}P_{\text {adm }} \\
(\mathrm{kPa})\end{array}$} \\
\hline & Média (kPa) & Desvio (kPa) & CV $(\%)$ & Média (kPa) & Desvio (kPa) & CV $(\%)$ & & & & & \\
\hline Análise 1 & 14709.6 & 7133.1 & $48.5 \%$ & 4951.5 & 0.0 & $0.0 \%$ & 3.0 & 1.37 & 0.08565 & 12 & 4951.5 \\
\hline Análise 2 & 14709.6 & 7133.1 & $48.5 \%$ & 7354.8 & 0.0 & $0.0 \%$ & 2.0 & 1.03 & 0.15125 & 7 & 7354.8 \\
\hline Análise 3 & 14709.6 & 7133.1 & $48.5 \%$ & -7334.5 & 0.0 & $0.0 \%$ & -2.0 & 3.09 & 0.00100 & 1000 & -7334.5 \\
\hline
\end{tabular}

As Figuras 74 a 76 do Apêndice A mostram as análises realizadas para a fundação localizada em Contagem/MG. Os valores de resistência utilizados nestas análises são os apresentados na Tabela 8.1.20. Sendo que os resultados das mesmas encontram-se resumidos na Tabela 8.1.21 acima.

Devido aos elevado valor do coeficiente de variação dos valores de resistência, a metodologia proposta resultou numa carga admissível negativa, mostrando que para altas variabilidades (coeficiente de variação superior a 30\%) o método da carga admissível não é aplicável, pois deixa de ter sentido prático.

A Tabela 58 do Apêndice A apresenta a relação entre o índice de confiabilidade e o coeficiente de segurança para a fundação analisada, enquanto que a Figura 77 do Apêndice A apresenta a curva de carga admissível proposta para a mesma.

A Tabela 59 do Apêndice A apresenta as curvas carga x recalque das estacas ensaiadas no Anel Rod. em Belo Horizonte/MG. Enquanto que a Tabela 60 do Apêndice A apresenta os parâmetros A e B e as cargas de ruptura estimadas para estas 
estacas pelo Critério de Van der Veen.

As Figuras 78, 79 e 80 do Apêndice A apresentam as provas de carga executadas no Anel Rodoviário em Belo Horizonte/MG.

Tabela 8.1.22. Estatísticas das Provas de Carga analisadas - Belo Horizonte (Anel Rod.) /MG.

\begin{tabular}{|c|c|c|c|c|c|c|c|c|c|c|c|}
\hline \multirow{2}{*}{ Número } & \multicolumn{3}{|c|}{ Localização } & \multicolumn{3}{|c|}{ Estaca } & \multirow{2}{*}{$\begin{array}{l}2 P \\
(\mathrm{kN})\end{array}$} & \multirow{2}{*}{$\begin{array}{l}P_{\text {rup }} \\
\text { (NN) }\end{array}$} & \multirow{2}{*}{$\begin{array}{c}\text { Resistência } \\
\text { (kPa) }\end{array}$} & \multirow{2}{*}{$\begin{array}{c}\text { Carga Adm. } \\
\text { (IN) }\end{array}$} & \multirow{2}{*}{$\begin{array}{c}\text { Solicitação } \\
(\mathrm{kPa})\end{array}$} \\
\hline & Estado & Bairro/Cidade & Enderef̧o & $\mathrm{D}(\mathrm{cm})$ & $L(m)$ & Área $\left(\mathrm{m}^{2}\right)$ & & & & & \\
\hline 43 & MG & B. Horizonte & Anel Rod., km21 & 60.0 & 18.8 & 0.2827 & 2500.0 & 3094.3 & 10943.9 & 1100.0 & 3890.5 \\
\hline 44 & NG & B. Horizonte & Anel Rod., km22 & 60.0 & 18.8 & 0.2827 & 2500.0 & 2756.0 & 9747.4 & 1100.0 & 3690.5 \\
\hline 45 & MG & B. Horizonte & Anel Rod., km23 & 40.0 & 17.0 & 0.1257 & 820.0 & 971.0 & 7726.8 & 500.0 & 3978.9 \\
\hline \multicolumn{4}{|l|}{ Média } & 53.3 & 18.2 & 0.2304 & 1940.0 & & 9472.7 & & 3919.9 \\
\hline \multicolumn{4}{|c|}{ Desvio Padrão } & 11.5 & 1.0 & 0.0907 & 909.9 & & 1626.0 & & 51.0 \\
\hline \multicolumn{4}{|c|}{ Coeficiente de Variação } & $21.7 \%$ & $5.6 \%$ & $39.4 \%$ & $50.0 \%$ & & $17.2 \%$ & & $1.3 \%$ \\
\hline
\end{tabular}

Com base nas estatísticas apresentadas na Tabela 8.1.22, foram realizadas as análises que se encontram apresentadas nas Figuras 81 a 82 Apêndice $A$, e cujos resultados estão indicados na Tabela 8.1 .23 abaixo.

Tabela 8.1.23. Resultados das análises realizadas - Belo Horizonte (Anel Rod.) /MG.

\begin{tabular}{|c|c|c|c|c|c|c|c|c|c|c|c|}
\hline \multirow{2}{*}{ Análises } & \multicolumn{3}{|c|}{ Resistência } & \multicolumn{3}{|c|}{ Solicitação } & \multirow{2}{*}{ cs } & \multirow{2}{*}{$\beta$} & \multirow{2}{*}{ Pr } & \multirow{2}{*}{$1 / \mathrm{Pr}$} & \multirow{2}{*}{$\begin{array}{l}P_{\text {adm }} \\
(\mathrm{KPa})\end{array}$} \\
\hline & Média (kPa) & Desvio (kPa) & CV (\%) & Média (kPa) & Desyio (kPa) & CV (\%) & & & & & \\
\hline Análise 1 & 9472.7 & 1626.0 & $17.2 \%$ & 3919.9 & 51.0 & $1.3 \%$ & 2.4 & 3.41 & 0.00032 & 3115 & 3919.9 \\
\hline Análise 2 & 9472.7 & 1626.0 & $17.2 \%$ & 4736.4 & 61.7 & $1.3 \%$ & 2.0 & 2.91 & 0.00180 & 555 & 4736.4 \\
\hline Análise 3 & 9472.7 & 1626.0 & $17.2 \%$ & 4444.4 & 57.9 & $1.3 \%$ & 2.1 & 3.09 & 0.00100 & 1000 & 4444.4 \\
\hline
\end{tabular}

Percebe-se que para esta fundação em específico, a Análise 2 e 3 resultam em valores próximos de carga admissível. Isso ocorre devido ao fato de que o valor de coeficiente de variação apresentado para as tensões resultantes, não ser um valor muito elevado.

A Tabela 61 Apêndice A apresenta a relação entre o índice de confiabilidade e o coeficiente de segurança, e a Figura 84 do Apêndice A apresenta a curva de carga admissível proposta para a fundação em análise.

A Tabela 62 do Apêndice A apresenta as curvas carga x recalque das estacas ensaiadas na Av. Flemig em Belo Horizonte/MG, e a Tabela 63 do Apêndice A apresenta os parâmetros A e B e as cargas de ruptura estimadas pelo Critério de Van der Veen para estas estacas.

As Figuras 85 a 87 do Apêndice A apresentam as provas de carga executadas na Av. Flemig em Belo Horizonte/MG. Enquanto que as Figuras 88 a 90 do Apêndice A trazem as análises realizadas para esta fundação, utilizando as estatísticas indicadas na Tabela 8.1.24. 
Tabela 8.1.24. Estatísticas das Provas de Carga analisadas - Belo Horizonte (Av. Flemig) /MG.

\begin{tabular}{|c|c|c|c|c|c|c|c|c|c|c|c|}
\hline \multirow{2}{*}{ Número } & \multicolumn{3}{|c|}{ Localização } & \multicolumn{3}{|c|}{ Estaca } & \multirow{2}{*}{$\begin{array}{l}2 \mathrm{P} \\
(\mathrm{kN})\end{array}$} & \multirow{2}{*}{$\begin{array}{l}P_{\text {rup }} \\
\text { (kN) }\end{array}$} & \multirow{2}{*}{$\begin{array}{c}\text { Resistência } \\
\text { (kPa) }\end{array}$} & \multirow{2}{*}{$\begin{array}{c}\text { Carga Adim. } \\
\text { (kN) }\end{array}$} & \multirow{2}{*}{$\begin{array}{c}\text { Solicitação } \\
\text { (kPa) }\end{array}$} \\
\hline & Estado & Bairro/Cidade & Endereço & $D(\mathrm{~cm})$ & $L(m)$ & Área $\left(\mathrm{m}^{2}\right)$ & & & & & \\
\hline 78 & MG & B. Horizonte & Av. Flemig & 35.0 & 7.0 & 0.0062 & 700.0 & 700.1 & 7276.4 & 400.0 & 4157.5 \\
\hline 79 & MG & B. Horizonte & Av. Flemig & 35.0 & 7.0 & 0.0962 & 650.0 & 656.6 & 6824.2 & 400.0 & 4157.5 \\
\hline 80 & MG & B. Horizonte & Av. Flemig & 35.0 & 10.0 & 0.0962 & 792.0 & 461.8 & 4799.7 & 400.0 & 4157.5 \\
\hline \multicolumn{4}{|l|}{ Média } & 35.0 & 8.0 & 0.0962 & 714.0 & & 6300.1 & & 4157.5 \\
\hline \multicolumn{4}{|c|}{ Desvio Padrão } & 0.0 & 1.7 & 0.0000 & 72.0 & & 1318.9 & & 0.0 \\
\hline \multicolumn{4}{|c|}{ Coeficiente de Variação } & $0.0 \%$ & $21.7 \%$ & $0.0 \%$ & $10.1 \%$ & & $20.9 \%$ & & $0.0 \%$ \\
\hline
\end{tabular}

Os resultados da análise desta fundação estão apresentados em resumo, na Tabela 8.1.25 abaixo.

Tabela 8.1.25. Resultados das análises realizadas - Belo Horizonte (Av. Flemig) /MG.

\begin{tabular}{|c|c|c|c|c|c|c|c|c|c|c|c|}
\hline \multirow{2}{*}{ Análises } & \multicolumn{3}{|c|}{ Resistência } & \multicolumn{3}{|c|}{ Solicitação } & \multirow{2}{*}{ CS } & \multirow{2}{*}{$\beta$} & \multirow{2}{*}{$\mathrm{Pr}$} & \multirow{2}{*}{$1 / \mathrm{Pr}$} & \multirow{2}{*}{$\begin{array}{l}P_{\text {adm }} \\
(\mathrm{KPa})\end{array}$} \\
\hline & Média $(\mathrm{kPa})$ & Desvio (kPa) & CV (\%) & Média (kPa) & Desvio (kPa) & CV (\%) & & & & & \\
\hline Análise 1 & 6300.1 & 1318.9 & $20.9 \%$ & 4157.5 & 0.0 & $0.0 \%$ & 1.5 & 1.62 & 0.05214 & 19 & 4157.5 \\
\hline Análise 2 & 6300.1 & 1318.9 & $20.9 \%$ & 3150.0 & 0.0 & $0.0 \%$ & 2.0 & 2.39 & 0.00846 & 118 & 3150.0 \\
\hline Análise 3 & 6300.1 & 1318.9 & $20.9 \%$ & 2224.1 & 0.0 & $0.0 \%$ & 2.8 & 3.09 & 0.00100 & 1000 & 2224.1 \\
\hline
\end{tabular}

A Tabela 64 do Apêndice A mostra a relação existente entre os valores de índice de confiabilidade e de coeficiente de segurança para a fundação em estudo, enquanto que a Figura 91 do Apêndice A apresenta as curva de carga admissível proposta para a mesma.

A Tabela 65 do Apêndice A apresenta o número de provas de cargas realizadas no estado do Rio Grande do Sul. A Tabela 66 do Apêndice A apresenta as provas de carga publicadas por Alonso (2000), e a Tabela 67 do Apêndice A as provas de carga publicadas por Alonso (2002).

Quanto à Tabela 68 do Apêndice A, esta apresenta todas as provas de carga publicadas, enquanto as Tabelas 69 e 70 do Apêndice A apresentam, respectivamente, as provas de carga executadas no Aeroporto Salgado Filho e na av. Sertório, em Porto Alegre/RS, que serão analisadas.

A Tabela 71 do Apêndice A apresenta as curva carga $x$ recalque das estacas ensaiadas no Aeroporto Salgado Filho, enquanto que a Tabela 72 do Apêndice A apresenta os parâmetros A e B e as cargas de ruptura estimadas pelo Critério de Van der Veen para as referidas estacas.

As Figuras 92 a 95 do Apêndice A trazem as provas de carga das estacas ensaiadas na fundação em análise. 
Tabela 8.1.26. Estatísticas das Provas de Carga analisadas - Rio Grande do Sul.

\begin{tabular}{|c|c|c|c|c|c|c|c|c|c|c|c|}
\hline \multirow{2}{*}{ Número } & \multicolumn{3}{|c|}{ Localização } & \multicolumn{3}{|c|}{ Estaca } & \multirow{2}{*}{$\begin{array}{l}2 \mathrm{P} \\
(\mathrm{kN})\end{array}$} & \multirow{2}{*}{$\begin{array}{l}P_{\text {rup }} \\
(\mathrm{kN})\end{array}$} & \multirow{2}{*}{$\begin{array}{c}\text { Resistência } \\
\text { (kPa) }\end{array}$} & \multirow{2}{*}{$\begin{array}{c}\text { Carga Adm. } \\
\text { (kN) }\end{array}$} & \multirow{2}{*}{$\begin{array}{c}\text { Solicitação } \\
(\mathrm{kPa})\end{array}$} \\
\hline & Estado & Bairro/Cidade & Endereço & $\mathrm{D}(\mathrm{cm})$ & $L(m)$ & Área $\left(\mathrm{m}^{2}\right)$ & & & & & \\
\hline 11 & RS & P. Alegre & Aerop. Salgado Filho & 60.0 & 22.0 & 0.2827 & 3320.0 & 36 & 12800.2 & 1100.0 & 3890.5 \\
\hline 12 & RS & P. Alegre & Aerop. Salgado Filho & 60.0 & 22.0 & 0.2827 & 3600.0 & 4324.4 & 15294.4 & 1100.0 & 3890.5 \\
\hline 13 & RS & P. Alegre & Aerop. Salgado Filho & 40.0 & 16.0 & 0.1257 & 1200.0 & 1306.8 & 10399.3 & 500.0 & 3978.9 \\
\hline 14 & RS & P. Alegre & Aerop. Salgado Filho & 60.0 & 27.0 & 0.2827 & 3600.0 & 5992.7 & 21194.8 & 1100.0 & 3890.5 \\
\hline \multicolumn{4}{|l|}{ Média } & 55.0 & 21.8 & 0.2435 & 2930.0 & & 14922.1 & & 3912.6 \\
\hline \multicolumn{4}{|c|}{ Desvio Padrão } & 10.0 & 4.5 & 0.0785 & 1160.9 & & 4634.8 & & 44.2 \\
\hline \multicolumn{4}{|c|}{ Coeficiente de Variação } & $18.2 \%$ & $20.6 \%$ & $32.3 \%$ & $39.6 \%$ & & $31.1 \%$ & & $1.1^{\circ}-x-a+2$ \\
\hline
\end{tabular}

Tabela 8.1.27. Resultados das análises realizadas - Rio Grande do Sul.

\begin{tabular}{|c|c|c|c|c|c|c|c|c|c|c|c|}
\hline \multirow{2}{*}{ Análises } & \multicolumn{3}{|c|}{ Resistência } & \multicolumn{3}{|c|}{ Solicitação } & \multirow{2}{*}{ CS } & \multirow{2}{*}{$\beta$} & \multirow{2}{*}{ Pr } & \multirow{2}{*}{$1 / \mathrm{Pr}$} & \multirow{2}{*}{$\begin{array}{l}\text { Perm } \\
\text { (kPa) }\end{array}$} \\
\hline & Média (kPa) & Desvio (kPa) & CV $(\%)$ & Média (kPa) & Desvio $(\mathrm{kPa})$ & CV (\%) & & & & & \\
\hline Análise 1 & 14922.1 & 4634.8 & $31.1 \%$ & 3912.6 & 44.2 & $1.1 \%$ & 3.8 & 2.38 & 0.00877 & 114 & 3912.6 \\
\hline Análise 2 & 14922.1 & 4634.8 & $31.1 \%$ & 7461.1 & 84.3 & $1.1 \%$ & 2.0 & 1.61 & 0.05375 & 19 & 7461.1 \\
\hline Análise 3 & 14922.1 & 4634.8 & $31.1 \%$ & 598.8 & 6.8 & $1.1 \%$ & 24.9 & 3.09 & 0.00100 & 1000 & 598.8 \\
\hline
\end{tabular}

Com base nas estatísticas dos valores de resistência das estacas ensaiadas, cujos valores estão apresentados na Tabela 8.1.26, foram realizadas as análises que estão apresentadas nas Figuras 96 a 98 do Apêndice A.

Os resultados dessas análises encontram-se resumidos na Tabela 8.1.27 acima. Observando esta tabela, percebe-se que devido ao elevado valor do coeficiente de variação (31.1\%) a Análise 2 indica uma elevada probabilidade de ruína. Enquanto que a Análise 3 indica que, o dimensionamento desta fundação para uma probabilidade de ruína de $1 / 1000$, é de certa forma inadequada, por exigir uma carga admissível muito reduzida, correspondente a um coeficiente de segurança muito elevado $(\mathrm{CS}=24.9)$.

A Tabela 73 do Apêndice A apresenta o índice de confiabilidade x coeficiente de segurança para a fundação em análise, enquanto que a Figura 99 do Apêndice A apresenta a curva de carga admissível proposta para essa fundação.

Tabela 8.1.28. Estatísticas das Provas de Carga analisadas - Rio Grande do Sul.

\begin{tabular}{|c|c|c|c|c|c|c|c|c|c|c|c|}
\hline \multirow{2}{*}{ Número } & \multicolumn{3}{|c|}{ Localização } & \multicolumn{3}{|c|}{ Estaca } & \multirow{2}{*}{$\begin{array}{l}2 \mathrm{P} \\
(\mathrm{kN}) \\
\end{array}$} & \multirow{2}{*}{$\begin{array}{l}P_{\text {rup }} \\
(\mathrm{kN})\end{array}$} & \multirow{2}{*}{$\begin{array}{c}\text { Resistência } \\
(\mathrm{kPa})\end{array}$} & \multirow{2}{*}{$\begin{array}{c}\text { Carga Adm. } \\
(\mathrm{kN})\end{array}$} & \multirow{2}{*}{$\begin{array}{c}\text { Solicitação } \\
(\mathrm{kPa})\end{array}$} \\
\hline & Estado & Bairro/Cidade & Endereço & $\mathrm{D}(\mathrm{cm})$ & $L(m)$ & Área $\left(\mathrm{m}^{2}\right)$ & & & & & \\
\hline 16 & RS & P. Alegre & av. Sertório, 4222 & 40.0 & 9.1 & 0.1257 & 1450.0 & 2058.8 & 16383.2 & 500.0 & 3978.9 \\
\hline 17 & RS & P. Alegre & av. Sertório, 4223 & 50.0 & 12.0 & 0.1963 & 1700.0 & 1718.7 & 8753.3 & 800.0 & 4074.4 \\
\hline 18 & RS & P. Alegre & av. Sertório, 4224 & 50.0 & 12.0 & 0.1963 & 1900.0 & 1943.3 & 9897.3 & 800.0 & 4074.4 \\
\hline \multicolumn{4}{|l|}{ Média } & 46.7 & 11.0 & 0.1728 & 1683.3 & & 11677.9 & & 4042.5 \\
\hline \multicolumn{4}{|c|}{ Desvio Pacrão } & 5.8 & 1.7 & 0.0408 & 225.5 & & 4114.8 & & 55.1 \\
\hline \multicolumn{4}{|c|}{ Coeficiente de Variação } & $12.4 \%$ & $15.5 \%$ & $23.6 \%$ & $13.4 \%$ & & $35.2 \%$ & & $1.4 \%$ \\
\hline
\end{tabular}


A Tabela 74 do Apêndice A apresenta as curvas carga $\mathrm{x}$ recalque das estacas ensaiadas na av. Sertório em Porto Alegre/RS, enquanto a Tabela 75 do Apêndice A apresenta os parâmetros A e B e as cargas de ruptura estimadas pelo Critério de Van der Veen para as mesmas. Quanto às provas de carga das estacas analisadas, estas se encontram nas Figuras 100, 101 e 102 do Apêndice A.

A Tabela 8.1.28 apresenta os valores de resistência utilizados nas análises realizadas e que se estão apresentadas nas Figuras 103 a 105 do Apêndice A.

Tabela 8.1.29. Resultados das análises realizadas - Rio Grande do Sul

\begin{tabular}{|c|c|c|c|c|c|c|c|c|c|c|c|}
\hline \multirow{2}{*}{ Análises } & \multicolumn{3}{|c|}{ Resistência } & \multicolumn{3}{|c|}{ Solicitação } & \multirow{2}{*}{ CS } & \multirow{2}{*}{$\beta$} & \multirow{2}{*}{ Pr } & \multirow{2}{*}{$1 / \mathrm{Pr}$} & \multirow{2}{*}{$\begin{array}{l}P_{\text {orim }} \\
(\mathrm{kPa})\end{array}$} \\
\hline & Média (kPa) & Desvio (kPa) & CV (\%) & Média (kPa) & Desvio $(\mathrm{kPa})$ & CV (\%) & & & & & \\
\hline Análise 1 & 11677.9 & 4114.8 & $35.2 \%$ & 4042.5 & 55.1 & $1.4 \%$ & 2.9 & 1.86 & 0.03177 & 31 & 4042.5 \\
\hline Análise 2 & 11677.9 & 4114.8 & $35.2 \%$ & 5839.0 & 79.6 & $1.4 \%$ & 2.0 & 1.42 & 0.07799 & 13 & 5839.0 \\
\hline Análise 3 & 11677.9 & 4114.8 & $35.2 \%$ & -1038.7 & 14.2 & $-1.4 \%$ & -11.2 & 3.09 & 0.00100 & 1000 & -1038.7 \\
\hline
\end{tabular}

Na Tabela 8.1.29 estão os resultados das análises realizadas. Percebe-se que, novamente, o elevado valor do coeficiente de variação impossibilita o dimensionamento da fundação com uma probabilidade de ruína de 1/1000 (Análise 3).

A Tabela 76 do Apêndice A mostra a relação entre o índice de confiabilidade e o coeficiente de segurança para esta fundação, assim como a Figura 106 do Apêndice A, que apresenta a curva de carga admissível proposta para a fundação em análise.

Tabela 8.1.30. Estatísticas das Provas de Carga analisadas - Paraná.

\begin{tabular}{|c|c|c|c|c|c|c|c|c|c|c|c|}
\hline \multirow{2}{*}{ Número } & \multicolumn{3}{|c|}{ Localização } & \multicolumn{3}{|c|}{ Estaca } & \multirow{2}{*}{$\begin{array}{l}2 \mathrm{P} \\
(\mathrm{kN})\end{array}$} & \multirow{2}{*}{$\begin{array}{l}P_{\text {rup }} \\
(k N)\end{array}$} & \multirow{2}{*}{$\begin{array}{c}\text { Resistência } \\
\text { (kPa) }\end{array}$} & \multirow{2}{*}{$\begin{array}{c}\text { Carga Adm. } \\
(\mathrm{kN})\end{array}$} & \multirow{2}{*}{$\begin{array}{c}\text { Solicitaçăo } \\
(\mathrm{kPa})\end{array}$} \\
\hline & Estado & Bairro/Cidade & Endereço & $\mathrm{D}(\mathrm{cm})$ & $L(m)$ & Área $\left(\mathrm{m}^{2}\right)$ & & & & & \\
\hline 89 & PR & SJ Pinhais & Fca. da AUDI & 40.0 & 10.5 & 0.1257 & 1260.0 & 1906.1 & 15168.3 & 500.0 & 3978.9 \\
\hline 90 & PR & SJ Pinhais & Fca. da AUDI & 40.0 & 7.8 & 0.1257 & 720.0 & 650.7 & 5177.8 & 500.0 & 3978.9 \\
\hline 91 & PR & SJ Pinhais & Fca. da AUDI & 40.0 & 14.5 & 0.1257 & 1260.0 & 1873.8 & 14911.3 & 500.0 & 3978.9 \\
\hline 92 & PR & SJ Pinhais & Fca. da AUDI & 40.0 & 12.5 & 0.1257 & 1260.0 & 2663.4 & 21194.8 & 500.0 & 3978.9 \\
\hline 93 & PR & SJ Pinhais & Fca. da AUDI & 50.0 & 19.0 & 0.1963 & 1800.0 & 1960.2 & 9983.3 & 800.0 & 4074.4 \\
\hline \multicolumn{4}{|l|}{ Média } & 42.0 & 12.9 & 0.1398 & 1260.0 & & 13287.1 & & 3998.0 \\
\hline \multicolumn{4}{|c|}{ Desvio Padrão } & 4.5 & 4.2 & 0.0316 & 381.8 & & 6028.8 & & 42.7 \\
\hline \multicolumn{4}{|c|}{ Coeficiente de Variação } & $10.6 \%$ & $32.9 \%$ & $22.6 \%$ & $30.3 \%$ & & $45.4 \%$ & & $1.1 \%$ \\
\hline
\end{tabular}

A Tabela 77 do Apêndice A apresenta o número de provas de cargas realizadas no Paraná. Enquanto que a Tabela 78 do Apêndice A apresenta as provas de carga que foram publicadas por Alonso (2000), e a Tabela 79 do Apêndice A as publicadas por Alonso (2002).

A Tabela 80 do Apêndice A apresenta todas as provas de carga publicadas 
reunidas. Destas somente as provas de carga apresentadas na Tabela 81 do Apêndice A serão analisadas.

A Tabela 82 do Apêndice A apresenta as curva carga $x$ recalque das estacas ensaiadas, e a Tabela 83 do Apêndice A apresenta os parâmetros A e B e os valores de carga de ruptura estimados pelo Critério de Van der Veen.

As Figuras 107 a 111 do Apêndice A apresentam as provas de carga das estaca ensaiadas em São José dos Pinhais/PR, cujos valores de resistência se encontram apresentados na Tabela 8.1.30.

Tabela 8.1.31. Resultados das análises realizadas - Paraná.

\begin{tabular}{|c|c|c|c|c|c|c|c|c|c|c|c|}
\hline \multirow{2}{*}{ Análises } & \multicolumn{3}{|c|}{ Resisténcia } & \multicolumn{3}{|c|}{ Solicitação } & \multirow{2}{*}{ CS } & \multirow{2}{*}{$\beta$} & \multirow{2}{*}{ Pr } & \multirow{2}{*}{$1 / \mathrm{Pr}$} & \multirow{2}{*}{$\begin{array}{l}P_{\text {adm }} \\
(\mathrm{kPa})\end{array}$} \\
\hline & Média (kPa) & Desvio (kPa) & CV $(\%)$ & Média (kPa) & Desvio (kPa) & $\mathrm{CV}(\%)$ & & & & & \\
\hline Análise 1 & 13287.1 & 6028.8 & $45.4 \%$ & 3998.0 & 42.7 & $1.1 \%$ & 3.3 & 1.54 & 0.06169 & 16 & 3998.0 \\
\hline Análise 2 & 13287.1 & 6028.8 & $45.4 \%$ & 6643.5 & 71.0 & $1.1 \%$ & 2.0 & 1.10 & 0.13525 & 7 & 6643.5 \\
\hline Análise 3 & 13287.1 & 6028.8 & $45.4 \%$ & -5345.1 & 57.1 & $-1.1 \%$ & -2.5 & 3.09 & 0.00100 & 1000 & -5345.1 \\
\hline
\end{tabular}

Utilizando as estatísticas apresentadas na Tabela 8.1 .30 foram realizadas as análises que estão apresentadas nas Figuras 112 a 114 do Apêndice A.

Os resultados dessas análises estão, em resumo, apresentadas na Tabela 8.1.31 acima. Nota-se o elevado valor do coeficiente de variação dos valores de resistência desta fundação, que resulta, como conseqüência, em elevadas probabilidades de ruína como pode-se observar pelos resultados das análises realizadas.

A Tabela 84 do Apêndice A mostra a relação existente entre os valores de índice de confiabilidade e de coeficiente de segurança para esta fundação, assim como a Figura 115 do Apêndice A apresenta as curvas de carga admissível proposta para a mesma.

Para cada uma das 13 fundações analisadas foi construído um gráfico relacionando os valores de carga admissível, de probabilidade de ruína e de coeficiente de segurança. Observa-se que através destes gráficos é possível prever qual é o valor da carga admissível e do coeficiente de segurança que permite dimensionar o estaqueamento para uma determinada probabilidade de ruína desejada. Para isso basta escolher para qual probabilidade de ruína se deseja projetar a fundação e, a partir desse valor determinar, através do gráfico, qual deve ser o correspondente valor da carga admissível a ser adotada e qual será o coeficiente de segurança da fundação. 
Percebe-se também, através das análises realizadas que quando se utiliza a metodologia proposta, qualquer alteração no valor do coeficiente de variação da solicitação ou da resistência, promove uma alteração no valor de carga admissível calculada, de forma que a probabilidade de ruína permaneça constante. Isso ocorre porque uma maior/menor dispersão dos valores de resistência conduz a um menor/maior índice de confiabilidade, conseqüentemente, para que a probabilidade de ruína permaneça constante, é necessário reduzir/aumentar o valor médio da solicitação, ou seja, reduzir/aumentar a carga admissível. No entanto, pode-se perceber, que o mesmo não ocorre quando se calcula a carga admissível do estaqueamento pela metodologia da norma. Pois, o coeficiente de segurança se mantém constante independentemente da maior ou menor dispersão dos dados.

\subsubsection{Comentários finais}

A Tabela 85 do Apêndice A apresenta um resumo de todas as análises realizadas na seqüência crescente do valor do coeficiente de variação, para que seja possível melhor analisar os resultados apresentados por essas análises.

Estes mesmos resultados encontram-se agrupados de acordo como o tipo de análise (Análise 1, 2 e 3) nas Tabelas 8.1.32, 8.1.33 e 8.1.34.

Tabela 8.1.32. Resultados de todas as Análises 1.

\begin{tabular}{|c|c|c|c|c|c|c|c|c|c|c|c|c|c|}
\hline \multicolumn{3}{|c|}{ Loca'zaçâo } & \multicolumn{3}{|c|}{ Resistenoia } & \multicolumn{3}{|c|}{ Soliotacialo } & \multirow{2}{*}{ cs } & \multirow{2}{*}{$\beta$} & \multirow{2}{*}{ Pr } & \multirow{2}{*}{$1 / P$} & \multirow{2}{*}{$\begin{array}{l}P_{\text {odst }} \\
(\mathrm{RPa})\end{array}$} \\
\hline Estado & Bainc'Odade & Enderespo & Molla $(\mathrm{kPa})$ & Desvio $(\mathrm{kPa})$ & $\mathrm{CV}(\%)$ & Mófia (kPa) & Destio $(\mathrm{kPa})$ & $\mathrm{CV}(\%)$ & & & & & \\
\hline RJ & Jacarepaguá & Bettan ind Cosm. & 115262 & 1517.7 & $132 \%$ & 39656 & 119.4 & $30 \%$ & 29 & 4.97 & 000000 & 2924093 & 39566 \\
\hline MG & 8. Horizonte & And $\mathrm{Rad}, \mathrm{km} 21$ & 94727 & 16230 & $17.2 \%$ & 3919.9 & 51.0 & $1.3 \%$ & 24 & 3.41 & 0,00032 & 3115 & 39199 \\
\hline$S P$ & Guaruhos & r. Beriamim Hunrigut & 135523 & $23 \$ 3.4$ & $17.5 \%$ & 4074.4 & 00 & $00 \%$ & 33 & 400 & 0,00003 & 31789 & 4074.4 \\
\hline MG & B. Horizonte & Av. Flsmig & 6300.1 & 13189 & $209 \%$ & 4157.5 & 00 & $0.0 \%$ & 15 & 1.62 & 005214 & 19 & 4157.5 \\
\hline ES & Araoruz & Arecinz Cellose & 10427.7 & 24039 & $23.1 \%$ & 35630 & 69.1 & $1.7 \%$ & 26 & 268 & 000065 & 274 & 30530 \\
\hline$S P$ & Imirin & r. bosé Fig Sovias & 10116.0 & 2519.9 & $25.9 \%$ & 4027.6 & 00 & $00 \%$ & 25 & 232 & 001007 & 99 & 4027.6 \\
\hline EA & Camacari & Fea fors & 141185 & 3769.1 & $287 \%$ & 4047.1 & 43.6 & $12 \%$ & 35 & 267 & $0,003 \pi$ & 2055 & 4047.1 \\
\hline sc & S. Foo $D 0$ Sul & Vega Sul & 11567.0 & 3093.6 & $28.8 \%$ & 40505 & 47.7 & $1.2 \%$ & 29 & 243 & 000761 & 131 & 4050.5 \\
\hline SP & Jacarei & Votorentin Celvose & 14423.4 & 43233 & $300 \%$ & 40405 & 74.0 & $18 \%$ & 36 & 240 & 0,00322 & 122 & 40405 \\
\hline RS & P. Alegre & Asrop. Se'gaso Fino & 149221 & 45348 & $31.1 \%$ & 39126 & 442 & $1.1 \%$ & 38 & 233 & $0003 \pi$ & 114 & 39126 \\
\hline RS & P. Alegre & av. Sstório, 4222 & 11677.9 & 4114.8 & $352 \%$ & 40425 & 55.1 & $1.4 \%$ & 29 & 1.83 & 003177 & 31 & 40425 \\
\hline$P R$ & SJ Pinha's & Fca da AUDI & 13237.1 & 60238 & $45.4 \%$ & 36030 & 427 & $1.1 \%$ & 3.3 & 1.54 & 0.05169 & 16 & 3993.0 \\
\hline MG & Contagem & R. Zeze C. X Av. E. Paceili & 14709.6 & 7133.1 & $435 \%$ & 4951.5 & 00 & $0 . \% \%$ & 30 & 1.37 & 006565 & 12 & 4951.5 \\
\hline
\end{tabular}

A Tabela 8.1.32 apresenta os resultados das Análises 1. Apresenta-se nesta tabela os valores de carga admissível calculados usando a metodologia da norma e os valores de carga admissível estrutural das estacas. 
Observando a Tabela 8.1.32 é possível perceber que as três primeiras fundações apresentadas na tabela, localizadas em Jacarepaguá/RJ, no Anel Rod. em Belo Horizonte/MG e em Guarulhos/SP, caso sejam projetadas com os valores de carga admissível estrutural, apresentarão segurança, ou seja, estas terão uma probabilidade de ruína adequada, inferior a $1 / 1000$.

Tabela 8.1.33. Resultados de todas as Análises 2.

\begin{tabular}{|c|c|c|c|c|c|c|c|c|c|c|c|c|c|}
\hline \multicolumn{3}{|c|}{ Locatizaçăo } & \multicolumn{3}{|c|}{ Resisțencia } & \multicolumn{3}{|c|}{ Solioteçşo } & \multirow{2}{*}{ cs } & \multirow{2}{*}{$\beta$} & \multirow{2}{*}{ PT } & \multirow{2}{*}{$1 / \mathrm{Pr}$} & \multirow{2}{*}{$\begin{array}{l}P_{a d n} \\
(\mathrm{KPa})\end{array}$} \\
\hline Estado & Bairrotidade & Endereco & Méda (kPa) & Desvio $(\mathrm{KPa})$ & $\mathrm{CV}(\%)$ & Meda $(\mathrm{kPa})$ & Desvio $(\mathrm{KPa})$ & $\mathrm{CV}(\%)$ & & & & & \\
\hline RJ & tacarepeguá & Batfan Ind Cosm. & 115262 & 1517.7 & $132 \%$ & 5763.1 & 1735 & $30 \%$ & 20 & 3.77 & 0.00003 & 12376 & 5763.1 \\
\hline MG & B. Horiante & And Rod, $\mathrm{km} 22$ & 94727 & 1626.0 & $17.2 \%$ & 4736.4 & 61.7 & $1.3 \%$ & 20 & 291 & 0.00180 & 555 & 4736.4 \\
\hline$S P$ & Quaruhos & r. Benjarrim Hunnigut & 135523 & 2369.4 & $17.5 \%$ & 6776.1 & 0.0 & $00 \%$ & 20 & 286 & 0.00211 & 473 & 6776.1 \\
\hline MG & B. Horizonte & Av. Flemig & 6300.1 & 1318.9 & $20.9 \%$ & 3150.0 & 0.0 & $0.0 \%$ & 20 & 239 & 0.00346 & 118 & 3150.0 \\
\hline ES & Araoruz & Aracruz Celúcose & 10427.7 & 2403.9 & $23.1 \%$ & 5213.8 & 91.0 & $1.7 \%$ & 20 & 216 & 0.01523 & 65 & 5213.8 \\
\hline$S P$ & Imirim & r. José Fig Sesias & 10116.0 & 2619.9 & $25.9 \%$ & 5058.0 & 0.0 & $0.0 \%$ & 20 & 1.93 & 0.02677 & 37 & 5053.0 \\
\hline BA & Cemaçaii & Fca Ford & 14118.5 & 3769.1 & $26.7 \%$ & 7059.3 & 81.3 & $12 \%$ & 20 & 1.87 & 0.03057 & 33 & 7059.3 \\
\hline$S C$ & S. $F \infty . D o S u$ & Vega Sul & 11567.0 & 3096.6 & $26.8 \%$ & 5783.5 & 632 & $12 \%$ & 20 & 1.87 & 0.03094 & 32 & 5783.5 \\
\hline $\mathrm{SP}$ & Jacarel & Votorantin Celulose & 14426.4 & 43233 & $30.0 \%$ & 7120.7 & 130.4 & $1.8 \%$ & 20 & 1.67 & 0.04783 & 21 & 72132 \\
\hline RS & P. Alege & Asrop. Sa'gado Fitho & 149221 & 4634.8 & $31.1 \%$ & 7461.1 & 84.3 & $1.1 \%$ & 20 & 1.61 & 0.05375 & 19 & 7461.1 \\
\hline RS & P. A'ege & av. Sertónio, 4223 & 11677.9 & 4114.8 & $352 \%$ & 5839.0 & 79.6 & $1.4 \%$ & 20 & 1.42 & 0.07759 & 13 & 5939.0 \\
\hline PR & SJ Pinhais & Fca da AUDI & 13287.1 & 6023.8 & $45.4 \%$ & 6643.5 & 71.0 & $1.1 \%$ & 20 & 1.10 & 0.13525 & 7 & 6543.5 \\
\hline MG & Corlagem & R Zeze C X AV. E Pacelii & 14709.6 & 7133.1 & $435 \%$ & 7354.8 & 00 & $00 \%$ & 20 & 1.03 & 0.15125 & 7 & 7354.8 \\
\hline
\end{tabular}

Tabela 8.1.34. Resultados de todas as Análises 3.

\begin{tabular}{|c|c|c|c|c|c|c|c|c|c|c|c|c|c|}
\hline \multicolumn{3}{|c|}{ Localizaçāo } & \multicolumn{3}{|c|}{ Resitandoia } & \multicolumn{3}{|c|}{ Saloteçăa } & \multirow{2}{*}{ cs } & \multirow{2}{*}{$B$} & \multirow{2}{*}{ A } & \multirow{2}{*}{$1 / \mathrm{Pr}$} & \multirow{2}{*}{$\begin{array}{l}P_{\text {adm }} \\
\text { (kPa) }\end{array}$} \\
\hline Estado & Bairrocidade & Endereso & Meda $(\mathrm{kPa})$ & Desvio $(\mathrm{kPa})$ & CV(\%) & Noda $(\mathrm{kPa})$ & Desvio $(\mathrm{kPa})$ & $C V(\%)$ & & & & & \\
\hline RJ & Jacarepaguśs & Batan ind cosm. & 115262 & 1517.7 & $132 \%$ & 6793.4 & 2045 & $30 \%$ & 1.7 & 309 & 0.00100 & 1000 & 6793.4 \\
\hline MG & B. Horizorte & Anel Rod, $\mathrm{kn} 23$ & 94727 & 1626.0 & $17.2 \%$ & 4444.4 & 57.9 & $1.3 \%$ & 21 & 3.09 & 0.00100 & 1000 & 4444.4 \\
\hline $\mathrm{sP}$ & Quaruhos & r. Benjarnim Humigut & 135523 & 2363.4 & $17.5 \%$ & 62328 & 0.0 & $0.0 \%$ & 22 & 309 & 0.00100 & 1000 & 62328 \\
\hline MG & B. Horizonte & Av. Femig & 6300.1 & 1318.9 & $209 \%$ & 2224.1 & 00 & $0.0 \%$ & 28 & 309 & 0.00100 & 1000 & 2224.1 \\
\hline ES & Areoruz & Arecruz Celulase & 10427.7 & 2403.9 & $23.1 \%$ & 2981.4 & 520 & $1.7 \%$ & 35 & 309 & 0.00100 & 1000 & 2931.4 \\
\hline SP & Imirim & r. José Fig Ssias & 10116.0 & 2619.9 & $25.9 \%$ & 2019.4 & 0.0 & $0.0 \%$ & 50 & 309 & 0.00100 & 1000 & 2019.4 \\
\hline BA & Cemaçari & Fca. Ford & 141185 & 3769.1 & $26.7 \%$ & 2470.1 & 23.4 & $12 \%$ & 5.7 & 3.09 & 0.00100 & 1000 & 2470.1 \\
\hline$S C$ & S. FCo. DoSOI & Vega Q I I & 11567.0 & 3096.6 & $26.8 \%$ & 1956.9 & 235 & $12 \%$ & 5.8 & 309 & 0.00100 & 1000 & 19569 \\
\hline SP & Jacerei & Vodorentin Celúose & 14426.4 & 4323.3 & $30.0 \%$ & 10502 & 192 & $1.8 \%$ & 13.7 & 309 & 0.00100 & 1000 & 10502 \\
\hline RS & P. Alege & Arrop. Sa'gado Fino & 149221 & 4634.8 & $31.1 \%$ & 5938 & 68 & $1.1 \%$ & 24.9 & 309 & 0.00100 & 1000 & 5938 \\
\hline RS & P. Alegre & av. Sertório, 4224 & 11677.9 & 4114.8 & $352 \%$ & -1038.7 & 142 & $-1.4 \%$ & -11.2 & 309 & 0.00100 & 1000 & -1033.7 \\
\hline$P R$ & SJ Prnha's & Fca da AUDI & 13287.1 & 6023.8 & $45.4 \%$ & -5345.1 & 57.1 & $-1.1 \%$ & -25 & 309 & 0.00100 & 1000 & -5345.1 \\
\hline MG & Cortegen & R Zeze C $\times$ Av. E Paceti & 147096 & 7133.1 & $43.5 \%$ & .7334 .5 & 0.0 & $00 \%$ & -20 & 309 & 0.00100 & 1000 & .7334 .5 \\
\hline
\end{tabular}

Apresenta-se na Tabela 8.1.33, para as diversas fundações analisadas, os valores de carga admissível estimados segundo a formulação expressa em norma usando um coeficiente de segurança igual a dois.

Nota-se que somente a fundação localizada em Jacarepaguá/RJ apresentará segurança caso seja projetada com o valor de carga admissível previsto. As demais, apesar de apresentarem um coeficiente de segurança adequado segundo a NBR 6122/1996, não serão seguras caso sejam projetadas com base nos resultados dessas análises. Pois, como se pode observar, os valores das probabilidades de ruína 
resultantes, iriam variar de $1 / 7$ a $1 / 555$, que são considerados elevados quando comparados aos valores sugeridos na literatura técnica.

Quanto à Tabela 8.1.34, esta apresenta os resultados das Análises 3. Apresentase nesta tabela os valores de carga admissível calculados usando a metodologia proposta para uma probabilidade de ruína aceitável (1/1000), e o correspondente coeficiente de segurança associado.

Nota-se que, os valores de coeficiente de segurança resultantes desta análise, são os valores que deveriam ser utilizados na estimativa das cargas admissíveis dessas fundações, para que as mesmas fossem projetadas com segurança.

Deve-se destacar ainda que, para as três fundações cujos resultados se encontram no final da tabela, o elevado valor de coeficiente de variação por elas apresentadas, não permite que as mesmas sejam projetadas com uma probabilidade de ruína de 1/1000. Motivo pelo qual os valores de coeficiente de segurança e de carga admissível resultantes são negativos.

Comparando os valores de carga admissíveis estimados pelas duas metodologias (Análise 2 e 3), pode-se observar que, em geral, com exceção da fundação executada em Jacarepaguá/RJ, o valor de carga admissível estimado segundo a norma, para as fundações analisadas, conduziu a um índice de confiabilidade inferior a três, ou seja, a uma probabilidade de ruína superior à adequada (1/1000).

Ao final destas análises, percebe-se a grande vantagem de se utilizar à metodologia proposta na garantia da segurança e da confiabilidade de uma fundação. Pois, a carga admissível calculada por essa formulação permite que se conheça a probabilidade de ruína da fundação e, conseqüentemente, torna-se possível calcular uma fundação que seja ao mesmo tempo segura e econômica. 


\subsection{Fundação em estacas pré-moldadas cravadas na Formação Guabirotuba}

Neste item, encontram-se os resultados da análise realizada com os dados publicados por Vianna (2000) na qual consta a análise de uma fundação composta por 34 estacas pré-moldadas de concreto, de diversos diâmetros, cravadas em solos problemáticos da Formação Guabirotuba na cidade de Curitiba e região metropolitana, Paraná.

Inicialmente, apresentam-se as resistências estimadas para os elementos isolados de fundação utilizando quatro métodos de previsão de capacidade de carga baseados nos resultados de ensaios in situ SPT realizados no local da obra e o resultado das provas de carga estática à compressão realizadas nos mesmos. Posteriormente, apresenta-se o resultado do cálculo da carga admissível do estaqueamento usando a formulação da norma e a formulação proposta nesta dissertação e as suas implicações com relação à segurança e a confiabilidade da fundação analisada.

\subsubsection{Análise dos dados}

Este sub-item apresenta a análise dos dados publicados: resultados das provas de carga estática, resultados das sondagens realizadas e as previsões de capacidade de carga para as 34 estacas que compõem a fundação em estudo.

Dentre os inúmeros métodos existentes para previsão da resistência de um elemento isolado de fundação, foram escolhidos para análise os métodos semiempíricos propostos por Aoki-Velloso (1975), Aoki-Velloso modificado para estacas de pequeno diâmetro (1985), Décourt-Quaresma (1978) e Amaral (1982, 1999). Segundo Vianna (2000), os três primeiros foram escolhidos por serem amplamente utilizados no Brasil e o último, por ter sido desenvolvido especialmente para estacas cravadas na Formação Guabirotuba.

A Formação Guabirotuba é uma formação sedimentar onde as argilas são os componentes litológicos mais abundantes. O solo desta formação é constituído, basicamente, por uma argila siltosa, rija e acinzentada, cuja natureza mineralógica é mista: esmectita, ilita e caulinita. A análise granulométrica deste solo indica em termos percentuais: $67 \%$ de argila, $30 \%$ de silte e $3 \%$ de areia. Trata-se de um solo altamente plástico e de elevada expansibilidade, devido tanto à presença de argilo minerais quanto ao fato de ser pré-adensado (VIANNA, 2000). 
Com o intuito de descrever a variabilidade geológica-geotécnica do maciço de solos local foram realizadas 34 sondagens à percussão SPT. Os valores de $\mathrm{N}_{\text {SPT }}$ encontrados foram publicados por Vianna (2000). Esses valores, assim como os valores mínimos, médios e máximos de $\mathrm{N}_{\mathrm{SPT}}$ para cada profundidade se encontram na Tabela 1 do Apêndice B. Com esses valores foram elaborados os gráficos das Figuras 1, 2 e 3 do Apêndice $B$, que apresentam a variação do índice de resistência à penetração $N_{S P T}$ ao longo da profundidade.

A Figura 2 do Apêndice B apresenta as curvas representativas do $\mathrm{N}_{\mathrm{SPT}}$ mínimo, médio e máximo e, a Figura 3 do Apêndice B apresenta o coeficiente de variação do $\mathrm{N}_{\text {SPT }}$ ao longo da profundidade, ambas considerando as 34 sondagens realizadas.

Os valores mínimos, médios e máximos para as 34 sondagens realizadas justificam os elevados valores dos coeficientes de variação encontrados. Observando a curva representativa dos valores de $\mathrm{N}_{\mathrm{SPT}}$ médio apresentada na Figura 2 e a Tabela 1 do Apêndice B percebe-se que até a profundidade de $10 \mathrm{~m}$ o $\mathrm{N}_{\text {SPT }}$ médio variou de 5 a 10 , que de 10 a $22 \mathrm{~m}$ o $\mathrm{N}_{\mathrm{SPT}}$ médio variou de 11 a 29 e, que a partir dos $22 \mathrm{~m}$ de profundidade este variou de 25 a 50 . A observação da Figura 3 e da Tabela 1 do Apêndice B pode-se notar que o coeficiente de variação do $\mathrm{N}_{\mathrm{SPT}}$ foi, em média igual a $52 \%$, variando de $42 \%$ (coeficiente de variação mínimo) a 109\% (coeficiente de variação máximo).

A partir dos valores de $\mathrm{N}_{\text {SPT }}$ obtidos por meio das sondagens realizadas foram estimadas as resistências dos 34 elementos isolados de fundação utilizando os 4 métodos de previsão de capacidade de carga anteriormente citados. A Tabela 2 do Apêndice B apresenta os valores das resistências previstas pelos métodos utilizados e das resistências medidas em prova de carga estática publicados por VIANNA (2000). Apresenta-se, também, nesta mesma tabela, as dimensões de cada um dos 34 elementos estruturais de fundação, ou seja, o comprimento, o diâmetro e a área da seção transversal correspondente.

Convém observar que não foi possível reconstituir as curvas carga $\mathrm{x}$ recalque, por não terem sido publicados os resultados das provas de carga estática realizadas, ou melhor, os pontos das curvas carga $x$ recalque obtidos. No entanto, os gráficos com as curvas carga $\mathrm{x}$ recalque das 34 estacas ensaiadas podem ser visualizadas em VIANNA (2000), assim como o perfil estratigráfico obtido nas 34 sondagens realizadas.

No entanto, deve-se observar que das 34 provas de carga estática utilizadas nesta análise, 30 não atingiram à ruptura. Somente as estacas de número $5,11,21$ e 30 foram 
levadas à ruptura (Tabela 3 do Apêndice B). Sendo assim, fez-se necessário, para as demais estacas, extrapolar as curvas carga x recalque para a obtenção dos valores de carga de ruptura do sistema.

Essa extrapolação foi realizada utilizando o Método de Van der Veen (1953) que propõe uma expressão para representar a curva carga $\mathrm{x}$ recalque, permitindo assim, realizar a sua extrapolação. O procedimento de se extrapolar a curva carga x recalque obtida do ensaio para se determinar à carga de ruptura, quando esta não indicar uma ruptura nítida, é legitimado pela NBR 6122/96 (item 7.2.2.3).

A Tabela 4 do Apêndice B apresenta quais as estacas cujas provas de carga foram conduzidas até a ruptura e quais as estacas que tiveram as suas provas de carga extrapoladas, e dessas últimas, quais as que podem ser extrapoladas pelo método de Van der Veen (Tabela 5 do Apêndice B) e quais não podem (Tabela 6 do Apêndice B) segundo o critério proposto em Vianna (2000).

Vianna (2000) com base nas 4 provas de carga estática citadas anteriormente, que foram conduzidas até a ruptura, estudou a aplicabilidade do método de Van der Veen e elaborou um critério para avaliar a qualidade da extrapolação da curva carga $x$ recalque dos ensaios encerrados antes de se atingir à ruptura. Esse critério propõe que: uma variação de no máximo $10 \%$ em módulo nos valores de carga última de Van der Veen obtidos a partir de dois estágios consecutivos da prova de carga garante um erro de no máximo $11 \%$ em módulo em relação ao valor experimental da carga de ruptura. No entanto, quando essa variação é superior a $10 \%$ em módulo, o método de Van der Veen não garante uma boa extrapolação e, sendo assim, não é recomendável utiliza-lo. Estes casos ocorrem quando as provas de carga deveriam ter continuado pelo menos por mais um estágio de carga, ou quando o modelo proposto por Van der Veen não é aplicável.

Segundo este critério, do total das 34 estacas (Tabela 4 do Apêndice B), apenas as estacas que romperam e as estacas em que o método de Van der Veen garante uma boa extrapolação devem ser utilizadas nas análises (Tabela 7 do Apêndice B). Dessas estacas, optou-se por utilizar somente as estacas com $0.25 \mathrm{~m}$ de diâmetro por serem uma das que possuem o maior número de provas de carga que podem ser utilizadas (sub-item 8.2.2.2). No entanto, com o intuito de aproveitar a totalidade dos dados disponíveis, também será realizada uma análise considerando todas as provas de carga executadas (sub-item 8.2.2.1). 
A Tabela 8 do Apêndice B apresenta a média, o desvio padrão e o coeficiente de variação obtidos a partir dos valores de resistências resultantes dos 4 métodos de previsão e dos valores de resistências medidos nas provas de carga estática para cada uma das 34 estacas analisadas. Através da observação dessa tabela percebe-se que o coeficiente de variação foi em média igual a $31 \%$ e que, o coeficiente de variação mínimo foi de $9 \%$ para a estaca 33 e o máximo de $54 \%$ para a estaca 01 .

Com a finalidade de comparar as resistências previstas (métodos de cálculo) com as resistências reais (medidas em provas de carga), define-se a variável $\mathrm{K}$ como sendo a variável obtida pela relação entre a resistência prevista por um determinado método de cálculo de capacidade de carga e a resistência real medida através de prova de carga estática ou dinâmica, ou seja:

$$
K=\frac{R_{\text {prevista }}}{R_{\text {real }}}
$$

Neste contexto, têm-se as seguintes variáveis:

- $K_{1}$ : Resistência prevista pelo Método Aoki-Velloso (1975),

- $K_{2}$ : Resistência prevista pelo Método Aoki-Velloso Modificado (1985),

- $K_{3}$ : Resistência prevista pelo Método Décourt-Quaresma (1978) e,

- $K_{4}$ : Resistência prevista pelo Método Amaral (1982, 1999).

A Tabela 9 do Apêndice B apresenta os valores das variáveis $K_{1}, K_{2}, K_{3}$ e $K_{4}$ obtidos para todas as estacas, juntamente com os valores médios, de desvio padrão e de coeficiente de variação de cada uma delas. As estatísticas das variáveis $\mathrm{K}$ estão também apresentadas nas Tabelas 10,11, 12 e 13 do Apêndice B e se encontram resumidas na Tabela 8.2.1 abaixo.

Tabela 8.2.1. Estatísticas das variáveis $\mathrm{K}$.

\begin{tabular}{|c|c|c|c|c|c|}
\hline Variável K & Média & Desvio & CV (\%) & $\mathrm{M}+\mathrm{D}$ & $\mathrm{M}-\mathrm{D}$ \\
\hline $\mathrm{K}_{1}=$ Aoki-Velloso / P.C. & 0.6 & 0.2 & $41.1 \%$ & 0.8 & 0.4 \\
\hline $\mathrm{K}_{2}=$ Aoki-Velloso modif. $/$ P.C. & 0.8 & 0.3 & $40.0 \%$ & 1.1 & 0.5 \\
\hline $\mathrm{K}_{3}=$ Décourt-Quaresma / P.C. & 0.9 & 0.2 & $27.5 \%$ & 1.1 & 0.6 \\
\hline $\mathrm{K}_{4}=$ Amaral/P.C. & 1.2 & 0.3 & $23.1 \%$ & 1.5 & 0.9 \\
\hline Média & 0.9 & 0.3 & $29.6 \%$ & 1.1 & 0.6 \\
\hline
\end{tabular}

Observando a Tabela 8.2.1 e as Tabelas 9, 10, 11, 12 e 13 do Apêndice B, percebe-se que o valor médio da variável $\mathrm{K}$ foi de 0.9 e o seu coeficiente de variação foi de, aproximadamente, $30.0 \%$. 
A partir dos valores das variáveis $K_{1}, K_{2}, K_{3}$ e $K_{4}$ foram elaborados os gráficos das Figuras 5, 7, 9 e 11 do Apêndice B. A partir desses gráficos é possível visualizar como é a distribuição de cada uma das variáveis em torno do valor ideal, ou seja, em torno de $\mathrm{K}=1$.

No Apêndice B também se encontram os gráficos de dispersão das resistências previstas e medidas para cada um dos 4 métodos utilizados na estimativa da capacidade de carga das 34 estacas (Figura 4, 6, 8 e 10 do Apêndice B). Observando esses gráficos é possível ter uma noção qualitativa da capacidade de previsão do método. Os pontos situados abaixo da reta $(\mathrm{K}=1)$ representam as estacas cuja capacidade de carga prevista foi inferior a sua capacidade de carga real medida em prova de carga. Do mesmo modo, os pontos situados acima da reta representam as estacas cuja capacidade de carga prevista foi superior à real, medida em prova de carga.

No entanto, ao invés de se trabalhar com as variáveis $\mathrm{K}$ pode-se fazer o estudo em termos de tensões resistentes, que podem ser definidas como o valor da resistência última dividida pela área da seção transversal do fuste da estaca. Pois, devido às estacas serem de diferentes diâmetros, as resistências devem ser analisadas em termos de tensões resistentes, para que seja possível analisar todas as estacas em conjunto.

A Tabela 14 do Apêndice B apresenta as tensões resistentes calculadas, assim como os valores de resistência média, de desvio padrão e de coeficiente de variação das resistências previstas pelos 4 métodos de cálculo utilizados neste trabalho e medidas nas 34 provas de carga realizadas. Esses valores também se encontram resumidos na Tabela 15 do Apêndice B e na Tabela 8.2.2 abaixo.

Tabela 8.2.2. Estatísticas das tensões resistentes considerando todas as estacas.

\begin{tabular}{|c|c|c|c|c|c|c|c|c|}
\hline \multirow{2}{*}{ Métodos } & \multirow{2}{*}{$\begin{array}{l}\mathrm{L} \\
\text { (m) }\end{array}$} & \multirow{2}{*}{$\begin{array}{l}\text { D } \\
\text { (m) }\end{array}$} & \multirow{2}{*}{$\begin{array}{l}\text { Área } \\
\left(\mathrm{m}^{2}\right)\end{array}$} & \multicolumn{4}{|c|}{ Resistências Previstas (kPa) } & \multirow{2}{*}{$\frac{\text { Resistência Medida (KPa) }}{\text { Prova de Carga }}$} \\
\hline & & & & Aoki-Velloso & Aoki-Velloso Modif. & Décourt-Quaresma & Amaral & \\
\hline Média & 128 & 0.25 & 0.052 & 6663.9 & 8751.5 & 97628 & 13346.2 & 11483.1 \\
\hline Desvio & 1.9 & 0.06 & 0.027 & 2397.1 & 3332.3 & 2739.3 & 3144.6 & 2249.6 \\
\hline$M+D$ & 14.7 & 0.31 & 0.080 & 9061.1 & 12083.8 & 12502.1 & 16490.8 & 13732.7 \\
\hline$M-D$ & 10.9 & 0.19 & 0.025 & 4206.8 & 54192 & 7023.4 & 10201.5 & 9233.5 \\
\hline $\operatorname{cv}(\%)$ & $15 \%$ & $25 \%$ & $52 \%$ & $36.0 \%$ & $38.1 \%$ & $28.1 \%$ & $23.6 \%$ & $19.6 \%$ \\
\hline
\end{tabular}

Analisando a Tabela 8.2.2 quanto aos valores médios, nota-se que os métodos de previsão de resistência Aoki-Velloso (1975), Aoki-Velloso modificado e DécourtQuaresma (1978) se mostraram conservadores, subestimando o valor médio da resistência real em $42 \%, 23 \%$ e $15 \%$, respectivamente. Com relação o método proposto 
por Amaral (1982, 1999), nota-se que este, ao contrário dos anteriores, superestimou o valor da resistência em $16 \%$. Logo, este método deve ser usado com cautela, pois, pode ser contrário à segurança.

Quanto ao coeficiente de variação, observa-se que nenhum método conseguiu refletir a real variabilidade do sistema, pois a variabilidade prevista em todos os métodos utilizados foi maior do que a variabilidade real. No entanto, de todos os coeficientes de variação, o estimado pelo método Amaral $(1982,1999)$ foi o que mais se aproximou do obtido em prova de carga. Isso pode ter ocorrido devido a esse método ter sido desenvolvido particularmente para esta formação geológica.

Geralmente, os métodos semi-empíricos de previsão da resistência última de um elemento isolado de fundação, utilizados nos projetos de fundações por estacas, foram desenvolvidos médiante retro-análises de diversas provas de carga executadas em maciços de solos de diferentes formações geológicas. Os métodos Aoki-Velloso (1975) e Décourt-Quaresma (1978) são amplamente utilizados em todo território brasileiro, entretanto, a experiência tem demonstrado que, em alguns casos, o uso destes métodos não é indicado, pois, algumas formações geológicas apresentam comportamento diferente do previsto por estes métodos. Conclui-se assim que, estes métodos não incluem o fator formação geológica local, como o método de Amaral (1982, 1999), sendo este o motivo da baixa precisão dos mesmos.

Amaral (1982) apresenta um método semi-empírico para a determinação da capacidade de carga de estacas pré-moldadas de pequenas dimensões $(\mathrm{D}<0.4 \mathrm{~m}) \mathrm{em}$ solos argilosos (argila siltosa) a partir de dados de sondagem à percusão (SPT). A análise de 22 provas de carga indicou que a relação entre a carga de ruptura medida e a calculada variou entre 0.55 a 1.42 . As extrapolações das cargas de ruptura foram obtidas pela expressão de Van der Veen.

Sabe-se que o comportamento de um elemento isolado de fundação depende, essencialmente, da geometria, da disposição e da reologia dos materiais constituintes do sistema (maciço de solos e elemento estrutural de fundação). No entanto, em algumas formações geológicas, devido à sua gênese, a perturbação causada pelo processo executivo da fundação pode provocar a destruição da estrutura do maciço de solos (um dos materiais constituintes do sistema) conduzindo à diminuição da sua variabilidade e de sua resistência original, modificando o comportamento do sistema (fundação). Esses solos, em geral, por serem de formação complexa, possuem estrutura e resistência muito variáveis ao longo da profundidade. Esta variabilidade é, usualmente, identificada pelo 
alto valor do coeficiente de variação dos resultados de ensaios in situ como SPT, CPT, etc. Como exemplo, observe as Figuras 1, 2 e 3 do Apêndice B.

Como os métodos semi-empíricos utilizados baseiam-se nesses ensaios, a variabilidade das resistências previstas por esses métodos deve estar diretamente relacionada com estes diagramas. Mas, comparando os coeficientes de variação das resistências previstas com o coeficiente de variação das provas de carga realizadas, observa-se que a Formação Guabirotuba é extremamente susceptível ao processo de execução por cravação, por este ter influenciado de modo decisivo o comportamento do sistema estaca-solo.

Considerando que a segurança de uma fundação depende do coeficiente de variação das resistências de seus elementos isolados, conclui-se que, se o método de cálculo, utilizado na estimativa da resistência dos elementos isolados de fundação, não levar em consideração a modificação das propriedades originais do maciço de solos devido aos efeitos de instalação dos elementos estruturais de fundação, ele poderá apresentar graves falhas na previsão do comportamento da mesma, de forma a comprometer a sua segurança. Nestes casos, tais métodos de cálculo não devem ser utilizados em sua forma original, necessitando ser ajustados à formação geológica em estudo e, ao processo de execução do estaqueamento que modifica, em maior ou menor intensidade, as propriedades do solo natural.

Com relação a este exemplo, pode-se perceber que os coeficientes de variação das resistências estimadas através do uso dos métodos de previsão de capacidade de carga (sistema) refletem a variabilidade dos dados de origem (material) representada através dos coeficientes de variação dos resultados dos ensaios in situ realizados (SPT). No entanto, a variabilidade real do sistema medida (representada pelo coeficiente de variação dos resultados das provas de carga estática realizadas) foi muito menor (inferior) que a variabilidade real do material (representada pelo coeficiente de variação dos resultados dos ensaios in situ SPT realizados). O que permite concluir que, em geral, os métodos semi-empíricos abordados não modelaram o processo de destruição (homogeneização) do material (maciço de solo) causado pela cravação das estacas (interferência do processo executivo). Pois, ao ser destruída a estrutura do material o comportamento do sistema tornou-se mais homogêneo, fato confirmado pelo coeficiente de variação das provas de carga.

Neste contexto, é possível perceber se um método de previsão é ou não "confiável", ou seja, se ele é ou não capaz de prever o comportamento do sistema. Para 
isso deve-se: a) verificar a variabilidade intrínseca do material; b) verificar a variabilidade real do sistema por meio de provas de carga e, c) comparar as duas variabilidades (coeficiente de variação). O método de cálculo (previsão) somente será seguro, quando não somente os valores médios previstos e medidos coincidirem, mas também quando o coeficiente de variação previsto for igual ao coeficiente de variação medido. Pois, quando é previsto um coeficiente de variação inferior ao real, corre-se o risco de se projetar uma fundação sem segurança, ou melhor dizendo, com uma elevada probabilidade de ruína.

\subsubsection{Análise de Segurança e Confiabilidade}

Neste item, será realizada a estimativa da carga admissível do estaqueamento usando a formulação da norma e a formulação proposta nessa dissertação usando os valores de resistências previstas e medidas pelas provas de carga.

As provas de carga que não apresentaram ruptura nítida, foram extrapoladas através da utilização do Método de Van der Veen (1953) e, os resultados dessas extrapolações foram limitados à resistência estrutural das estacas.

Com relação ao cálculo da resistência estrutural das estacas, a NBR 6122/96 no item 7.8.3.6.2 recomenda que "nas estacas comprimidas, quando é feita a verificação da capacidade de carga através de prova de carga ou de instrumentação, a carga de trabalho máxima é aquela calculada como peça estrutural de concreto armado ou protendido, restringido-se a $35 \mathrm{MPa}$ a resistência característica do concreto."

Neste contexto, o cálculo da resistência estrutural das estacas foi realizado adotando-se um coeficiente de variação de $10 \%$ para os valores de resistência do concreto, por se tratar de estacas pré-moldadas, e o valor de $35 \mathrm{MPa}$ para a resistência característica do concreto como recomendado em norma.

Com relação às cargas nominais das estacas, estas foram calculadas em função da seção transversal e da tensão média do fuste, que em se tratando de estacas do tipo pré-moldada centrifugada, deve variar de 9 a $11 \mathrm{MPa}$ (Cintra \& Aoki,1999). As cargas nominais adotadas nesta análise foram calculadas usando a tensão média de $9 \mathrm{MPa}$ e, os valores encontrados, assim como os correspondentes diâmetros das estacas, estão apresentados na Tabela 16 do Apêndice B.

Com os valores de carga nominais adotados foram estimadas as tensões solicitações atuantes em cada uma das estacas. As tensões solicitações encontradas 
apresentaram uma média igual a $8064.2 \mathrm{kPa}$ e um coeficiente de variação de $2.5 \%$. Todos esses valores encontram-se na Tabela 17 do Apêndice B.

\subsubsection{Análise de todas as estacas em termos de tensões}

Com as estatísticas dos valores de tensões resistentes e solicitantes apresentados na Tabela 8.2.2 (Tabela 14 e 17 do Apêndice B) foram realizadas as análises apresentadas nas Figuras 12 a 26 do Apêndice B. Os resultados encontrados, assim como, os comentários relativos a esses resultados, estão apresentados na seqüência.

As Figuras 12, 13 e 14 do Apêndice B apresentam as análises realizadas com as estatísticas dos valores de tensões resistentes previstas pelo Método Aoki-Velloso considerando todas as estacas. O resumo dessas análises está apresentado na Tabela 8.2 .3 abaixo.

Tabela 8.2.3. Resultados das análises realizadas - Método Aoki-Velloso para todas as estacas.

\begin{tabular}{|c|c|c|c|c|c|c|c|c|c|c|c|}
\hline \multirow{2}{*}{ Anáíses } & \multicolumn{3}{|c|}{ Resisténcia } & \multicolumn{3}{|c|}{ Solictay̧a } & \multirow{2}{*}{ cs } & \multirow{2}{*}{$\beta$} & \multirow{2}{*}{ Pr } & \multirow{2}{*}{$1 / \mathrm{Pr}$} & \multirow{2}{*}{$\begin{array}{l}P_{\text {axm }} \\
\text { (KPa) }\end{array}$} \\
\hline & Méda (KPa) & Desvio $(k \mathrm{~Pa})$ & CV (\%) & Néda (KPa) & Desvio (KPa) & CV (\%) & & & & & \\
\hline Anáise 1 & 6663.9 & 2397.1 & $36.0 \%$ & 80642 & 204.4 & $25 \%$ & 0.8 & .0 .58 & 0.71973 & 1 & 80642 \\
\hline Análise 2 & 6003.9 & 2397.1 & $36.0 \%$ & 33320 & 84.5 & $25 \%$ & 20 & 1.39 & 0.03240 & 12 & 33320 \\
\hline Anä́se 3 & 6603.9 & 2397.1 & $36.0 \%$ & .744 .3 & 188 & $-25 \%$ & -9.0 & 3.09 & 0.00100 & 1000 & -744.3 \\
\hline
\end{tabular}

Os resultados das análises (Análises 1, 2 e 3) mostram que se o estaqueamento for projetado utilizando as previsões do Método Aoki-Velloso e com:

$\checkmark$ as estatísticas das solicitações calculadas em função das cargas nominais das estacas (Análise 1), este irá apresentar um $\mathrm{CS}=0.8$ e a probabilidade de ruína será de $1 / 1$, ou seja, todas as estacas poderão vir a falhar.

$\checkmark$ a carga admissível da norma com um $\mathrm{CS}=2.0$ (Análise 2), este terá um $\beta=1.39$ que corresponde a uma probabilidade de ruína de $1 / 12$.

$\checkmark$ uma probabilidade de ruína de $1 / 1000$, ou seja, $\operatorname{com} \beta=3.09$ (Análise 3) este não poderá ser dimensionado, pois o elevado valor do coeficiente de variação das tensões resistentes (36.0\%) não permite que a fundação seja projetada com a probabilidade de ruína estipulada.

As Figuras 15, 16 e 17 do Apêndice B apresentam as análises realizadas com as resistências previstas pelo Método Aoki-Velloso modificado. O resumo dessas análises encontra-se na Tabela 8.2.4. 
Tabela 8.2.4. Resultados das análises realizadas - Método Aoki-Velloso modificado para todas as estacas.

\begin{tabular}{|c|c|c|c|c|c|c|c|c|c|c|c|}
\hline \multirow{2}{*}{ Anấises } & \multicolumn{3}{|c|}{ Resistència } & \multicolumn{3}{|c|}{ Salcictaşäo } & \multirow{2}{*}{ cs } & \multirow{2}{*}{$\beta$} & \multirow{2}{*}{$\mathrm{Pr}$} & \multirow{2}{*}{$1 / \mathrm{Pr}$} & \multirow{2}{*}{$\begin{array}{l}\text { PaIm } \\
\text { (kPa) }\end{array}$} \\
\hline & Média (KPa) & Desvio (KPa) & CV(\%) & Méda $(\mathrm{KPa})$ & Desvio $(\mathrm{kPa})$ & $\mathrm{CV}(\%)$ & & & & & \\
\hline Anà'se 1 & 8751.5 & 33323 & $38.1 \%$ & 80642 & 204.4 & $25 \%$ & 1.1 & 021 & 0.41844 & 2 & 80642 \\
\hline Anälse 2 & 8751.5 & 33323 & $38.1 \%$ & 4375.8 & 110.9 & $25 \%$ & 20 & 1.31 & 0.09409 & 11 & 4375.8 \\
\hline Anál'se 3 & 8751.5 & 33323 & $38.1 \%$ & -1547.2 & 392 & $-25 \%$ & -5.7 & 3.09 & 0.00100 & 1000 & -1547.2 \\
\hline
\end{tabular}

Utilizando as previsões do Método Aoki-Velloso modificado, os resultados das análises (Análises 1, 2 e 3) apresentadas na Tabela 8.2.4 mostram que:

$\checkmark$ a Análise 1 resultou num CS $=1.1$ e numa probabilidade de ruína de $1 / 2$.

$\checkmark$ se for utilizada a carga admissível da norma com um CS $=2.0$ (Análise 2), a fundação terá um $\beta=1.31$ correspondente a uma probabilidade de ruína de $1 / 11$.

$\checkmark$ o elevado valor do coeficiente de variação das tensões resistentes (38.1\%) impossibilita o dimensionamento da fundação com uma probabilidade de ruína de $1 / 1000$, ou seja, usando $\beta=3.09$ (Análise 3).

As análises realizadas com as resistências previstas pelo Método DécourtQuaresma estão apresentadas nas Figuras 18, 19 e 20 do Apêndice B e o resumo dessas análises na Tabela 8.2.5 abaixo.

Tabela 8.2.5. Resultados das análises realizadas - Método Décourt-Quaresma para todas as estacas.

\begin{tabular}{|c|c|c|c|c|c|c|c|c|c|c|c|}
\hline \multirow{2}{*}{ Análises } & \multicolumn{3}{|c|}{ Resisténcia } & \multicolumn{3}{|c|}{ Solicitaçäo } & \multirow{2}{*}{ cs } & \multirow{2}{*}{$\beta$} & \multirow{2}{*}{ Pr } & \multirow{2}{*}{$1 / \mathrm{Pr}$} & \multirow{2}{*}{$\begin{array}{l}\text { Palm } \\
(\mathrm{NPa})\end{array}$} \\
\hline & Méda $\left(\mathrm{AP}_{2}\right)$ & Desvio (KPa) & $\mathrm{CV}(\%)$ & Méda (KPa) & Desvio (KPa) & $\mathrm{CV}(\%)$ & & & & & \\
\hline Anấ'se 1 & 97628 & 2739.3 & $28.1 \%$ & 80642 & 204.4 & $25 \%$ & 1.2 & 0.62 & 026817 & 4 & 80642 \\
\hline Anä'se 2 & 97628 & 2739.3 & $28.1 \%$ & 4881.4 & 123.7 & $25 \%$ & 20 & 1.78 & 0.03753 & 27 & 4881.4 \\
\hline Análise 3 & 97628 & 2739.3 & $28.1 \%$ & 1296.5 & 329 & $25 \%$ & 7.5 & 300 & 0.00100 & 1000 & 1296.5 \\
\hline
\end{tabular}

A observação da Tabela 8.2 .5 permite concluir que:

$\checkmark$ a Análise 1 resultou num $\mathrm{CS}=1.2$ e numa probabilidade de ruína de 1/4.

$\checkmark$ utilizando a carga admissível da norma com um CS $=2.0$ (Análise 2), a fundação terá um $\beta=1.79$ e uma probabilidade de ruína de 1/27.

$\checkmark$ para que a fundação seja projetada com uma probabilidade de ruína aceitável de $1 / 1000$, ou seja, com um $\beta=3.09$ (Análise 3) esta deverá ser dimensionada com uma carga admissível de $1296.5 \mathrm{kPa}$ que equivale a utilizar a formulação da norma com um $\mathrm{CS}=7.5$.

As Figuras 21, 22 e 23 do Apêndice B apresentam as análises realizadas com as resistências previstas pelo Método Amaral. O resumo dessas análises pode ser observado na Tabela 8.2.6. 
Tabela 8.2.6. Resultados das análises realizadas - Método Amaral para todas as estacas.

\begin{tabular}{|c|c|c|c|c|c|c|c|c|c|c|c|}
\hline \multirow{2}{*}{ Anấises } & \multicolumn{3}{|c|}{ Resistència } & \multicolumn{3}{|c|}{ Saicitaçăo } & \multirow{2}{*}{ cs } & \multirow{2}{*}{$\beta$} & \multirow{2}{*}{ Pr } & \multirow{2}{*}{$1 / \mathrm{Pr}$} & \multirow{2}{*}{$\begin{array}{l}\text { Parm } \\
\text { (kPa) }\end{array}$} \\
\hline & Mèća (kPa) & Desvio (kPa) & CV (\%) & Média (kPa) & Deswio (kPa) & $\mathrm{CV}(\%)$ & & & & & \\
\hline Anäl'se 1 & 133462 & 31446 & $23.6 \%$ & 80642 & 204.4 & $25 \%$ & 1.7 & 1.68 & 0.04685 & 21 & 80642 \\
\hline Anál'se 2 & 133462 & 3144.6 & $23.6 \%$ & 6673.1 & 169.1 & $25 \%$ & 20 & 212 & 0.01704 & 59 & 6673.1 \\
\hline Análise 3 & 133462 & 3144.6 & $23.6 \%$ & 3623.9 & 91.8 & $25 \%$ & 3.7 & 3.09 & 0.00100 & 1000 & 3623.9 \\
\hline
\end{tabular}

A partir dos resultados das análises apresentados na Tabela 8.2.6 (Análises 1, $2 \mathrm{e}$ 3) pode-se concluir que se o estaqueamento for projetado com as previsões obtidas da utilização do Método Amaral, este:

$\checkmark$ apresentará uma probabilidade de ruína de $1 / 21$ e um CS $=1.7$ se forem utilizadas as estatísticas das solicitações, que foram calculadas em função das cargas nominais das estacas (Análise 1).

$\checkmark$ terá um $\beta=2.12$ correspondente a uma probabilidade de ruína de 1/59 quando da utilização da carga admissível da norma com CS = 2.0 (Análise 2).

$\checkmark$ deverá ser projetado com uma carga admissível de $3623.9 \mathrm{kPa}$ equivalente a um $\mathrm{CS}=3.7$ para que este tenha uma probabilidade de ruína de no máximo 1/1000 (Análise 3).

Finalmente, as Figuras 24, 25 e 26 do Apêndice B apresentam as análises realizadas com os valores de resistência medidos por meio das prova de carga estática executadas. O resumo dessas análises está apresentado na Tabela 8.2.7.

Tabela 8.2.7. Resultados das análises realizadas - Provas de Carga de todas as estacas.

\begin{tabular}{|c|c|c|c|c|c|c|c|c|c|c|c|}
\hline \multirow{2}{*}{ Anáises } & \multicolumn{3}{|c|}{ Resistencia } & \multicolumn{3}{|c|}{ Solictação } & \multirow{2}{*}{ CS } & \multirow{2}{*}{$\beta$} & \multirow{2}{*}{ Pr } & \multirow{2}{*}{$1 / \mathrm{Pr}$} & \multirow{2}{*}{$\begin{array}{l}\text { Poim } \\
(\mathrm{kPa})\end{array}$} \\
\hline & Méda (KPa) & Desvio $(k \mathrm{~Pa})$ & CV (\%) & Méda (kPa) & Desvio $(\mathrm{HPa})$ & CV (\%) & & & & & \\
\hline Aná'se 1 & 11483.1 & 2249.6 & $19.6 \%$ & 80642 & 204.4 & $25 \%$ & 1.4 & 1.51 & 0.06507 & 15 & 8064.2 \\
\hline Anárse 2 & 114831 & 2249.6 & $19.6 \%$ & 5741.6 & 145.5 & $25 \%$ & 20 & 255 & 0,00543 & 184 & 5741.6 \\
\hline Análise 3 & 11483.1 & 2249.6 & $19.6 \%$ & 4521.9 & 114.6 & $25 \%$ & 25 & 3.09 & 0.00100 & 1000 & 4521.9 \\
\hline
\end{tabular}

Observando a Tabela 8.2.7, que apresenta os resultados das análises realizadas com os valores reais de resistência, percebe-se que:

$\checkmark$ se a fundação for projetada utilizando-se as estatísticas das solicitações calculadas em função das cargas nominais das estacas (Análise 1), esta irá apresentar um CS = 1.4 e uma probabilidade de ruína de 1/15.

$\checkmark$ se a fundação for projetada utilizando-se a carga admissível da norma com um $\mathrm{CS}=2.0$ (Análise 2), esta terá um $\beta=2.55$ correspondente a uma probabilidade de ruína de $1 / 184$. 
$\checkmark$ para que a fundação seja projetada com uma probabilidade de ruína aceitável (Análise 3), ou seja, uma probabilidade de ruína de $1 / 1000(\beta=3.09)$ esta deverá ser dimensionada com uma carga admissível de $4521.9 \mathrm{kPa}$ correspondente a um CS $=2.5$.

A Tabela 20 do Apêndice B traz um resumo geral das análises apresentadas. Da observação dessa tabela, é possível traçar os seguintes comentários finais:

$\checkmark$ independente do método de previsão de capacidade de carga utilizado, quando a fundação é projetada com base na adoção das tensões solicitantes oriundas das cargas nominais das estacas (Análise 1), apesar do valor do coeficiente de segurança e do índice de confiabilidade variar (observe as Tabelas 8.2.3 a 8.2.6), a realidade é somente uma e é dada pelos resultados da Análise 1 (coeficiente de segurança, índice de confiabilidade e probabilidade de ruína) apresentados na Tabela 8.2.7 referente às provas de carga.

$\checkmark$ de forma semelhante, quando se projeta uma fundação estabelecendo previamente o valor da probabilidade de ruína desejada, através da adoção de um índice de confiabilidade na formulação proposta (Análise 3), independentemente do método de previsão utilizado, esta será a probabilidade de ruína da fundação, mesmo quando a utilização desses métodos de previsão resulte em coeficientes de segurança e carga admissíveis distintas (compare a os resultados da Análise 3 da Tabela 8.2.7 com os apresentados nas Tabelas 8.2.3 a 8.2.6).

$\checkmark$ já com relação aos resultados das Análises 2, ou seja, quando se utiliza a formulação da norma para o cálculo da carga admissível do estaqueamento, pode-se perceber que a adoção de um coeficiente de segurança igual a dois, além de não ser garantia de segurança, por este ser diretamente relacionado com o valor médio da resistência, este sofre a influência do método de cálculo o que pode resultar na adoção de uma carga admissível superior a que deveria ser adotada na realidade. Como exemplo, observe que a carga admissível prevista quando da utilização do Método Amaral (Análise 2 da Tabela 8.2.6) foi superior à determinada com os valores reais de resistência (Análise 2 da Tabela 8.2.7), devido a este método de cálculo haver superestimado a capacidade de carga da fundação.

Com base neste raciocínio, é possível perceber mais uma vantagem que a formulação proposta apresenta com relação à formulação expressa em norma. 


\subsubsection{Análise das estacas com $D=0.25 m$}

Este sub-item apresenta os resultados das análises realizadas com o conjunto das estacas de $0.25 \mathrm{~m}$ de diâmetro. Inicialmente, serão analisadas todas estacas de $0.25 \mathrm{~m}$ de diâmetro (11 estacas) e, posteriormente, serão analisadas somente as estacas de $0.25 \mathrm{~m}$ de diâmetro (5 estacas) cujas provas de carga romperam ou podem ser extrapoladas por meio do Método de Van der Veen segundo o critério proposto em Vianna (2000).

Esta análise complementar possui dois objetivos:

$\checkmark$ o primeiro objetivo é que ao se realizar as análises com estacas de mesmo diâmetro se reduz uma variável do problema, ou seja, uma fonte de variabilidade;

$\checkmark$ o segundo, é verificar se há ou não diferença significativa nos resultados das análises quando se utilizam todas as provas de carga, de quando se utilizam somente as estacas cujas provas de carga atingiram à ruptura e as que podem ser extrapoladas segundo o critério proposto por Vianna (2000).

\section{a) Análise de todas as estacas com $\mathrm{D}=0.25 \mathrm{~m}$}

Considerando somente as provas de carga executadas nas estacas com diâmetro igual a $0.25 \mathrm{~m}$ foram realizadas as análises apresentadas a seguir.

Tabela 8.2.8. Estatísticas de todas as estacas com D $=0.25 \mathrm{~m}$.

\begin{tabular}{|c|c|c|c|c|c|c|c|c|c|c|c|c|}
\hline \multirow{3}{*}{ Estacas } & \multirow{3}{*}{$\mathrm{D}(\mathrm{m})$} & \multirow{3}{*}{ Área $\left(\mathrm{m}^{2}\right)$} & \multicolumn{8}{|c|}{ Resistências Previstas } & \multirow{2}{*}{\multicolumn{2}{|c|}{$\begin{array}{c}\text { Resistência Medida } \\
\text { Prova de Carga } \\
\end{array}$}} \\
\hline & & & \multicolumn{2}{|c|}{ Aokj-Velloso } & \multicolumn{2}{|c|}{ Aokj-Velloso Modif. } & \multicolumn{2}{|c|}{ Décourt-Quaresma } & \multicolumn{2}{|r|}{ Amaral } & & \\
\hline & & & $\mathrm{R}(\mathrm{kN})$ & Tensăo (KPa) & $R(\mathrm{kN})$ & Tensão (KPa) & $\mathrm{R}(\mathrm{kN})$ & Tensão (KPa) & $\mathrm{R}(\mathrm{kN})$ & Tensão (kPa) & $\mathrm{R}(\mathrm{kN})$ & Tensāo (kPa) \\
\hline 1 & 0.25 & 0.049 & 156 & 3178.1 & 203 & 4237.5 & 380 & 7741.5 & 544 & 110826 & 629 & 128143 \\
\hline 3 & 0.25 & 0.049 & 164 & 3341.1 & 204 & 4156.0 & 353 & 7191.5 & 509 & 10369.6 & 516 & 105122 \\
\hline 7 & 0.25 & 0.049 & 388 & 7904.5 & 741 & 15096.0 & 565 & 11510.4 & 794 & 16175.7 & 757 & 15421.9 \\
\hline 9 & 0.25 & 0.049 & 390 & 79452 & 520 & 10593.7 & 664 & 13527.3 & 983 & 20026.1 & 865 & 176222 \\
\hline 10 & 0.25 & 0.049 & 329 & 67025 & 439 & 8943.5 & 576 & 117345 & 745 & 15177.5 & 739 & 15055.2 \\
\hline 12 & 0.25 & 0.049 & 413 & 8413.8 & 549 & 111845 & 489 & 99621 & 710 & 14464.4 & 529 & 10777.0 \\
\hline 15 & 0.25 & 0.049 & 223 & 4543.1 & 296 & 6030.2 & 186 & 3789.3 & 481 & 9799.1 & 501 & 10206.6 \\
\hline 19 & 0.25 & 0.049 & 297 & 6050.6 & 396 & 8067.5 & 504 & 10267.7 & 720 & 14668.2 & 563 & 11469.7 \\
\hline 20 & 0.25 & 0.049 & 197 & 4013.4 & 321 & 6539.6 & 338 & 6885.9 & 510 & 10389.9 & 541 & 11021.5 \\
\hline 21 & 0.25 & 0.049 & 231 & 4706.0 & 295 & 6009.9 & 335 & 6824.8 & 503 & 10349.2 & 450 & 9167.6 \\
\hline 24 & 0.25 & 0.049 & 385 & 7843.4 & 513 & 10451.1 & 504 & 10267.7 & 698 & 14220.0 & 523 & 106548 \\
\hline \multicolumn{3}{|c|}{ Média } & 288.5 & 5876.5 & 407.5 & 8300.8 & \begin{tabular}{|l|l|}
44.9 \\
\end{tabular} & 9063.9 & 654.7 & 13338.4 & 601.2 & 12247.5 \\
\hline \multicolumn{3}{|c|}{ Desvio } & 97.9 & 1993.5 & 164.3 & 3347.2 & 138.5 & 2821.0 & 158.3 & 3225.4 & 130.5 & 2657.8 \\
\hline \multicolumn{3}{|c|}{ CV (\%) } & \multicolumn{2}{|r|}{$33.9 \%$} & \multicolumn{2}{|r|}{$40.3 \%$} & \multicolumn{2}{|r|}{$31.1 \%$} & \multicolumn{2}{|r|}{$24.2 \%$} & \multicolumn{2}{|r|}{$21.7 \%$} \\
\hline
\end{tabular}


A Tabela 8.2.8 apresenta os valores das resistências previstas pelos 4 métodos de cálculo utilizados e resistências medidas em prova de carga. Nesta tabela, também se encontram as estatísticas (média, desvio padrão e coeficiente de variação) das resistências, tanto em termos de força, como em termos de tensão.

Tabela 8.2.9. Resultados das análises realizadas

- Método Aoki-Velloso para todas as estacas com $\mathrm{D}=0.25 \mathrm{~m}$.

\begin{tabular}{|c|c|c|c|c|c|c|c|c|c|c|c|}
\hline \multirow{2}{*}{ Anárises } & \multicolumn{3}{|c|}{ Resistência } & \multicolumn{3}{|c|}{ Solictação } & \multirow{2}{*}{ cs } & \multirow{2}{*}{$\beta$} & \multirow{2}{*}{ Pr } & \multirow{2}{*}{$1 / \mathrm{Pr}$} & \multirow{2}{*}{$\begin{array}{l}P_{\text {edm }} \\
\text { (NN) }\end{array}$} \\
\hline & Médáa (kN) & Desvio (KN) & CV (\%) & Meda $(\mathrm{KN})$ & Desvio (KN) & $\mathrm{CV}(\%)$ & & & & & \\
\hline Aná'se 1 & 288.5 & 97.9 & $33.9 \%$ & 400.0 & 0.0 & $0.0 \%$ & 0.7 & -1.14 & 0.87284 & 1 & 4000 \\
\hline Aná'se 2 & 288.5 & 97.9 & $33.9 \%$ & 1442 & 0.0 & $0.0 \%$ & 20 & 1.47 & 0.07026 & 14 & 1442 \\
\hline Aná'se 3 & 288.5 & 97.9 & $33.9 \%$ & -14.0 & 0.0 & $0.0 \%$ & -20.7 & 3.09 & 0.00100 & 1000 & -14.0 \\
\hline
\end{tabular}

As análises realizadas foram executadas com as estatísticas dos valores de resistência apresentados na Tabela 8.2 .8 e com as estatísticas dos valores de solicitação apresentados na Tabela 18 do Apêndice B. Essas análises, encontram-se apresentadas nas Figuras 27 a 41 do Apêndice B.

As análises realizadas com as resistências previstas pelo Método Aoki-Velloso estão apresentadas nas Figuras 27, 28 e 29 do Apêndice B, e o resumo dessas análises está apresentado na Tabela 8.2.9.

Da observação dessa tabela, pode-se perceber que devido ao elevado valor do coeficiente de variação das resistências previstas (33.9\%), a Análise 3 resultou numa carga admissível negativa evidenciando a impossibilidade de projetar a fundação com a probabilidade de ruína desejada (1/1000). O mesmo ocorreu com o Método AokiVelloso modificado que também apresentou um elevado coeficiente de variação (40.3\%), observe as Figuras 30, 31 e 32 do Apêndice B e a Tabela 8.2.10 abaixo.

Tabela 8.2.10. Resultados das análises realizadas

- Método Aoki-Velloso modificado para todas as estacas com $\mathrm{D}=0.25 \mathrm{~m}$.

\begin{tabular}{|c|c|c|c|c|c|c|c|c|c|c|c|}
\hline \multirow{2}{*}{ Anälises } & \multicolumn{3}{|c|}{ Resistência } & \multicolumn{3}{|c|}{ Soliciteç̃o } & \multirow{2}{*}{ CS } & \multirow{2}{*}{$\beta$} & \multirow{2}{*}{ Pr } & \multirow{2}{*}{$1 / \mathrm{Pr}$} & \multirow{2}{*}{$\begin{array}{l}\text { Pasm } \\
(\mathrm{kN})\end{array}$} \\
\hline & Méda (kN) & Desvio (KN) & $\mathrm{CV}(\%)$ & Méda (KN) & Desvio (KN) & $\mathrm{CV}(\%)$ & & & & & \\
\hline Análise 1 & 407.5 & 1643 & $40.3 \%$ & 400.0 & 0.0 & $00 \%$ & 1.0 & 0.05 & 0.48191 & 2 & 4000 \\
\hline Análse 2 & 407.5 & 164.3 & $40.3 \%$ & 203.7 & 0.0 & $0.0 \%$ & 20 & 1.24 & 0.10749 & 9 & 203.7 \\
\hline Análise 3 & 407.5 & 164.3 & $40.3 \%$ & -100.3 & 00 & $0.0 \%$ & .4 .1 & 3.09 & 0,00100 & 1000 & -100.3 \\
\hline
\end{tabular}

Observando os resultados apresentados na Tabela 8.2.11 pode-se perceber que o Método Décourt-Quaresma (Figuras 33, 34 e 35 do Apêndice B) por ter também apresentado um elevado coeficiente de variação resultou numa carga admissível de apenas 17.0 kN (Análise 3). 
Tabela 8.2.11. Resultados das análises realizadas

- Método Décourt-Quaresma para todas as estacas com $\mathrm{D}=0.25 \mathrm{~m}$.

\begin{tabular}{|c|c|c|c|c|c|c|c|c|c|c|c|}
\hline \multirow{2}{*}{ Anáises } & \multicolumn{3}{|c|}{ Resistència } & \multicolumn{3}{|c|}{ Saicitaçäo } & \multirow{2}{*}{ CS } & \multirow{2}{*}{$\beta$} & \multirow{2}{*}{ Pr } & \multirow{2}{*}{$1 / \mathrm{Pr}$} & \multirow{2}{*}{$\begin{array}{l}\text { Padm } \\
\text { (ks) }\end{array}$} \\
\hline & Média (kN) & Desvio (KN) & CV (\%) & Méda (IN) & Desvio (kN) & CV (\%) & & & & & \\
\hline Análise 1 & 444.9 & 138.5 & $31.1 \%$ & 400.0 & 0.0 & $0.0 \%$ & 1.1 & 0.32 & 0.37265 & 3 & 4000 \\
\hline Anál'se 2 & 444.9 & 138.5 & $31.1 \%$ & 2225 & 00 & $0.0 \%$ & 20 & 1.61 & 0.05403 & 18 & 2225 \\
\hline Anáise 3 & 444.9 & 1385 & $31.1 \%$ & 17.0 & 0.0 & $0.0 \%$ & 262 & 3.09 & 0.00100 & 1000 & 17.0 \\
\hline
\end{tabular}

Com relação ao Método Amaral as análises realizadas mostram que a adoção de um $\mathrm{CS}=4.0$ é possível projetar a fundação de forma que a sua probabilidade de ruína seja de 1/1000 e que caso se opte por utilizar a formulação da norma com um CS = 2.0 esta resultará numa probabilidade de ruína de $1 / 52$. Observe a Tabela 8.2.12 e as Figuras 36, 37 e 38 do Apêndice B.

Tabela 8.2.12. Resultados das análises realizadas - Método Amaral para todas as estacas com D $=0.25 \mathrm{~m}$.

\begin{tabular}{|c|c|c|c|c|c|c|c|c|c|c|c|}
\hline \multirow{2}{*}{ Análises } & \multicolumn{3}{|c|}{ Resistència } & \multicolumn{3}{|c|}{ Solicitaçāo } & \multirow{2}{*}{ CS } & \multirow{2}{*}{$\beta$} & \multirow{2}{*}{ Pr } & \multirow{2}{*}{$1 / \mathrm{Pr}$} & \multirow{2}{*}{$\begin{array}{l}\text { Parm } \\
\text { (kv) }\end{array}$} \\
\hline & Méda (kN) & Desvio (KN) & CV (\%) & Méda (kNV) & Desvio (kV) & CV (\%) & & & & & \\
\hline Anáise 1 & 654.7 & 158.3 & $242 \%$ & 400.0 & 0.0 & $0.0 \%$ & 1.6 & 1.61 & 0.05382 & 19 & 4000 \\
\hline Análise 2 & 654.7 & 158.3 & $242 \%$ & 327.4 & 0.0 & $0.0 \%$ & 20 & 207 & 0.01933 & 52 & 327.4 \\
\hline Análise 3 & 654.7 & 158.3 & $242 \%$ & 165.5 & 0.0 & $0.0 \%$ & 40 & 309 & 000100 & 1000 & 165.5 \\
\hline
\end{tabular}

A Tabela 8.2.13 apresenta o resumo das análises realizadas com os valores de resistência medidos pelas provas de carga.

Tabela 8.2.13. Resultados das análises realizadas

- Prova de Carga para todas as estacas com D $=0.25 \mathrm{~m}$.

\begin{tabular}{|c|c|c|c|c|c|c|c|c|c|c|c|}
\hline \multirow{2}{*}{ Análises } & \multicolumn{3}{|c|}{ Resistencia } & \multicolumn{3}{|c|}{ Solicitaçāo } & \multirow{2}{*}{ CS } & \multirow{2}{*}{$\beta$} & \multirow{2}{*}{ Pr } & \multirow{2}{*}{$1 / \mathrm{Pr}$} & \multirow{2}{*}{$\begin{array}{l}\text { Parm } \\
\text { (kov) }\end{array}$} \\
\hline & Méda (kN) & Desvio (kN) & CV (\%) & Méda (WN) & Desvio (KN) & CV (\%) & & & & & \\
\hline Análise 1 & 601.2 & 1305 & $21.7 \%$ & 400.0 & 00 & $0.0 \%$ & 1.5 & 1.54 & 0.05153 & 16 & 4000 \\
\hline Análise 2 & 601.2 & 130.5 & $21.7 \%$ & 300.6 & 0.0 & $0.0 \%$ & 20 & 230 & 0.01061 & 94 & 3006 \\
\hline Análise 3 & 601.2 & 130.5 & $21.7 \%$ & 183.0 & 0.0 & $0.0 \%$ & 30 & 3.09 & 0.00100 & 1000 & 193.0 \\
\hline
\end{tabular}

Através da observação da Tabela 8.2.13 e das Figuras 39, 40 e 41 do Apêndice $\mathrm{B}$, pode-se perceber que devido à variabilidade do sistema, representado pelo coeficiente de variação das resistências medidas nas provas de carga, ser inferior à prevista pelos métodos de cálculo, a adoção de um coeficiente de segurança igual a 3.0 na formulação da norma, é na realidade, suficiente para que a fundação seja projetada com uma probabilidade de ruína aceitável (1/1000).

Um resumo geral dessas análises, pode ser visualizado na Tabela 21 do Apêndice B. 
b) Análise das estacas com $\mathrm{D}=0.25 \mathrm{~m}$ "que podem ser utilizadas"

Fazendo uso de apenas 5 estacas, das 11 com $0.25 \mathrm{~m}$ de diâmetro, foram realizadas as análises apresentadas neste item.

A Tabela 8.2.14 e a Tabela 19 do Apêndice B trazem as estatísticas dos valores de resistência e de solicitação das 5 estacas com $\mathrm{D}=0.25 \mathrm{~m}$ cujas provas de carga podem ser utilizadas (provas de carga que atingiram à ruptura e provas de carga que podem ser extrapoladas pelo Método de Van der Veen). As análises apresentadas nas Figuras 42 a 56 do Apêndice B foram executadas com base nestes valores.

Tabela 8.2.14. Estatísticas das estacas com $\mathrm{D}=0.25 \mathrm{~m}$ que podem ser utilizadas.

\begin{tabular}{|c|c|c|c|c|c|c|c|c|c|c|c|c|}
\hline \multirow{3}{*}{ Estacas } & \multirow{3}{*}{$D(m)$} & \multirow{3}{*}{ Área $\left(\mathrm{m}^{2}\right)$} & \multicolumn{8}{|c|}{ Resistências Previstas } & \multirow{2}{*}{\multicolumn{2}{|c|}{$\begin{array}{c}\text { Resistência Medida } \\
\text { Prova de Carga } \\
\end{array}$}} \\
\hline & & & \multicolumn{2}{|c|}{ Aoki-Velloso } & \multicolumn{2}{|c|}{ Aoki-Velloso Modif. } & \multicolumn{2}{|c|}{ Décourt-Quaresma } & \multicolumn{2}{|r|}{ Amaral } & & \\
\hline & & & $\mathrm{R}(\mathrm{kN})$ & Tensão (kPa) & $\mathrm{R}(\mathrm{kN})$ & Tensão (kPa) & $R(\mathrm{kN})$ & Tensão (kPa) & $\mathrm{R}(\mathrm{kN})$ & Tensão (kPa) & $\mathrm{R}(\mathrm{kN})$ & Tensão (kPa) \\
\hline 3 & 0.25 & 0.049 & 164 & 3341.1 & 204 & 4156.0 & 353 & 7191.5 & 509 & 10369.6 & 516 & 105122 \\
\hline 10 & 0.25 & 0.049 & 329 & 67025 & 439 & 8943.5 & 576 & 117345 & 745 & 15177.5 & 739 & 150552 \\
\hline 15 & 025 & 0.049 & 223 & 4543.1 & 296 & 60302 & 186 & 3789.3 & 481 & 9799.1 & 501 & 10206.6 \\
\hline 20 & 0.25 & 0.049 & 197 & 4013.4 & 321 & 6539.6 & 338 & 6885.9 & 510 & 10389.9 & 541 & 11021.5 \\
\hline 21 & 0.25 & 0.049 & 231 & 4706.0 & 295 & 6009.9 & 335 & 6824.8 & 508 & 10349.2 & 450 & 9167.6 \\
\hline \multicolumn{3}{|c|}{ Média } & 228.8 & 4661.2 & 311.0 & 6335.8 & \begin{tabular}{|l|l|}
357.6 \\
\end{tabular} & 7285.2 & 550.6 & 11217.1 & 549.4 & 11192.6 \\
\hline \multicolumn{3}{|c|}{ Desvio } & 61.8 & 1259.5 & 84.3 & 1717.0 & 139.7 & 2846.0 & \begin{tabular}{|l|}
109.3 \\
\end{tabular} & 2227.7 & \begin{tabular}{|l|}
111.1 \\
\end{tabular} & 2263.0 \\
\hline \multicolumn{3}{|c|}{ cv (\%) } & \multicolumn{2}{|r|}{$27.0 \%$} & \multicolumn{2}{|r|}{$27.1 \%$} & \multicolumn{2}{|r|}{$39.1 \%$} & \multicolumn{2}{|r|}{$19.9 \%$} & \multicolumn{2}{|r|}{$20.2 \%$} \\
\hline
\end{tabular}

A Tabela 8.2.15, assim como as Figuras 42, 43 e 44 do Apêndice B, apresentam as análises realizadas com os valores de resistência previstos pelo Método AokiVelloso.

Tabela 8.2.15. Resultados das análises realizadas - Método Aoki-Velloso para as estacas com $\mathrm{D}=0.25 \mathrm{~m}$ que podem ser utilizadas.

\begin{tabular}{|c|c|c|c|c|c|c|c|c|c|c|c|}
\hline \multirow{2}{*}{ Análises } & \multicolumn{3}{|c|}{ Resistència } & \multicolumn{3}{|c|}{ Solcitação } & \multirow{2}{*}{ CS } & \multirow{2}{*}{$\beta$} & \multirow{2}{*}{ Pr } & \multirow{2}{*}{$1 / \mathrm{Pr}$} & \multirow{2}{*}{$\begin{array}{l}\text { Parm } \\
\text { (kiv) }\end{array}$} \\
\hline & Méda (ks) & Desvio (kil) & CV (\%) & Nédia (kN) & Desvio (KV) & CV (\%) & & & & & \\
\hline Análse 1 & 2238 & 61.8 & $27.0 \%$ & 400.0 & 0.0 & $0.0 \%$ & 0.6 & -277 & 099719 & 1 & 4000 \\
\hline Análise 2 & 228.8 & 61.8 & $27.0 \%$ & 114.4 & 0.0 & $0.0 \%$ & 20 & 1.85 & 0.03214 & 31 & 114.4 \\
\hline Análse 3 & 228.8 & 61.8 & $27.0 \%$ & 37.7 & 0.0 & $0.0 \%$ & 6.1 & 309 & 0.00100 & 1000 & 37.7 \\
\hline
\end{tabular}

Observando a Tabela 8.2.15, pode-se perceber, pelo valor do índice de confiabilidade e da probabilidade de ruína (1/1), que é inviável projetar o estaqueamento com as cargas nominais das estacas (Análise 1), e que se o mesmo for projetado usando a formulação da norma com um CS $=2.0$ (Análise 2), este terá uma probabilidade de ruína de $1 / 31$. Sendo assim, para que o estaqueamento apresente segurança, é necessário utilizar um $\mathrm{CS}=6.1$ para que a probabilidade de ruína seja de $1 / 1000$. 
As Figuras 45, 46 e 47 do Apêndice B são relativas às análises realizadas com as resistências previstas pelo Método Aoki-Velloso modificado. O resumo dessas análises está apresentado na Tabela 8.2.16.

Tabela 8.2.16. Resultados das análises realizadas

- Método Aoki-Velloso modificado para as estacas com $\mathrm{D}=0.25 \mathrm{~m}$ que podem ser utilizadas.

\begin{tabular}{|c|c|c|c|c|c|c|c|c|c|c|c|}
\hline \multirow{2}{*}{ Análises } & \multicolumn{3}{|c|}{ Resistência } & \multicolumn{3}{|c|}{ Salcitay̆ăo } & \multirow{2}{*}{ cs } & \multirow{2}{*}{$\beta$} & \multirow{2}{*}{ Pr } & \multirow{2}{*}{$1 / \mathrm{Pr}$} & \multirow{2}{*}{$\begin{array}{l}\text { Pasm } \\
(\mathrm{NN})\end{array}$} \\
\hline & Méda (KN) & Deswio (KN) & $\mathrm{CV}(\%)$ & Méda (NN) & Desvio (NN) & CV(\%) & & & & & \\
\hline Análise 1 & 311.0 & 84.3 & $27.1 \%$ & 400.0 & 0.0 & $0.0 \%$ & 0.8 & -1.06 & 0.85450 & 1 & 4000 \\
\hline Anárise 2 & 311.0 & 84.3 & $27.1 \%$ & 1555 & 0.0 & $0.0 \%$ & 20 & 1.84 & 0.03252 & 31 & 155.5 \\
\hline Análse 3 & 311.0 & 84.3 & $27.1 \%$ & 50.5 & 0.0 & $0.0 \%$ & 62 & 309 & 0.00100 & 1000 & 50.5 \\
\hline
\end{tabular}

A Tabela 8.2.16 indica que se o estaqueamento for projetado usando as resistências previstas pelo Método Aoki-Velloso modificado e a formulação da norma com $\mathrm{CS}=2.0$ (Análise 2) este terá uma probabilidade de ruína de $1 / 31$, e para que o mesmo seja projetado com uma probabilidade de ruína adequada (1/1000) este deverá ser dimensionado com uma $\mathrm{P}_{\mathrm{adm}}=50.5 \mathrm{kN}$, correspondente a um CS $=6.2$ (Análise 3).

As análises realizadas com as resistências previstas pelo Método DécourtQuaresma (Tabela 8.2.17 e Figuras 48, 49 e 50 do Apêndice B) indicam que não é possível projetar o estaqueamento com a probabilidade de ruína de 1/1000 (Análise 3) devido ao elevado valor do coeficiente de variação das resistências previstas (39.1\%), e que se o mesmo for projetado usando a formulação da norma com $\mathrm{CS}=2.0$, este terá uma probabilidade de ruína de 1/10.

Tabela 8.2.17. Resultados das análises realizadas

- Método Décourt-Quaresma para as estacas com $\mathrm{D}=0.25 \mathrm{~m}$ que podem ser utilizadas.

\begin{tabular}{|c|c|c|c|c|c|c|c|c|c|c|c|}
\hline \multirow{2}{*}{ Análises } & \multicolumn{3}{|c|}{ Resistència } & \multicolumn{3}{|c|}{ Solcitação } & \multirow{2}{*}{ CS } & \multirow{2}{*}{$\beta$} & \multirow{2}{*}{$\mathrm{Pr}$} & \multirow{2}{*}{$1 / \mathrm{Pr}$} & \multirow{2}{*}{$\begin{array}{l}\text { Padm } \\
\text { (kN) }\end{array}$} \\
\hline & Méda (kN) & Desvio (KN) & CV (\%) & Méda (kV) & Desvio (kN) & CV (\%) & & & & & \\
\hline Anáise 1 & 357.6 & 139.7 & $39.1 \%$ & 400.0 & 00 & $0.0 \%$ & 09 & -0.30 & 061925 & 2 & 4000 \\
\hline Anáise 2 & 357.6 & 139.7 & $39.1 \%$ & 178.8 & 0.0 & $00 \%$ & 20 & 128 & 0.10029 & 10 & 1788 \\
\hline Análse 3 & 357.6 & 139.7 & $39.1 \%$ & -74.1 & 0.0 & $00 \%$ & -48 & 3.09 & 0.00100 & 1000 & -74.1 \\
\hline
\end{tabular}

As Figuras 51, 52 e 53 do Apêndice B apresentam as análises realizadas com as resistências previstas pelo Método Amaral para todas as estacas com D $=0.25 \mathrm{~m}$. O resumo dessas análises está apresentado na Tabela 8.2.18.

Observando a Tabela 8.2.18, pode-se perceber que se o estaqueamento for projetado com as cargas nominais das estacas (Análise 1) este apresentará uma probabilidade de ruína de $1 / 12$, e que se for utilizada a formulação da norma com $\mathrm{CS}=2.0$, a probabilidade de ruína será de 1/169 (Análise 2). Mas, caso se deseje 
projetar o estaqueamento com uma probabilidade de ruína de 1/1000 (Análise 3), deve ser utilizado um $\mathrm{CS}=2.6$ na formulação da norma.

Tabela 8.2.18. Resultados das análises realizadas

- Método Amaral para as estacas com $\mathrm{D}=0.25 \mathrm{~m}$ que podem ser utilizadas.

\begin{tabular}{|c|c|c|c|c|c|c|c|c|c|c|c|}
\hline \multirow{2}{*}{ Anáises } & \multicolumn{3}{|c|}{ Resistència } & \multicolumn{3}{|c|}{ Soicitaçäa } & \multirow{2}{*}{ CS } & \multirow{2}{*}{$\beta$} & \multirow{2}{*}{ Pi } & \multirow{2}{*}{$1 / \mathrm{Pr}$} & \multirow{2}{*}{$\begin{array}{l}\text { Pasm } \\
\text { (WN) }\end{array}$} \\
\hline & Méda (kN) & Desvio (KN) & CV $(\%)$ & Méda (KN) & Desio (WN) & CV (\%) & & & & & \\
\hline Aná'se 1 & 550.6 & 109.3 & $19.9 \%$ & 4000 & 00 & $0.0 \%$ & 1.4 & 1.38 & 003422 & 12 & 400.0 \\
\hline Aná'se 2 & 550.6 & 109.3 & $19.9 \%$ & 275.3 & 0.0 & $0.0 \%$ & 20 & 252 & 0.00591 & 169 & 275.3 \\
\hline Anärse 3 & 550.6 & 109.3 & $19.9 \%$ & 2127 & 0.0 & $0.0 \%$ & 26 & 300 & 0.00100 & 1000 & 2127 \\
\hline
\end{tabular}

Finalmente, as Figuras 54, 55 e 56 do Apêndice B e a Tabela 8.2.19 apresentam as análises realizadas com os valores de resistência medidos nas provas de carga executadas nas 5 estacas analisadas. Da observação dessas análises, percebe-se que se for utilizada a formulação da norma com $C S=2.0$, a probabilidade de ruína do estaqueamento será de 1/149 e que caso se deseje projeta-lo com uma probabilidade de ruína adequada (1/1000), este deverá ser igual à $\mathrm{CS}=3.0$ (Análise 3).

Tabela 8.2.19. Resultados das análises realizadas

- Prova de Carga para as estacas com $\mathrm{D}=0.25 \mathrm{~m}$ que podem ser utilizadas.

\begin{tabular}{|c|c|c|c|c|c|c|c|c|c|c|c|}
\hline \multirow{2}{*}{ Análises } & \multicolumn{3}{|c|}{ Resistència } & \multicolumn{3}{|c|}{ Scicitaç̃o } & \multirow{2}{*}{ CS } & \multirow{2}{*}{$\beta$} & \multirow{2}{*}{ Pr } & \multirow{2}{*}{$1 / \mathrm{Pr}$} & \multirow{2}{*}{$\begin{array}{l}\text { Padm } \\
\text { (NN) }\end{array}$} \\
\hline & Méda (KN) & Desvio (kN) & CV (\%) & Méda (KN) & Desvio (kN) & CV (\%) & & & & & \\
\hline Análise 1 & 549.4 & 111.1 & $202 \%$ & 400.0 & 0.0 & $0.0 \%$ & 1.4 & 1.34 & 0.08933 & 11 & 4000 \\
\hline Anáise 2 & 549.4 & 111.1 & $202 \%$ & 274.7 & 0.0 & $0.0 \%$ & 20 & 247 & 0,00670 & 149 & 274.7 \\
\hline Anáise 3 & 549.4 & 111.1 & $202 \%$ & 1930 & 0.0 & $00 \%$ & 3.0 & 309 & 0.00100 & 1000 & 198.0 \\
\hline
\end{tabular}

Comparando os resultados das análises das Tabelas 8.2.18 e 8.2.19, percebe-se que apesar do Método Amaral haver superestimado o valor médio da resistência e ter previsto uma variabilidade um pouco inferior à real, este resultou em valores de $\mathrm{P}_{\text {adm }}$ muito próximos dos obtidos por meio da utilização dos valores de resistência observadas nas provas de carga (Tabela 8.2.19).

A Tabela 22 do Apêndice B apresenta o resumo geral dessas análises.

\subsubsection{Comentários finais}

Observando os resultados das análises realizadas, que se encontram resumidas nas Tabelas 20, 21 e 22 do Apêndice B, pode-se perceber que:

$\checkmark$ os resultados das análises realizadas com todas as estacas (34 estacas) em termos de tensões (Tabela 20 do Apêndice B) se apresentaram semelhantes aos 
resultados das análises realizadas com as 11 estacas de $0.25 \mathrm{~m}$ de diâmetro (Tabela 21 do Apêndice B). Semelhantes no sentido de apresentarem o mesmo padrão de comportamento que o exposto pelas estatísticas das resistências. Pois, pode-se observar, comparando as estatísticas apresentadas nas Tabelas $8.2 .2 \mathrm{e}$ 8.2.8, que em ambos os casos, os métodos de previsão que apresentaram os maiores coeficientes de variação foram, em ordem decrescente: Aoki-Velloso modificado (38.1\% e 40.3\%), Aoki-Velloso (36.0\% e 33.9\%), DécourtQuaresma (28.1\% e 31.1\%) e Amaral (23.6\% e 24.2\%) e os que apresentaram os maiores valores médios foram, também em ordem decrescente: Amaral (13346.2 kPa e 13338.4 kPa), Décourt-Quaresma (9762.8 kPa e $9063.9 \mathrm{kPa})$; Aoki-Velloso modificado (8751.5 kPa e $8300.8 \mathrm{kPa})$ e Aoki-Velloso $(6663.9 \mathrm{kPa}$ e $5876.5 \mathrm{kPa})$, respectivamente.

$\checkmark$ No entanto, quando se compara o resultado das análises realizadas com todas as estacas (Tabela 20 do Apêndice B) e das 11 estacas de $0.25 \mathrm{~m}$ de diâmetro (Tabela 21 do Apêndice B) com o resultado das análises realizadas com apenas 5 estacas de $0.25 \mathrm{~m}$ de diâmetro (Tabela 22 do Apêndice B) percebe-se que, ao contrário da situação anterior, esses não se assemelham. Isso ocorre, devido ao fato das estatísticas das resistências apresentarem padrões de comportamento diferentes. Pois, comparando as estatísticas apresentadas nas Tabelas 8.2.2, 8.2.8 e 8.2.14, verifica-se uma redução nos valores médios de resistências, assim como uma redução do coeficiente de variação dos mesmos (com exceção do método Décourt-Quaresma). Uma possível explicação para esse comportamento pode ser o fato de que ao utilizar somente as 5 estacas cujas provas de carga podem ser extrapoladas pela expressão de Van der Veen, houve a eliminação dos valores extremos de resistência que por ventura poderiam estar superestimados, o que também provocou a redução do coeficiente de variação das resistências, apesar da quantidade de dados haver diminuído.

Logo, como conclusão final, pode-se destacar que apesar da utilização do critério proposto por Vianna (2000) ser extremamente válida, as análises realizadas com a formulação proposta sem a sua consideração, não trazem nenhum prejuízo, devido ao fato de serem a favor da segurança. 


\subsection{Fundações em estacas centrifugadas de concreto armado}

Neste item, encontram-se os resultados das análises realizadas com algumas fundações executadas em estacas de seção circular vazada confeccionadas em concreto armado. São apresentados os resultados das análises de 7 fundações, sendo 3 localizadas no estado do Rio de Janeiro e 4 localizadas no estado de São Paulo.

As informações utilizadas nestas análises foram obtidas na literatura técnica (SCAC, vol. 2) e consistem de dados de provas de carga estática à compressão que foram realizadas em diversas fundações localizadas em diferentes regiões do Brasil.

\subsubsection{Análise dos dados}

Os elementos estruturais de fundação utilizadas nesta análise são elementos de concreto armado obtidos através do processo de centrifugação, com seção circular vazada com diâmetro externo, D, variando de $20 \mathrm{~cm}$ a $70 \mathrm{~cm}$ e espessura da parede, E, variando de $6 \mathrm{~cm}$ a $12 \mathrm{~cm}$ (vide Figura 8.3.1).

As provas de carga divulgadas são as apresentadas na Tabela 1 do Apêndice C. Essa tabela apresenta as principais informações a respeito do ensaio (carga máxima do ensaio e carga de ruptura) das 51 provas de carga na ordem em que estas foram publicadas, assim como o diâmetro, a espessura da parede, o comprimento e a carga admissível das estacas, ou seja, as características dos elementos estruturais de fundação. Posteriormente, essas mesmas provas de carga foram agrupadas por cidade, vide Tabela 2 do Apêndice $\mathrm{C}$, e destas, somente as provas de carga executadas, no mesmo local, em número superior a três, foram utilizadas nas análises, totalizando 32 estacas.

As cargas de ruptura das provas de carga utilizadas nestas análises foram estimadas pelo Método de extrapolação de Van Der Veen (1953). Na Tabela 3 do Apêndice $\mathrm{C}$ estão apresentados os valores de carga de ruptura publicados, assim como os parâmetros A e B, para as provas de carga que serão utilizadas nas análises.

Ressalta-se que não foi possível obter a curva carga $\mathrm{x}$ recalque de cada uma das provas de carga realizadas, pois não foram divulgados os dados das mesmas. Sendo assim, somente foi possível plotar a curva carga x recalque prevista pelo Método de Van der Veen, fazendo uso dos dados publicados (carga de ruptura e parâmetros A e B). As Figuras 1 a 32 do Apêndice $C$ trazem as curvas carga $x$ recalque de cada uma das 32 estacas analisadas. 
Com os resultados das provas de carga agrupados por formação geológicageotécnica, foi feita a análise estatística das resistências e das solicitações em termos de tensão, devido aos diferentes diâmetros das estacas que foram submetidas às provas de carga. A tensão média de ruptura das estacas foi obtida pela média das suas cargas de ruptura dividida pela média das áreas da seção transversal das mesmas, assim como a tensão média solicitante das estacas foi obtida pela relação entre a média das suas cargas admissíveis estruturais e a média das áreas de seção transversal.

Entretanto, deve-se observar que a geometria do elemento estrutural permite uma dúbia interpretação do que possa ser considerado como a área da seção transversal das estacas. Sendo assim, as provas de carga realizadas foram analisadas de duas formas distintas: considerando a área "plena" correspondente a área de uma estaca maciça e a área "anelar" correspondente à área real de concreto da estaca (vide Figura 8.3.1).
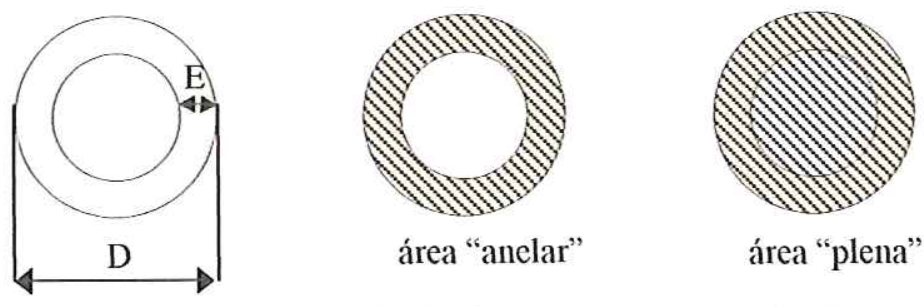

Figura 8.3.1. Geometria do elemento estrutural de fundação.

Neste contexto, as 32 provas de carga que serão analisadas, foram divididas em 7 grupos em função do local onde as estacas foram executadas e as tensões resistentes das estacas que serão utilizadas nas análises foram calculadas de duas formas distintas. A denominada "resistência 1" foi obtida dividindo a carga de ruptura da estaca pela área "plena" de sua seção transversal. Enquanto que a denominada "resistência 2" foi obtida dividindo a carga de ruptura da estaca pela área "anelar" de sua seção transversal. Da mesma forma, foram calculadas as tensões solicitantes, ou seja, a denominada "solicitação 1" foi obtida dividindo a carga admissível estrutural da estaca apresentada em catálogo, pela área "plena" da seção transversal da mesma. Enquanto que a denominada "solicitação 2 " foi obtida dividindo a carga admissível estrutural da estaca pela área "anelar" de sua seção transversal. Em resumo:

- "resistência 1": carga de ruptura / área "plena",

- "resistência 2": carga de ruptura / área "anelar"; e,

• "solicitação 1": carga admissível estrutural / área "plena",

• "solicitação 2": carga admissível estrutural / área "anelar". 


\subsubsection{Análise de Segurança e Confiabilidade}

Neste item, será realizada a estimativa da carga admissível dos vários estaqueamentos analisados, utilizando a formulação da norma e a formulação proposta nessa dissertação, fazendo uso dos valores de resistências medidas nas provas de carga estática.

Como as provas de carga não apresentaram ruptura nítida, estas foram extrapoladas através da utilização do Método de Van der Veen (1953) e, as cargas de ruptura estimadas por meio destas extrapolações, foram limitadas à resistência estrutural das estacas, sendo com base nesses valores, que as tensões resistentes das estacas foram calculadas.

O cálculo da resistência estrutural das estacas foi realizado adotando-se um coeficiente de variação igual a 10\%, segundo Aoki et al. (1995), para os valores de resistência do concreto, e o valor de $25 \mathrm{MPa}$ para a resistência característica à compressão do concreto.

Com relação às cargas nominais das estacas, estas foram adotadas de acordo com os valores indicados no catálogo do fabricante referente a um $f_{c k}=25 \mathrm{MPa}$ e a um $\mathrm{f}_{\mathrm{yk}}=500 \mathrm{MPa}$. Com os valores de carga nominais adotados, foram estimadas as tensões solicitações atuantes em cada uma das estacas.

Para cada um dos 7 grupos foram calculados o valor médio, o desvio padrão e o coeficiente de variação dos valores de resistência e de solicitação das estacas e, a partir das estatísticas de cada grupo, foram realizadas, para cada um deles, três tipos de análises: Análise 1, Análise 2 e Análise 3; conforme apresentado no capítulo referente à metodologia. Essas análises foram realizadas para as 7 fundações usando as estatísticas das tensões "resistentes 1" e "solicitantes 1" e, posteriormente, as mesmas análises foram realizadas utilizando-se as tensões "resistentes 2 " e "solicitantes 2 ".

A realização dos dois estudos possui o objetivo de verificar se há ou não diferença significativa nos resultados das análises quando se utiliza a área "plena" ao invés da área "anelar", e vice-versa. Sendo assim, inicialmente serão apresentadas as análises realizadas com as tensões resistentes e solicitantes calculadas usando a área "plena" (sub-item 8.3.2.1) e depois, serão apresentadas as análises realizadas com as tensões resistentes e solicitantes calculadas usando a área "anelar" (sub-item 8.3.2.2). 


\subsubsection{Carga admissível - "Resistência 1" e "Solicitação 1"}

Este sub-item apresenta os resultados das análises realizadas para as 7 fundações com os valores de resistência e de solicitação estimados considerando a área da seção transversal das estacas como "plena" ("resistência 1" e "solicitação 1").

A Tabela 4 do Apêndice $C$ apresenta a área da seção transversal das estacas (área "plena”), os valores de resistência estrutural das estacas (calculados considerando a área real de concreto, ou seja, a área anelar, e um $\mathrm{f}_{\mathrm{ck}}=25 \mathrm{MPa}$ ), a carga de ruptura das estacas e as tensões resistentes resultantes da relação entre as referidas cargas de ruptura com as áreas plenas. Os valores de carga de ruptura apresentados nessa tabela foram obtidos usando os valores de carga de ruptura extrapolados pelo Método de Van der Veen (1953) que foram publicados limitando-os às resistências estruturais calculadas. Os valores de resistência estrutural e de carga de ruptura em negrito indicam quais as estacas tiveram a sua carga de ruptura limitada à resistência do elemento estrutural de fundação.

A Tabela 5 do Apêndice $\mathrm{C}$ apresenta a área da seção transversal das estacas (área "plena"), os valores de carga admissível estrutural adotados relativos a um $\mathrm{f}_{\text {ck }}=25$ $\mathrm{MPa}$, e as tensões solicitantes resultantes da relação entre essas cargas admissíveis com as referidas áreas.

A Tabela 6 do Apêndice $C$ apresenta os valores de tensão resistente e solicitante que foram adotados nesta análise (a seqüência em que os grupos estão apresentados na tabela deve-se a ordem crescente do número de estacas no grupo). Nesta tabela também se encontram as estatísticas (média, desvio padrão e coeficiente de variação) das tensões resistentes e solicitantes para cada grupo de estacas, ou seja, para cada fundação analisada. Esses valores também se encontram resumidos na Tabela 8.3.1.

Logo, as análises apresentadas neste sub-item foram executadas com as estatísticas dos valores de resistência e de solicitação apresentados na Tabela 6 do Apêndice C e resumidos na Tabela 8.3.1. Essas análises, encontram-se apresentadas nas Figuras 33 a 60 do Apêndice $C$, que além das 3 análises realizadas para cada fundação analisada, também apresentam as curvas de carga admissível x coeficiente de segurança $\mathrm{x}$ probabilidade de ruína de cada uma das fundações analisadas. 
Tabela 8.3.1. Resumo das estatísticas das tensões resistentes I e solicitantes 1 .

\begin{tabular}{|l|c|c|c|c|c|c|c|}
\hline \multirow{2}{*}{ Local } & \multirow{2}{*}{ Número } & \multicolumn{3}{|c|}{ Resistência 1 } & \multicolumn{3}{c|}{ Solicitação 1 } \\
\cline { 3 - 8 } & & $\begin{array}{c}\text { Média } \\
(\mathrm{kPa})\end{array}$ & $\begin{array}{c}\text { Desvio } \\
(\mathrm{kPa})\end{array}$ & $\begin{array}{c}\mathrm{CV} \\
\%\end{array}$ & $\begin{array}{c}\text { Média } \\
(\mathrm{kPa})\end{array}$ & $\begin{array}{c}\text { Desvio } \\
(\mathrm{kPa})\end{array}$ & $\begin{array}{c}\mathrm{CV} \\
\%\end{array}$ \\
\hline ANGRA DOS REIS / RJ & 3 & 14493.3 & 201.8 & $1.4 \%$ & 6620.8 & 0.0 & $0.0 \%$ \\
\hline CUBATÃO/SP & 3 & 17228.1 & 593.7 & $3.4 \%$ & 7361.0 & 299.6 & $4.1 \%$ \\
\hline SUMARÉ / SP & 3 & 16598.0 & 1685.0 & $10.2 \%$ & 7188.0 & 599.2 & $8.3 \%$ \\
\hline SANTOS / SP & 4 & 11658.3 & 2214.3 & $19.0 \%$ & 6415.2 & 492.1 & $7.7 \%$ \\
\hline DUQUE DE CAXIAS / RJ & 5 & 13786.4 & 1004.0 & $7.3 \%$ & 6230.9 & 302.3 & $4.9 \%$ \\
\hline BARUERI/SP & 6 & 12497.1 & 2704.4 & $21.6 \%$ & 6310.7 & 340.0 & $5.4 \%$ \\
\hline SANTA CRUZ/RJ & 8 & 13027.5 & 1337.2 & $10.3 \%$ & 6193.8 & 373.7 & $6.0 \%$ \\
\hline
\end{tabular}

As Figuras 33, 34 e 35 do Apêndice $C$ apresentam as análises realizadas com as estatísticas dos valores de tensões resistentes ("resistência 1": área plena) apresentados na Tabela 8.3.1 e na Tabela 6 do Apêndice C para Angra dos Reis/RJ. O resumo dessas análises está apresentado na Tabela 8.3.2.

Tabela 8.3.2. Resultados das análises realizadas - Angra dos Reis/RJ.

\begin{tabular}{|c|c|c|c|c|c|c|c|c|c|c|c|}
\hline \multirow{2}{*}{ Anárises } & \multicolumn{3}{|c|}{ Resisténcia } & \multicolumn{3}{|c|}{ Solicitaçāo } & \multirow{2}{*}{ CS } & \multirow{2}{*}{$\beta$} & \multirow{2}{*}{ Pr } & \multirow{2}{*}{$1 / \mathrm{Pt}$} & \multirow{2}{*}{$\begin{array}{l}\text { Padm } \\
(\mathrm{KPa})\end{array}$} \\
\hline & $\mathrm{Meda}(\mathrm{KPa})$ & Desvio $(\mathrm{kPa})$ & $\mathrm{CV}(\%)$ & Méda $(\mathrm{KPa})$ & Desvio (kPa) & $\mathrm{CV}(\%)$ & & & & & \\
\hline Análise 1 & 144933 & 201.8 & $1.4 \%$ & 6620.8 & 0.0 & $0.0 \%$ & 22 & 3898 & 0.00000 & $\infty$ & 66208 \\
\hline Anárse 2 & 144933 & 201.8 & $1.4 \%$ & 7246.7 & 0.0 & $0.0 \%$ & 20 & 35.85 & 0,00000 & $\infty$ & 7246.7 \\
\hline Anäise 3 & 144933 & 201.8 & $1.4 \%$ & 13867.3 & 0.0 & $0.0 \%$ & 1.0 & 300 & 0.00100 & 1000 & 13867.3 \\
\hline
\end{tabular}

Os resultados das análises realizadas (Análise 1, 2 e 3) mostram que se o estaqueamento for projetado utilizando as resistências medidas, e:

$\checkmark$ as estatísticas das solicitações calculadas em função das cargas nominais das estacas (Análise 1), este estaqueamento irá apresentar um CS $=2.2$ e uma probabilidade de ruína praticamente nula, devido ao elevado índice de confiabilidade obtido.

$\checkmark$ a carga admissível proposta em norma com um CS $=2.0$ (Análise 2), este terá um $\beta=35.85$ referente a uma probabilidade de ruína praticamente nula.

$\checkmark$ uma probabilidade de ruína pré-estabelecida de $1 / 1000$, referente a um $\beta=3.09$ (Análise 3), o estaqueamento apresentará um $\mathrm{CS}=1.05$ e uma carga admissível igual a $13867.3 \mathrm{kPa}$.

A Tabela 7 do Apêndice $\mathrm{C}$ apresenta os dados utilizados na construção do gráfico da Figura 36 do Apêndice $\mathrm{C}$ que apresenta a relação existente entre a carga 
admissível, o coeficiente de segurança e a probabilidade de ruína para a fundação em estudo. Por meio da observação desse gráfico, é possível perceber que, devido ao baixo valor do coeficiente de variação das tensões resistentes da fundação analisada, as curvas se encontram à direita do gráfico indicando os baixos valores de probabilidade de ruína existentes.

As Figuras 37, 38 e 39 do Apêndice $\mathrm{C}$ apresentam as análises realizadas com as resistências obtidas para a fundação localizada em Cubatão/SP. O resumo dessas análises encontra-se na Tabela 8.3.3.

Tabela 8.3.3. Resultados das análises realizadas - Cubatão/SP.

\begin{tabular}{|c|c|c|c|c|c|c|c|c|c|c|c|}
\hline \multirow{2}{*}{ Anáises } & \multicolumn{3}{|c|}{ Resistência } & \multicolumn{3}{|c|}{ Solicitaçäo } & \multirow{2}{*}{ CS } & \multirow{2}{*}{$\beta$} & \multirow{2}{*}{ Pr } & \multirow{2}{*}{$1 / \mathrm{Pr}$} & \multirow{2}{*}{$\begin{array}{l}P_{\text {adm }} \\
(\mathrm{HPa})\end{array}$} \\
\hline & Méda (KPa) & Desvio $\left(\mathrm{KPa}_{2}\right)$ & $\mathrm{CV}(\%)$ & Méda (KPa) & Destio (KPa) & $\mathrm{CV}(\%)$ & & & & & \\
\hline Análise 1 & 17228.1 & 593.7 & $3.4 \%$ & 7361.0 & 299.6 & $4.1 \%$ & 23 & 14.84 & 0.00000 & $\infty$ & 7361.0 \\
\hline Anáise 2 & 172281 & 593.7 & $3.4 \%$ & 8614.0 & 350.6 & $4.1 \%$ & 20 & 1249 & 0.00000 & $\infty$ & 86140 \\
\hline Anàisse 3 & 172281 & 593.7 & $3.4 \%$ & 146292 & 595.6 & $4.1 \%$ & 1.2 & 3.09 & 0.00100 & 1000 & 14629.2 \\
\hline
\end{tabular}

Os resultados das análises (Análises 1, 2 e 3) apresentadas na Tabela 8.3.3 mostram que:

$\checkmark$ a Análise 1 resultou num $\mathrm{CS}=2.3$ e numa probabilidade de ruína praticamente nula.

$\checkmark$ se for utilizada a carga admissível como indicada em norma com um $\mathrm{CS}=2.0$ (Análise 2), a fundação terá um $\beta=12.49$, correspondente a uma probabilidade de ruína desprezível.

$\checkmark$ o baixo valor do coeficiente de variação das tensões resistentes (3.4\%) permite o dimensionamento da fundação com uma probabilidade de ruína de 1/1000, ou seja, com $\beta=3.09$ (Análise 3) usando um coeficiente de segurança de apenas 1.2 .

A Tabela 8 e o gráfico da Figura 40 do Apêndice $C$ mostram a relação existente entre a carga admissível, o coeficiente de segurança e a probabilidade de ruína para a fundação analisada. Observe que, devido ao coeficiente de variação das resistências medidas para Cubatão/SP, ser aproximadamente igual, ao coeficiente de variação obtido para a fundação localizada em Angra dos Reis/RJ, os gráficos das Figuras 36 e 40 são extremamente parecidos. 
As análises realizadas com as resistências medidas nas provas de cargas realizadas em Sumaré/SP estão apresentadas nas Figuras 41, 42 e 43 do Apêndice C e o resumo dessas análises na Tabela 8.3.4.

Tabela 8.3.4. Resultados das análises realizadas - Sumaré/SP.

\begin{tabular}{|c|c|c|c|c|c|c|c|c|c|c|c|}
\hline \multirow{2}{*}{ Anä́rses } & \multicolumn{3}{|c|}{ Resistència } & \multicolumn{3}{|c|}{ Saictiaçäo } & \multirow{2}{*}{$\operatorname{cs}$} & \multirow{2}{*}{$\beta$} & \multirow{2}{*}{$\mathrm{Pr}$} & \multirow{2}{*}{$1 / \mathrm{Pr}$} & \multirow{2}{*}{$\begin{array}{l}\text { Pasm } \\
(\mathrm{PPa})\end{array}$} \\
\hline & Méda (KPa) & Desvio $(\mathrm{kPa})$ & CV (\%) & Méda (KPa) & Desvio $(\mathrm{kPa})$ & $\mathrm{CV}(\%)$ & & & & & \\
\hline Anáise 1 & 16598.0 & 16850 & $102 \%$ & 7188.0 & 5992 & $83 \%$ & 23 & 520 & 0.00000 & 13991607 & 7188.0 \\
\hline Anà'se 2 & 16598.0 & 1685.0 & $102 \%$ & 8299.0 & 691.8 & $83 \%$ & 20 & 4.56 & 0.00000 & 383547 & 8299.0 \\
\hline Aná'se 3 & 165980 & 16850 & $102 \%$ & 10705.3 & 8925 & $83 \%$ & 1.6 & 3.09 & 0.00100 & 1000 & 10705.3 \\
\hline
\end{tabular}

A observação da Tabela 8.3.4 permite concluir que:

$\checkmark$ a Análise 1 resultou num $\mathrm{CS}=2.3$ e numa probabilidade de ruína desprezível.

$\checkmark$ utilizando a carga admissível da norma com um $\mathrm{CS}=2.0$ (Análise 2), a fundação terá um $\beta=4.56$ e uma baixa probabilidade de ruína.

$\checkmark$ para que a fundação seja projetada com uma probabilidade de ruína aceitável de $1 / 1000$, ou seja, com um $\beta=3.09$ (Análise 3), esta deverá ser dimensionada com uma carga admissível de $10705.3 \mathrm{kPa}$, o que equivale a utilizar a formulação da norma com um $\mathrm{CS}=1.6$.

O gráfico da Figura 44 do Apêndice C, assim como os valores apresentados na Tabela 9 do Apêndice C, indicam que devido ao coeficiente de variação das tensões resistentes ser maior do que o encontrado para as duas fundações anteriores, é necessário o uso de coeficientes de segurança maiores e de cargas admissíveis menores, para que a fundação possa ser projetada com uma probabilidade de ruína adequada, o que é representado pelo fato das curvas estarem localizadas mais à esquerda do gráfico,

As Figuras 45, 46 e 47 do Apêndice C apresentam as análises realizadas com as resistências medidas para a fundação executada em Santos/SP. O resumo dessas análises pode ser observado na Tabela 8.3.5.

Tabela 8.3.5. Resultados das análises realizadas - Santos/SP.

\begin{tabular}{|c|c|c|c|c|c|c|c|c|c|c|c|}
\hline \multirow{2}{*}{ Análises } & \multicolumn{3}{|c|}{ Resisténcia } & \multicolumn{3}{|c|}{ Solicitação } & \multirow{2}{*}{ cs } & \multirow{2}{*}{$\beta$} & \multirow{2}{*}{$\mathrm{Pr}$} & \multirow{2}{*}{$1 / \mathrm{Pr}$} & \multirow{2}{*}{$\begin{array}{l}\text { Pasm } \\
\left(\mathrm{KPa}_{3}\right)\end{array}$} \\
\hline & Méda $(\mathrm{kPa})$ & Desvio (kPa) & CV (\%) & Méda (KPa) & Desvio (KPa) & CV (\%) & & & & & \\
\hline Análise 1 & 116583 & 22143 & $19.0 \%$ & 64152 & 4921 & $7.7 \%$ & 1.8 & 231 & 0.01040 & 96 & 64152 \\
\hline Anáise 2 & 116583 & 2214.3 & $19.0 \%$ & 58292 & 447.1 & $7.7 \%$ & 20 & 258 & 000493 & 203 & $58 \not 292$ \\
\hline Análise 3 & 116583 & 2214.3 & $19.0 \%$ & 47242 & 3624 & $7.7 \%$ & 25 & 309 & 0.00100 & 1000 & 47242 \\
\hline
\end{tabular}


A partir dos resultados das análises apresentados na Tabela 8.3.5 (Análises 1, 2 e 3) pode-se concluir que se o estaqueamento for projetado com a estatística das resistências medidas nas provas de carga realizadas, este:

$\checkmark$ apresentará uma probabilidade de ruína de 1/96 e um CS $=1.8$ se forem utilizadas as estatísticas das solicitações que foram calculadas em função das cargas nominais das estacas (Análise 1).

$\checkmark$ terá um $\beta=2.58$ correspondente a uma probabilidade de ruína de $1 / 200$, quando da utilização da carga admissível proposta em norma com um $\mathrm{CS}=2.0$ (Análise 2).

$\checkmark$ deverá ser projetado com uma carga admissível de $4724.2 \mathrm{kPa}$, equivalente a um $\mathrm{CS}=2.5$, para que este tenha uma probabilidade de ruína de no máximo 1/1000 (Análise 3).

A Figura 48 e a Tabela 10 do Apêndice C apresentam a variação da probabilidade de ruína com o coeficiente de segurança e com a carga admissível que pode ser adotada no projeto da fundação em análise. Comparando o gráfico da Figura $48 \mathrm{com}$ os das Figuras 36, 40 e 44 comentados anteriormente, pode-se notar que as curvas da Figura 48 apresentam uma posição mais à esquerda em relação ao gráfico. Isso ocorre devido ao fato de que o coeficiente de variação das resistências medidas ser igual a $19.0 \%$, um valor superior aos anteriores, que eram da ordem de $0.0 \%, 3.4 \%$ e $10.2 \%$, respectivamente.

Essa observação permite perceber a enorme praticidade e utilidade desses gráficos, por permitirem, através de uma rápida visualização, identificar se a fundação estudada terá uma alta ou uma baixa probabilidade de ruína devido a sua maior ou menor variabilidade, respectivamente; expressa através do coeficiente de variação das resistências dos elementos isolados de fundação que compõem o estaqueamento analisado.

Observando a Tabela 8.3.6 e as Figuras 49, 50 e 51 do Apêndice C, referentes à análise realizada com a fundação localizada em Duque de Caxias/RJ, pode-se perceber que se o estaqueamento for projetado com as cargas nominais das estacas (Análise 1) este apresentará uma probabilidade de ruína desprezível, sendo que o mesmo ocorre quando é utilizada a formulação da norma com $\mathrm{CS}=2.0$ (Análise 2). Mas, caso se deseje projetar o estaqueamento com uma probabilidade de ruína de 1/1000 (Análise 3), pode ser utilizado um $\mathrm{CS}=1.3$ na formulação da norma, o que resulta numa carga 
admissível igual a $10319.2 \mathrm{kN}$, que é de praticamente o dobro do valor estimado quando da utilização da metodologia da norma.

Tabela 8.3.6. Resultados das análises realizadas - Duque de Caxias/RJ.

\begin{tabular}{|c|c|c|c|c|c|c|c|c|c|c|c|}
\hline \multirow{2}{*}{ Anál'ses } & \multicolumn{3}{|c|}{ Resistencia } & \multicolumn{3}{|c|}{ Solcitaçāo } & \multirow{2}{*}{ CS } & \multirow{2}{*}{$\beta$} & \multirow{2}{*}{ Pr } & \multirow{2}{*}{$1 / \mathrm{Pr}$} & \multirow{2}{*}{$\begin{array}{l}\text { Pasm } \\
\left(\mathrm{F}_{2}\right)\end{array}$} \\
\hline & Méda $(\mathrm{PPa})$ & Desvio (kPa) & CV (\%) & Méda $\left(\mathrm{KP}_{\mathrm{a}}\right)$ & Desvio $\left(\mathrm{KP}_{\mathrm{a}}\right)$ & CV (\%) & & & & & \\
\hline Análse 1 & 13786.4 & 1004.0 & $7.3 \%$ & 6230.9 & 3023 & $49 \%$ & 22 & 7.21 & 0.00000 & $\infty$ & 6230.9 \\
\hline Anä́rse 2 & 137864 & 1004.0 & $7.3 \%$ & 69932 & 334.4 & $4.9 \%$ & 20 & 651 & 000000 & $\infty$ & 68932 \\
\hline Análise 3 & 13786.4 & 1004.0 & $7.3 \%$ & 103192 & 500.7 & $4.9 \%$ & 1.3 & 309 & 0.00100 & 1000 & 10319.2 \\
\hline
\end{tabular}

A Figura 52 e a Tabela 11 do Apêndice C apresentam a relação existente entre os valores de coeficiente de segurança, probabilidade de ruína e de carga admissível para a fundação em análise.

A Tabela 8.3 .7 e as Figuras 53, 54 e 55 do Apêndice C apresentam as análises realizadas com a fundação executada em Barueri/SP.

Tabela 8.3.7. Resultados das análises realizadas - Barueri/SP.

\begin{tabular}{|c|c|c|c|c|c|c|c|c|c|c|c|}
\hline \multirow{2}{*}{ Anälises } & \multicolumn{3}{|c|}{ Resisténcia } & \multicolumn{3}{|c|}{ Solictaçāo } & \multirow{2}{*}{ cs } & \multirow{2}{*}{$\beta$} & \multirow{2}{*}{$\mathrm{Pr}$} & \multirow{2}{*}{$1 / \mathrm{Pr}$} & \multirow{2}{*}{$\begin{array}{l}\text { Pajm } \\
(\mathrm{kPa})\end{array}$} \\
\hline & Média (kPa) & Desvio (KPa) & CV (\%) & Méda (kPa) & Desvio $\left(\mathrm{KP}_{\mathrm{a}}\right)$ & CV (\%) & & & & & \\
\hline Aná'se 1 & 12497.1 & 2704.4 & $21.6 \%$ & 63107 & 3400 & $5.4 \%$ & 20 & 227 & 0.01161 & 86 & 6310.7 \\
\hline Aná'se 2 & 12497.1 & 2704.4 & $21.6 \%$ & 6248.5 & 336.7 & $5.4 \%$ & 20 & 229 & 001093 & 91 & 6248.5 \\
\hline Análise 3 & 12497.1 & 2704.4 & $21.6 \%$ & 4111.4 & 221.5 & $5.4 \%$ & 30 & 3.09 & 000100 & 1000 & 4111.4 \\
\hline
\end{tabular}

Observando a Tabela 8.3.7 pode-se perceber que devido ao valor do coeficiente de variação das resistências previstas (21.6\%), a Análise 3 resultou numa carga admissível de $4111.4 \mathrm{kPa}$, equivalente a um $\mathrm{CS}=3.0$. Por meio dessa tabela, assim como da Figura 56 e da Tabela 12 do Apêndice C, também se percebe que se essa fundação for projetada usando as cargas admissíveis estruturais das estacas (Análise 1) ou a carga admissível proposta em norma, esta terá uma probabilidade de ruína de 1/86 e 1/91, respectivamente; apesar do coeficiente de segurança ser aproximadamente igual a 2.0 em ambas as análises.

A Figura 56 e a Tabela 12 do Apêndice $\mathrm{C}$ mostram que devido ao maior valor do coeficiente de variação das tensões resistentes, é necessário adotar maiores coeficientes de segurança para que possa ser possível "cobrir" a maior variabilidade e as incertezas existentes quanto ao comportamento da fundação analisada. Entretanto, observando a figura e os valores da tabela, percebe-se que, a partir de um determinado coeficiente de segurança, para este exemplo pode-se citar o $\mathrm{CS}=10.0$, a probabilidade de ruína não sofre uma redução significativa com o aumento do coeficiente de segurança e a 
conseqüente redução da carga admissível. Isso significa que o "benefício" obtido com esta redução, passa a não ser compensatória, em relação aos custos necessários na garantia da mesma. Logo, através desse gráfico é também possível identificar qual o valor do coeficiente de segurança ótimo, ou seja, qual o valor ideal de coeficiente de segurança que permite realizar um projeto, ao mesmo tempo, seguro e econômico.

As Figuras 57, 58 e 59 do Apêndice C apresentam as análises realizadas com os valores de resistência medidos nas das prova de carga estática realizadas em Santa Cruz/RJ. O resumo dessas análises está apresentado na Tabela 8.3.8.

Tabela 8.3.8. Resultados das análises realizadas - Santa Cruz/RJ.

\begin{tabular}{|c|c|c|c|c|c|c|c|c|c|c|c|}
\hline \multirow{2}{*}{ Análises } & \multicolumn{3}{|c|}{ Resistência } & \multicolumn{3}{|c|}{ Salcitarăo } & \multirow{2}{*}{ cs } & \multirow{2}{*}{$\beta$} & \multirow{2}{*}{ Pr } & \multirow{2}{*}{$1 / \mathrm{Pr}$} & \multirow{2}{*}{$\begin{array}{l}\text { Pasm } \\
(\mathrm{XPa})\end{array}$} \\
\hline & Média (KPa) & Desvio (kPa) & CV (\%) & Méda $(k P a)$ & Desvio (kPa) & CV (\%) & & & & & \\
\hline Aná'se 1 & 13027.5 & 1337.2 & $10.3 \%$ & 61938 & 373.7 & $60 \%$ & 21 & 4.92 & 0.00000 & 2329552 & 6193.8 \\
\hline Anä'se 2 & 13027.5 & 1337.2 & $10.3 \%$ & 6513.7 & 393.0 & $60 \%$ & 20 & 4.67 & 0.00000 & 674707 & 6513.7 \\
\hline Anáise 3 & 13027.5 & 1337.2 & $103 \%$ & 8595.1 & 518.6 & $6.0 \%$ & 1.5 & 3.09 & 0.00100 & 1000 & 8595.1 \\
\hline
\end{tabular}

Observando a Tabela 8.3.8, que apresenta os resultados das análises realizadas, percebe-se que:

$\checkmark$ se a fundação for projetada utilizando-se as estatísticas das solicitações calculadas em função das cargas nominais das estacas (Análise 1), esta irá apresentar um $\mathrm{CS}=2.1$ e uma probabilidade de ruína desprezível.

$\checkmark$ se a fundação for projetada utilizando-se a carga admissível proposta em norma com um $\mathrm{CS}=2.0$ (Análise 2), esta terá um $\beta=4.67$, correspondente a uma probabilidade de ruína também desprezível.

$\checkmark$ para que o estaqueamento seja projetado com uma probabilidade de ruína de $1 / 1000$, ou seja, com $\beta=3.09$ (Análise 3), é suficiente o uso de um $\mathrm{CS}=1.5$ na formulação da norma, o que correspondente à adoção de uma carga admissível de $8595.1 \mathrm{kPa}$.

A Figura 60 e a Tabela 13 do Apêndice C quando comparados com a Figura 44 e com a Tabela 9 do Apêndice $C$, indicam que a fundação em estudo possui um comportamento semelhante ao apresentado pela fundação analisada anteriormente (Sumaré/SP), provavelmente devido aos coeficientes de variação de suas tensões resistentes serem valores praticamente iguais: $10.2 \%$ e $10.3 \%$, respectivamente.

A Tabela 14 do Apêndice $C$ apresenta o resumo de todas as análises comentadas neste sub-item, de forma a permitir uma rápida comparação e avaliação dos resultados das análises realizadas. 


\subsubsection{Carga admissível - "Resistência 2" e "Solicitação 2"}

Este sub-item apresenta os resultados das análises realizadas com os valores de resistência e de solicitação estimados considerando a área da seção transversal das estacas como "anelar" ("resistência 2" e "solicitação 2").

A Tabela 15 e a Tabela 16 do Apêndice $C$ trazem os valores de tensão resistente e solicitante resultantes da consideração da área da seção transversal como "anelar". As estatísticas dos valores de resistência e de solicitação utilizadas nas análises estão resumidas na Tabela 17 do Apêndice $\mathrm{C}$ e na Tabela 8.3.9 abaixo.

Tabela 8.3.9. Resumo das estatísticas das tensões resistentes 2 e solicitantes 2 .

\begin{tabular}{|l|c|c|c|c|c|c|c|}
\hline \multirow{2}{*}{ Local } & \multirow{2}{*}{ Número } & \multicolumn{3}{|c|}{ Resistência 2 } & \multicolumn{3}{c|}{ Solicitação 2 } \\
\cline { 3 - 8 } & & Média & Desvio & CV & Média & Desvio & CV \\
\cline { 3 - 8 } & $(\mathrm{kPa})$ & $(\mathrm{kPa})$ & $\%$ & $(\mathrm{kPa})$ & $(\mathrm{kPa})$ & $\%$ \\
\hline ANGRA DOS REIS / RJ & 3 & 24548.3 & 341.8 & $1.4 \%$ & 11214.2 & 0.0 & $0.0 \%$ \\
\hline CUBATÃO/SP & 3 & 24745.6 & 0.0 & $0.0 \%$ & 10571.5 & 67.3 & $0.6 \%$ \\
\hline SUMARÉ / SP & 3 & 24415.8 & 571.2 & $2.3 \%$ & 10584.3 & 45.0 & $0.4 \%$ \\
\hline SANTOS / SP & 4 & 19598.9 & 2695.9 & $13.8 \%$ & 10838.2 & 294.7 & $2.7 \%$ \\
\hline DUQUE DE CAXIAS/RJ & 5 & 24006.1 & 1653.6 & $6.9 \%$ & 10842.8 & 242.7 & $2.2 \%$ \\
\hline BARUERI/SP & 6 & 21852.4 & 4061.1 & $18.6 \%$ & 11094.7 & 212.4 & $1.9 \%$ \\
\hline SANTA CRUZ/RJ & 8 & 22705.0 & 1800.3 & $7.9 \%$ & 10802.4 & 238.7 & $2.2 \%$ \\
\hline
\end{tabular}

Usando os valores dessas estatísticas (Tabela 17 do Apêndice C e Tabela 8.3.9) foram realizadas as análises apresentadas nas Figuras 61 a 81 do Apêndice C. Os resultados encontrados, assim como, os comentários relativos a esses resultados, estão apresentados na seqüência.

As análises realizadas com as resistências estimadas para Angra dos Reis/RJ estão apresentadas nas Figuras 61, 62 e 63 do Apêndice C, e o resumo dessas análises está apresentado na Tabela 8.3.10.

Tabela 8.3.10. Resultados das análises realizadas - Angra dos Reis/RJ.

\begin{tabular}{|c|c|c|c|c|c|c|c|c|c|c|c|}
\hline \multirow{2}{*}{ Análises } & \multicolumn{3}{|c|}{ Resistència } & \multicolumn{3}{|c|}{ Sácitaçäo } & \multirow{2}{*}{ CS } & \multirow{2}{*}{$\beta$} & \multirow{2}{*}{ Pr } & \multirow{2}{*}{$1 / \mathrm{Pr}$} & \multirow{2}{*}{$\begin{array}{l}\text { Paim } \\
(\mathrm{kPa})\end{array}$} \\
\hline & Méda (kPa) & Desvio (kPa) & CV (\%) & Méća (KPa) & Desvio (kPa) & CV $(\%)$ & & & & & \\
\hline Análise 1 & 245483 & 341.8 & $1.4 \%$ & 112142 & 00 & $00 \%$ & 22 & 39.00 & 000000 & $\infty$ & 11214.2 \\
\hline Análse 2 & 24548.3 & 341.8 & $1.4 \%$ & 12274.1 & 00 & $0.0 \%$ & 20 & 35.90 & 0.00000 & $\infty$ & 12274.1 \\
\hline Análse 3 & 245483 & 341.8 & $1.4 \%$ & 234906 & 00 & $0.0 \%$ & 1.0 & 300 & 0,00100 & 1000 & 234906 \\
\hline
\end{tabular}


Da observação dessa tabela, pode-se perceber que devido ao baixo valor do coeficiente de variação das resistências (1.4\%), a Análise 3 resultou numa carga admissível próxima à média das tensões resistentes, mostrando que, neste caso, para se projetar à fundação com uma probabilidade de ruína adequada (1/1000) não é necessário usar o coeficiente de segurança mínimo recomendado em norma $(\mathrm{CS}=2.0)$. O mesmo ocorreu com a fundação executada em Cubatão/SP que apresentou um coeficiente de variação nulo $(0.0 \%)$, observe as Figuras 64, 65 e 66 do Apêndice C e a Tabela 8.3.11 abaixo.

Tabela 8.3.11. Resultados das análises realizadas - Cubatão/SP.

\begin{tabular}{|c|c|c|c|c|c|c|c|c|c|c|c|}
\hline \multirow{2}{*}{ Aná'ses } & \multicolumn{3}{|c|}{ Resisténcia } & \multicolumn{3}{|c|}{ Solicitaşão } & \multirow{2}{*}{ CS } & \multirow{2}{*}{$\beta$} & \multirow{2}{*}{ Pr } & \multirow{2}{*}{$1 / \mathrm{Pr}$} & \multirow{2}{*}{$\begin{array}{l}\text { Padm } \\
\left(\mathrm{kPa}_{\mathrm{a}}\right)\end{array}$} \\
\hline & Méda (kPa) & Desvio $\left(\mathrm{kP}_{\mathrm{a}}\right)$ & $\mathrm{CV}(\%)$ & Méda $(\mathrm{kPa})$ & Desvio $(\mathrm{kPa})$ & $\mathrm{CV}(\%)$ & & & & & \\
\hline Análse 1 & 247456 & 0.0 & $0.0 \%$ & 10571.5 & 67.3 & $0.6 \%$ & 23 & 210.51 & 0.00000 & $\infty$ & 10571.5 \\
\hline Anấ'se 2 & 247456 & 00 & $00 \%$ & 123728 & 788 & $0.6 \%$ & 20 & 157.01 & 0.00000 & $\infty$ & 123728 \\
\hline Análise 3 & 247456 & 0.0 & $00 \%$ & 24267.8 & 154.6 & $0.6 \%$ & 1.0 & 309 & 0.00100 & 1000 & 24267.8 \\
\hline
\end{tabular}

Com relação aos resultados apresentados na Tabela 8.3.12 pode-se perceber que a fundação executada em Sumaré/SP (Figuras 67, 68 e 69 do Apêndice C), por também ter apresentado um baixo coeficiente de variação, requer um coeficiente de segurança de apenas 1.1 (Análise 3) para que seja projetado com segurança.

Tabela 8.3.12. Resultados das análises realizadas - Sumaré/SP.

\begin{tabular}{|c|c|c|c|c|c|c|c|c|c|c|c|}
\hline \multirow{2}{*}{ Análises } & \multicolumn{3}{|c|}{ Resistència } & \multicolumn{3}{|c|}{ Solictaçāo } & \multirow{2}{*}{ CS } & \multirow{2}{*}{$\beta$} & \multirow{2}{*}{$\mathrm{Pr}$} & \multirow{2}{*}{$1 / \mathrm{Pl}$} & \multirow{2}{*}{$\begin{array}{l}\text { Padm } \\
(\mathrm{kPa})\end{array}$} \\
\hline & Méda (kPa) & Desvio $(\mathrm{kPa})$ & CV (\%) & Méda $(\mathrm{kPa})$ & Destio (KPa) & CV (\%) & & & & & \\
\hline Anälse 1 & 244158 & 5712 & $23 \%$ & 10584.3 & 450 & $0.4 \%$ & 23 & 24.14 & 0.00000 & $\infty$ & 10584.3 \\
\hline Aná'se 2 & 244158 & 571.2 & $23 \%$ & 12207.9 & 520 & $0.4 \%$ & 20 & 21.28 & 0.00000 & $\infty$ & 12207.9 \\
\hline Análise 3 & 244158 & 571.2 & $23 \%$ & 22625.5 & 96.4 & $0.4 \%$ & 1.1 & 3.09 & 0.00100 & 1000 & 22025.5 \\
\hline
\end{tabular}

Quanto à fundação executada em Santos/SP, as análises realizadas mostram que com a adoção de um CS $=1.7$ é possível projetar a fundação de forma que a sua probabilidade de ruína seja de 1/1000 e que, caso se opte por utilizar a formulação da norma com um $\mathrm{CS}=2.0$, esta resultará numa probabilidade de ruína de apenas $1 / 6716$. Observe a Tabela 8.3.13 e as Figuras 70, 71 e 72 do Apêndice C.

Tabela 8.3.13. Resultados das análises realizadas - Santos/SP.

\begin{tabular}{|c|c|c|c|c|c|c|c|c|c|c|c|}
\hline \multirow{2}{*}{ Anáises } & \multicolumn{3}{|c|}{ Resistència } & \multicolumn{3}{|c|}{ Solicitação } & \multirow{2}{*}{ cs } & \multirow{2}{*}{$\beta$} & \multirow{2}{*}{ Pr } & \multirow{2}{*}{$1 / \mathrm{Pr}$} & \multirow{2}{*}{$\begin{array}{l}P_{\text {adm }} \\
(\mathrm{kPa})\end{array}$} \\
\hline & Méda $(\mathrm{kPa})$ & Desrio (KPa) & CV (\%) & Méda (kPa) & Desvio $(\mathrm{kPa})$ & $\mathrm{CV}(\%)$ & & & & & \\
\hline Aná'se 1 & 195989 & 20959 & $13.8 \%$ & 108382 & 294.7 & $27 \%$ & 1.8 & 323 & 0.00062 & 1617 & 108382 \\
\hline Anár'se 2 & 19598.9 & 20959 & $13.8 \%$ & 9799.4 & 260.4 & $27 \%$ & 20 & 362 & 0.00015 & 6716 & 9799.4 \\
\hline Análise 3 & 195989 & 26959 & $13.6 \%$ & 112142 & 304.9 & $27 \%$ & 1.7 & 3.09 & 0,00100 & 1000 & 112142 \\
\hline
\end{tabular}


As Figuras 73, 74 e 75 do Apêndice $C$ apresentam as análises realizadas com as resistências previstas para a fundação localizada em Duque de Caxias/RJ. O resumo dessas análises está apresentado na Tabela 8.3.14.

Tabela 8.3.14. Resultados das análises realizadas - Duque de Caxias/RJ.

\begin{tabular}{|c|c|c|c|c|c|c|c|c|c|c|c|}
\hline \multirow{2}{*}{ Anä́rses } & \multicolumn{3}{|c|}{ Resistencia } & \multicolumn{3}{|c|}{ Saicitaçăo } & \multirow{2}{*}{ cs } & \multirow{2}{*}{$\beta$} & \multirow{2}{*}{ Pr } & \multirow{2}{*}{$1 / \mathrm{Pr}$} & \multirow{2}{*}{$\begin{array}{l}\text { Pasm } \\
(\mathrm{KPa})\end{array}$} \\
\hline & Méda (kPa) & Desvio (kPa) & CV(\%) & Méda (KPa) & Desvio (KPa) & $\mathrm{CV}(\%)$ & & & & & \\
\hline Análse 1 & 24006.1 & 16536 & $69 \%$ & 108428 & 2427 & $22 \%$ & 22 & 7.88 & 0.00000 & $\infty$ & 103428 \\
\hline Anáise 2 & 24006.1 & 1653.6 & $69 \%$ & 12003.1 & 238.6 & $22 \%$ & 20 & 7.16 & 0.00000 & $3 . E+12$ & 120031 \\
\hline Anál'se 3 & 24006.1 & 16536 & $6.9 \%$ & 18734.3 & 4192 & $22 \%$ & 1.3 & 3.09 & 0.00100 & 1000 & 187343 \\
\hline
\end{tabular}

Observando a Tabela 8.3.14, pode-se perceber que se o estaqueamento for projetado com as cargas nominais das estacas (Análise 1), este apresentará uma probabilidade de ruína nula e, o mesmo acontecerá se for utilizada a formulação da norma com um $\mathrm{CS}=2.0$ (Análise 2), devido aos baixos valores dos coeficientes de variação de suas tensões resistentes e solicitantes. Mas, caso se deseje projetar o estaqueamento com uma probabilidade de ruína de 1/1000 (Análise 3), é necessário utilizar um coeficiente de segurança igual a 1.3 na formulação da norma.

As Figuras 76, 77 e 78 do Apêndice C apresentam as análises realizadas com as resistências obtidas para a fundação localizada em Barueri/SP. O resumo dessas análises encontra-se na Tabela 8.3.15.

Tabela 8.3.15. Resultados das análises realizadas - Barueri/SP.

\begin{tabular}{|c|c|c|c|c|c|c|c|c|c|c|c|}
\hline \multirow{2}{*}{ Anáises } & \multicolumn{3}{|c|}{ Resistència } & \multicolumn{3}{|c|}{ Solicitaçāo } & \multirow{2}{*}{ CS } & \multirow{2}{*}{$\beta$} & \multirow{2}{*}{$\mathrm{Pr}$} & \multirow{2}{*}{$1 / \mathrm{Pr}$} & \multirow{2}{*}{$\begin{array}{l}\text { Pasm } \\
\text { (kPa) }\end{array}$} \\
\hline & Méda (KPa) & Desvio $(k \mathrm{~Pa})$ & $\mathrm{CV}(\%)$ & Méda (KPa) & Desvio $(\mathrm{kPa})$ & CV (\%) & & & & & \\
\hline Análise 1 & 218524 & 4061.1 & $186 \%$ & 110047 & 2124 & $1.9 \%$ & 20 & 265 & 0.00403 & 245 & 11094.7 \\
\hline Aná'se 2 & 218524 & 4061.1 & $186 \%$ & 109262 & 2092 & $1.9 \%$ & 20 & 269 & 0.00361 & 277 & 109262 \\
\hline Anáise 3 & 218524 & 4061.1 & $186 \%$ & 9290.0 & 177.8 & $1.9 \%$ & 24 & 309 & 0.00100 & 1000 & 92900 \\
\hline
\end{tabular}

Os resultados das Análises 1 e 2 apresentadas na Tabela 8.3.15 mostram que apesar de ambas apresentarem um coeficiente de segurança igual à aproximadamente 2.0, as fundações projetadas com o valor de carga admissível previsto por essas análises, terão uma probabilidade de ruína de 1/245 e 1/277, respectivamente. Entretanto, para que a fundação seja projetada com uma probabilidade de ruína de $1 / 1000$, deve-se utilizar um coeficiente de segurança igual a 2.4 na formulação da norma. 
Tabela 8.3.16. Resultados das análises realizadas - Santa Cruz/RJ.

\begin{tabular}{|c|c|c|c|c|c|c|c|c|c|c|c|}
\hline \multirow{2}{*}{ Análises } & \multicolumn{3}{|c|}{ Resistencia } & \multicolumn{3}{|c|}{ Solicitaçāo } & \multirow{2}{*}{ CS } & \multirow{2}{*}{$\beta$} & \multirow{2}{*}{ Pr } & \multirow{2}{*}{$1 / \mathrm{Pr}$} & \multirow{2}{*}{$\begin{array}{l}P_{a J m} \\
\left(\mathrm{KPa}_{3}\right)\end{array}$} \\
\hline & Méda (KPa) & Desvio $(\mathrm{kPa})$ & $\mathrm{CV}(\%)$ & Méda (kPa) & Desvio $(\mathrm{kPa})$ & CV (\%) & & & & & \\
\hline Anáise 1 & 227050 & 1800.3 & $7.9 \%$ & 105024 & 238.7 & $22 \%$ & 21 & 6.55 & 0.00000 & $4 . E+10$ & 105024 \\
\hline Análise 2 & 227050 & 1800.3 & $7.9 \%$ & 113525 & 250.9 & $22 \%$ & 20 & 6.25 & 0.00000 & $5 E+\infty 9$ & 113525 \\
\hline Aná'se 3 & 22705.0 & 1800.3 & $7.9 \%$ & 17021.1 & 3762 & $22 \%$ & 1.3 & 3.09 & 0.00100 & 1000 & 17021.1 \\
\hline
\end{tabular}

A Tabela 8.3.16 apresenta o resumo das análises realizadas com os valores de resistência medidos pelas provas de carga realizadas na fundação executada em Santa Cruz/RJ. Através da observação dessa tabela e das Figuras 79, 80 e 81 do Apêndice C, pode-se perceber que devido à baixa variabilidade do sistema, representado pelo baixo valor do coeficiente de variação das tensões resistentes, a adoção de um coeficiente de segurança igual a 1.3 na formulação da norma, é na realidade, suficiente para que a fundação seja projetada com uma probabilidade de ruína aceitável (1/1000), não sendo necessário o uso de um $\mathrm{CS}=2.0$ como recomendado pela norma.

Um resumo geral dessas análises encontra-se na Tabela 18 do Apêndice C.

\subsubsection{Comentários finais}

Observando os resultados das análises realizadas, que se encontram resumidas nas Tabelas 19, 20 e 21 do Apêndice $C$ relativas às análises realizadas no item 8.3.2.1 e nas Tabelas 22, 23 e 24 do Apêndice $C$ relativas às análises apresentadas no item 8.3.2.2, pode-se traçar os seguintes comentários expostos na seqüência. Para facilitar a análise, as tabelas apresentam os resultados das Análises 1, 2 e 3 separadamente e as fundações foram apresentadas nessas tabelas em ordem crescente do valor do coeficiente de variação das tensões resistentes.

Dos 7 grupos analisados pode-se notar a variação encontrada nos valores de coeficiente de variação das tensões resistentes. Mesmo nos grupos com o mesmo número de provas de carga, como por exemplo, Angra dos Reis/RJ, Cubatão/SP e Sumaré/SP, os coeficientes de variação apresentaram uma significativa variação, mostrando a influência da formação geológica-geotécnica na resistência de uma fundação.

A Tabela 19 do Apêndice C mostra os resultados das Análises 1 realizadas usando as tensões resistentes e solicitantes calculadas considerando a área da seção transversal das estacas como "plena". Observando esses resultados pode-se perceber que com exceção das estacas cravadas em Santos/SP, todas as demais fundações 
apresentarão um coeficiente de segurança superior a 2.0 (mínimo exigido em norma), caso sejam dimensionadas com as cargas admissíveis de catálogo. No entanto, das 7 fundações analisadas existem duas (Santos/SP e Barueri/SP) que apresentaram uma probabilidade de ruína inadequada, representada por um índice de confiabilidade inferior a $3.09(\beta=2.31$ e $\beta=2.27$, respectivamente).

No caso da Análise 2 (Tabela 20 do Apêndice C) em que as fundações são projetadas como indicado em norma, pode-se observar que, em geral, os valores de carga admissível estimados com o uso de um coeficiente de segurança igual a dois a partir dos resultados das provas de carga realizadas, conduziriam a projetos seguros. Existem somente duas fundações (Santos/SP e Barueri/SP) que apresentam um índice de confiabilidade inadequado, as demais apresentaram um índice de confiabilidade superior ao recomendado pela literatura técnica, ou seja, superior a 3.09.

Observando a Tabela 21 do Apêndice $C$, correspondente aos resultados das Análises 3, percebe-se que na realidade, de todas as fundações analisadas, existem somente duas (Santos/SP e Barueri/SP) que devem ser projetadas com o uso de um coeficiente de segurança superior a 2.0, por apresentarem uma maior variabilidade. Esses estaqueamentos devem ser projetados com uma carga admissível menor o que a indicada na Análise 2. Pois, a Análise 3 permitiu visualizar que por apresentarem "baixos" coeficientes de variação (variabilidade inferior à "resguardada" pelo uso do coeficiente de segurança) as demais fundações estão sendo superestimadas, caso sejam projetas usando um $\mathrm{CS}=2.0$, podendo ser projetadas de forma mais econômica e com boa segurança, usando os coeficientes de segurança indicados na Análise 3 quando em comparação com a Análise 2.

Por outro lado, duas fundações (Santos/SP e Barueri/SP) devem ter o coeficiente de segurança superior ao recomendado em norma, pois o uso de um coeficiente de segurança igual a dois, conduziria a uma probabilidade de ruína superior à recomendada, que é de 1/1000. Deve-se observar que, para que estas fundações apresentem um índice de confiabilidade adequado, correspondente a uma probabilidade de ruína aceitável (1/1000), o valor da carga admissível a ser utilizada no projeto do estaqueamento deve ser o calculado na Análise 3, ou seja, deve ser igual a $4724.2 \mathrm{kPa}$ para Santos/SP e de $4111.4 \mathrm{kPa}$ para Barueri/SP, o que equivale a utilizar um coeficiente de segurança igual a 2.5 e 3.0, respectivamente, na formulação da norma. Logo, neste caso, a carga admissível adotada no projeto do estaqueamento, para conduzir a uma fundação segura, deve ser inferior à calculada usando a formulação da norma. 
Quanto às análises apresentadas no item 8.3.2.2 e resumidas nas Tabelas 22, $23 \mathrm{e}$ 24 do Apêndice $C$, pode-se dizer que devido aos baixos valores dos coeficientes de variação das tensões resistentes, se os estaqueamentos forem projetados de acordo com a formulação expressa em norma usando um coeficiente de segurança igual a dois (Análises 2 apresentadas na Tabela 23 do Apêndice C), somente o estaqueamento localizado em Barueri/SP irá apresentar uma probabilidade de ruína superior à recomendada (1/277), os demais estaqueamentos apresentarão segurança.

Com relação ao cálculo das tensões, pode-se observar, pelos resultados das análises, que o cálculo das tensões resistentes e solicitantes em função da área "plena" da seção transversal das estacas é a favor da segurança, pois os valores de carga admissível resultantes das análises foram, em geral, inferiores aos obtidos quando da consideração da área "anelar", pelo fato dos coeficientes de variação serem maiores no primeiro caso. Sendo assim, como conclusão dos dois estudos realizados, é possível perceber que a consideração da área da seção transversal como "plena" pode ser usada com tranqüilidade, por resultar em valores de carga admissível a favor da segurança. Além do mais, deve-se recordar a existência do denominado "embuchamento" e que, para efeito de resistência por atrito lateral, é o diâmetro externo da estaca que representa a área real em contato com o maciço de solos e que, portanto, é responsável pela resistência do sistema.

Como conclusão geral, pode-se dizer que as análises realizadas com as 7 fundações estudadas, permitem perceber a grande vantagem que o uso da formulação proposta apresenta em relação à formulação expressa em norma, por permitir que as mesmas sejam projetadas com segurança e economia com o uso de uma carga admissível adequada. 


\subsection{Análise das fundações em estacas ômega executadas em Paulínia/SP}

Este item tem como objetivo apresentar as análises realizadas da fundação em estacas de concreto armado in silu hélice tipo ômega, executadas mecanicamente em Paulínia - São Paulo, considerando os resultados de 10 provas de carga estática à compressão e as respectivas solicitações atuantes de projeto.

A partir dos valores das solicitações atuantes em cada estaca do conjunto de estacas que compõem o estaqueamento da obra e, dos valores das resistências medidas nas provas de carga, determinou-se a distribuição estatística das solicitações e das resistências. Destas curvas avaliou-se a probabilidade de ruína e o coeficiente de segurança do estaqueamento executado.

\subsubsection{Características Geotécnicas do Maciço de Solos}

A caracterização geológica-geotécnica foi realizada com base em 12 sondagens à percussão tipo SPT realizadas no local da obra. Com base nos resultados dessas sondagens, foi possível elaborar 5 seções geotécnicas do maciço de solos ensaiado, que possibilitaram a formação de uma idéia geral sobre a estratigrafia do mesmo.

O perfil geotécnico do terreno é constituído predominantemente por um aterro de britas seguido de um aterro de argila muito arenosa pouco siltosa marrom-claro. Após o aterro, têm-se camadas de solo argiloso alternadas com camadas de areia e, em alguns pontos do maciço, é possível identificar a presença de lâminas de silte.

\subsubsection{Projeto de Fundação}

\subsubsection{Elemento estrutural de fundação}

Na execução da fundação foram utilizadas estacas de concreto armado in situ hélice tipo ômega de diversos diâmetros.

As características dos elementos estruturais selecionados para a fundação, assim como todos as informações publicadas que serão utilizadas nesta análise, estão apresentadas na Tabela 1 e na Tabela 2 do Apêndice D. As estacas submetidas às provas de carga possuem as armações apresentadas na Tabela 8.4.1. 
Tabela 8.4.1. Armação das estacas submetidas às provas de carga.

\begin{tabular}{|c|c|c|c|}
\hline Estaca & Tipo & Ferragem & Estribo \\
\hline$E-01$ & A & $7 \phi 16 \mathrm{~mm}$ & $\phi 6,3 \mathrm{~mm} \mathrm{c} / 12,5 \mathrm{~cm}$ \\
\hline E-89C & A5 & $7 \phi 16 \mathrm{~mm}$ & $\phi 6,3 \mathrm{~mm} \mathrm{c} / 12,5 \mathrm{~cm}$ \\
\hline E - 232A & A5 & $7 \phi 16 \mathrm{~mm}$ & $\phi 6,3 \mathrm{~mm} \mathrm{c} / 12,5 \mathrm{~cm}$ \\
\hline$E-184 A$ & B3 & $10 \phi 20 \mathrm{~mm}$ & $\phi 6,3 \mathrm{~mm} \mathrm{c} / 15,0 \mathrm{~cm}$ \\
\hline E324 & B4 & $6 \phi 20 \mathrm{~mm}$ & $\phi 6,3 \mathrm{~mm} \mathrm{c} / 12,5 \mathrm{~cm}$ \\
\hline$E-258$ & B4 & $6 \phi 20 \mathrm{~mm}$ & $\phi 6,3 \mathrm{~mm} \mathrm{c} / 12,5 \mathrm{~cm}$ \\
\hline$E-406$ & $\mathrm{BE}$ & $9 \phi 20 \mathrm{~mm}$ & $\phi 6,3 \mathrm{~mm} \mathrm{c} / 17,5 \mathrm{~cm}$ \\
\hline$E-368$ & $\mathrm{BE}$ & $9 \phi 20 \mathrm{~mm}$ & $\phi 6,3 \mathrm{~mm} \mathrm{c} / 17,5 \mathrm{~cm}$ \\
\hline E- $18 C$ & $\overline{\mathrm{BE}}$ & $9 \phi 20 \mathrm{~mm}$ & $\phi 6,3 \mathrm{~mm} \mathrm{c} / 17,5 \mathrm{~cm}$ \\
\hline E-065A (tração) & B1 & $6 \phi 16 \mathrm{~mm}$ & $\phi 6,3 \mathrm{~mm} \mathrm{c} / 12,5 \mathrm{~cm}$ \\
\hline E-205 (horizontal) & A4 & $11 \phi 20 \mathrm{~mm}$ & $\phi 6,3 \mathrm{~mm} \mathrm{c} / 17,5 \mathrm{~cm}$ \\
\hline E-100 (horizontal) & $\mathrm{BE}$ & $9 \phi 20 \mathrm{~mm}$ & $\phi 6,3 \mathrm{~mm} \mathrm{c} / 17,5 \mathrm{~cm}$ \\
\hline
\end{tabular}

\subsubsection{Esforços solicitantes nas estacas}

As solicitações ou cargas de serviço que cada estaca estará sujeita, foram calculadas com base nas "cargas" atuantes nos pilares e na distribuição geométrica do estaqueamento de forma a conduzir ao dimensionamento mais econômico.

As solicitações atuantes nas estacas estão apresentadas na Tabela 3 do Apêndice D e o seu resumo na Tabela 8.4 .2 abaixo. Nesta tabela encontram-se os valores das cargas de serviço e as respectivas tensões médias nas seções nominais do fuste das estacas.

Tabela 8.4.2. Resumo das estatísticas das solicitações.

\begin{tabular}{|c|c|c|c|c|c|}
\hline \multirow{2}{*}{ Estatisticas } & \multicolumn{3}{|c|}{ Estaca } & Carga Serviço & Solicitação \\
\cline { 2 - 4 } & $\mathrm{D}(\mathrm{m})$ & $\mathrm{L}(\mathrm{m})$ & Área $\left(\mathrm{m}^{2}\right)$ & $(\mathrm{kN})$ & $(\mathrm{kPa})$ \\
\hline Média & 0.37 & 13.5 & 0.1064 & 440.0 & 4062.4 \\
\hline Desvio & 0.05 & 2.0 & 0.03 & 150.6 & 362.9 \\
\hline CV $(\%)$ & $13.6 \%$ & $14.8 \%$ & $27.1 \%$ & $34.2 \%$ & $8.9 \%$ \\
\hline
\end{tabular}

Como as provas de carga foram executadas em estacas de diferentes diâmetros, a análise estatística das solicitações foi realizada em termos das tensões solicitantes referenciadas às áreas nominais do fuste dos elementos estruturais de fundação.

Observando a Tabela 8.4.2, percebe-se que os valores obtidos conduziram a:

- Solicitação média

- Desvio padrão das solicitações

- Coeficiente de variação
$=4062.4 \mathrm{kPa}$.

$=362.9 \mathrm{kPa}$.

$=8.9 \%$. 


\subsubsection{Apresentação dos resultados dos ensaios realizados}

Os dados utilizados nesta análise encontram-se na Tabela 1 e Tabela 2 do Apêndice D, como comentado anteriormente. A partir desses dados foram plotadas as curvas carga $\mathrm{x}$ recalque das provas de carga estática realizadas. As curvas carga $\mathrm{x}$ recalque obtidas estão apresentadas nas Figuras 1 a 10 do Apêndice D.

As provas de carga realizadas não foram conduzidas à ruptura, sendo assim, para se obter o valor da carga de ruptura de cada uma das estacas, foi necessário realizar a extrapolação da curva carga x recalque através da utilização do Método de Van der Veen (1953). Os valores dos parâmetros A e B e as cargas de ruptura calculadas encontram-se resumidos na Tabela 8.4.3.

Tabcla 8.4.3. Parâmetros A e B e carga de ruptura - Método de Van der Veen.

\begin{tabular}{|l|c|c|c|}
\hline Estaca & $P_{\text {rup }}(\mathrm{kN})$ & $\mathrm{A}$ & $\mathrm{B}$ \\
\hline (Estaca 1) E - 368 & 1119.3 & 0.2947 & 0.2248 \\
\hline (Estaca 2) E - 232A & 698.4 & 0.8310 & 0.0200 \\
\hline (Estaca 3) E - 406 & 1213.7 & 0.2349 & 0.2784 \\
\hline (Estaca 4) E - 01 & 670.9 & 0.8002 & -0.0811 \\
\hline (Estaca 5) E - 368 & 1206.1 & 1.3828 & -0.0462 \\
\hline (Estaca 6) E - 184A & 1093.3 & 0.0989 & 0.2464 \\
\hline (Estaca 7) E324 & 860.4 & 0.6931 & -0.0158 \\
\hline (Estaca 8) E - 89C & 1207.3 & 0.8752 & -0.0330 \\
\hline (Estaca 9) E - 258 & 1128.1 & 0.8968 & -0.0416 \\
\hline (Estaca 10) E - 18C & 1899.4 & 0.2604 & 0.0927 \\
\hline
\end{tabular}

O resumo dos resultados das provas de carga estáticas à compressão realizadas em 10 estacas da obra está apresentado na Tabela 4 do Apêndice D e na Tabela 8.4.4.

Tabela 8.4.4. Estatísticas das resistências medidas nas provas de carga estáticas.

\begin{tabular}{|c|c|c|c|c|c|c|}
\hline \multirow{2}{*}{ Estatísticas } & \multicolumn{3}{|c|}{ Estaca } & \multirow{2}{*}{$\begin{array}{l}P_{\text {rup }} \\
(\mathrm{kN})\end{array}$} & \multirow{2}{*}{$\begin{array}{c}\text { Resistência' } \\
\text { (kPa) }\end{array}$} & \multirow{2}{*}{$\begin{array}{c}\text { CS } \\
\text { "individual" }\end{array}$} \\
\hline & $\mathrm{D}(\mathrm{m})$ & $L(m)$ & Área $\left(m^{2}\right)$ & & & \\
\hline Média & 0.37 & 13.5 & 0.1064 & 1109.7 & 10618.5 & 2.6 \\
\hline Desvio & 0.05 & 2.0 & 0.03 & 346.0 & 2649.0 & 0.8 \\
\hline CV (\%) & $13.6 \%$ & $14.8 \%$ & $27.1 \%$ & $31.2 \%$ & $24.9 \%$ & $29.1 \%$ \\
\hline
\end{tabular}

'resistência medida. 
A Tabela 8.4.4 mostra que a análise estatística das tensões resistentes referenciadas às áreas nominais dos elementos estruturais de fundação conduziu a:

- Resistência média $\quad=10618.5 \mathrm{kPa}$.

- Desvio padrão das resistências $=2649.0 \mathrm{kPa}$.

- Coeficiente de variação $\quad=24.9 \%$.

No entanto, tendo em vista a não disponibilidade de resultados de ensaios de resistência à compressão de corpos de prova de concreto da fundação, adotou-se uma resistência estrutural máxima igual a três vezes a carga nominal da estaca, considerando ser este o coeficiente de segurança global exigido pela antiga norma NB-1 para o material concreto. Sendo assim, as resistências obtidas através das provas de carga PCC-08, PCC-09 e PCC-10, que conduziram a coeficientes de segurança de 4.02, 3.76 e 3.17, tiveram seus resultados limitados a $11190.6,11190.6$ e $12922.2 \mathrm{kPa}$, respectivamente.

A Tabela 8.4.5 apresenta a média, o desvio padrão e o coeficiente de variação para os novos valores de resistências.

Tabela 8.4.5. Estatísticas das resistências limitadas.

\begin{tabular}{|c|c|c|c|c|c|c|c|c|}
\hline \multirow{2}{*}{ Estatisticas } & \multicolumn{3}{|c|}{ Estaca } & \multirow{2}{*}{$\begin{array}{l}P_{\text {nup }} \\
(\mathrm{kN})\end{array}$} & \multirow{2}{*}{$\begin{array}{c}\text { Tensão } \\
\text { Serviço (kPa) }\end{array}$} & \multirow{2}{*}{$\begin{array}{l}3 \times \text { Tensão } \\
\text { Serviço }(\mathrm{kPa})\end{array}$} & \multirow{2}{*}{$\begin{array}{l}\text { Resistência" } \\
\text { (kPa) }\end{array}$} & \multirow{2}{*}{$\begin{array}{c}\text { CS } \\
\text { "Limitado" }\end{array}$} \\
\hline & $\mathrm{D}(\mathrm{m})$ & $\mathrm{L}(\mathrm{m})$ & Área $\left(\mathrm{m}^{2}\right)$ & & & & & \\
\hline Média & 0.37 & 13.5 & 0.1064 & 1109.7 & $4,062.4$ & 12187.3 & 9881.2 & 2.5 \\
\hline Desvio & 0.05 & 2.0 & 0.03 & 346.0 & 362.9 & 1088.8 & 1617.3 & 0.5 \\
\hline CV (\%) & $13.6 \%$ & $14.8 \%$ & $27.1 \%$ & $31.2 \%$ & $8.9 \%$ & $8.9 \%$ & $16.4 \%$ & $18.9 \%$ \\
\hline
\end{tabular}

"resistência limitada.

Segundo a Tabela 8.4 .5 a análise estatística das tensões resistentes da fundação conduziu a:

- Resistência média $\quad=9881.2 \mathrm{kPa}$.

- Desvio padrão das resistências $=1617.3 \mathrm{kPa}$.

- Coeficiente de variação $\quad=16.4 \%$.

Pode-se notar que a limitação do valor de resistência extrapolada da prova de carga levou a uma redução do coeficiente de variação, fato que será favorável ao projeto da mesma, apesar do valor médio da resistência haver reduzido, como poderá ser observado posteriormente através das análises que foram realizadas. 


\subsubsection{Análise de todas as estacas em termos de tensões}

No Apêndice D encontram-se as curvas de distribuição estatística dos valores de solicitações e resistências das estacas da obra. As Figuras 11, 12 e 13 do Apêndice D apresentam as Análises 1, 2 e 3 realizadas com os valores de resistência apresentadas na Tabela 8.4.4, ou seja, com os valores "reais" de resistência. Os resultados das análises realizadas conduziram aos seguintes valores:

Tabela 8.4.6. Resultado das análises realizadas.

\begin{tabular}{|c|c|c|c|c|c|c|c|c|c|c|c|}
\hline \multirow{2}{*}{ Análises } & \multicolumn{3}{|c|}{ Resistência "Real" } & \multicolumn{3}{|c|}{ Solicitação } & \multirow{2}{*}{ cs } & \multirow{2}{*}{$\boldsymbol{\beta}$} & \multirow{2}{*}{$\mathrm{Pr}$} & \multirow{2}{*}{$1 / \mathrm{Pr}$} & \multirow{2}{*}{$\begin{array}{l}P_{\text {adm }} \\
(\mathrm{kPa})\end{array}$} \\
\hline & Média (kPa) & Desvio (kPa) & CV $(\%)$ & Média (kPa) & Desvio (kPa) & $\mathrm{CV}(\%)$ & & & & & \\
\hline Análise 1 & 10618.5 & 2649.0 & 24.9 & 4062.4 & 3629 & 8.9 & 26 & 245 & 0.00710 & 141 & 4062.4 \\
\hline Análise 2 & 10618.5 & 2649.0 & 24.9 & 5309.3 & 4743 & 8.9 & 20 & 1.97 & 0.02425 & 41 & 5309.3 \\
\hline Análise 3 & 10618.5 & 2649.0 & 24.9 & 2405.3 & 2142 & 8.9 & 4.4 & 3.09 & 0.00100 & 1000 & 2405.3 \\
\hline
\end{tabular}

Com os valores de resistência apresentados na Tabela 8.4.5, ou seja, com os valores de resistência "limitados", foram realizadas as análises (Análises 1, 2 e 3) apresentadas nas Figuras 15, 16 e 17 do Apêndice D. Os resultados das análises realizadas conduziram aos seguintes valores:

Tabela 8.4.7. Resultado das análises realizadas com as resistências "limitadas".

\begin{tabular}{|c|c|c|c|c|c|c|c|c|c|c|c|}
\hline \multirow{2}{*}{ Análises } & \multicolumn{3}{|c|}{ Resistência "Limitada" } & \multicolumn{3}{|c|}{ Solicitação } & \multirow{2}{*}{ cs } & \multirow{2}{*}{ B } & \multirow{2}{*}{ Pr } & \multirow{2}{*}{$1 / \mathrm{Pr}$} & \multirow{2}{*}{$\begin{array}{l}P_{\text {adm }} \\
(\mathrm{kPa})\end{array}$} \\
\hline & Méda (kPa) & Desvio (KPa) & CV $(\%)$ & Méda (kPa) & Desvio (KPa) & $\mathrm{CV}(\%)$ & & & & & \\
\hline Análise 1 & 9881.2 & 1617.3 & 16.4 & 40624 & 3629 & 8.9 & 24 & 3.51 & 0.00022 & 4472 & 40624 \\
\hline Análise 2 & 9881.2 & 1617.3 & 16.4 & 4940.6 & 441.4 & 8.9 & 20 & 295 & 0.00160 & 623 & 4940.6 \\
\hline Análise 3 & 9881.2 & 1617.3 & 16.4 & 4717.4 & 419.9 & 8.9 & 2.1 & 3.09 & 0.00100 & 1000 & 4717.4 \\
\hline
\end{tabular}

As Figuras 14 e 18 apresentadas no Apêndice D trazem os gráficos da carga admissível em função do coeficiente de segurança e da probabilidade de ruína da fundação. Através desses gráficos é possível determinar qual deve ser o valor da carga admissível para uma probabilidade de ruína desejada.

Os resultados das análises apresentadas permitem fazer algumas observações:

a) Considerando as resistências "reais", ou seja, as resistências medidas pelas provas de carga estáticas, têm-se os seguintes resultados:

$\checkmark$ Análise 1: Fixando a carga admissível em $4062.4 \mathrm{kPa}$, que é o valor médio das solicitações, tem-se:

$$
\begin{aligned}
& -\mathrm{CS}=2.60 . \\
& -\beta=2.45
\end{aligned}
$$


$-\operatorname{Pr}=1$ para 141.

Análise 2: Com um coeficiente de segurança igual a dois, ou seja, $\mathrm{CS}=2.0$, tem-se:

$-\mathrm{P}_{\mathrm{adm}}=5309.3 \mathrm{kPa}$.

$-\beta=1.97$.

- $\operatorname{Pr} \quad=1$ para 41.

$\checkmark$ Análise 3: Fixando a probabilidade de ruína em 1/1000, ou seja, $\beta=3.09$, tem-se:

$-\mathrm{P}_{\mathrm{adm}}=2405.3 \mathrm{kPa}$

$-\mathrm{CS}=4.4$.

b) Considerando as estatísticas dos valores de resistências "limitadas", tem-se:

$\checkmark$ Análise 1: Fixando a carga admissível em $4062.4 \mathrm{kPa}$, que é o valor médio das solicitações, tem-se:

$-\mathrm{CS}=2.4$.

$-\beta=3.51$.

- $\operatorname{Pr}=1$ para 4472.

Análise 2: Adotando o coeficiente de segurança igual a dois, ou seja, $\mathrm{CS}=2.0$, temse:

$$
\begin{aligned}
& -\mathrm{P}_{\mathrm{adm}}=4940.6 \mathrm{kPa} . \\
& -\beta \quad=2.95 . \\
& -\operatorname{Pr}=1 \text { para } 623 .
\end{aligned}
$$

Análise 3: Fixando a probabilidade de ruína em 1/1000, ou seja, $\beta=3.09$, tem-se:

$$
\begin{aligned}
& -\mathrm{P}_{\mathrm{adm}}=4717.4 \mathrm{kPa} \\
& -\mathrm{CS}=2.1 .
\end{aligned}
$$

\subsubsection{Comentários finais}

Observando as três primeiras análises apresentadas na Tabela 8.4.6, percebe-se que se o estaqueamento for projetado utilizando a carga admissível que foi pré-fixada na Análise 1, este não apresentará segurança, uma vez que esta análise resultou num índice de confiabilidade inferior a 3.09, apesar do coeficiente de segurança ser superior a 2.0. Para que esta fundação seja segura, ela deverá ser projetada com um coeficiente de segurança no mínimo igual a 4.4, como mostra a Análise 3. 
Entretanto, ao contrário destas análises, ao se observar as três análises apresentadas na Tabela 8.4 .7 , pode-se perceber que a fundação será projetada com segurança ao ser utilizada a carga admissível que está prevista para o estaqueamento (Análise 1), pois esta apresentou um índice de confiabilidade superior a 3.09, mais precisamente um índice de confiabilidade igual a 3.51, que corresponde a uma probabilidade de falha em 4472 estacas (1/4472). Neste caso, a metodologia proposta permite observar que é possível reduzir o coeficiente de segurança de 2.4 para 2.1, ou melhor, aumentar a carga admissível de $4062.4 \mathrm{kPa}$ (Análise 1) para $4717.4 \mathrm{kPa}$ (Análise 3) e, ainda assim, obter uma fundação segura.

Observando a Análise 2 de ambas as tabelas, percebe-se que o uso de um coeficiente de segurança adequado, considerado geralmente igual a 2.0 , não seria suficiente para garantir a segurança da fundação. Neste contexto, é possível perceber a grande vantagem do uso da carga admissível proposta na realização de um projeto de fundação seguro e otimizado. 


\subsection{Estacas pré-moldadas cravadas em Duque de Caxias/RJ}

Apresenta-se neste item a análise da fundação de um complexo de prédios industriais para armazenamento de alimentos. Foram cravadas, nessa obra, 2.522 estacas pré-moldadas de concreto protendido com diâmetros variados e com comprimento médio de cerca de $20 \mathrm{~m}$. Durante a execução do estaqueamento, foram realizadas 23 provas de carga dinâmicas de energia constante para avaliação do estaqueamento.

Como informações básicas para essa análise, serão apresentadas as características geotécnicas do terreno, a descrição do projeto de fundação, e os resultados experimentais dos ensaios realizados para a verificação da capacidade de carga das estacas, ou seja, os resultados das provas de carga dinâmica realizadas. Todos os dados utilizados nesta análise foram publicados por Santa Maria \& Siqueira (2002).

\subsubsection{Características Geotécnicas do Maciço de Solos}

O local na qual a obra foi implantada faz parte de um terreno situado às margens da rodovia Washington Luís, próximo ao $\mathrm{km} \mathrm{1,} \mathrm{e} \mathrm{junto} \mathrm{ao} \mathrm{Canal} \mathrm{do} \mathrm{Rio} \mathrm{Meriti,} \mathrm{no}$ Município de Duque de Caxias, RJ. O terreno, possui cerca de $1.276 .500 \mathrm{~m}^{2}$, é aproximadamente plano, tendo sido formado pela execução de um aterro, executado há aproximadamente 16 anos, constituído por uma primeira camada de aterro hidráulico arenoso, subjacente a uma manta de argila arenosa (SANTA MARIA \& SIQUEIRA, 2002).

Em julho e agosto de 1998 foi realizada uma campanha de prospecção geotécnica, abrangendo a execução de 18 furos de sondagem à percussão, 13 ensaios de palheta e a retirada de amostras indeformadas de argila para realização de ensaios de laboratório. Dos 18 furos de sondagem, apenas 6 prosseguiram até o material impenetrável à percussão, tendo sido os demais interrompidos precocemente. Durante a execução do estaqueamento, houve a necessidade de realizar mais 4 furos de sondagem, com o objetivo de verificar as características do terreno em pontos onde os diagramas de cravação das estacas apresentavam divergências em relação ao previsto (SANTA MARIA \& SIQUEIRA, 2002).

$\mathrm{Na}$ região da obra, o perfil geotécnico do terreno é constituído predominantemente por uma camada superficial de areia fina e média com pedregulhos, com espessura de até $2.20 \mathrm{~m}$, sobrejacente a uma camada de silte argiloso com areia 
fina e média, com espessura entre $0.90 \mathrm{~m}$ e $6.00 \mathrm{~m}$. Essas duas camadas constituem o aterro realizado há cerca de 16 anos. Em seguida, observa-se a presença de uma camada de argila orgânica com pouca areia fina, com $6.70 \mathrm{~m}$ a $9.50 \mathrm{~m}$ de espessura. Em alguns trechos, subjacente à argila orgânica, há uma camada de argila siltosa com pouca areia fina, com espessura máxima de $2.30 \mathrm{~m}$, sobrejacente a uma camada de areia fina e média com espessura variando entre $0.90 \mathrm{~m}$ e $5.50 \mathrm{~m}$. Abaixo dessa camada encontra-se um solo residual de predominância siltosa e que apresenta espessura superior a $5 \mathrm{~m}$ (SANTA MARIA \& SIQUEIRA, 2002).

\subsubsection{Informações sobre o Projeto da Fundação}

\subsubsection{Elemento Estrutural}

Foram utilizadas estacas pré-moldadas quadradas de concreto protendido devido ao reduzido prazo de execução, à presença de camada de argila muito mole e à necessidade de monitoração da execução em virtude do reduzido número de furos de sondagens (SANTA MARIA \& SIQUEIRA, 2002). As características dos elementos estruturais selecionados para a fundação da obra estão listadas na Tabela 8.5.1.

Tabela 8.5.1. Estacas selecionadas.

\begin{tabular}{|c|c|c|c|c|}
\hline $\begin{array}{c}\text { Dimensöes da } \\
\text { seção }(\mathrm{m})\end{array}$ & $\begin{array}{c}\text { Número de } \\
\text { estacas }\end{array}$ & $\begin{array}{c}\text { Área } \\
\left(\mathbf{m}^{2}\right)\end{array}$ & $\begin{array}{c}\text { Perímetro } \\
(\mathbf{m})\end{array}$ & $\begin{array}{c}\text { Carga estrutural } \\
\text { admissível }(\mathrm{kN})\end{array}$ \\
\hline $0.215 \times 0.215$ & 290 & 0.0462 & 0.86 & 670 \\
\hline $0.235 \times 0.235$ & 468 & 0.0552 & 0.94 & 820 \\
\hline $0.265 \times 0.265$ & 1669 & 0.0702 & 1.06 & 1060 \\
\hline $0.295 \times 0.295$ & 95 & 0.0870 & 1.18 & 1340 \\
\hline
\end{tabular}

\subsubsection{Esforços nas Estacas}

A solicitação ou carga de trabalho que cada estaca estará sujeita, será composta pela sua carga útil acrescida do atrito negativo atuante na estaca.

As cargas íteis a serem suportadas pelas estacas foram calculadas tendo em vista as solicitações (cargas) atuantes nos pilares e a modulação do estaqueamento dos pisos dos depósitos, de forma a conduzir ao dimensionamento mais econômico.

Quanto ao atrito negativo, foi realizada uma análise probabilística para a sua 
determinação. Os valores de cargas úteis e de atrito negativo obtidos estão resumidos na Tabela 8.5.2, assim como as cargas de trabalho resultantes.

Tabela 8.5.2. Carga útil e atrito negativo.

\begin{tabular}{|c|c|c|c|c|c|}
\hline \multirow{2}{*}{$\begin{array}{c}\text { Seçäo da } \\
\text { estaca }\end{array}$} & \multirow{2}{*}{$\begin{array}{c}\text { Carga útil } \\
(\mathrm{Pt})\end{array}$} & \multicolumn{3}{|c|}{ Atrito Negativo (AN) } & Carga deTrabalho \\
\cline { 3 - 5 } & & Média & Desvio & $\mathbf{A N}_{\mathrm{k}}{ }^{*}$ & \multirow{2}{*}{$\begin{array}{c}\mathrm{Pt}+0.85 . \mathrm{AN}_{\mathrm{k}} \\
(\mathrm{m})\end{array}$} \\
\cline { 3 - 5 } & $(\mathrm{kN})$ & $(\mathrm{kN})$ & $(\mathrm{kN})$ & $(\mathrm{kN})$ & \\
\hline $0.215 \times 0.215$ & 350 & 187.9 & 25.4 & 232 & 547 \\
\hline $0.235 \times 0.235$ & 500 & 194.8 & 30.0 & 248 & 711 \\
\hline $0.265 \times 0.265$ & 600 & 215.6 & 34.5 & 277 & 835 \\
\hline $0.295 \times 0.295$ & 800 & 228.4 & 40.9 & 301 & 1056 \\
\hline
\end{tabular}

* $\mathrm{AN}_{\mathrm{k}}$ : valor característico do atrito negativo.

Segundo Santa Maria \& Siqueira (2002), o fator de minoração de 0.85 (1.2/1.4), utilizado no cálculo da solicitação ou carga de trabalho quando da utilização do atrito negativo, decorre do fato de que este fenômeno é antes um problema de recalque do que um problema de ruptura (NBR 6122/1996 e NBR 8681/1984).

\subsubsection{Cálculo do estaqueamento}

A previsão da capacidade de carga das estacas foi realizada utilizando-se o Método Aoki-Velloso (1975). O critério adotado pelo projetista para realizar essa previsão, foi calcular individualmente para cada estaca da obra, o comprimento necessário para garantir que a mesma apresente a capacidade de carga necessária (Santa Maria \& Siqueira, 2002). Ou seja, o projetista trabalha com uma "carga admissível" para cada estaca e não com o conceito de carga admissível aplicado à fundação (CINTRA \& AOKI, 1999). A Tabela 8.5.3 apresenta a relação entre a carga de trabalho e a carga admissível estrutural para cada um dos quatro tipos de elementos estruturais utilizados na fundação desta obra.

Tabela 8.5.3. Relação: Solicitação e Resistência estrutural.

\begin{tabular}{|c|c|c|c|}
\hline $\begin{array}{c}\text { Seção da } \\
\text { estaca }(\mathrm{m})\end{array}$ & $\begin{array}{c}\text { Carga de Trabalho }(\mathrm{kN}) \\
\mathrm{Pt}+0.85 . \mathrm{AN}_{\kappa}\end{array}$ & $\begin{array}{c}\text { Carga estrutural } \\
\text { admissivel }(\mathrm{kN})\end{array}$ & $\begin{array}{c}\text { Carga de Trabalho } \\
\text { Carga admissivel }\end{array}$ \\
\hline $0.215 \times 0.215$ & 547 & 670 & 0.82 \\
\hline $0.235 \times 0.235$ & 711 & 820 & 0.87 \\
\hline $0.265 \times 0.265$ & 835 & 1060 & 0.79 \\
\hline $0.295 \times 0.295$ & 1056 & 1340 & 0.79 \\
\hline
\end{tabular}




\subsubsection{Apresentação das Análises}

\subsubsection{Ensaios realizados}

Como todas as estacas da obra apresentaram tensão média atuante na seção de concreto superior a $6 \mathrm{MPa}$ (considerando a ação do atrito negativo), de acordo com a NBR 6122/1996 a verificação da capacidade de carga deve ser feita através de prova de carga ou instrumentação. Segundo a norma, deveriam ser executadas provas de carga estática em número de $1 \%$ do conjunto de estacas de mesmas características na obra ou ensaios de carregamento dinâmico em número de $3 \%$ de cada conjunto. Apesar das quantidades previstas em norma, realizaram-se, nesta obra, apenas 23 ensaios de carregamento dinâmico (SANTA MARIA \& SIQUEIRA, 2002).

A monitoração da cravação, com seus resultados analisados pela Teoria da Equação da Onda, pode ser utilizada na verificação da qualidade e desempenho das estacas. Esse procedimento tem sido chamado de Ensaio de Carregamento Dinâmico ou Prova de Carga Dinâmica (SANTA MARIA \& SIQUEIRA, 2002).

Os resultados das 23 provas de carga dinâmicas de energia constante realizadas estão apresentados na Tabela 1 do Apêndice E. Das 23 estacas ensaiadas, apenas uma apresentou danos estruturais (E-278) e quatro apresentaram coeficientes de segurança inferiores a 2.0. Dessas quatro, apenas a estaca E-297 foi recravada; as demais foram aceitas, pois se considerou provável a ocorrência de um ganho de resistência com o tempo (SANTA MARIA \& SIQUEIRA, 2002). Os resultados dos ensaios dinâmicos realizados na obra indicaram que os coeficientes de segurança variaram entre 1.6 e 2.9, ficando em média, em torno de 2.4 .

\subsubsection{Análise de todas as estacas em termos de tensões}

Inicialmente, optou-se por analisar em conjunto todas as provas de carga realizadas. Sendo assim, devido ao fato dessas provas de carga terem sido realizadas em estacas com diferentes dimensões de seções transversais, essas primeiras análises foram realizadas em termos de tensões.

A Tabela 2 do Apêndice $\mathrm{E}$ apresenta os valores de tensões resistentes e de tensões solicitantes para as 23 estacas ensaiadas, assim como os seus respectivos valores médios, de desvio padrão e de coeficiente de variação. Esses últimos também encontram-se resumidos na Tabela 8.5.4. 
Tabela 8.5.4. Variabilidade das tensões resistentes e solicitantes.

\begin{tabular}{|c|c|c|c|}
\hline Tensão & Média $(\mathrm{kPa})$ & Desvio $(\mathrm{kPa})$ & $\mathrm{CV}(\%)$ \\
\hline Resistente & 28542.3 & 5594.0 & 19.6 \\
\hline Solicitante & 12188.1 & 467.9 & 3.8 \\
\hline
\end{tabular}

Com os valores médios, de desvio padrão e de coeficiente de variação de resistência e de solicitação da Tabela 8.5 .4 foi realizada as três primeiras análises apresentadas no Apêndice E (Figura 1, 2 e 3).

Da primeira análise, Análise 1 (Figura 1 do Apêndice E), resulta que o coeficiente de segurança da fundação é de 2.34 e que seu índice de confiabilidade é de 2.91, o que implica numa probabilidade de ruína de 1.8/1000, ou seja, 1 estaca em cada 559 estacas poderão falhar. Essa probabilidade de ruína é relativamente aceitável quando comparada com a recomendada para os projetos de fundação que é de 1/1000. No entanto, recordando que está obra possui 2522 estacas, tem-se que há a probabilidade de, aproximadamente, 5 estacas da fundação falharem, ou melhor, apresentarem coeficiente de segurança individual menor que um, o que teoricamente, pode ser preocupante.

A Análise 2 foi realizada fixando o valor médio e o coeficiente de variação da resistência da Tabela 8.5 .4 e o coeficiente de segurança igual a 2.0. Essa análise resultou numa carga admissível de $14271.2 \mathrm{kPa}$ e numa probabilidade de ruína de 5.6/1000 (ou seja, de 1/180), apesar do coeficiente de segurança estar de acordo com o recomendado em norma , ou seja, CS = 2.0 (NBR 6122/1996), vindo a confirmar que este índice não é representativo da segurança de uma fundação.

A Análise 3 foi realizada fixando o valor médio e o coeficiente de variação da resistência da Tabela 8.5 .4 e a probabilidade de ruína em 1/1000, o que corresponde a um índice de confiabilidade igual a 3.09. A partir dessa análise percebe-se que, para esta fundação, a carga admissível recomendada para se realizar o projeto da mesma com segurança é a que corresponde ao uso de um coeficiente de segurança de 2.55.

Os resultados dessas três análises encontram-se resumidos na Tabela 8.5.5. Deve-se destacar, entretanto, que apesar da Análise 1 mostrar o fato de existir a probabilidade de 5 estacas dessa fundação falharem, não há motivo de preocupação, pois, essa análise foi realizada utilizando-se dados de provas de carga dinâmicas de energia constante. Sabe-se que neste tipo de prova de carga não existe a garantia de que as cargas mobilizadas nas mesmas sejam as cargas de ruptura das estacas. Logo, as 
resistências estimadas por essas provas de carga costumam ser inferiores às reais capacidades resistentes das estacas. Sendo assim, apesar da probabilidade de ruína prevista para a fundação em questão ser elevada, esta não deverá apresentar maiores problemas devido ao fato das resistências terem sido subestimadas.

Tabcla 8.5.5. Resultados das análises realizadas em termos de tensões.

\begin{tabular}{|c|c|c|c|c|c|c|c|c|c|c|c|}
\hline \multirow{2}{*}{ Análises } & \multicolumn{3}{|c|}{ Resistência } & \multicolumn{3}{|c|}{ Solicitaçāo } & \multirow{2}{*}{ cs } & \multirow{2}{*}{$\beta$} & \multirow{2}{*}{ Pr } & \multirow{2}{*}{$1 / \mathrm{Pr}$} & \multirow{2}{*}{$\begin{array}{l}P_{a d m} \\
(\mathrm{kPa})\end{array}$} \\
\hline & Méoía (kPa) & Desvio $(\mathrm{kPa})$ & CV (\%) & Média (kPa) & Desvio (kPa) & CV (\%) & & & & & \\
\hline Análise 1 & 28,5423 & 55940 & 19.6 & $12,188.1$ & 467.9 & $3.8 \%$ & 2.3 & 2.91 & 0.00179 & 559 & $12,188.1$ \\
\hline Análise 2 & 28,5423 & 55940 & 19.6 & $14,271.2$ & 547.9 & $3.8 \%$ & 2.0 & 2.54 & 0.00556 & 180 & $14,271.2$ \\
\hline Análise 3 & 28,5423 & 5594.0 & 19.6 & $11,203.6$ & 430.0 & $3.8 \%$ & 2.5 & 3.09 & 0.00100 & 1000 & $11,203.6$ \\
\hline
\end{tabular}

Conclui-se, desta análise que, dentre as inúmeras vantagens apresentadas pela carga admissível proposta em relação à carga admissível convencional, destaca-se o fato dela permitir que se conheça a probabilidade de ruína da fundação, o que possibilita projetar a fundação de forma mais consciente dos riscos que estão envolvidos, e permitir que se determine o valor do coeficiente de segurança que conduz ao projeto de uma fundação segura, uma vez que se conhece a probabilidade de ruína envolvida.

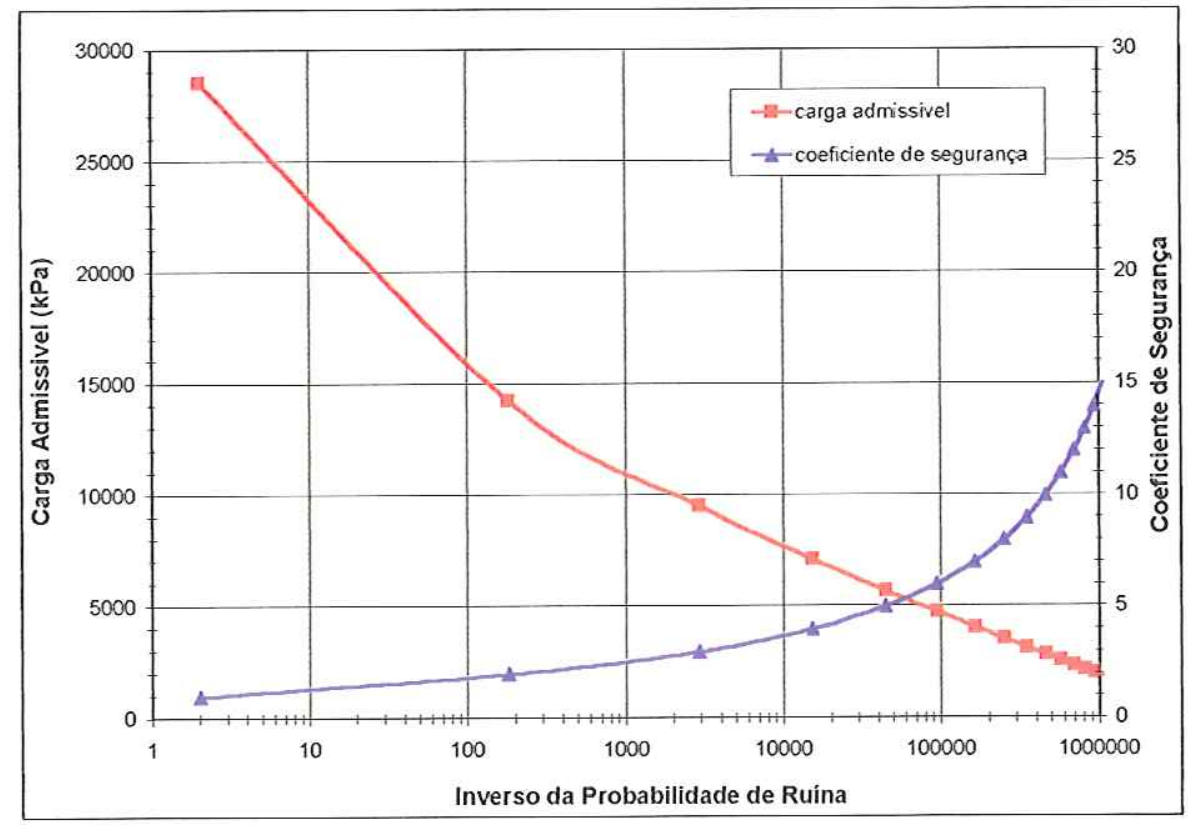

Figura 8.5.1. Carga admissível proposta - Duque de Caxias/RJ.

A carga admissível proposta permite elaborar o gráfico da Figura 8.5.1, a partir do qual é possível determinar a carga admissível correspondente à probabilidade de ruína desejada e o seu respectivo coeficiente de segurança. 


\subsubsection{Análise das estacas em termos de carga admissível}

Neste item, as provas de carga realizadas foram agrupadas em função das dimensões da seção transversal das estacas, o que deu origem a quatro grupos de estacas. Para cada grupo foi calculado o valor médio, de desvio padrão e de coeficiente de variação das resistências e das solicitações das estacas do grupo. A Tabela 3 do Apêndice E apresenta as provas de carga que compõem cada um dos quatro grupos, assim como a média, o desvio padrão e o coeficiente de variação para cada um deles. A Tabela 8.5.6 apresenta em resumo as estatísticas obtidas.

Tabela 8.5.6. Resistências e solicitações para os quatro grupos de estacas.

\begin{tabular}{|c|c|c|c|c|c|c|c|}
\hline \multirow{2}{*}{$\begin{array}{c}\text { Provas } \\
\text { de carga }\end{array}$} & \multirow{2}{*}{$\begin{array}{c}\text { Dimensões da } \\
\text { seção }(\mathrm{m})\end{array}$} & \multicolumn{3}{|c|}{ Resistência } & \multicolumn{3}{c|}{ Solicitação } \\
\cline { 3 - 8 } & Média $(\mathrm{kN})$ & Desvio $(\mathrm{kN})$ & $\mathrm{CV}(\%)$ & Média $(\mathrm{kN})$ & Desvio $(\mathrm{kN})$ & $\mathrm{CV}(\%)$ \\
\hline 5 & $0.215 \times 0.215$ & 1460.0 & 126.1 & 8.6 & 547.0 & 0.0 & 0.0 \\
\hline 7 & $0.235 \times 0.235$ & 1675.7 & 264.7 & 15.8 & 711.0 & 0.0 & 0.0 \\
\hline 10 & $0.265 \times 0.265$ & 1840.0 & 454.9 & 24.7 & 835.0 & 0.0 & 0.0 \\
\hline 1 & $0.295 \times 0.295$ & 2100.0 & 0.0 & 0.0 & 1056.0 & 0.0 & 0.0 \\
\hline
\end{tabular}

Observando a Tabela 8.5.6, é interessante notar que o coeficiente de variação aumentou do primeiro para o terceiro grupo. Isso pode ter ocorrido devido ao aumento do número de provas de carga do primeiro (5 provas de carga) para o terceiro grupo (10 provas de carga) ou devido ao aumento da área da seção transversal das estacas tornar os resultados das provas de carga, ou seja, as resistências, mais sensíveis com relação à variabilidade do maciço de solos. Neste exemplo, pode-se observar que apesar do valor da resistência média aumentar à medida que aumentam as dimensões da seção transversal da estaca, a variabilidade da capacidade de carga dessas estacas também aumenta. Logo, para esta obra, em particular, parece ser mais vantajoso realizar o projeto de fundações com um número maior de estacas de dimensões reduzidas do que com poucas estacas de dimensões maiores.

A partir dos valores apresentados na Tabela 8.5.6 foram realizadas três análises para cada grupo de provas de carga, com exceção do último grupo que contêm apenas uma estaca. As análises realizadas estão apresentadas no Apêndice E (Figura 4, 5 e 6 para o grupo 1; Figura 7, 8 e 9 para o grupo 2; e Figura 10, 11 e 12 para o grupo 3). Os resultados das análises realizadas encontram-se resumidas na Tabela 8.5.7. 
Tabela 8.5.7. Resultados das análises dos 3 grupos de provas de carga.

\begin{tabular}{|c|c|c|c|c|c|c|c|c|c|c|c|}
\hline \multirow{2}{*}{ Análise 1} & \multicolumn{3}{|c|}{ Resistência } & \multicolumn{3}{|c|}{ Solicitação } & \multirow{2}{*}{ cs } & \multirow{2}{*}{$\beta$} & \multirow{2}{*}{ Pr } & \multirow{2}{*}{$1 / \mathrm{Pr}$} & \multirow{2}{*}{$\begin{array}{l}P_{\text {adm }} \\
\text { (kN) }\end{array}$} \\
\hline & Média $(\mathrm{kN})$ & Desvio $(\mathrm{kN})$ & CV $(\%)$ & Média $(\mathrm{kN})$ & Desvio $(\mathrm{kN})$ & $\mathrm{CV}(\%)$ & & & & & \\
\hline $1^{\circ}$ grupo & $1,460.0$ & 126.1 & 8.6 & 547.0 & 0.0 & $0.0 \%$ & 2.7 & 7.2 & 0.00000 & $\infty$ & 547.0 \\
\hline $2^{\circ}$ grupo & $1,675.7$ & 264.7 & 15.8 & 711.0 & 0.0 & $0.0 \%$ & 2.4 & 3.6 & 0.00013 & 7,463 & 711.0 \\
\hline $3^{\circ}$ grupo & $1,840.0$ & 454.9 & 24.7 & 835.0 & 0.0 & $0.0 \%$ & 2.2 & 2.2 & 0.01358 & 74 & 835.0 \\
\hline
\end{tabular}

\begin{tabular}{|c|c|c|c|c|c|c|c|c|c|c|c|}
\hline \multirow{2}{*}{ Análise 2} & \multicolumn{3}{|c|}{ Resistência } & \multicolumn{3}{|c|}{ Solicitação } & \multirow{2}{*}{ cs } & \multirow{2}{*}{$\beta$} & \multirow{2}{*}{ Pr } & \multirow{2}{*}{$1 / \mathrm{Pr}$} & \multirow{2}{*}{$\begin{array}{l}P_{\text {adm }} \\
\text { (kN) }\end{array}$} \\
\hline & Média $(\mathrm{kN})$ & Desvio $(\mathrm{kN})$ & CV $(\%)$ & Média $(\mathrm{kN})$ & Desvio $(\mathrm{kN})$ & CV $(\%)$ & & & & & \\
\hline $1^{\circ}$ grupo & $1,460.0$ & 126.1 & 8.6 & 730.0 & 0.0 & $0.0 \%$ & 2.0 & 5.8 & 0.00000 & $\infty$ & 730.0 \\
\hline $2^{\circ}$ grupo & $1,675.7$ & 264.7 & 15.8 & 837.9 & 0.0 & $0.0 \%$ & 2.0 & 3.2 & 0.00077 & 1,291 & 837.9 \\
\hline $3^{\circ}$ grupo & $1,840.0$ & 454.9 & 24.7 & 920.0 & 0.0 & $0.0 \%$ & 2.0 & 2.0 & 0.02157 & 46 & 920.0 \\
\hline
\end{tabular}

\begin{tabular}{|c|c|c|c|c|c|c|c|c|c|c|c|}
\hline \multirow{2}{*}{ Análise 3 } & \multicolumn{3}{|c|}{ Resistência } & \multicolumn{3}{c|}{ Solicitação } & \multirow{2}{*}{ CS } & $\beta$ & Pr & $1 / \mathrm{Pr}$ & $\begin{array}{c}\text { Padm } \\
(\mathrm{kN})\end{array}$ \\
\cline { 2 - 12 } & Média (kN) & Desvio (kN) & $\mathrm{CV}(\%)$ & Média (kN) & Desvio (kN) & $\mathrm{CV}(\%)$ & & & & & \\
\hline $1^{\circ}$ grupo & $1,460.0$ & 126.1 & 8.6 & 1070.3 & 0.0 & $0.0 \%$ & 1.4 & 3.1 & 0.00100 & 1000 & 1070.3 \\
\hline $2^{\circ}$ grupo & $1,675.7$ & 264.7 & 15.8 & 857.7 & 0.0 & $0.0 \%$ & 2.0 & 3.1 & 0.00100 & 1000 & 857.7 \\
\hline $3^{\circ}$ grupo & $1,840.0$ & 454.9 & 24.7 & 434.2 & 0.0 & $0.0 \%$ & 4.2 & 3.1 & 0.00100 & 1000 & 434.2 \\
\hline
\end{tabular}

A partir dos resultados apresentados na Tabela 8.5.7 pode-se perceber que os três grupos de estacas apresentam comportamentos bastante distintos. A Análise 1 demonstra que as estacas do $1^{\circ}$ grupo e do $2^{\circ}$ grupo apresentaram um índice de confiabilidade superior ao recomendado que é de 3.09 , o que resultou em probabilidades de ruína aceitáveis. Ao contrário do que ocorreu com as estacas do $3^{\circ}$ grupo que apesar de apresentarem um coeficiente de segurança superior ao recomendado pela norma, tiveram um índice de confiabilidade de apenas 2.2 que corresponde a uma probabilidade de ruína de aproximadamente 14/1000, ou seja, 1 a cada 74 estacas pode falhar.

Considerando que a obra possui 1669 estacas do tipo das estacas do $3^{\circ}$ grupo, conclui-se que há a probabilidade de 23 estacas falharem. Logo, percebe-se que o valor estimado anteriormente de 5 estacas falharem é na realidade muito superior quando se analisam as provas de carga separadamente por tipo de seção transversal. Esse segundo tipo de análise permitiu perceber que o "problema" se encontra com as estacas do $3^{\circ}$ grupo, por elas apresentarem um coeficiente de variação relativamente alto. Logo, deste segundo item, percebe-se que há um desequilíbrio no projeto de fundações, pois as capacidades de carga das estacas do $3^{\circ}$ grupo estão sendo superestimadas, enquanto que as capacidades de carga das estacas do $1^{\circ}$ e do $2^{\circ}$ grupo estão sendo subestimadas.

Na Análise 2, as cargas admissíveis foram estimadas usando um coeficiente de segurança igual a 2.0. Nesta análise, as estacas do $1^{\circ}$ e do $2^{\circ}$ grupo continuaram a 
apresentar segurança, mostrando que a utilização da carga admissível proposta pela norma, neste caso, é viável. Quanto às estacas do $3^{\circ}$ grupo, estas tiveram um aumento de sua probabilidade de ruína de 14/1000 (1/74) para 22/1000 (1/46) com a redução do coeficiente de segurança de 2.2 para 2.0 , vindo a demonstrar que o uso da carga admissível proposta pela norma com um coeficiente de segurança igual a 2.0 , neste caso, não é suficiente para garantir a segurança da fundação.

Utilizando a carga admissível proposta com um índice de confiabilidade igual a 3.09, foi realizada a Análise 3. Está análise permitiu que se determinassem quais as os valores de cargas admissíveis e de coeficiente de segurança devem ser adotados na realização do projeto de fundações para que este apresente segurança. Desta análise resulta uma fundação projetada de forma mais otimizada e econômica, com uma probabilidade de ruína uniforme e adequada aos padrões de segurança.

Comparando a Análise $3 \mathrm{com}$ a Análise 1, percebe-se que as estacas do $1^{\circ} \mathrm{e}$ do $2^{\circ}$ grupo podem ter a sua carga admissível aumentada de $547.0 \mathrm{kN}(\mathrm{CS}=2.7)$ para $1070.3 \mathrm{kN}(\mathrm{CS}=4)$ para as estacas do $1^{\circ}$ grupo, e de $711.0 \mathrm{kN}(\mathrm{CS}=2.4)$ para $857.7 \mathrm{kN}(\mathrm{CS}=2.0)$ para as estacas do $2^{\circ}$ grupo; enquanto que as estacas do $3^{\circ}$ grupo devem ter a sua carga admissível reduzida de $835.0 \mathrm{kN}(\mathrm{CS}=2.2)$ para $434.2 \mathrm{kN}(\mathrm{CS}=$ 4.2) para que estas apresentem uma probabilidade de ruína aceitável, ou seja, uma probabilidade de ruína de no máximo 1/1000.

Para cada um dos três grupos de estacas analisados foram elaborados os gráficos das Figuras 13, 14 e 15 utilizando os valores das Tabelas 4, 5 e 6, respectivamente, todos apresentados no Apêndice E. A partir desses gráficos é possível determinar a carga admissível correspondente à probabilidade de ruína desejada e o respectivo coeficiente de segurança para cada grupo de estacas. Observando esses três gráficos pode-se perceber que à medida que o coeficiente de variação aumenta mais as curvas dos gráficos se deslocam para a esquerda, devido ao aumento da probabilidade de ruína.

\subsubsection{Comentários finais}

As análises realizadas neste item permitem extrair as seguintes conclusões:

- Ao avaliar a probabilidade de ruína prevista para uma fundação a partir de resultados de provas de carga dinâmicas de energia constante deve-se recordar que esse tipo de prova de carga, em geral, costuma subestimar as resistências das estacas; logo, a 
probabilidade de ruína real pode ser inferior à prevista.

- Neste item, a fundação foi analisada de duas formas distintas: em termos de tensões admissíveis (item 8.5.3.2) e, em termos de carga admissível (item 8.5.3.3), o que nos fez perceber que existem diferenças bastante nítidas entre elas. A análise em termos de carga admissível parece ser a mais indicada, pois, ao realizar as análises individualmente de cada grupo de estacas é possível calcular quais são os valores de coeficiente de segurança e de índice de confiabilidade de cada um deles, e dessa forma, identificar qual o grupo de estacas apresenta ou não segurança, e sendo assim, otimizar a fundação a ser projetada.

- As análises realizadas no item 8.5.3.3. mostram que até determinado valor de coeficiente de variação (até o coeficiente de variação do segundo grupo), a carga admissível proposta pela norma com um coeficiente de segurança igual a 2.0 é capaz de garantir a segurança da fundação, ou seja, a fundação terá um índice de confiabilidade de no mínimo 3.09 (probabilidade de ruína máxima de 1/1000). Mas, à medida que o coeficiente de variação aumenta, do primeiro para o terceiro grupo de provas de carga, a carga admissível proposta pela norma deixa de ser suficiente para a garantia da segurança, sendo que, a partir desse ponto (para o terceiro grupo), é necessário utilizar a metodologia proposta, para conhecer o valor do coeficiente de segurança que deve ser usado para que a fundação seja projetada com segurança.

- À medida que o coeficiente de variação aumenta mais as curvas dos gráficos de carga admissível proposta se deslocam para a esquerda, pois há o aumento da probabilidade de ruína. 


\subsection{Estacas metálicas cravadas na Formação Tremembé}

Apresenta-se neste item a análise de uma fundação em estacas metálicas, do tipo perfil soldado, cravadas na Formação Tremembé, na Bacia de Taubaté, no estado de São Paulo. Durante a execução do estaqueamento, foram realizadas 14 provas de carga dinâmicas de energia crescente para avaliação do mesmo.

Como informações básicas para essa análise, serão apresentadas as características geotécnicas do maciço de solos, a descrição do projeto de fundação, e os resultados experimentais dos ensaios realizados para a verificação da capacidade de carga das estacas, ou seja, os resultados das provas de carga dinâmica realizadas. Todos os dados utilizados nesta análise foram publicados por Ávila (2001).

\subsubsection{Características Geotécnicas do Maciço de Solos}

O local da obra encontra-se na Bacia de Taubaté, localizada na região do Vale do Paraíba. A Bacia de Taubaté é limitada pelos municípios paulistas de Guararema e Cachoeira Paulista, tem aproximadamente $20 \mathrm{~km}$ de largura e $150 \mathrm{~km}$ de comprimento, e possui duas sub-unidades geológicas denominadas de "Embasamento Cristalino" e de "Sedimentos antigos" (ÁVILA, 2001).

O "Embasamento Cristalino" é composto de rochas metamórficas, na sua maioria constituída por gnaisses e micaxistos. Os "Sedimentos antigos" constitui uma grande subunidade geológica que se subdivide, de acordo com a sua composição litoestratigráfica, nas Formações Tremembé e Caçapava. A Formação Tremembé constitui-se de um pacote sedimentar, e encontra-se diretamente sobre o "Embasamento Cristalino", sendo caracterizada por folhelhos pirobetuminosos compostos predominantemente por argilas montmoriloníticas (ÁVILA, 2001).

\subsubsection{Informações a respeito do elemento estrutural de fundação}

Como elemento estrutural de fundação, foram utilizados perfis metálicos soldados, da série CS, do tipo USIMEC (Usiminas Mecânica), cujas características geométricas estão apresentadas na Figura 8.6.1. 


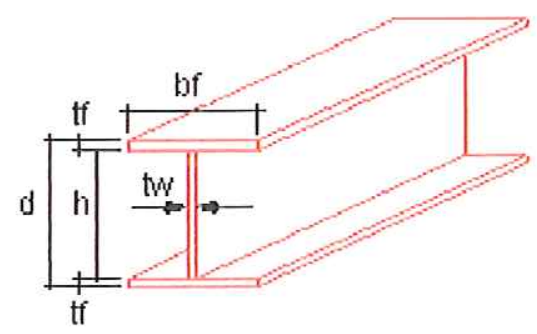

Figura 8.6.1. Características geométricas das estacas tipo perfil I metálico.

As dimensões geométricas dos elementos estruturais selecionados para a fundação da obra, ou melhor, dos perfis utilizados, estão apresentadas na Tabela 8.6.1.

Tabela 8.6.1. Dimensões Geométricas dos elementos estruturais de fundação.

\begin{tabular}{|c|c|c|c|c|c|c|c|}
\hline Perfil & $\mathrm{d}(\mathrm{mm})$ & $\mathrm{bf}(\mathrm{mm})$ & $\mathrm{tf}(\mathrm{mm})$ & $\mathrm{tw}(\mathrm{mm})$ & $\mathrm{h}(\mathrm{mm})$ & $\mathrm{A}\left(\mathrm{cm}^{2}\right)$ & $\mathrm{U}\left(\mathrm{m}^{2} / \mathrm{m}\right)$ \\
\hline $250 \times 63$ & 250 & 250 & 12.5 & 8.0 & 225.0 & 80.5 & 1.5 \\
\hline $350 \times 93$ & 350 & 350 & 12.5 & 9.5 & 325.0 & 118.4 & 2.1 \\
\hline $350 \times 153$ & 350 & 350 & 22.4 & 12.5 & 305.2 & 195.0 & 2.1 \\
\hline $450 \times 198$ & 450 & 450 & 22.4 & 12.5 & 405.2 & 252.3 & 2.7 \\
\hline $500 \times 221$ & 500 & 500 & 22.4 & 12.5 & 455.2 & 280.9 & 3.0 \\
\hline $550 \times 228$ & 550 & 550 & 19.0 & 16.0 & 512.0 & 290.9 & 3.3 \\
\hline
\end{tabular}

A Tabela 8.6.2 apresenta as principais características a respeito das 14 estacas ensaiadas, tais como: o tipo de perfil cravado e as suas dimensões (a área da seção transversal, o perímetro do perfil, assim como o comprimento cravado). É possível visualizar as plantas de locação das estacas da obra em estudo em Ávila (2001).

Tabela 8.6.2. Características Geométricas das estacas analisadas.

\begin{tabular}{|c|c|c|c|c|}
\hline Estacas & Perfil & $\begin{array}{l}\text { Área } \\
\left(\mathrm{m}^{2}\right)\end{array}$ & $\begin{array}{c}\text { Perímetro } \\
\text { (m) }\end{array}$ & $\begin{array}{c}\mathrm{L} \text { (cravação) } \\
\text { (m) }\end{array}$ \\
\hline $11 \mathrm{~L} 1$ & $\operatorname{cs} 450 \times 198$ & 0.2523 & 2.7 & 13.0 \\
\hline $11 \mathrm{Q1}$ & $\operatorname{CS} 450 \times 198$ & 0.2523 & 2.7 & 13.0 \\
\hline $11 \mathrm{~V} 1$ & $\operatorname{cs} 450 \times 198$ & 0.2523 & 2.7 & 15.5 \\
\hline 12E2 & $\operatorname{cs} 500 \times 221$ & 0.2809 & 3.0 & 16.0 \\
\hline $14 \mathrm{~A} 2$ & $\operatorname{CS} 450 \times 198$ & 0.2523 & 2.7 & 17.2 \\
\hline 1411 & $\operatorname{CS} 550 \times 228$ & 0.2909 & 3.3 & 16.9 \\
\hline $14 \mathrm{~J} 1$ & $\operatorname{cs} 450 \times 198$ & 0.2523 & 2.7 & 13.0 \\
\hline $18 \mathrm{M} 2$ & $\operatorname{cs} 350 \times 93$ & 0.1184 & 2.1 & 13.0 \\
\hline $21 \mathrm{~A} 1$ & CS $450 \times 198$ & 0.2523 & 27 & 19.1 \\
\hline $21 \mathrm{E} 1$ & CS $500 \times 221$ & 0.2809 & 3.0 & 16.2 \\
\hline 21E2 & CS $500 \times 221$ & 0.2809 & 3.0 & 18.8 \\
\hline 8L1 & $\operatorname{cs} 350 \times 153$ & 0.1950 & 2.1 & 13.0 \\
\hline 8P1 & $\operatorname{CS} 350 \times 153$ & 0.1950 & 2.1 & 13.0 \\
\hline 9V1 & CS 250x63 & 0.0805 & 1.5 & 13.0 \\
\hline
\end{tabular}




\subsubsection{Análise dos dados dos ensaios realizados}

\subsubsection{Investigação geotécnica}

Foram realizadas 19 sondagens à percussão SPT com profundidades em torno de 20m em relação ao nível do terreno. A Tabela 1 do Apêndice $\mathrm{F}$ apresenta os valores de $\mathrm{N}_{\text {SPT }}$ das 19 sondagens realizadas, assim como os valores mínimos, médios e máximos e o correspondente coeficiente de variação em cada profundidade.

Ávila (2001) apresenta os perfis geotécnicos de algumas destas sondagens. No entanto, uma sondagem típica representativa do maciço de solos da obra encontra-se apresentada na Figura 8.6.2.

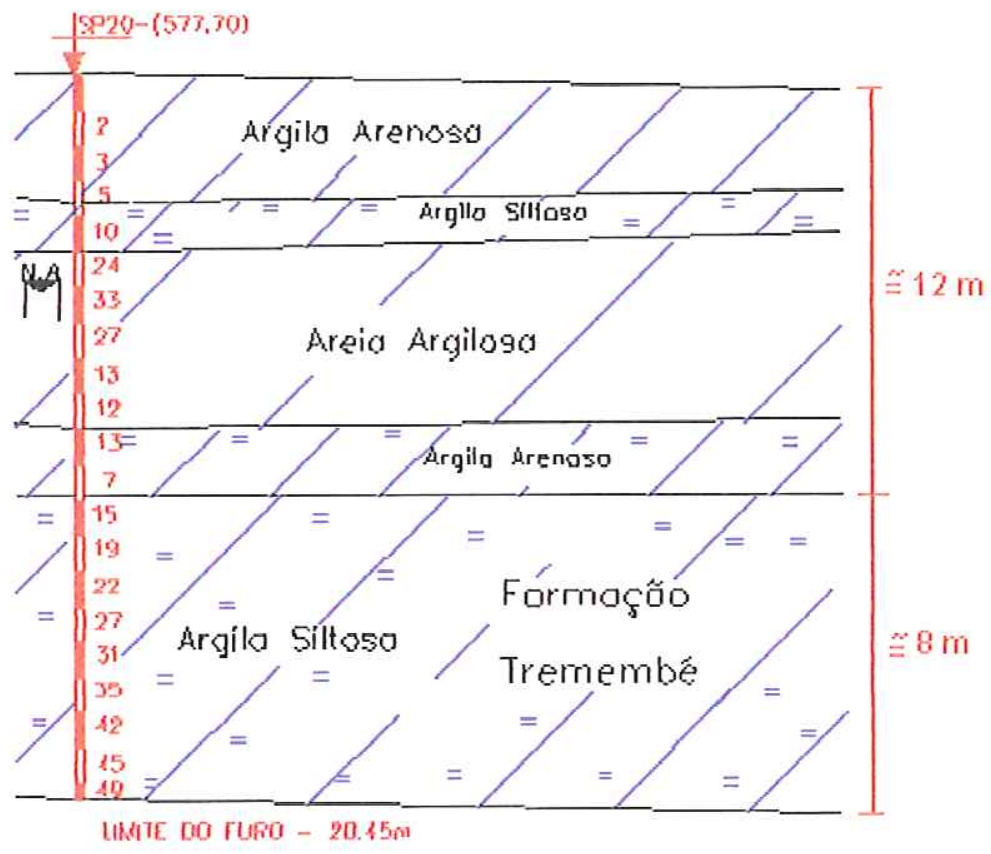

Figura 8.6.2. Perfil estratigráfico do maciço de solos.

Observando a Figura 8.6.2, é possível perceber que a primeira camada de solos deste maciço, tem aproximadamente $12.0 \mathrm{~m}$ de espessura e é composta por sedimentos aluvionares. O nível d'água foi localizado nessa primeira camada, a $5.2 \mathrm{~m}$ de profundidade, em relação à cota da boca do furo de sondagem. A segunda camada apresentada no perfil é a Formação Tremembé composta por uma argila siltosa (folhelho), de consistência rija a dura, de cor cinza escuro com, aproximadamente, $8.0 \mathrm{~m}$ de espessura.

Com o objetivo de descrever a variabilidade geológica-geotécnica do local ensaiado, foram traçadas as curvas das Figuras 1, 2 e 3 do Apêndice F. 
A Figura 1 do Apêndice F apresenta o resultado das 19 sondagens realizadas. Os gráficos dessa figura mostram como é a variação dos valores de $\mathrm{N}_{\mathrm{SPT}}$ ao longo da profundidade do local da obra. Porém, para melhor visualização, foi elaborado o gráfico da Figura 2 do Apêndice $\mathrm{F}$, que apresenta os valores de $\mathrm{N}_{\mathrm{SPT}}$ mínimo, médio e máximo encontrados ao longo da profundidade, enquanto que a Figura 3 do Apêndice F mostra como é a variação do coeficiente de variação da resistência $N_{S P T}$ longo da profundidade.

Com a análise estatística dos valores de $\mathrm{N}_{\mathrm{SPT}}$ a cada profundidade, nota-se que o coeficiente de variação dos valores de $\mathrm{N}_{\mathrm{SPT}}$ oscila entre 36 e $94 \%$ nas camadas de sedimentos aluvionares, e entre 38 e $52 \%$ nas camadas de sedimentos antigos da Formação Tremembé, ou seja, na Formação Tremembé a variabilidade da resistência à penetração $\mathrm{N}_{\mathrm{SPT}}$ foi em média igual a $43 \%$, e se mantém aproximadamente constante em toda a camada.

Comparando o coeficiente de variação da camada de folhelho com a camada superior, nota-se que essa diferença de variabilidade tem como causa provável a influência da formação geológica. Espera-se que a variabilidade da resistência do sistema estaca-solo se correlacione diretamente com estes diagramas. Entretanto, como será observado posteriormente através das análises realizadas, não foi essa a realidade observada.

\subsubsection{Provas de carga dinâmica de energia crescente}

Na obra analisada, foram realizadas 14 provas de carga dinâmica de energia crescente (DIET), de um total de 280 estacas, o que corresponde a 5\% das estacas da obra. O sistema estaca-solo foi levado à ruptura em todas os ensaios, o que permitiu a determinação da resistência última de todas as estacas ensaiadas.

Na metodologia DIET de ensaio, os impactos sofridos pelo sistema estaca-solo são de energias crescentes, pois entende-se que somente assim é possível mobilizar a resistência última do sistema. As energias crescentes são obtidas pelo aumento das alturas de queda do martelo que golpeia a estaca durante a realização do ensaio. Assim, quando em sucessivos impactos de energia crescente a resistência mobilizada passa por um valor máximo tem-se a resistência última do sistema (AOKI, 1989).

As provas de carga foram executadas com idades que variaram de 3 a 18 dias após a cravação. Para a interpretação dos resultados utilizou-se o método numérico do programa CAPWAPC, que através dos sinais de força e velocidade coletados pelo 
sistema PDA, permite determinar o diagrama de transferência de carga para cada nível de energia aplicada.

Com base nos resultados das análises CAPWAPC estudou-se o comportamento estático e dinâmico do sistema estaca-solo. O comportamento estático foi estudado segundo o modelo CAPWAPC e comparado com o previsto por meio de dois métodos semi-empíricos: Método Aoki-Velloso (1975) e Método Décourt-Quaresma (1978).

Logo, em toda esta análise, a verificação de resistência estática diz respeito aos valores interpretados segundo o modelo CAPWAPC. Sendo assim, quando se referir a valores estáticos medidos, deve-se entender que se trata de resultados interpretados segundo este modelo.

\subsubsection{Resistências previstas}

Neste item, os valores previstos, segundo os métodos semi-empíricos AokiVelloso e Décourt-Quaresma, foram comparados com os medidos e interpretados segundo o modelo CAPWAPC.

A utilização dos métodos semi-empirícos para a previsão da resistência estática das estacas do tipo metálica na formação geológica em estudo (Formação Tremembé), foi avaliada por meio da comparação dos valores previstos pelos métodos Aoki-Velloso e Décourt-Quaresma com os medidos e interpretados pela instrumentação dinâmica.

Com base nos valores de $\mathrm{N}_{\mathrm{SPT}}$ determinados por meio das sondagens realizadas foram estimadas as resistências dos 14 elementos isolados de fundação utilizando dois métodos de previsão de capacidade de carga: Aoki-Velloso e Décourt-Quaresma.

As Tabelas 2, 3 e 4 do Apêndice F apresentam os valores de resistência lateral, resistência de ponta e resistência total previstas pelo Método Aoki-Velloso, assim como os valores mínimos, médios, máximos e o coeficiente de variação dos valores de resistências estimadas em cada profundidade. Do mesmo modo, as Tabelas 5, 6 e 7 do Apêndice $\mathrm{F}$ apresentam os valores de resistências previstas pelo Método DécourtQuaresma.

A Tabela 8 do Apêndice $\mathrm{F}$ apresenta o resumo (estatísticas: mínimo, média, máximo, desvio padrão e coeficiente de variação) das resistências previstas pelo Método Aoki-Velloso e a Tabela 9 do Apêndice F apresenta o resumo das resistências previstas pelo Método Décourt-Quaresma. Com esses valores foram elaborados os gráficos das Figuras 4 a 28 do Apêndice F, que tem como objetivo comparar os dois métodos de 
previsão no tocante às resistências por eles previstas e as medidas em prova de carga.

A Figura 4 apresenta como é a variação da resistência lateral prevista pelo Método Aoki-Velloso ao longo da profundidade. A Figura 5 apresenta o coeficiente de variação dos valores de resistência lateral prevista pelo Método Aoki-Velloso ao longo da profundidade. Observando a Figura 5 e os valores apresentados na Tabela 2, pode-se perceber que o coeficiente de variação foi em média igual a $18 \%$ na camada de solo entre 12 a $20 \mathrm{~m}$ de profundidade, correspondente a Formação Tremembé.

O gráfico da Figura 6 do Apêndice F mostra a variação da resistência lateral ao longo da profundidade prevista pelo Método Décourt-Quaresma. A Figura 7 do Apêndice F, apresenta o coeficiente de variação da resistência lateral prevista pelo Método Décourt-Quaresma ao longo da profundidade. Com relação ao coeficiente de variação previsto pelo Método Décourt-Quaresma pode-se perceber que este variou de 19 a $35 \%$ na camada de sedimentos aluvionares e variou em torno de $16 \%$ na camada de solo correspondente à Formação Tremembé.

A Figura 8 do Apêndice F reúne os gráficos das Figuras 4 e 6, ou seja, reúnem as curvas de variação da resistência lateral ao longo da profundidade prevista pelos Métodos Aoki-Velloso e Décourt-Quaresma. Quanto à Figura 9 do Apêndice F, essa traz reunidas as curvas de coeficientes de variação dos valores de resistência lateral previstas pelos métodos Aoki-Velloso e Décourt-Quaresma ao longo da profundidade. Pode-se perceber que a partir dos $12 \mathrm{~m}$ de profundidade (Formação Tremembé), os coeficientes de variação previstos pelos dois métodos se aproximam. A Figura 8 do Apêndice $\mathrm{F}$ permite visualizar que os valores de resistência lateral previstos pelo Método Aoki-Velloso são inferiores aos previstos pelo Método Décourt-Quaresma e, a Figura 9 do Apêndice F mostra que os coeficientes de variação previstos pelo Método Aoki-Velloso foram maiores que os apresentados pelo Método Décourt-Quaresma.

A Figura 10 do Apêndice F apresenta a variação da resistência de ponta ao longo da profundidade prevista pelo Método Aoki-Velloso e, a Figura 11 do Apêndice F apresenta o coeficiente de variação dos valores de resistência de ponta previstos pelo Método Aoki-Velloso ao longo da profundidade. Pode-se perceber que a resistência de ponta, com exceção do coeficiente de variação previsto para a profundidade de $2 \mathrm{~m}$, que foi de $36 \%$, os demais coeficientes de variação foram superiores a $50 \%$, variando de $51 \%$ a $100 \%$. Observando esse gráfico pode-se notar que este não seguiu nenhum padrão de comportamento.

A Figura 12 do Apêndice $\mathrm{F}$ apresenta a variação da resistência de ponta ao longo 
da profundidade prevista pelo Método Décourt-Quaresma e a Figura 13 do Apêndice F apresenta o coeficiente de variação da resistência de ponta ao longo da profundidade prevista pelo Método Décourt-Quaresma.

A Figura 14 do Apêndice F apresenta a variação da resistência de ponta ao longo da profundidade pelos Métodos Aoki-Velloso e Décourt-Quaresma. A Figura 15 do Apêndice $\mathrm{F}$ apresenta o coeficiente de variação da resistência de ponta ao longo da profundidade prevista pelos Métodos Aoki-Velloso e Décourt-Quaresma.

A Figura 15 do Apêndice F permite visualizar que, ao contrário do que ocorreu com os valores de resistência lateral, os valores de resistência de ponta previstos pelo Método Aoki-Velloso foram superiores aos previstos pelo Método Décourt-Quaresma. Quanto ao coeficiente de variação, pode-se perceber pela Figura 15 que o Método AokiVelloso contínua prevendo uma variabilidade maior que a do Método DécourtQuaresma. No entanto, a diferença entre os valores dos coeficientes de variação previstos pelos dois métodos para a resistência de ponta é de maior magnitude que a diferença entre os valores dos coeficientes de variação previstos pelos dois métodos para a resistência lateral, compare os gráficos das Figuras 9 e 15 do Apêndice F.

A Figura 16 do Apêndice $\mathrm{F}$ apresenta a variação da resistência total (lateral + ponta) ao longo da profundidade prevista pelo Método Aoki-Velloso e a Figura 17 do Apêndice $\mathrm{F}$ apresenta o coeficiente de variação da resistência total prevista pelo Método Aoki-Velloso ao longo da profundidade.

A Figura 18 do Apêndice $\mathrm{F}$ apresenta a variação da resistência total ao longo da profundidade prevista pelo Método Décourt-Quaresma e, a Figura 19 apresenta o coeficiente de variação da resistência total ao longo da profundidade prevista pelo Método Décourt-Quaresma. O coeficiente de variação oscilou de 25 a $61 \%$ na camada de sedimentos aluvionares e permaneceu em torno de $30 \%$ na Formação Tremembé.

A Figura 20 do Apêndice $\mathrm{F}$ mostra a variação da resistência total ao longo da profundidade previstas pelos Métodos Aoki-Velloso e Décourt-Quaresma. Da observação dessa figura pode-se perceber que as resistências previstas pelo Método Décourt-Quaresma foram menores que as previstas pelo Método Aoki-Velloso. Com relação ao coeficiente de variação, a Figura 21 do Apêndice $F$ mostra que não há nenhuma relação entre o coeficiente de variação da resistência total previstos pelos dois métodos e que, o coeficiente de variação previsto pelo Método Décourt-Quaresma foi inferior ao previsto pelo Método Aoki-Velloso.

A Figura 22 apresenta as curvas de resistências previstas (lateral, ponta e total) 
pelo Método Aoki-Velloso ao longo da profundidade. Nota-se que a resistência lateral aumentou praticamente de forma linear com a profundidade, enquanto que a resistência de ponta e a resistência total também aumentaram, porém de forma não linear e que essas últimas apresentam uma forte relação como pode ser observado na figura.

A Figura 23 mostra como o coeficiente de variação da resistência prevista pelo Método Aoki-Velloso varia ao longo da profundidade. A variabilidade da resistência total está nitidamente relacionada com a variabilidade da resistência de ponta como pode ser observado pela forma semelhante das curvas de coeficiente de variação ao longo da profundidade das resistências totais e de ponta. Enquanto que, com exceção dos primeiros $6 \mathrm{~m}$ de profundidade, o coeficiente de variação da resistência lateral permanece aproximadamente constante ao longo da profundidade, oscilando em torno de $20 \%$ até a profundidade de $20.0 \mathrm{~m}$.

$\mathrm{O}$ mesmo comportamento pode ser observado com relação às resistências previstas pelo Método Décourt-Quaresma. A Figura 24 do Apêndice F apresenta as curvas de resistências previstas (lateral, ponta e total) ao longo da profundidade pelo Método Décourt-Quaresma e, a Figura 25 apresenta as curvas de variação do coeficiente de variação das resistências previstas pelo Método Décourt-Quaresma.

A Figura 26 do Apêndice $\mathrm{F}$ apresenta o coeficiente de variação da resistência total prevista pelo Método Aoki-Velloso e o coeficiente de variação da resistência $\mathrm{N}_{\mathrm{SPT}}$. Pode-se perceber que aparentemente não existe nenhuma relação entre a variabilidade ao longo da profundidade dos dois coeficientes de variação.

A Figura 27 do Apêndice F apresenta o coeficiente de variação da resistência total prevista pelo Método Décourt-Quaresma e o coeficiente de variação da resistência $\mathrm{N}_{\text {SPT }}$. Essas duas curvas apresentam, quando comparadas com as da Figura 26 do Apêndice F (observe a Figura 28 do Apêndice F), uma pequena semelhança. No entanto, também não se pode perceber uma relação entre ambas.

\subsubsection{Resistências previstas $\mathrm{x}$ medidas - Efeito executivo}

No Apêndice F estão apresentadas as Tabelas 10, 11 e 12, que apresentam os valores de resistência lateral unitária obtidos através das análises CAPWAPC e os valores de resistência lateral unitária previstos pelo Método Aoki-Velloso e DécourtQuaresma, respectivamente. Com base nos valores de resistência lateral apresentados foram elaborados os gráficos das Figuras 29 a 34 do Apêndice F. 
A Figura 29 do Apêndice F mostra a variação da resistência lateral unitária média ao longo da profundidade resultante das provas de carga dinâmicas realizadas. Na seqüência, a Figura 30 do Apêndice F que apresenta as curvas de resistência lateral unitária média e de $\mathrm{N}_{\mathrm{SPT}}$ ao longo da profundidade, com o intuito de identificar alguma relação entre elas. Porém, como se pode observar, apesar de ambas aumentarem ao longo da profundidade, não é possível dizer que exista uma relação entre elas.

A Figura 31 do Apêndice $\mathrm{F}$ apresenta a variação da resistência lateral unitária média ao longo da profundidade medida e as previstas com os Métodos DécourtQuaresma e Aoki-Velloso. Pela observação da Figura 31 pode-se perceber que os métodos de previsão não conseguiram retratar a variação da resistência lateral unitária média ao longo da profundidade, e que ambos os métodos superestimaram os valores de resistência como pode ser observado pelo fato das duas curvas previstas estarem à direita da curva de resistência lateral unitária real a partir dos $6.0 \mathrm{~m}$ de profundidade.

A Figura 32 do Apêndice $\mathrm{F}$ mostra como varia o coeficiente de variação da resistência lateral unitaria média determinada pelas provas de carga dinâmica ao longo da profundidade e, a Figura 33 do Apêndice F apresenta conjuntamente a curva anterior e o gráfico do coeficiente de variação dos valores $\mathrm{N}_{\mathrm{SPT}}$ ao longo da profundidade, em que é possível notar que não há nenhuma relação entre ambas.

A Figura 34 do Apêndice F apresenta as curvas de coeficiente de variação da resistência lateral unitária média medida pelas provas de carga dinâmica e previstas pelos métodos Décourt-Quaresma e Aoki-Velloso. Observando essa figura, é possível perceber que até a profundidade de $10 \mathrm{~m}$, os valores das resistências previstas foram maiores que o valor da resistência real e que, a partir dos $10 \mathrm{~m}$ de profundidade essa relação se inverte, ou seja, os valores das resistências previstas foram inferiores aos valores reais medidos pelas provas de carga dinâmica. Também é possível perceber que não há nenhuma relação entre essas curvas (previstas $\mathrm{x}$ medida), o que evidencia a incapacidade dos métodos de previsão em determinar e reproduzir a variação da resistência lateral unitária ao longo da profundidade.

$\mathrm{Na}$ seqüência são apresentadas as Tabelas 13 e 14 do Apêndice $\mathrm{F}$ que apresentam os valores de $\mathrm{N}_{\text {SPT }}$ acumulado ao longo da profundidade e os valores de resistência lateral unitária acumulada resultantes das análises CAPWAPC. Os valores apresentados nestas tabelas foram utilizados na elaboração dos gráficos das Figuras 35 a 44 do Apêndice F.

A Figura 35 do Apêndice $\mathrm{F}$ apresenta as curvas de resistência lateral unitária 
mínima, média e máxima ao longo da profundidade, enquanto que a Figura 36 do Apêndice $\mathrm{F}$ apresenta as curvas de resistência lateral acumulada mínima, média e máxima ao longo da profundidade. Comparando essas duas figuras, percebe-se que as curvas de resistência acumulada da Figura 36, ao contrário das curvas da Figura 35, apresentam um crescimento linear com a profundidade.

A Figura 37 do Apêndice F apresenta a variação da resistência lateral acumulada média ao longo da profundidade. Enquanto que a Figura 38 apresenta a resistência lateral acumulada média e o $\mathrm{N}_{\mathrm{SPT}}$ acumulado médio, também ao longo da profundidade, mostrando que ambos apresentam um aumento gradual com a profundidade

Quanto a Figura 39 do Apêndice F, percebe-se que esta tem como objetivo mostrar a relação existente entre a resistência lateral acumulada média medida por meio dos ensaios realizados com as resistências previstas pelos dois métodos de cálculo utilizados nesta análise. Observando essa figura, percebe-se que as resistências laterais previstas, em se tratando de valores acumulados, foram superiores à medida em prova de carga. Sendo o Método Décourt-Quaresma o que apresentou os maiores valores de resistência.

A Figura 40 do Apêndice F mostra como se dá a variação do coeficiente de variação da resistência lateral acumulada média ao longo da profundidade e, as Figuras 41 e 42 do Apêndice F tentam identificar se existe alguma relação entre o coeficiente de variação da resistência lateral acumulada média com o coeficiente de variação dos valores de $\mathrm{N}_{\mathrm{SPT}}$ e de $\mathrm{N}_{\mathrm{SPT}}$ acumulado. Da observação da Figura 42 é possível perceber que o coeficiente de variação previsto foi inferior ao encontrado em prova de carga, o que permite concluir que o processo executivo conduziu a um aumento na variabilidade.

A Figuras 43 do Apêndice $\mathrm{F}$ mostra relação existente entre a variação do coeficiente de variação da resistência lateral acumulada prevista pelos Métodos AokiVelloso e Décourt-Quaresma com a determinada no ensaio de carregamento dinâmico. Observa-se que a variação apresentada pelos dois métodos possui o mesmo padrão de comportamento e que ambas as curvas indicam que os coeficientes de variação previstos foram inferiores ao determinados.

A Figura 44 do Apêndice F mostra que a variação do coeficiente de variação da resistência lateral acumulada prevista é muito semelhante à apresentada pelos valores de $\mathrm{N}_{\text {SPT }}$ acumulado. O que vem a demonstrar a estreita relação existente entre elas, pois, sabe-se que os dois métodos de previsão analisados baseiam-se em ensaios SPT na realização de suas previsões. 
Na seqüência, são apresentados no Apêndice F, as Figuras 45 a 72 que englobam dois tipos distintos de gráficos:

- curvas carga $x$ recalque, originadas das análises CAPWAPC referentes ao golpe adotado como o responsável pela ruptura do sistema, para cada uma das 14 estacas ensaiadas.

- curvas de transferência de carga para cada uma das 14 estacas ensaiadas.

\subsubsection{Carga admissível - Análise de Segurança e Confiabilidade}

Os valores de resistência adotados nas análises foram àqueles referentes ao golpe que provocou a ruptura do sistema isolado de fundação. A Tabela 15 do Apêndice $\mathrm{F}$ apresenta os valores de resistência lateral, de ponta e total resultantes dos ensaios de carregamento dinâmico realizado, enquanto que a Tabela 16 do Apêndice F apresenta esses mesmos valores em termos de tensão, juntamente com as estatísticas resultantes. A Tabela 8.6.3 abaixo apresenta um resumo dos valores resultantes.

Tabela 8.6.3. Valores de tensão resistente obtidos das provas de carga dinâmica.

\begin{tabular}{|c|c|c|c|c|}
\hline Estacas & $\begin{array}{c}\text { Área da seçāo } \\
\left(\mathrm{m}^{2}\right)\end{array}$ & $\begin{array}{c}\text { Res. Lateral } \\
(\mathrm{kPa})\end{array}$ & $\begin{array}{c}\text { Res. Ponta } \\
(\mathrm{kPa})\end{array}$ & $\begin{array}{c}\text { Res. Total } \\
(\mathrm{kPa})\end{array}$ \\
\hline Média & 0.2 & 7702.0 & 2693.2 & 10395.1 \\
\hline Desvio & 0.1 & 3452.8 & 1991.5 & 3562.9 \\
\hline $\mathrm{CV}(\%)$ & 27.3 & 44.8 & 73.9 & 34.3 \\
\hline
\end{tabular}

A Tabela 17 do Apêndice F apresenta os valores de resistência lateral, de ponta e total previstas pelo Método Décourt-Quaresma, assim como as estatísticas desses valores. A Tabela 8.6.4 abaixo apresenta um resumo dos valores obtidos.

Tabela 8.6.4. Estatísticas das resistências previstas pelo método Decóurt-Quaresma.

\begin{tabular}{|c|c|c|c|c|c|}
\hline Estatisticas & NSPT & $\begin{array}{c}\text { Prof. } \\
(\mathrm{m})\end{array}$ & $\begin{array}{c}\text { Res. Lateral } \\
(\mathrm{kPa})\end{array}$ & $\begin{array}{c}\text { Res. Ponta } \\
(\mathrm{kPa})\end{array}$ & $\begin{array}{c}\text { Res. Total } \\
(\mathrm{kPa})\end{array}$ \\
\hline Média & 45.3 & 19.8 & 1549.3 & 4915.8 & 6465.1 \\
\hline Desvio-Padräo & 15.5 & 0.6 & 247.0 & 1468.1 & 1647.7 \\
\hline $\mathrm{CV}(\%)$ & 34.3 & 3.0 & 15.9 & 29.9 & 25.5 \\
\hline
\end{tabular}

Da mesma forma, a Tabela 18 do Apêndice F apresenta os valores de resistência lateral, de ponta e total previstas pelo Método Aoki-Velloso, enquanto que as estatísticas desses valores se encontram na Tabela 8.6.5. 
Tabela 8.6.5. Estatísticas das resistências previstas pelo método Aoki-Velloso.

\begin{tabular}{|c|c|c|c|c|c|}
\hline Estatisticas & $\mathrm{N}_{\text {SPT }}$ & $\begin{array}{c}\text { Prof. } \\
(\mathrm{m})\end{array}$ & $\begin{array}{c}\text { Res. Lateral } \\
(\mathrm{kPa})\end{array}$ & $\begin{array}{c}\text { Res. Ponta } \\
(\mathrm{kPa})\end{array}$ & $\begin{array}{c}\text { Res. Total } \\
(\mathrm{kPa})\end{array}$ \\
\hline Média & 45.3 & 19.8 & 1262.1 & 7906.3 & 9168.4 \\
\hline Desvio-Padrão & 15.5 & 0.6 & 208.7 & 5412.3 & 5478.3 \\
\hline $\mathrm{CV}(\%)$ & 34.3 & 3.0 & 16.5 & 68.5 & 59.8 \\
\hline
\end{tabular}

Comparando os valores médios e de coeficiente de variação de resistência total apresentados nas três tabelas anteriores percebe-se que, em termos de valores médios o Método Décourt-Quaresma subestimou os valores de resistência para esta fundação, enquanto que o Método Aoki-Velloso apresentou um boa estimativa. Entretanto, como relação à variabilidade, o Método Aoki-Velloso indicou um coeficiente de variação muito superior ao obtido através das provas de carga realizadas, ao contrário do que ocorreu como o uso do Método Décourt-Quaresma que estimou um coeficiente de variação inferior ao real. Logo, percebe-se que para esta fundação, os dois métodos de cálculo analisados se mostraram incapazes de realizar uma previsão coerente.

Com base nos valores das estatísticas de tensões resistentes apresentados foram realizadas as análises apresentadas nas Figuras 73 a 81 do Apêndice F. Os resultados dessas análises se encontram resumidos nas Tabelas 8.6.6, 8.6.7 e 8.6.8 abaixo.

Tabela 8.6.6. Resumo provas de carga dinâmica.

\begin{tabular}{|c|c|c|c|c|c|c|c|c|c|c|c|}
\hline \multirow{2}{*}{ Análises } & \multicolumn{3}{|c|}{ Resistência } & \multicolumn{3}{|c|}{ Solicitaçäo } & \multirow{2}{*}{ CS } & \multirow{2}{*}{$\beta$} & \multirow{2}{*}{ Pr } & \multirow{2}{*}{$1 / \mathrm{Pr}$} & \multirow{2}{*}{$\begin{array}{l}\text { Pasm } \\
(\mathrm{kPa})\end{array}$} \\
\hline & Méda (kPa) & Desvio (kPa) & CV (\%) & Méda (kPa) & Desvio $(\mathrm{kPa})$ & CV (\%) & & & & & \\
\hline Anáise 1 & 10395.1 & 35629 & $34.3 \%$ & 80000.0 & 0.0 & $0.0 \%$ & 0.1 & -19.54 & 1.00000 & 1 & 800000 \\
\hline Anáise 2 & 10395.1 & 35629 & $34.3 \%$ & 5197.5 & 0.0 & $0.0 \%$ & 20 & 1.40 & 0.07231 & 14 & 5197.5 \\
\hline Aná'se 3 & 103951 & 35629 & $34.3 \%$ & .6159 & 0.0 & $0.0 \%$ & -169 & 309 & 0,00100 & 1000 & -6159 \\
\hline
\end{tabular}

Tabela 8.6.7. Resumo Método Décourt-Quaresma.

\begin{tabular}{|c|c|c|c|c|c|c|c|c|c|c|c|}
\hline \multirow{2}{*}{ Anäises } & \multicolumn{3}{|c|}{ Resistencia } & \multicolumn{3}{|c|}{ Solicitą̧̃o } & \multirow{2}{*}{ CS } & \multirow{2}{*}{$\beta$} & \multirow{2}{*}{ Pr } & \multirow{2}{*}{$1 / \mathrm{PI}$} & \multirow{2}{*}{$\begin{array}{l}P_{\text {adm }} \\
(\mathrm{XPa})\end{array}$} \\
\hline & Méda (KPa) & Desvio (kPa) & CV (\%) & Médáa (kPa) & Desvio $(\mathrm{KPa})$ & CV (\%) & & & & & \\
\hline Análise 1 & 6465.1 & 1647.7 & $25.5 \%$ & 800000 & 0.0 & $0.0 \%$ & 0.1 & -44.63 & 1.00000 & 1 & 800000 \\
\hline Anáse 2 & 6465.1 & 1647.7 & $255 \%$ & 32325 & 00 & $0.0 \%$ & 20 & 1.96 & 0.02489 & 40 & 32325 \\
\hline Análise 3 & 6465.1 & 1647.7 & $255 \%$ & 1373.1 & 00 & $00 \%$ & 4.7 & 309 & 0.00100 & 1000 & 1373.1 \\
\hline
\end{tabular}

Tabela 8.6.8. Resumo Método Aoki-Velloso.

\begin{tabular}{|c|c|c|c|c|c|c|c|c|c|c|c|}
\hline \multirow{2}{*}{ Análises } & \multicolumn{3}{|c|}{ Resistencia } & \multicolumn{3}{|c|}{ Solicitação } & \multirow{2}{*}{ CS } & \multirow{2}{*}{$\beta$} & \multirow{2}{*}{ Pr } & \multirow{2}{*}{$1 / \mathrm{Pr}$} & \multirow{2}{*}{$\begin{array}{l}\text { Paim } \\
(\mathrm{KPa})\end{array}$} \\
\hline & Méda (kPa) & Desio $(\mathrm{KPa})$ & CV $(\%)$ & Média (KPa) & Desvio (kPa) & CV (\%) & & & & & \\
\hline Anä́rse 1 & 91684 & 5478.3 & $59.8 \%$ & 800000 & 00 & $0.0 \%$ & 0.1 & -1293 & 1.00000 & 1 & 80000.0 \\
\hline Análise 2 & 91684 & 54783 & $59.8 \%$ & 4584.2 & 0.0 & $00 \%$ & 20 & 0.84 & 020136 & 5 & 4584.2 \\
\hline Anátise 3 & 9168.4 & 5478.3 & $59.8 \%$ & -7761.8 & 0.0 & $00 \%$ & -1.2 & 300 & 000100 & 1000 & $\cdot-7761.8$ \\
\hline
\end{tabular}


Observando os resultados das análises realizadas, nota-se que se o elevado coeficiente de variação dos valores de resistência medidas nos ensaios realizados, conduz a uma fundação com uma probabilidade de ruína de $1 / 14$, caso esta seja projetada com a carga admissível expressa em norma com um $\mathrm{CS}=2.0$. Enquanto que, se o estaqueamento for projetado com base nos valores de resistência previstos pelos métodos de cálculo, este também não apresentará segurança.

A Análise 3 da Tabela 8.6.7 referente ao uso dos valores de resistência previstos pelo Método Décourt-Quaresma e a um índice de confiabilidade igual a 3.09, correspondente a uma probabilidade de ruína de $1 / 1000$, indica que, se o estaqueamento for projetado com um $\mathrm{CS}=4.7$ este apresentará uma probabilidade de ruína adequada. Sendo que esta parece ser a solução mais indicada para o dimensionamento desta fundação. Pois, o fato do método subestimar a resistência média, apesar de ser antieconômico, é a favor da segurança, já com relação ao fator negativo do método indicar uma variabilidade inferior à real, o que é contrário à segurança, pode ser minimizado com o uso de métodos de controle que proporcionem uma real redução na variabilidade dos valores finais de resistência.

\subsubsection{Comentários finais}

Esta análise vem novamente a reforçar a importância do conhecimento da formação geológica-geotécnica na qual a fundação será executada. Pois, percebe-se que é em função do tipo de formação que é possível identificar se o comportamento previsto para fundação terá ou não alterações devido ao processo executivo.

Nota-se que é de fundamental importância identificar como o processo executivo pode intervir de forma positiva ou negativa na garantia da segurança de uma fundação.

Percebe-se que à medida que o processo executivo da fundação atue de forma a homogeneizar o maciço de solos, reduzindo a sua variabilidade, este terá um efeito positivo para a segurança da fundação. Em contrapartida, quando o processo executivo contribui para o aumento da variabilidade natural do maciço de solos, como neste caso em análise, este torna-se preocupante, uma vez que as análises de segurança baseadas nas resistências previstas não condizem com à realidade encontrada.

A solução para estes casos é a conscientização dos profissionais da área, como forma de torná-los conscientes dos riscos envolvidos na utilização de métodos de previsão que não levem em conta os efeitos do processo executivo em sua formulação. 


\subsection{Fundação em estacas pré-moldadas cravadas no Rio de Janeiro}

Neste item, encontram-se os resultados da análise da fundação de uma instalação industrial, situada no distrito de Caju na cidade do Rio de Janeiro, composta por estacas de concreto armado de diversos diâmetros.

Os dados utilizados nesta análise foram publicados por Balech (2000) na qual consta os resultados de 25 provas de carga dinâmica de energia crescente (DIET) realizadas na avaliação do estaqueamento, todas monitoradas com o auxilio do PDA, e as análises CAPWAP de todas as estacas para todos os níveis de carregamento dinâmico.

Inicialmente, são apresentadas as informações básicas utilizadas nessa análise, ou seja, as características geotécnicas do terreno obtidas a partir das sondagens realizadas no local da obra, a descrição dos elementos estruturais de fundação utilizados, e os resultados experimentais dos ensaios realizados para a verificação da capacidade de carga das estacas, ou seja, os resultados das provas de carga dinâmica executadas e, posteriormente, será apresentada a análise de segurança e confiabilidade da fundação em estudo.

\subsubsection{Características Geotécnicas do Maciço de Solos}

O maciço de solos, onde se encontra a obra analisada, é caracterizado pela presença de uma espessa camada de argila mole que apresenta uma espessura variável de 8 a $16 \mathrm{~m}$ e que está sobrejacente a uma camada arenosa de solo residual de gnaisse (BALECH, 2000).

O maciço de argila mole, leva o nome do distrito local, e é denominado depósito de argila Caju. Este depósito, assim como outros existentes na cidade do Rio de Janeiro, tem sua origem a partir de depósitos marinhos e lacustres. Esta argila apresenta, em média, $5 \%$ de matéria orgânica, o que é responsável pela coloração marrom a cinza e até mesmo preta do material (BALECH, 2000).

\subsubsection{Informações a respeito do elemento estrutural de fundação}

As fundações foram executadas em estacas pré-moldadas de concreto armado com, seção circular vazada e, resistência característica à compressão de $35 \mathrm{MPa}$. 
As estacas apresentam diâmetros variados, sendo que das 25 estacas analisadas, 14 apresentam um diâmetro de 50 centímetros, 10 apresentam um diâmetro de 42 centímetros e somente 1 estaca apresenta o diâmetro de 26 centímetros.

As características geométricas dos elementos estruturais selecionados para a fundação da obra estão apresentadas na Tabela 1 do Apêndice G. Nesta tabela, estão as dimensões de cada um dos 25 elementos estruturais de fundação, ou seja, o diâmetro, a espessura da parede e o seu comprimento, assim como a sondagem correspondente.

Deve-se observar que as estacas ensaiadas possuem a mesma nomenclatura referente as sondagens. Por exemplo, as estacas denominadas " $A$ ", referem-se as sondagens do "local A", as estacas denominadas "B" se referem a sondagem do "local B", e assim sucessivamente até a estaca tipo "J".

Deve-se destacar que o elemento estrutural de fundação utilizado nesta obra possui a mesma geometria do elemento estrutural usado na fundação que foi analisada no item 8.3 e que se encontra representado na Figura 8.3.1 do mesmo. Entretanto, apesar da forma de sua seção transversal, foi mostrado naquele item que é, para fins de análise, coerente calcular a área da seção transversal da estaca como se a mesma fosse maciça (área plena). Sendo assim, as áreas usadas no cálculo das tensões resistentes e solicitantes utilizadas nas análises seguintes, foram calculadas fazendo uso desta consideração.

\subsubsection{Análise dos resultados dos ensaios realizados}

Este item apresenta a análise dos dados publicados: resultados das 10 sondagens SPT realizadas (sub-item 8.7.3.1) e os resultados das provas de carga dinâmica de energia crescente (DIET) realizadas em 25 estacas que fazem parte da fundação em estudo (sub-item 8.7.3.2).

\subsubsection{Investigação Geotécnica - Sondagem à percussão (SPT)}

Com o intuito de descrever a variabilidade geológica-geotécnica do maciço de solos onde a obra foi executada, foram realizadas 10 sondagens à percussão SPT. Os valores de $\mathrm{N}_{\text {SPT }}$ encontrados, assim como os perfis de solo identificados (perfil estratigráfico) em cada uma das sondagens realizadas, podem ser visualizados em Balech (2000). 
Os valores publicados, assim como os valores mínimos, médios e máximos de $N_{\text {SPT }}$ para cada profundidade se encontram na Tabela 2 do Apêndice G. Com esses valores foram elaborados os gráficos das Figuras 1,2 e 3 do Apêndice G, que apresentam a variação do índice de resistência à penetração $\mathrm{N}_{\mathrm{SPT}}$ ao longo da profundidade. No entanto, deve-se destacar que os valores de $\mathrm{N}_{\text {SPT }}$ publicados não estão de "metro em metro", mais sim por camadas. Logo, para a elaboração da Tabela 2 e dos gráficos das Figuras 1, 2 e 3 do Apêndice G, foi necessário considerar que o valor do $\mathrm{N}_{\text {SPT }}$ de cada metro fosse igual ao valor publicado para a camada de solo correspondente.

A Figura 1 do Apêndice $G$ apresenta a variação dos valores de $N_{\text {SPT }}$ encontrados nas 10 sondagens realizadas ao longo da profundidade. Enquanto que a Figura 2 do Apêndice $\mathrm{G}$ apresenta as curvas representativas do $\mathrm{N}_{\mathrm{SPT}}$ mínimo, médio e máximo e, a Figura 3 do Apêndice $G$ apresenta o coeficiente de variação do $N_{\text {SPT }}$ ao longo da profundidade, ambas considerando as 10 sondagens realizadas.

Observando a curva representativa dos valores de $\mathrm{N}_{\text {SPT }}$ médio apresentada na Figura 2 e os valores da Tabela 2 do Apêndice G, percebe-se que até os $11 \mathrm{~m}$ de profundidade, os valores de $\mathrm{N}_{\mathrm{SPT}}$ encontrados foram desprezíveis e que, somente a partir dessa profundidade é que os valores de $\mathrm{N}_{\mathrm{SPT}}$ apresentaram um aumento gradativo com a profundidade.

Observando a Figura 3 e a Tabela 2 do Apêndice G pode-se notar que nos primeiros metros de profundidade, o coeficiente de variação do $\mathrm{N}_{\mathrm{SPT}}$ apresentou um aumento gradativo com a profundidade, atingindo o teu valor máximo aos $12 \mathrm{~m}$, quando começou a reduzir atingindo valores da ordem de $30 \%$. O coeficiente de variação foi, em média igual a $166 \%$, oscilando de $32 \%$ (coeficiente de variação mínimo) a $303 \%$ (coeficiente de variação máximo).

A variação do coeficiente de variação dos valores de $\mathrm{N}_{\text {SPT }}$ está relacionada com o perfil geotécnico do maciço de solos da região onde a obra foi executada. Pelos resultados das sondagens, percebe-se que o maciço de solos é caracterizado pela presença de uma camada de argila mole com espessura variável, sendo que, em alguns locais, existe a presença de camadas intercaladas de areia e, logo sobrejacente à camada de argila, tem-se o solo residual de gnaisse. O nível de água encontra-se na cota do nível do terreno (BALECH, 2000).

Comparando o perfil estratigráfico do maciço de solos com a variação dos valores de $\mathrm{N}_{\mathrm{SPT}}$ encontrados ao longo da profundidade percebe-se que, os baixos valores 
de $\mathrm{N}_{\text {SPT }}$ existentes nos primeiros metros de profundidade ocorrem devido à primeira camada de solo ser constituída, predominantemente, pelo material argiloso e, a mudança do solo argiloso para o solo residual de gnaisse, justifica o aumento dos valores médios de $\mathrm{N}_{\mathrm{SPT}}$ encontrados. O mesmo raciocínio é válido para a mudança significativa nos valores de coeficiente de variação, pois a primeira camada de solo apresentou os elevados coeficientes de variação, enquanto que a segunda camada, apresentou um comportamento mais homogêneo.

\subsubsection{Provas de carga dinâmica de energia crescente}

As estacas submetidas às provas de carga dinâmica de energia crescente foram monitoradas com o sistema PDA e todos os sinais obtidos em campo através desta instrumentação foram submetidos à análise CAPWAP.

Ressalta-se que todas as provas de carga dinâmica foram realizadas após a cravação, ou seja, na recravação, e que os ensaios foram realizados em diferentes intervalos de tempo, que variou de 1 a 43 dias após o final da cravação. O intervalo de tempo decorrido do final da cravação até a data da realização do ensaio, de cada uma das estacas ensaiadas, pode ser visualizado em Balech (2000).

Este item tem como objetivo analisar os dados obtidos a partir da realização das provas de carga dinâmicas de energia crescente nas estacas da fundação analisada.

Inicialmente, será apresentada a estimativa das cargas de ruptura das estacas submetidas às provas de carga. Na seqüência, será apresentado o estudo da transferência de carga, da resistência lateral unitária e unitária acumulada ao longo do fuste, de todas as estacas ensaiadas.

\subsection{Ruptura dos sistemas isolados de fundação}

Sabe-se que o sistema isolado estaca-solo apresenta ruptura quando a resistência do solo é totalmente mobilizada. A ruptura do sistema pode ser facilmente visualizada através dos diagramas de força normal mobilizada. Pois, quando o sistema é sujeito a dois ou mais níveis crescentes de energia e, mesmo assim, os diagramas de força normal mobilizada permanecem constantes, significa que o sistema não consegue mais mobilizar resistência, o que caracteriza a ruptura do sistema por parte do solo.

Logo, através dos diagramas de força normal mobilizada é possível determinar o 
golpe que provocou a ruptura do sistema, visto que a partir de determinado nível de energia aplicado, a resistência estática mobilizada permanece constante após a aplicação de golpes com níveis de energia crescente, ou seja, o solo não oferece mais resistência, caracterizando assim, a ruptura do sistema estaca-solo (AOKI, 1997).

Balech (2000) apresenta os diagramas de força normal mobilizada (resistência total mobilizada ao longo da profundidade para todos os níveis de energia do ensaio) para todas as estacas, resultante a partir do impacto do martelo sobre o sistema isolado estaca-solo, obtidos através da metodologia PDA e das análises CAPWAP, realizadas para cada golpe de energia crescente, ao longo da profundidade.

Através da observação desses diagramas, pode-se observar que das 25 provas de carga utilizadas nesta análise, 20 não atingiram a ruptura. Somente as estacas $\mathrm{C} 1, \mathrm{C} 2$, E2, G1 e I1 foram levadas à ruptura. Sendo assim, fez-se necessário, para as demais estacas, adotar um critério para a determinação da carga de ruptura. O critério adotado consiste em adotar o golpe responsável pela mobilização da máxima resistência, como o golpe correspondente à ruptura, para a obtenção dos valores de carga de ruptura do sistema.

A Tabela 3 do Apêndice G apresenta, para cada uma das 25 estacas ensaiadas, o golpe que foi considerado como representativo da ruptura da estaca, juntamente com os valores de resistência lateral, de ponta e total correspondente. Com base nesses valores de resistência foram calculadas as tensões resistentes utilizadas em algumas das análises realizadas. Os valores obtidos estão apresentados na Tabela 4 do Apêndice G..

\subsection{Mobilização da resistência estática}

Quando acontece o impacto do martelo sobre o sistema estaca-solo, a resistência do solo é mobilizada e, o atrito lateral e a resistência de ponta variam de acordo com a natureza e reologia dos diferentes tipos de solo ao longo da profundidade com o tempo.

A resistência de ponta e a resistência lateral mobilizada, assim como a resistência total mobilizada, para cada nível de energia aplicado nas estacas analisadas, são apresentadas nos gráficos das Figuras 4 a 53 do Apêndice G. Com base nesses gráficos tem-se uma melhor compreensão do comportamento do sistema estaca-solo, no que diz respeito à distribuição da resistência lateral e da resistência de ponta ao longo dos níveis de energia aplicada. Essas figuras apresentam dois tipos de gráficos:

$\checkmark$ um gráfico de mobilização da resistência estática total, lateral e de ponta para 
cada estaca analisada, cujo objetivo é mostrar como se processa a mobilização da resistência no decorrer do ensaio de acordo com a aplicação dos golpes de energia crescente, e

$\checkmark$ as curvas de transferência de carga, que como o próprio nome diz, tem como objetivo estudar a distribuição de resistência entre atrito lateral e ponta a cada nível de energia aplicado, ou seja, a transferência de carga.

As Tabelas 5 a 29 do Apêndice G apresentam os valores de resistência lateral, ponta, total e de deslocamento máximo, utilizados na elaboração dos gráficos das figuras citadas.

Observando esses gráficos, pode-se perceber que as estacas apresentaram diferentes comportamentos quanto à mobilização da resistência estática durante a realização das provas de carga dinâmicas realizadas.

No caso das estacas ensaiadas após um curto intervalo de tempo à sua cravação, devido ao espesso maciço de argila mole, houve uma desprezível mobilização da resistência lateral em todos os níveis de energia aplicados. Nestes casos, a resistência lateral das estaca foi desprezível e somente a resistência de ponta foi mobilizada. As outras estacas, em que o tempo de ensaio foi maior, a pressão neutra dissipou resultando num aumento da mobilização da resistência lateral. Entretanto, deve-se ressaltar que as estacas A2 e F1, apesar de terem sido ensaiadas logo após a sua cravação, não obedeceram a esta hipótese.

Das vinte e cinto estacas ensaiadas, dez (B3, B6, C1, C4, C5, D1, D2, E1, G1 e J1) apresentaram uma resistência lateral desprezível, tendo portanto somente a resistência de ponta mobilizada. Essas estacas apresentaram no mínimo 70\% em média da sua resistência total mobilizada constituída por resistência de ponta, tendo no máximo, somente $30 \%$ em média da sua resistência total como resistência lateral. Foram essas as estacas ensaiadas depois de um curto intervalo de tempo após a cravação, com exceção das estacas B3 e E1 que foram ensaiadas após um maior intervalo de tempo.

O motivo desse comportamento está no fato que a pressão neutra gerada durante a cravação, provoca a perda da resistência lateral e toda a resistência é transferida para a ponta, pois quando se ensaia uma estaca com um curto intervalo de tempo após a sua cravação, não há tempo de dissipar toda a pressão neutra gerada. Terminada a cravação, esta pressão neutra se dissipa gradualmente com o tempo, ocorrendo o adensamento do solo ao redor da estaca. Com o adensamento, a resistência ao cisalhamento do solo aumenta com o tempo e também a sua capacidade de carga (BALECH, 2000). 
Nota-se que, mesmo se tratando de estacas cravadas num mesmo maciço de solos, neste caso maciço de argila mole sobrejacente a solo residual de gnaisse, diversos tipos de comportamento foram observados. Esses diagramas mostram que, mesmo quando as estacas têm como referência uma mesma sondagem, o diferente comportamento observado, pode ser explicado pela grande variabilidade natural do solo local e pelos diferentes tempos de realização dos ensaios (BALECH, 2000).

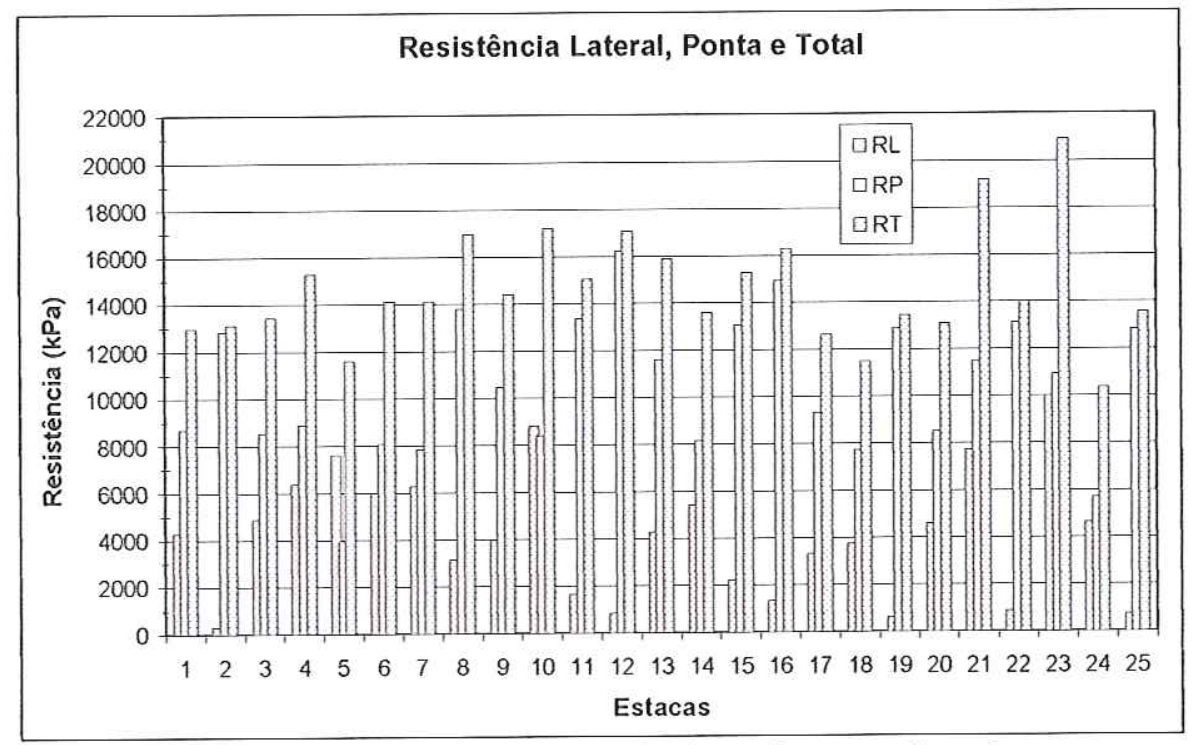

Figura 8.7.1. Variação da resistência total, ponta e lateral.

Os gráficos das Figuras 54, 55 e 56 do Apêndice G apresentam como é a variação da resistência de ruptura lateral, de ponta e total para cada estaca ensaiada, considerando o golpe referente à ruptura. A Figura 8.7.1 foi formada a partir da reunião dos três gráficos anteriores. Esta figura permite visualizar quais as estacas possuem a maior porcentagem de sua resistência total constituída por resistência lateral e quais possuem a maior porcentagem de sua resistência total constituída por resistência de ponta.

A Tabela 30 do Apêndice $G$ apresenta a porcentagem média de resistência de ponta e de atrito lateral em relação à resistência total mobilizada de cada estaca ensaiada. Observando essa tabela é possível identificar quais as estacas apresentam maior porcentagem de resistência lateral e quais as estacas que tiveram maior porcentagem de resistência de ponta. Nota-se que, em geral, as estacas tiveram, aproximadamente, $37 \%$ de sua resistência total constituída por resistência lateral e, conseqüentemente, $63 \%$ de sua resistência total constituída por resistência de ponta. 


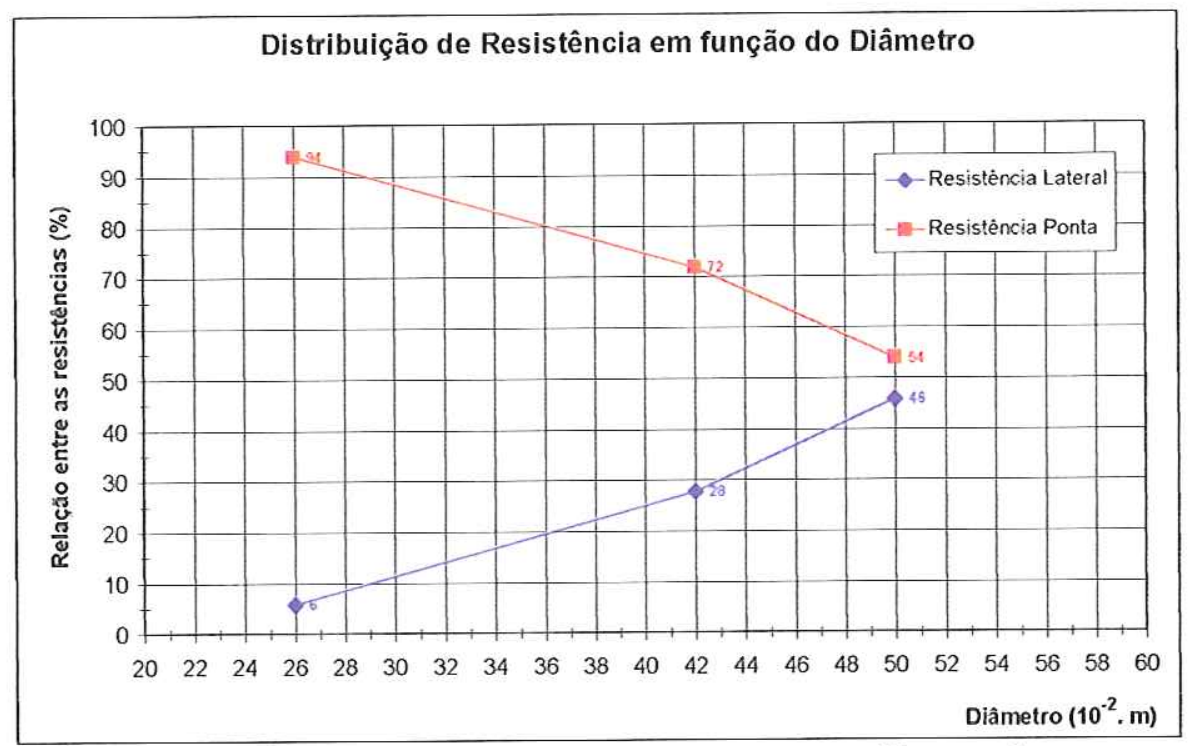

Figura 8.7.2. Relação entre a distribuição da resistência e o diâmetro das estacas.

Analisando as estacas em função de seus diâmetros e calculando os valores médios, de desvio padrão e de coeficiente de variação para cada grupo (vide Tabelas 31 e 32 do Apêndice G), percebe-se que à medida que há o aumento do diâmetro das estacas, há a redução da porcentagem de resistência de ponta e o aumento da porcentagem de resistência lateral. Observe o gráfico da Figura 8.7.2 elaborado com os valores médios, aproximados, apresentados nas tabelas do apêndice.

\subsection{Resistência estática lateral unitária}

Este sub-item trata da análise da resistência lateral unitária desenvolvida ao longo do fuste das estacas ensaiadas quando da execução das provas de carga dinâmica de energia crescente para o impacto que conduziu à ruptura.

A Tabela 33 do Apêndice $\mathrm{G}$ apresenta os valores de resistência lateral unitária, obtidas para todas as estacas por meio das análises CAPWAP, em função da profundidade. A tabela também apresenta os valores mínimos, médios e máximos de resistência encontrados em cada profundidade, assim como os coeficientes de variação dos mesmos.

Usando os valores médios de resistência lateral unitária apresentados na tabela anterior foi elaborado o gráfico da Figura 57 do Apêndice G que mostra a variação desses valores ao longo da profundidade. Analisando o gráfico é possível perceber que a resistência lateral unitária média se apresentou aproximadamente constante, oscilando 
em torno de $10 \mathrm{kPa}$ até os $10 \mathrm{~m}$ de profundidade. Após essa profundidade, nota-se um aumento gradativo dos valores de resistência com a profundidade.

Os baixos valores de resistência lateral unitária, mobilizados ao longo do fuste das estacas, apresentados nos primeiros $10 \mathrm{~m}$, se devem à presença da espessa camada de argila mole. Ao término dessa camada e início da camada de solo residual, observa-se o aumento gradual dos valores de resistência.

A Figura 58 do Apêndice $G$ apresenta os valores mínimos, médios e máximos de resistência lateral unitária ao longo da profundidade. Por meio da observação desse gráfico pode-se perceber a dispersão existente entre os valores encontrados.

A Figura 59 do Apêndice G apresenta o coeficiente de variação dos valores de resistência lateral unitária ao longo da profundidade. Observe que os maiores valores de coeficiente de variação ocorreram nos primeiros $10 \mathrm{~m}$ do maçico de solos. Há um aumento do coeficiente de variação até a profundidade de $7 \mathrm{~m}$, onde se dá o valor máximo (187\%), seguido de uma reduçao até a profundidade de $10 \mathrm{~m}$, onde se atinge um coeficiente de variação da ordem de $100 \%$, que se reduz aos poucos com o aumento da profundidade.

Comparando a variabilidade dos valores de resistência lateral unitária com a variabilidade dos valores de $\mathrm{N}_{\mathrm{SPT}}$ ao longo da profundidade, nota-se as semelhanças por eles apresentados.

A Figura 60 do Apêndice $G$ apresenta a variação da resistência lateral unitária média e do $\mathrm{N}_{\mathrm{SPT}}$ médio ao longo da profundidade. Em ambas as curvas, percebe-se um comportamento aproximadamente constante até os $10 \mathrm{~m}$ de profundidade, seguido de um aumento gradual com a profundidade.

Quanto ao coeficiente de variação, a Figura 61 do Apêndice G traz as curvas de coeficiente de variação em função da profundidade para os valores de resistência lateral unitária e de $\mathrm{N}_{\mathrm{SPT}}$. Nota-se que o coeficiente de variação previsto pelo ensaio SPT é maior que o apresentado pelos resultados das provas de carga. Logo, da comparação entre essas duas curvas pode-se perceber que a variabilidade do maciço de solos reduziu com o processo de cravação das estacas.

Como conclusão geral dessas análises, pode-se dizer que o ensaio SPT não é capaz de retratar a variabilidade final do maciço de solos em estudo. Pois, nota-se que esta formação geológica é suscetível aos efeitos do processo executivo do estaqueamento e o ensaio SPT consegue identificar somente a variabilidade do solo natural. 


\subsection{Resistência estática lateral unitária acumulada}

Somando os valores de resistência lateral unitária mobilizadas a cada metro de profundidade, têm-se os valores de resistência lateral unitária acumulada apresentados na Tabela 34 do Apêndice G. Da mesma forma, têm-se os valores de $\mathrm{N}_{\text {SPT }}$ acumulado apresentados na Tabela 35 do Apêndice G.

Fazendo uso dos valores de resistência lateral unitária acumulada encontrados, elaborou-se os gráficos das Figuras 62, 63 e 64 do Apêndice G. A Figura 62 do Apêndice $G$ apresenta a variação da resistência lateral acumulada média ao longo da profundidade e a Figura 63 do Apêndice G apresenta os valores mínimos, médios e máximos de resistência lateral acumulada ao longo da profundidade. Em ambas as figuras, é possível notar que os valores de resistência aumentam com a profundidade, entretanto, até os $10 \mathrm{~m}$ de profundidade esse aumento apresenta-se aproximadamente linear, e a partir dessa profundidade há um aumento proporcionalmente maior com o aumento da profundidade.

A Figura 64 do Apêndice $G$ apresenta a variação do coeficiente de variação dos valores de resistência lateral acumulada ao longo da profundidade. Nota-se que os mesmos se apresentaram aproximadamente constantes até a profundidade de $10 \mathrm{~m}$, após a qual percebe-se uma pequena redução com o aumento da mesma. Comparando a Figura 64 com a Figura 59 do Apêndice G percebe-se que o coeficiente de variação do atrito local é mais variável que o coeficiente de variação do atrito acumulado.

A Figura 65 do Apêndice G apresenta variação dos valores médios de resistência lateral acumulada e de $\mathrm{N}_{\text {SPT }}$ acumulado ao longo da profundidade. Enquanto que a Figura 66 do Apêndice G apresenta o coeficiente de variação da resistência lateral acumulada e do $\mathrm{N}_{\text {SPT }}$ acumulado ao longo da profundidade e a Figura 67 do Apêndice G apresenta essa mesma curva só que agora com o coeficiente de variação dos valores de $\mathrm{N}_{\text {SPT }}$. Da observação dessas duas figuras pode-se perceber que, em se tratando de valores acumulados, não é possível notar nenhuma relação entre o coeficiente de variação dos valores de resistência lateral com os valores de $\mathrm{N}_{\text {SPT }}$ das sondagens.

\subsubsection{Análise de Segurança e Confiabilidade}

Neste item será realizada a estimativa da carga admissível do estaqueamento usando a formulação da norma e a formulação proposta nessa dissertação e serão 
apresentadas as suas implicações com relação à segurança e a confiabilidade da fundação analisada.

Como exposto anteriormente, a determinação dos valores de carga de ruptura das estacas cujas provas de carga não apresentaram ruptura nítida foi feita considerando os valores de resistência referente ao golpe responsável pela mobilização da máxima resistência. Entretanto, deve-se observar que nem sempre este golpe corresponde ao golpe de maior energia do ensaio. Após identificar os valores de resistência última, esses foram limitados à resistência estrutural das estacas.

O cálculo da resistência estrutural das estacas foi realizado adotando-se um coeficiente de variação de $10 \%$ para os valores de resistência do concreto (AOKI et al., 1995), e o valor de 35 MPa para a resistência característica do concreto. Enquanto que as cargas nominais adotadas nesta análise são às indicadas no catálogo do fabricante do elemento estrutural referente a uma resistência característica de $35 \mathrm{MPa}$.

Inicialmente, optou-se por analisar em conjunto todas as provas de carga realizadas. Sendo assim, devido ao fato dessas provas de carga terem sido realizadas em estacas com diferentes dimensões de seções transversais, essas primeiras análises foram realizadas em termos de tensões. Posteriormente, os resultados das provas de carga realizadas foram separados em função do diâmetro das estacas ensaiadas, dando origem a três grupos compostos por: 14 estacas com $\mathrm{D}=0.50 \mathrm{~m}, 10$ estacas com $\mathrm{D}=0.42 \mathrm{~m}$ e 1 estaca com $\mathrm{D}=0.26 \mathrm{~m}$. Considerando somente os dois primeiros grupos foram realizadas mais duas análises.

Há dois objetivos principais para a realização dessas análises complementares:

$\checkmark$ verificar se há ou não uma diferença significativa nos resultados das análises quando se utilizam todas as provas de carga, de quando se realizam as análises com os grupos de estacas de mesmo diâmetro; e,

$\checkmark$ reduzir uma fonte de variabilidade, ao se analisar em conjunto, somente estacas de mesmo diâmetro.

\subsubsection{Análise de todas as estacas em termos de tensões}

Este sub-item apresenta os resultados das análises realizadas em termos de tensão considerando todas as provas de carga realizadas.

A Tabela 4 do Apêndice $G$ apresenta as tensões resistentes calculadas com os valores de resistência da Tabela 3 do Apêndice G, assim como os valores de resistência 
média, de desvio padrão e de coeficiente de variação das resistências lateral, de ponta e total, medidas nas 25 provas de carga realizadas. Esses valores também se encontram resumidos na Tabela 8.7.1.

Tabela 8.7.1. Estatísticas das tensões resistentes considerando todas as estacas.

\begin{tabular}{|c|c|c|c|c|c|}
\hline Estatisticas & $\begin{array}{c}\text { Diamêtro } \\
(\mathrm{m})\end{array}$ & $\begin{array}{c}\text { Área cheia } \\
\left(\mathrm{m}^{2}\right)\end{array}$ & $\begin{array}{c}\text { Res. Lateral } \\
(\mathrm{kPa})\end{array}$ & $\begin{array}{c}\text { Res. Ponta } \\
(\mathrm{kPa})\end{array}$ & $\begin{array}{c}\text { Res. Total } \\
(\mathrm{kPa})\end{array}$ \\
\hline Média & 0.46 & 0.17 & 4148.6 & 10452.5 & 14600.7 \\
\hline Desvio & 0.06 & 0.04 & 2713.4 & 2993.9 & 2402.8 \\
\hline CV (\%) & 12.5 & 22.2 & 65.4 & 28.6 & 16.5 \\
\hline
\end{tabular}

Com os valores de carga nominais adotadas foram estimadas as tensões solicitantes atuantes em cada uma das estacas. As cargas nominais adotadas, assim como as correspondentes tensões solicitantes estão apresentadas na Tabela 36 do Apêndice G. As tensões solicitantes encontradas apresentaram média igual a $8545.4 \mathrm{kPa}$ e coeficiente de variação de $3.0 \%$, como pode ser observado na Tabela 8.7.2.

Tabela 8.7.2. Estatísticas das tensões solicitantes considerando todas as estacas.

\begin{tabular}{|c|c|c|c|c|}
\hline Estatísticas & $\begin{array}{c}\text { Diamêtro } \\
(\mathrm{m})\end{array}$ & $\begin{array}{c}\text { Área cheia } \\
\left(\mathrm{m}^{2}\right)\end{array}$ & $\begin{array}{c}\text { Carga adm. } \\
(\mathrm{kN})\end{array}$ & $\begin{array}{c}\text { Solicitação } \\
(\mathrm{kPa})\end{array}$ \\
\hline Média & 0.46 & 0.17 & 1432.0 & 8545.4 \\
\hline Desvio & 0.06 & 0.04 & 333.5 & 253.1 \\
\hline CV $(\%)$ & 12.5 & 22.2 & 23.3 & 3.0 \\
\hline
\end{tabular}

Com as estatísticas dos valores de tensões resistentes e solicitantes apresentados nas Tabelas 8.7.1 e 8.7.2 (Tabcla 4 e 36 do Apêndice G) foram realizadas as análises apresentadas nas Figuras 68, 69 e 70 do Apêndice G. O resumo dos resultados encontrados está apresentado na Tabela 8.7 .3 e os comentários relativos a esses resultados, estão apresentados na sequiência.

Tabela 8.7.3. Resultados das análises realizadas - todas as estacas.

\begin{tabular}{|c|c|c|c|c|c|c|c|c|c|c|c|}
\hline \multirow{2}{*}{ Análises } & \multicolumn{3}{|c|}{ Resistencia } & \multicolumn{3}{|c|}{ Solictaçä } & \multirow{2}{*}{ CS } & \multirow{2}{*}{$\beta$} & \multirow{2}{*}{ Pr } & \multirow{2}{*}{$1 / \mathrm{Pr}$} & \multirow{2}{*}{$\begin{array}{l}\text { Pasm } \\
(\mathrm{PPa})\end{array}$} \\
\hline & Méda (kPa) & Desvio (kPa) & CV (\%) & Méda (kPa) & Desvio (kPa) & $\mathrm{CV}(\%)$ & & & & & \\
\hline Análise 1 & 146007 & 24028 & $16.5 \%$ & 8545.4 & 253.1 & $30 \%$ & 1.7 & 251 & 0.00610 & 164 & 8545.4 \\
\hline Anáise 2 & 146007 & 24028 & $16.5 \%$ & 73003 & 2162 & $30 \%$ & 20 & 3.03 & 0.00124 & 807 & 7300.3 \\
\hline Análise 3 & 146007 & 24028 & $16.5 \%$ & 7146.4 & 211.6 & $30 \%$ & 20 & 309 & 0.00100 & 1000 & 7146.4 \\
\hline
\end{tabular}

Os resultados das análises (Análise 1, 2 e 3) mostram que se o estaqueamento for projetado com: 
$\checkmark$ as estatísticas das solicitações calculadas em função das cargas nominais das estacas (Análise 1), este irá apresentar um CS $=1.7$ e uma probabilidade de ruína de $1 / 164$.

$\checkmark$ a carga admissível proposta em norma com um $\mathrm{CS}=2.0$ (Análise 2), este terá um $\beta=3.03$ correspondente a uma probabilidade de ruína de $1 / 807$, que é relativamente aceitável.

$\checkmark$ uma probabilidade de ruína de $1 / 1000$ correspondente a um $\beta=3.09$ (Análise 3), este deverá ser dimensionado com uma carga admissível de $7146.4 \mathrm{kPa}$, para que o mesmo apresente segurança, o que equivale a utilizar a formulação da norma com um coeficiente de segurança igual à, aproximadamente, 2.0 .

Usando a formulação de carga admissível proposta, foram calculados os valores apresentados na Tabela 37 do Apêndice G, que permitem elaborar o gráfico da Figura 71 do Apêndice $G$, a partir do qual é possível determinar a carga admissível correspondente à probabilidade de ruína desejada e o seu respectivo coeficiente de segurança.

Deve-se observar que neste caso, em específico, devido ao coeficiente de variação das tensões resistentes do estaqueamento ser igual a $16.5 \%$, percebe-se que o uso de um coeficiente de segurança igual a 2.0 é "representativo" da segurança da fundação em estudo, por conduzir a uma probabilidade de ruína adequada. Logo, se neste caso a fundação em análise for projetada segundo as recomendações existentes em norma, esta apresentará segurança.

\subsubsection{Análise dos dois grupos de estacas com mesmo diâmetro}

Neste sub-item serão analisados os dois grupos de provas de carga que foram formados em função das dimensões da seção transversal das estacas. Para cada grupo foi calculado o valor médio, o desvio padrão e o coeficiente de variação das resistências e das solicitações das estacas do grupo.

A Tabela 38 do Apêndice $G$ apresenta as estacas e as estatísticas do primeiro grupo, formado por todas as estacas com $\mathrm{D}=0.50 \mathrm{~m}$ e, a Tabela 39 do Apêndice $\mathrm{G}$ apresenta as estacas e as estatísticas do segundo grupo, formado por todas as estacas com $\mathrm{D}=0.42 \mathrm{~m}$.

Comparando as estatísticas dos valores de resistência apresentadas nessas 
tabelas é interessante notar que, neste exemplo, o grupo de estacas com $0.50 \mathrm{~m}$ de diâmetro apresentou o menor coeficiente de variação e a maior resistência média, sendo portanto, em termos estatísticos, o melhor grupo. Percebe-se que o valor da resistência média aumentou com o aumento das dimensões da seção transversal das estacas e o coeficiente de variação das resistências diminuiu.

A redução do coeficiente de variação das resistências, com o aumento das dimensões da seção transversal das estacas, pode estar relacionada ao fato de, com o aumento do diâmetro das estacas, houve a redução da resistência de ponta e o conseqüente aumento da resistência lateral (Figura 8.7.2), e esta pode estar sendo a responsável pela maior variabilidade detectada anteriormente.

Isso pode ter ocorrido devido ao maior número de provas de carga do grupo (14 provas de carga) quando em comparação com o outro grupo (10 provas de carga) formado por estacas com $0.42 \mathrm{~m}$ de diâmetro ou, devido à maior dimensão da seção transversal das estacas tornar o comportamento do sistema estaca-solo menos sensível com relação à variabilidade do maciço de solos.

Logo, para esta obra, em particular, parece ser mais vantajoso realizar o projeto de fundações com um menor número de estacas de dimensões maiores $(\mathrm{D}=0.50 \mathrm{~m})$ do que com uma quantidade maior de estacas de dimensões menores $(D=0.42 \mathrm{~m})$. Na seqüência, estão apresentados os resultados das duas análises realizadas.

\subsection{Análise das estacas com $D=0.50 \mathrm{~m}$}

Este sub-item apresenta os resultados das análises realizadas considerando somente as provas de carga executadas nas estacas com diâmetro igual a $0.50 \mathrm{~m}$. Essas análises foram executadas com as estatísticas dos valores de resistência apresentados na Tabela 38 do Apêndice G e resumidos na Tabela 8.7.4 abaixo, e com os valores de solicitação apresentados na Tabela 36 do Apêndice G.

Tabela 8.7.4. Estatísticas dos valores de resistência das estacas com D $=0.50 \mathrm{~m}$.

\begin{tabular}{|c|c|c|c|}
\hline Estatisticas & $\begin{array}{c}\text { Res. Lateral } \\
(\mathrm{kN})\end{array}$ & $\begin{array}{c}\text { Res. Ponta } \\
(\mathrm{kN})\end{array}$ & $\begin{array}{c}\text { Res. Total } \\
(\mathrm{kN})\end{array}$ \\
\hline Média & 926.6 & 1872.9 & 2799.4 \\
\hline Desvio & 456.2 & 630.7 & 403.6 \\
\hline CV (\%) & 49.2 & 33.7 & 14.4 \\
\hline
\end{tabular}


As análises realizadas estão apresentadas nas Figuras 72, 73 e 74 do Apêndice $\mathrm{G}$, e os resultados dessas análises podem ser observados na Tabela 8.7.5.

Tabela 8.7.5. Resultados das análises realizadas - estacas com $\mathrm{D}=0.50 \mathrm{~m}$.

\begin{tabular}{|c|c|c|c|c|c|c|c|c|c|c|c|}
\hline \multirow{2}{*}{ Análises } & \multicolumn{3}{|c|}{ Resistência } & \multicolumn{3}{|c|}{ Solcitação } & \multirow{2}{*}{ CS } & \multirow{2}{*}{$\beta$} & \multirow{2}{*}{ Pr } & \multirow{2}{*}{$1 / \mathrm{Pr}$} & \multirow{2}{*}{$\begin{array}{l}\text { Pajm } \\
\text { (WN) }\end{array}$} \\
\hline & Néda (IN) & Desvio (kiv) & CV (\%) & Méda (KN) & Desvio (Kov) & CV (\%) & & & & & \\
\hline Aná'se 1 & 2799.4 & 403.6 & $14.4 \%$ & 17000 & 0.0 & $0.0 \%$ & 1.6 & 272 & 0.00322 & 310 & 17000 \\
\hline Anáise 2 & 2799.4 & 4036 & $14.4 \%$ & 1399.7 & 0.0 & $0.0 \%$ & 20 & 3.47 & 0.00026 & 3816 & 1309.7 \\
\hline Anáise 3 & 2799.4 & 403.6 & $14.4 \%$ & 15522 & 0.0 & $0.0 \%$ & 1.8 & 3.09 & 0.00100 & 1000 & 15522 \\
\hline
\end{tabular}

Observando a Tabela 8.7.5, pode-se perceber que se o estaqueamento for projetado com as cargas nominais das estacas, este apresentará uma probabilidade de ruína de $1 / 310$ e um $\mathrm{CS}=1.6$. Caso o estaqueamento seja projetado utilizando a formulação da norma com um $\mathrm{CS}=2.0$ (Análise 2), a sua probabilidade de ruína será desprezível (1/3816). Mas, caso se deseje projeta-lo com uma probabilidade de ruína de 1/1000 (Análise 3) é suficiente utilizar um CS = 1.8 na formulação da norma.

\subsection{Análise das estacas com $\mathrm{D}=0.42 \mathrm{~m}$}

Usando somente os resultados das provas de carga realizadas nas 10 estacas com $0.42 \mathrm{~m}$ de diâmetro, foram realizadas as análises apresentadas neste sub-item.

A Tabela 39 e a Tabela 36 do Apêndice G trazem as estatísticas dos valores de resistência e de solicitação das estacas cujas provas de carga serão utilizadas. As análises realizadas com base nestes valores estão apresentadas nas Figuras 75, 76 e 77 do Apêndice G.

Tabela 8.7.6. Estatísticas dos valores de resistência das estacas com $\mathrm{D}=0.42 \mathrm{~m}$.

\begin{tabular}{|c|c|c|c|}
\hline Estatisticas & $\begin{array}{c}\text { Res. Lateral } \\
(\mathrm{kN})\end{array}$ & $\begin{array}{c}\text { Res. Ponta } \\
(\mathrm{kN})\end{array}$ & $\begin{array}{c}\text { Res. Total } \\
(\mathrm{kN})\end{array}$ \\
\hline Média & 511.1 & 1592.8 & 2103.9 \\
\hline Desvio & 434.0 & 335.7 & 406.5 \\
\hline CV (\%) & 84.9 & 21.1 & 19.3 \\
\hline
\end{tabular}

A Tabela 8.7.6 apresenta o valor médio e o coeficiente de variação utilizado nas análises, enquanto que a Tabela 8.7.7 apresenta os resultados das análises realizadas. 
Tabela 8.7.7. Resultados das análises realizadas - estacas com D $=0.42 \mathrm{~m}$.

\begin{tabular}{|c|c|c|c|c|c|c|c|c|c|c|c|}
\hline \multirow{2}{*}{ Anál'ses } & \multicolumn{3}{|c|}{ Resistència } & \multicolumn{3}{|c|}{ Scrictasăo } & \multirow{2}{*}{ cs } & \multirow{2}{*}{$\beta$} & \multirow{2}{*}{ Pr } & \multirow{2}{*}{$1 / \mathrm{Pr}$} & \multirow{2}{*}{$\begin{array}{l}\text { Patm } \\
\text { (kN) }\end{array}$} \\
\hline & Méda (kN) & Desvio (KN) & $\mathrm{CV}(\%)$ & Méda (kN) & Desrio (kV) & CV (\%) & & & & & \\
\hline Anáise 1 & 21039 & 406.5 & $19.3 \%$ & 1150.0 & 0.0 & $0 . \%$ & 1.8 & 235 & 0.00048 & 100 & 1150.0 \\
\hline Anáíse 2 & 2103.9 & 406.5 & $193 \%$ & 10520 & 0.0 & $0.0 \%$ & 20 & 259 & 0.00483 & 207 & 10520 \\
\hline Anäíse 3 & 21039 & 406.5 & $19.3 \%$ & 847.6 & 0.0 & $0.0 \%$ & 25 & 3.09 & 0.00100 & 1000 & 847.6 \\
\hline
\end{tabular}

Observando a Tabela 8.7.7, é possível perceber que se o estaqueamento for projetado usando as cargas nominais das estacas (Análise 1), a sua probabilidade de ruína será igual a $1 / 106$, e que se o mesmo for projetado usando a formulação da norma com um $\mathrm{CS}=2.0$ (Análise 2), este terá uma probabilidade de ruína de 1/207. Entretanto, a Análise 3 permite perceber que para o estaqueamento apresentar segurança, é necessário utilizar um $\mathrm{CS}=2.3$, para que a probabilidade de ruína seja de 1/1000.

\subsubsection{Comentários finais}

Observando os resultados apresentados, pode-se perceber que as análises realizadas com todas as estacas (25 estacas) em termos de tensões (Tabela 8.7.3) se apresentaram semelhantes aos resultados das análises realizadas com as 14 estacas de $0.50 \mathrm{~m}$ de diâmetro (Tabela 8.7.5) e com as 10 estacas de $0.42 \mathrm{~m}$ de diâmetro (Tabela 8.7.7). Semelhantes no sentido de apresentarem, nas três análises realizadas (Análises 1, 2 e 3), aproximadamente, o mesmo valor numérico para o coeficiente de segurança e índice de confiabilidade.

Nota-se também que, neste estudo, a fundação foi analisada de duas formas distintas: em termos de tensões admissíveis (item 8.7.4.1) e, em termos de carga admissível (item 8.7.4.2), para que fosse possível identificar ser há diferença entre elas. $\mathrm{O}$ que permitiu concluir que, a análise em termos de carga admissível, sempre que possível de realizar, parece ser a mais indicada, pois, ao realizar as análises para cada grupo de estacas, é possível calcular quais são os valores de coeficiente de segurança e de índice de confiabilidade indicados para cada um deles, e dessa forma, otimizar a fundação a ser projetada. 


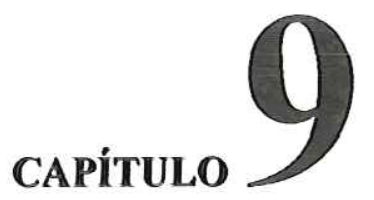

ANÁLISE DOS RESULTADOS

A partir das análises realizadas é possível perceber que a Teoria da Confiabilidade pode ser aplicada na Engenharia de Fundações através de procedimentos simples, e não necessita de mais dados do que são necessários em uma análise determinística convencional.

Segundo Li \& Lam (2001), os métodos probabilísticos, em geral, apresentam dificuldades matemáticas, enquanto que a análise determinística envolve somente o simples conceito de coeficiente de segurança. Devido às complexas técnicas matemáticas da análise probabilística, os engenheiros têm encontrado dificuldades no uso dos conceitos probabilísticos, causando o desinteresse dos engenheiros geotécnicos.

Entretanto, como foi possível perceber, o tipo de análise de confiabilidade desenvolvido nesta dissertação requer somente um modesto esforço quando comparado com àquele necessário na análise com o uso do coeficiente de segurança. Mas, em compensação, este tipo de análise adiciona um considerável valor aos resultados das análises, apresentando excelentes contribuições.

A análise de confiabilidade fornece uma ferramenta lógica para calcular o coeficiente de segurança que é apropriado para o grau de incertezas e às conseqüências de falha da fundação em análise. Com o uso da Teoria da Confiabilidade é possível distinguir as situações onde o uso de um baixo coeficiente de segurança é apropriado das situações onde um elevado coeficiente de segurança é necessário. 
Atualmente, espera-se que a probabilidade de falha possa ser usada como um complemento do coeficiente de segurança, não um substituto. Segundo Duncan (2001), conhecer ambos, o valor do coeficiente de segurança e o valor da probabilidade de falha, é melhor que conhecer apenas um.

Deve-se notar que uma análise probabilística pode dar ao projetista uma idéia das incertezas e dos riscos associados ao projeto geotécnico, enquanto que, mesmo num cálculo preciso usando o coeficiente de segurança estas estarão implícitas e desconhecidas.

Em Duncan (2001) é possível visualizar uma tabela com o resumo dos benefícios proporcionados pela análise de confiabilidade apresentado por vários autores.

Segundo Vanmarcke (1977), para relatar os diferentes níveis de variabilidade, são necessárias informações sobre o grau de heterogeneidade do solo. Sem qualquer informação sobre a variabilidade do solo, o coeficiente de variação obtido de uma quantidade de dados pode ser de pouca utilidade.

Neste contexto, deve-se destacar que as análises realizadas permitiram perceber a importância de se conhecer o número de ensaios (amostras) necessários para bem caracterizar um determinado tipo de formação geológica-geotécnica. Foi possível observar que este número depende da formação que está sendo analisada e que, a partir de uma certa quantidade de ensaios (amostras), a média e o desvio não variam. O que permite identificar qual é a quantidade mínima de ensaios que é necessária para a adequada caracterização da formação.

É possível perceber que a determinação da quantidade de amostras necessárias é uma preocupação há tempos existente. Por exemplo, Preiss \& Shapiro (1981) comentam que quando se usam testes de integridade para o controle de qualidade de estacas ou paredes diafragmas, o engenheiro responsável precisa decidir quantos testes ou elementos serão testados. Este artigo comenta sobre o efeito do tamanho da amostra nos métodos estatísticos e fornece uma solução estatística para esta questão.

Deve-se também destacar a importância da qualidade dos dados utilizados numa análise de confiabilidade de projetos. Pois, a análise de confiabilidade pode ter um pequeno beneficio para os engenheiros geotécnicos quando as análises não são baseadas em dados realísticos e em condições de campo nas quais os parâmetros de projeto não são representativos do comportamento do solo. Logo, um componente essencial da arte da Engenharia de Fundações é a habilidade de estimar, com razoável precisão, os valores dos parâmetros de cálculo com base nos dados medidos. 
As investigações geotécnicas são de suma importância pois, grandes transtornos podem advir se as condições encontradas na fase de execução forem diferentes daquelas previstas na etapa de projeto (AOKI, 1982). Entretanto, das análises realizadas com os dados publicados por Vianna (2000), Ávila (2001) e Balech (2000) percebe-se que mesmo dentro de um mesmo universo geológico-geotécnico, as capacidades de carga de estacas próximas podem variar, e que pequenas variações de dificil detecção por investigações geotécnicas convencionais, podem provocar alterações nos valores de capacidade de carga previstas para as estacas.

Outro ponto de fundamental importância que deve ser ressaltado referece-se ao fato de que o coeficiente de segurança é capaz de garantir a segurança de uma fundação quando esta apresenta uma variabilidade, representada pelo valor do coeficiente de variação das resistências, máxima inferior ao indicado no Anexo E.

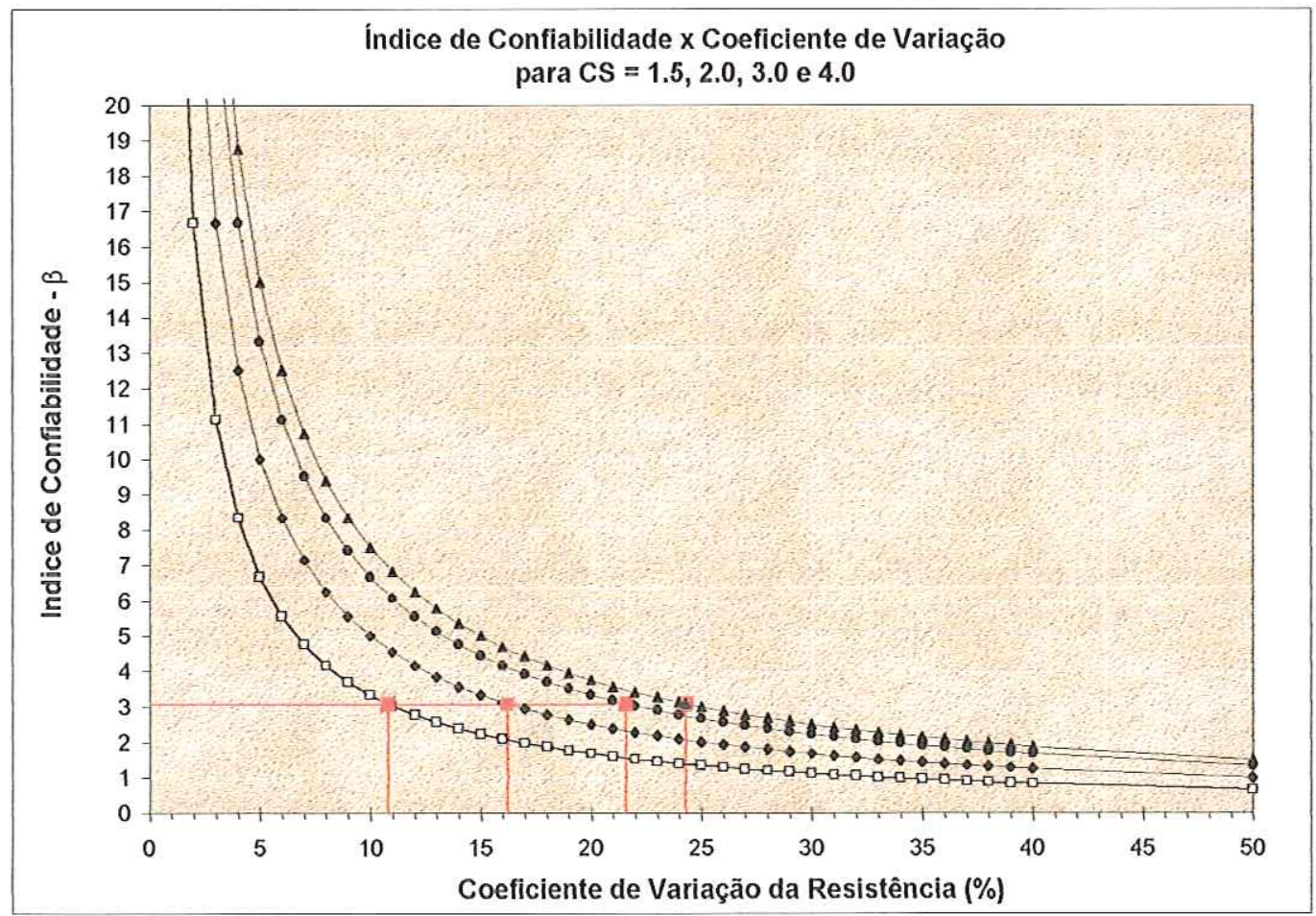

Figura 9.1. Relação entre índice de confiabilidade e coeficiente de segurança.

A Figura 9.1 apresenta, em resumo, a reunião dos gráficos apresentados no Anexo E. A observação dessa figura, assim como o exposto no anexo, permite perceber que, por exemplo, para um coeficiente de segurança igual a 2.0 tem-se, até um coeficiente de variação no valor de $16.18 \%$, a possibilidade de utilização do Método da Carga Admissível na garantia da segurança de uma fundação. Entretanto, para maiores coeficientes de variação, este método mostra-se incapaz de estimar um valor de carga 
admissível que permita a realização de um projeto com níveis adequados de segurança. Em resumo, percebe-se que,

- $\mathrm{CV}<16.18 \% \rightarrow \mathrm{CS}=2.0 \rightarrow \beta>3.09$

- $\mathrm{CV}>16.18 \% \rightarrow \mathrm{CS}=2.0 \rightarrow \beta<3.09$.

Sendo que o mesmo raciocínio pode ser estendido para os demais valores de coeficiente de segurança.

Ao mesmo tempo, foi observado nas análises que um coeficiente de variação superior $30 \%$ (mais precisamente, $32.3 \%$ ) resulta em coeficientes de segurança e cargas admissíveis com valores negativos, como já havia sido constatado por Li et al. (1993).

Para estes casos, em que existe uma grande variabilidade, percebe-se que a metodologia proposta, assim como a metodologia expressa em norma, é incapaz de garantir a segurança.

Uma possível solução para o problema pode ser especificar probabilidades de ruína superiores à recomendada $(1 / 1000)$ para que se seja possível determinar um valor de carga admissível para a realização do projeto, e prescrever um controle executivo com o objetivo de minimizar as variabilidades existentes de forma a se ter uma probabilidade de ruína inferior à especificada em projeto.

Outra observação importante, se refere aos gráficos de carga admissível $\mathrm{x}$ probabilidade de ruína $\mathrm{x}$ coeficiente de segurança elaborados para cada uma das fundações analisadas. Esses gráficos permitem obter de forma rápida, o valor de carga admissível e seu correspondente coeficiente de segurança, para uma determinada probabilidade de ruína desejada. Sendo assim, práticos e eficientes na garantia da segurança. Da observação desses gráficos percebe-se que as curvas têm a tendência de se deslocarem para a esquerda (maiores valores de probabilidade de ruína) à medida que a variabilidade aumenta.

Também pode-se observar que, com o aumento da variabilidade, as curvas têm a tendência de apresentarem um assíntota. A existência dessa assíntota demonstra que, a partir de determinado valor de coeficiente de segurança, qualquer aumento no mesmo, (com, conseqüentemente, redução do valor de carga admissível), deixa de ser vantajoso, pois as reduções nos valores de probabilidade de ruína apresentados serão cada vez menores.

Nestes casos, o aumento do coeficiente de segurança na tentativa de redução da probabilidade de ruína, será apenas dispendioso, pois apresentará um benefício desprezível. 


\section{CONSIDERAÇÕES FINAIS}

\subsection{Conclusões}

A prática atual de fundações profundas no Brasil utiliza ainda, na sua grande maioria, o Método da Carga Admissível na realização dos projetos de fundações. Porém, essa dissertação demonstrou que o cálculo da carga admissível de uma fundação através da aplicação de um coeficiente de segurança global não é suficiente para garantir a segurança da mesma.

Pois, de acordo com os conceitos atuais de segurança, este é um problema essencialmente baseado em probabilidades, devido às inúmeras incertezas e variabilidades presentes nos projetos e nas análises de engenharia, que não permitem afirmar que uma determinada fundação não falhará. Logo, é a probabilidade de ruína que quantifica, na realidade, a segurança de uma obra. Assim, o coeficiente de segurança por não estar vinculado à probabilidade de ruína, não é capaz de garantir a segurança de uma obra. Neste contexto, através do uso de conceitos da Teoria da Confiabilidade foi proposta uma formulação para o cálculo da carga admissível de um estaqueamento baseada no índice de confiabilidade, que permite projetar uma fundação para a probabilidade de ruína desejada.

Destacou-se também, a importância de se considerar, nas análises, a formação geológica na qual a fundação está instalada. Estudos realizados com elementos estruturais de fundação, executados em diferentes locais, não possuem nenhum 
significado físico, pois para que as análises sejam representativas da segurança da fundação estas devem estar relacionadas à superfície resistente da obra em análise naquela formação geológica-geotécnica.

Um dos principais objetivos deste trabalho foi mostrar a importância de se fazer o estudo do projeto e da execução das fundações através de uma abordagem probabilística, contemplando as complexidades do comportamento geológicogeotécnico, dos materiais estruturais e reconhecendo as limitações inerentes aos modelos e teorias. Espera-se que no futuro, análises semelhantes sejam feitas a partir de bancos de dados com diversos tipos de estacas nas mais variadas formações geológicas deste país, para que os valores de carga admissível, coeficiente de segurança, índice de confiabilidade e probabilidade de ruína possam ser conhecidos de forma a permitir projetos da fundação mais seguros e confiáveis.

Espera-se que os conhecimentos adquiridos nesta dissertação possam ser, em tempo relativamente curto, adicionados à prática de fundações. De modo a permitir a realização dos futuros projetos sob bases técnicas mais seguras e, eventualmente, conduzir a soluções mais econômicas.

Acredita-se que as informações contidas nos diversos trabalhos referenciados ao longo deste trabalho, somados a outros, assim como o presente trabalho, constitui um acervo importante e considerável, no que diz respeito à Segurança de Fundações. E que estes devem ser analisados sob o olhar crítico do meio técnico para que possa ser possível o crescente desenvolvimento da análise de confiabilidade na Engenharia de Fundações.

Neste contexto, a utilização de processos que levem em consideração a natureza aleatória das várias variáveis envolvidas nos modelos de comportamento das fundações é uma ferramenta indispensável e talvez até a única realmente apropriada para a estimativa da segurança de fundações.

Sabe-se que todos os projetos geotécnicos envolvem compromissos legítimos entre a realidade e a simplicidade. O nível de segurança exigido é, em geral, proporcional à responsabilidade, que é função das conseqüências da ocorrência de uma eventual ruína.

A expressão do coeficiente de segurança global é, como pôde ser observado, uma expressão determinista, que ao contrário da conceituação de segurança que utiliza o índice de confiabilidade, na qual a variabilidade, tanto das ações quanto das resistências é considerada. 
A utilização de probabilidades de ruína, referenciadas na forma do parâmetro $\beta$ (índice de confiabilidade), ao invés de coeficientes de segurança, parece ser o caminho mais racional de garantir a segurança de fundações, e tem sido a tendência internacional. Entretanto, para uma implementação prática, as variabilidades das resistências e ações precisam ser mais bem conhecidas e avaliadas.

Foi demonstrado nesta dissertação que a verificação do coeficiente de segurança é necessária, porém é insuficiente para garantir a segurança de uma fundação. Os resultados obtidos nas análises realizadas permitem extrair uma série de conclusões, porém o mais imprescindível de todo o trabalho realizado foi demonstrar a partir de dados experimentais (a partir da "realidade") que o coeficiente de segurança de uma obra de fundação não pode ser desvinculado da probabilidade de ruína a ele associado.

Logo, propõe-se, em função dos resultados obtidos, uma mudança no conceito de carga admissível estabelecido pela norma NBR 6122/1996, para que seja possível projetar fundações de forma mais segura e com maior consciência dos riscos envolvidos.

Os projetistas estão prontos para aplicar novos e avançados procedimentos de avaliação de segurança, caso esses sejam claros, de forma a consumir o mínimo de tempo e esforço e, principalmente se o seu uso acarretar numa economia não desprezível de materiais e serviço. Pois, assim eles podem perceber que o seu trabalho não está limitado à aplicação de equações e que o benefício é visível. Sendo essa uma das mais importantes características da metodologia proposta: simplicidade e aplicabilidade.

Com o uso da metodologia proposta será possível estudar formas de reduzir o custo de uma fundação sem comprometer a sua segurança, ou seja, mantendo a sua probabilidade de ruína num nível aceitável, pré-fixada a priori.

\subsection{Sugestões para pesquisas futuras}

O tema abordado nesta dissertação é de suma importância e merece ser desenvolvido mais profundamente através de pesquisas futuras. Neste sentido, algumas sugestões podem ser apresentadas:

- Para a realização de estudos que envolvam aspectos probabilísticos é de fundamental importância o conhecimento das variabilidades dos parâmetros de projeto. Existe atualmente na bibliografia geotécnica uma grande quantidade de dados 
publicados. Entretanto, grande parte destes dados, estão apresentados de forma determinística, e no caso de estudos que envolvam estatística e probabilidades, é necessário o conhecimento das variabilidades desses parâmetros. A determinação da real variabilidade é de fundamental importância e precisa ser investigada de forma a permitir o conhecimento das diversas formações geológicas-geotécnicas existentes no país. A partir deste conhecimento é possível avaliar melhor a variabilidade no interior de uma mesma obra e aferir os métodos de previsão de capacidade de carga através de resultados de provas de carga de forma que estes levem em conta o processo executivo. Logo, a caracterização estatística da variabilidade do solo e a variabilidade dos valores médios de capacidade de carga resultantes, constituem um vasto campo de pesquisa, pois o seu conhecimento é de fundamental importância na quantificação dos riscos e da segurança das estruturas geotécnicas.

- Outro ponto de fundamental importância é o uso de provas de carga dinâmicas. Atualmente, a proporção entre as provas de carga dinâmicas e estáticas realizadas numa obra tem crescido significantemente, sendo que em parte significativa delas não se executam mais provas de carga estática. Devido à maior facilidade executiva, rapidez e custo significativamente menor, as provas de carga dinâmica estão sendo executadas em freqüências cada vez maiores, o que permite a realização de uma avaliação probabilística da segurança em fundações, devido à grande quantidade de dados obtidos. Assim, para aumentar o espaço amostral de dados, é de fundamental importância que a prova de carga dinâmica seja aceita sem ressalvas pelo meio técnico. Com esse intuito, sugere-se que, o desenvolvimento de pesquisas no sentido de "validar" o uso da prova de carga dinâmica e de ressaltar a sua aplicação e importância no estudo da segurança de fundações, será de grande utilidade a todos.

- Os controles de campo são ferramentas usadas na avaliação da uniformidade do estaqueamento em execução. Como comentado nesta dissertação, o uso dos denominados controles de campo interferem na variabilidade do estaqueamento. Sendo assim, uma sugestão de pesquisa pode ser a de avaliar como este tipo de controle altera a segurança de uma fundação e como este pode ser considerado ainda durante a realização do projeto de forma a permitir o dimensionamento de fundações mais econômicas e seguras. 
- Sugere-se também, o uso dos conceitos da Teoria da Confiabilidade em estudos em que envolvam os estados limites de utilização, como por exemplo, as análises de recalque. $\mathrm{O}$ uso dessa teoria pode permitir a estimativa da precisão dos recalques calculados, assim como determinar a magnitude do recalque que tenha uma determinada probabilidade de ser excedido.

Essas são algumas das inúmeras sugestões que poderiam ser apresentadas dentro do enorme universo de possibilidades existentes. Espera-se que o desenvolvimento da Teoria da Confiabilidade venha a se consolidar como ferramenta na garantia da Segurança de Fundações e que haja um crescente aumento do número de pesquisas nesta área no país. 
ASSOCIAÇÃO BRASILEIRA DE NORMAS TÉCNICAS (1984). NBR 8681: Norma Brasileira de Ações e Segurança nas Estruturas - Procedimento. Rio de Janeiro.

ASSOCIAÇÃO BRASILEIRA DE NORMAS TÉCNICAS (1996). NBR 6122: Norma Brasileira para Projeto e Execução de Fundações. Rio de Janeiro.

ALONSO, U. R. (2000). Contribuição para a formação de um banco de dados de provas de carga estáticas em estacas hélice contínua. $4^{\circ}$ Seminário Nacional de Engenharia de Fundações Especiais e Geotecnia - SEFE IV, vol. 2, pp. 430-450.

ALONSO, U. R. (2002). Complementação do banco de dados de provas de carga estáticas em estacas hélice contínua. $5^{\circ}$ Seminário Nacional de Engenharia de Fundações Especiais e Geotecnia - SEFE V.

AMARAL, A. B. T. (1982). Capacidade de carga de estacas em solos argilosos da Formação Guabirotuba. In: CONGRESSO BRASILEIRO DE MECANICA DOS SOLOS E ENGENHARIA DE FUNDAÇÕES, VII, Anais, ABMS, vol.2, p. 9-18, Olinda/Recife (PE).

ANG, A. H-S. (1975). A Comprehensive Basis for Reliability Analysis and Design. In: Japan - U. S. Joint Seminar on Reliability Approach in Structural Engineering, 1974, Tokyo. Reliability Approach in Structural Engineering, 1975, Maruzen Co. Ltd., Tokyo. 
ANG, A. H-S.; TANG, W. H. (1975). Probability concepts in engineering planning and design: basic principles. New York: John Wiley. vol. 1.

ANG, A. H-S.; TANG, W. H. (1984). Probability concepts in engineering planning and design: decision, risk and reliability. New York: John Wiley. vol. 2.

ANTUNES, H. M. C. C.; IWAMOTO, R. K. (2000). Comparação entre resultados observados in situ e modelos numéricos para a interação estrutura - solo. Simpósio Interação Estrutura-Solo em Edificios, 27 a 28 de novembro de 2000, USP/SC, São Carlos - SP.

AOKI, N. (1982). Relatório Geral. In: VII Congresso Brasileiro de Mecânica dos Solos e Engenharia de Fundações - ABMS, pp. 101-148, Recife/PE.

AOKI, N. et al. (1995). Durabilidade e absorção de água do concreto centrifugado. IBRACON - 37 REIBRAC. 03 a 07 de julho de 1995. Goiânia/GO. pp. 193-204.

AOKI, N. (2000a). Reflexões sobre o comportamento de sistema isolado de fundação. Seminário de Engenharia de Fundações Especiais e Geotecnia - SEFE IV. Anais vol.1, pp. 23-39, São Paulo: ABMS/ABEF. São Paulo/SP.

AOKI, N. (2000b). Reflexões sobre a prática de fundações no Brasil. GEOSUL'2000, pp. 19-31.

AOKI, N. (2000c). Antes da análise matricial do comportamento dos pontos de contato estrutura $X$ fundação e de uma abordagem através de integração numérica . Debate Interação de Solos e Engenharia de Estruturas - IESP, 2000. São Paulo.

AOKI, N. (2001). Confiabilidade e Segurança em Fundações. Workshop "Prática Atual de Fundações Profundas”. SindusCon - SP/ABMS - SP. São Paulo/SP.

AOKI, N; CINTRA J. C. A. (1996). Influência da variabilidade dos maciços de solos no comprimento de estacas. Seminário de Engenharia de Fundações Especiais e Geotecnia - SEFE III. Anais vol.1, pp.173-184, São Paulo: ABMS/ABEF. São Paulo/SP.

AOKI, N.; CINTRA, J. C.; MENEGOTTO M. L. (2001). Segurança e Confiabilidade de Fundações Profundas. Portugal. 
ÁVILA, I. A. de (2001) Análise do comportamento de estacas metálicas cravadas na Bacia de Taubaté através de provas de carga dinâmica de energia crescente. São Carlos. Dissertação (Mestrado). Escola de Engenharia de São Carlos, Universidade de São Paulo.

BALECH, J. (2000). Análise de transferência de carga de estacas cravadas em argila mole a partir de provas de carga dinâmica de energia crescente. Dissertação (Mestrado). Escola de Engenharia de São Carlos, Universidade de São Paulo. 153 p. São Carlos.

BASMA, A. A. (1994). Risk - reduction factor for bearing capacity of shallow foundations. Canadian Geotechnical Journal, vol. 31, No 1, February 1994, pp.12-16.

BAUER, J.; PULA, W. (2000). Reliability with respect to settlement limit-states of shallow foundations on linearly-deformable subsoil. Computers and Geotechnics, vol., pp. 281-308.

BECKER, D. E. (1996a). Eighteenth Canadian Geotechnical Colloquium: Limit States Design for Foundations. Part I. Development for the National Building Code of Canada. Canadian Geotechnical Journal, vol. 33, pp. 956-983.

BECKER, D. E. (1996b). Eighteenth Canadian Geotechnical Colloquium: Limit States Design for Foundations. Part II. Development for the National Building Code of Canada. Canadian Geotechnical Journal, vol. 33, pp. 984-1007.

BERNARDO, T. R. R. (1999). Contribuição à Análise da Confiabilidade em Pavimentos de Edificios de Concreto Armado. Dissertação (Mestrado). Escola de Engenharia de São Carlos, Universidade de São Paulo. 175 p. São Carlos.

BILFINGER, W. (2002). Critérios de segurança de fundações em estacas cravadas com consideração de controles executivos. Tese (doutorado), 2 v - Escola Politécnica da Universidade de São Paulo. Departamento de Estruturas e Fundações. São Paulo.

BOLTON, M. D. (1989). The development of codes of practice for design. Proceedings of the Twelfth International Conference on Soil Mechanics and Foundation Engineering. XII - ICSMFE/CIMSTF, Rio de Janeiro, 1989, vol. 3, pp. 2073-2076.

BRONOWSKI, J. (1977). O Senso Comum da Ciência. Traduzido por Neil Ribeiro da Silva. São Paulo, EDUSP. 
BRZAKALA, W.; PULA, W. (1996). A probabilistic analysis of foundations settlements. Computers and Geotechnics, vol. 18, n. 4, pp. 291-309.

BUENO \& VILAR (1984). Mecânica dos Solos. EDUSP, São Carlos.

CARDOSO, A. S.; FERNANDES, M. M. (2001). Characteristic values of ground parameters and probability of failure in design according to Eurocode 7. Geotechnique 51, august 2001, No. 6, pp. 519-531.

CASTRO, L. A. (1997). Análise da segurança no projeto de estruturas: método dos estados limites. São Carlos. 119p. Dissertação (Mestrado) - Escola de Engenharia de São Carlos, Universidade de São Paulo.

CINTRA, J.C.A; AOKI, N. (1999). Carga admissível em fundações profundas. Publicação da Escola de Engenharia de São Carlos, Universidade de São Paulo, SP (EESC-USP), Projeto REENGE, 61p.

CHERUBINI, C. (2000). Probabilistic approach to the design of anchored sheet pile walls. Computers and Geotechnics, vol. 26, pp. 309-330. Computers and Geotechnics, vol. 26, pp. 309-330.

CHERUBINI, C.; CUCCHIARARO, L.; GIASI, C. I. (1991). Probabilistic Analysis of shallow foundations bearing capacity. IX Pan-American Conference on Soil Mechanics and Foundation Engineering. Vol. II, 1991. Edited by Sociedad Chilena de Geotecnia. Viña del Mal, Chile, pp. 971-977.

CHERUBINI, C.; GARRASI, A.; PETROLLA, C. (1992). The reliability of an anchored sheet-pile wall embedded in a cohesionless soil. Canadian Geotechnical Journal, vol. 29, n. 3, June 1992, pp. 426-434.

CHERUBINI, C. (2001). Discussion: Factor of Safety and Reliability in Geotechnical. Engineering Journal of Geotechnical and Geoenvironmental Engineering, vol. 127, n. 8, pp. 700-721.

CORNELL, C. A. (1975). Some Comments on Second-Moment Codes and on Bayesianos Methods. In: Japan - U. S. Joint Seminar on Reliability Approach in Structural Engineering, 1974, Tokyo. Reliability Approach in Structural Engineering, 1975, Maruzen Co. Ltd., Tokyo. 
COSTA NETO, P. L. O.; CYMBALISTA, M. (1974). Probabilidades: resumos teóricos, exercícios resolvidos, exercícios propostos. Editora Edgard Blucher Ltda.

DITLEVSEN, O. (1997). Structural reliability codes for probabilistic design - a debate paper on elementary reliability and decision analysis concepts. Structural Safety, vol. 19, n. 3, pp. 253-270.

DITLEVSEN, O.; MADSEN, H.O. (1996). Structural Reliability Methods. Chichester, John Wiley \& Sons, New York, 1996.

DUNCAN, J. M. (2000). Factors of safety and reliability in geotechnical engineering. Journal of Geotechnical and Geoenvironmental Engineering, April 2000, pp. 307-316.

DUNCAN, J. M. (2001). Discussion: Factor of Safety and Reliability in Geotechnical Engineering Journal of Geotechnical and Geoenvironmental Engineering, vol. 127, n. 8, pp. 700-721.

ELLINGWOOD, B. R. (2000). LRFD: implementing structural reliability in professional practice. Engineering Structures, vol. 22, pp. 106-115.

FANG, H. Y. (1997). Introduction to Environmental Geotechnology. Environmental Geotechnical Engineering Applications, pp. 378-381, CRC Press LLC.

FERREIRA, A. B. H. (1986). Dicionário Aurélio. Editora Nova Europa.

FERREIRA, N. S. S., CUNHA J. (2000). Introdução às estruturas de concreto. Notas de aula. Universidade Federal de Uberlândia, Uberlândia/MG.

FREUDENTHAL A. M. (1975). Structural Safety, Reliability and Risk Assessment. In: Japan-U. S. Joint Seminar on Reliability Approach in Structural Engineering, 1974, Tokyo. Reliability Approach in Structural Engineering, 1975, Maruzen Co. Ltd., Tokyo.

GENEVOIS, B. B. P. (1991). Efeito da variabilidade espacial dos parâmetros do solo na capacidade de carga de uma fundação superficial. Solos e Rocha, São Paulo, vol. 14, pp. 55-58, 1991.

GIMENES, E. A.; HACHICH, W. (1992). Aspectos quantitativos em análise de risco geotécnico. Solos e Rochas, São Paulo, vol. 15, pp. 3-9. 
GOBLE, G. G. (2000). LRFD design codes for pile foundations - A review. Application of Stress-Wave Theory to Piles, Niyama \& Beim (eds), Balkema, Rotterdam, pp. 305311 .

GUSMÃO, A. D.; GUSMÃO FILHO, J. A.; MAIA, G. B. (2000). Medições de recalque de um prédio em Recife. Simpósio Interação Estrutura-Solo em Edificios, 27 a 28 de novembro de 2000, USP/SC, São Carlos - SP.

HASOFER, A. M.; LIND, N. C. (1974). Exact and invariant second-moment code format. Journal of the Engineering Mechanics Division (ASCE), February 1974, vol. 100, n. 1, pp. 111-121.

HONJO, Y. et al (2000). National Report on Limit State Design in Geotechnical Engineering: Japan. In: LSD 2000: International Workshop on Limit State Design in Geotechnical Engineering. Melbourne, Australia, 18 November 2000.

HONJO, Y.; SUSUKI, M.; MATSUO, M. (2000). Reliability analysis of shallow foundations in reference to design codes development. Computers and Geotechnics, vol. 26, pp. 331-346.

JEARY, A. (1997). Designer's guide to the dynamic response of structures. E \& FN SPON. London, UK.

KAY, J. N. (1976). Safety factor evaluation for single piles in sand. Journal of the Geotechnical Engineering Division. October 1976, vol. 102, pp. 1093-1108.

KAY, J. N. (1993). Probabilistic design of foundations and earth structures. Probabilistic Methods in Geotechnical Engineering, Li \& Lo (eds), Balkema, Rotterdam, pp. 49-62.

KOUTSOFTAS, D. C. (2001). Discussion: Factor of Safety and Reliability in Geotechnical Engineering Journal of Geotechnical and Geoenvironmental Engineering, vol. 127, n. 8 , pp. $700-721$.

KULHAWY, F. H. (1996). From Casagrande's "Calculated Risk" to Reliability-Based Design in Foundation Engineering. Civil Engineering Practice, Journal of the Boston Society of Civil Engineering's Section/ASCE, vol.11, n. 2, pp.43-56. 
LACASSE S.; GOULOIS, A.(1989). Reliability analysis of axial pile capacity. In: Proceedings of the Twelfth International Conference on Soil Mechanics and Foundation Engineering, Rio de Janeiro, 1989. Publications Committee of XII ICSMFE, vol. 2, pp. 845-848.

LACASSE, S.; NADIM, F. (1997). Uncertainties in characterization soil properties. Publ. No. 201, Norwegian Geotechnical Institute, Oslo, Norway, pp. 49-75.

LEGGET, R. F. (1979). Geology and Geotechnical Engineering. Journal of the Geotechnical Engineering Division, ASCE. March, 1979, vol. 105, pp. 342-391.

LI, K. S.; LAM, J. (2001). Discussion: Factor of Safety and Reliability in Geotechnical Engineering Journal of Geotechnical and Geoenvironmental Engineering, vol. 127, n. 8, pp. 700-721.

LI, K. S.; LEE, I. K.; LO, C. R. (1993). Limit state designs geotechnics. Probabilistic Methods in Geotechnical Engineering, Li \& Lo eds, Balkema, Rotterdam, pp. 29-47.

MAGAlhães, M. N.; LIMA, A. C. P. (2002). Noções de Probabilidade e Estatística. Editora da Universidade de São Paulo, 2002, 4 ed., São Paulo.

MAGNAN, J. P. (1989). Variabilité des propriétés des sols et dimensionnement des ouvrages. In: Proceedings of the Twelfth International Conference on Soil Mechanics and Foundation Engineering, Rio de Janeiro, 1989. Publications Committee of XII ICSMFE, vol. 2, p. 853-854.

MASCHWITZ, G.; CUNZE, G. (1989). Determination of significant material parameters for quality control of new techniques in geotechnical engineering using statistical methods. In: Proceedings of the Twelfth International Conference on Soil Mechanics and Foundation Engineering, Rio de Janeiro, 1989. Publications Committee of XII ICSMFE, vol. 2, pp. 855-57.

MENDONÇA, J. C.; AOKI, N. (2000). Previsão da variação dos recalques de um edificio pela inundação permanente do maciço suporte considerando a interação com a superestrutura. Simpósio Interação Estrutura-Solo em Edificios, 27 a 28 de novembro de 2000, USP/SC, São Carlos - SP.

MELCHERS, R. E. (1987). Structural reliability, analysis and prediction. Chichester, John Wiley. New York, 1987. 
MEYER, P.L. (1972). Probabilidade, Aplicações à Estatística, Ed. Livros Técnicos e Científicos Editora S.A., 1972.

MEYERHOF, G. G. (1969). Safety factors in soil mechanics. Proceedings of the Seventh International Conference on soil mechanics and foundation engineering. México, 1969, vol. 3, pp. 479-481.

MEYERHOF, G. G. (1995). Development of geotechnical limit state design. Canadian Geotechnical Journal, vol. 32, No 1, February 1995, pp. 128-13.

MOURA, A. R. L. U. (1995). Interação solo-estrutura em edifícios. Dissertação (mestrado) - Universidade Federal de Pernambuco, Recife, 135p.

OBONI, F. (1989). Probabilistic models for axially loaded bored shafts. In: Proceedings of the Twelfth International Conference on Soil Mechanics and Foundation Engineering, Rio de Janeiro, 1989. Publications Committee of XII ICSMFE, vol. 2, p. 859-64.

OLIVEIRA, S. K. F. (1998). Contribuição ao estudo da verificação da segurança das fundações profundas. Dissertação (Mestrado). Escola de Engenharia de São Carlos, Universidade de São Paulo. 106 p. + anexos. São Carlos.

OLIVEIRA, S. K .F.; AOKI, N. (1998). Análise da Segurança no Projeto de Fundações por Estacas: Método dos Estados Limites. XI COBRAMSEG, Brasília, pp.1399-1406.

OLSSON, L. et al. (1989). Reliability based partial coefficients - A simplified approach. pp. 2081-2084. In: Proceedings of the Twelfth International Conference on Soil Mechanics and Foundation Engineering, Rio de Janeiro, 1989. Publications Committee of XII ICSMFE, vol. 2, pp. 859-64.

ORTIGÃO, J. A. R. (1995). Introdução à Mecânica dos Solos dos Estados Críticos. Editora LTC. $2^{\circ}$ edição. Rio de Janeiro - RJ.

ORR, T. L. L. (2000). Selection of characteristic values and partial factors in geotechnical designs to Eurocode 7. Computers and Geotechnics, vol. 26, pp. 263-279.

PACHECO, M. (1990). Conceitos de Probabilidade e Análise de Risco em Estudos e Projetos de Geotecnia. Conferência Especial sobre Métodos Probabilísticos em Geotecnia - $6^{\circ}$ CBGE / IX COBRAMSEF, vol. III, Salvador, BA, 1990. 
PACHECO, M.; LIMA, L. S. A. L. (1996). Um critério estatístico para interpretação de ensaios geotécnicos. Solos e Rochas, vol. 19, n. 3, pp. 177-188, dez. 1996, São Paulo.

PAIKOWSKY, S. G.; STENERSEN, K. L. (2000). Keynote lecture: The performance of the dynamic methods, their controlling parameters and deep foundations specifications. Application of Stress-Wave Theory to Piles, Niyama \& Beim (eds), Balkema, Rotterdam, pp. 281-304.

PREISS, K.; SHAPIRO, J. (1981). Statistical considerations in pile testing. In: X ICSMFE - Soil Mechanics and Foundation Engineering Tenth International Conference, Stockholm, 1981, vol. 2, pp. 799-802.

PLI, J.; GAO, D.Z. (1993). Reliability analyses on pile bearing capacity. Probabilistic Methods in Geotechnical Engineering, Li\& Lo (eds), Balkema, Rotterdam.

PHOON, K-K.; KULHAWY, F. H.; GRIGORIU, M. D. (2000). Reliability-based design for transmission line structure foundations. Computers and Geotechnics, vol. 26, pp. 169-185.

REIS, J. H. C.; AOKI, N. (2000). Análise de interação solo-estrutura em maciço de argila mole. Simpósio Interação Estrutura-Solo em Edifícios, 27 a 28 de novembro de 2000, USP/SC, São Carlos - SP.

SANTA MARIA, P. E. L.; SIQUEIRA, T. M. G. (2002). Estudo e controle do estaqueamento de um depósito de alimentos em Caxias, RJ. XII COBRAMSEG. Vol. 3, pp. 1753-1763, São Paulo.

SÁLES, J. J. et al. (2000). Segurança nas Estruturas. EDUSP, São Carlos.

SIMONS, H. (1981). Statistics, reliability theory and safety factors. Design Parameters in Geotechnical Engineering. VII E.C.S.M.F.E. 1979, Brichton, vol. 5. British Geotechnical Society, London, 1981. pp. 81-90.

SOARES, R. C. (2001) Um estudo sobre modelos mecânico-probabilísticos para pórticos de concreto armado. Tese (doutorado) - Escola de Engenharia de São Carlos, Universidade de São Paulo.

SCAC - Sociedade Concreto Armado Centrifugado S.A. Elementos Técnicos, vol. 2, estacas. $40 \mathrm{p}$. 
SPIEGEL, M. L. (1978). Probabilidade e Estatística, Coleção Schaum, Ed. McGrawHill., 1978.

TAVARES, L. V. (1999). A review of major paradigms and models for the design of civil engineering systems. European Journal of Operational Research, vol. 119, pp. 0113 .

TANG, W. H. (1981). Probabilistic evaluation of loads. Journal of the Geotechnical Engineering Division, vol. 107, No GT3, March 1981.

TANG, W. H. (1993). Recent developments in Geotechnical reliability. In: Proc. of the Conf. on Probabilistic Methods in Geotechnical Engineering, Li\& Lo (eds), Balkema, Rotterdam. pp. 3-27.

TANG, W. H. (1971). A Bayesian evaluation of information for foundation engineering in design. In: Proceedings Int. Conf. on Applications of Statistics and Probability to Soil Mechanics and Structural Engineering, Hong Kong, 1971, pp. 362-384.

TANDJIRIA, V.; TEH, C. I.; LOW, B. K. (2000). Reliability analysis of laterally loaded piles using response surface methods. Structural Safety, vol. 22, pp. 335-355.

TSCHEBOTARIOFF, G. P. (1973). Foundations, retaining and earth structures. 2 ed. New Jersey, McGraw-Hill Koga Kusha Ltda, pp. 01-19.

VARGAS, M. (1990). " Provas de Carga em Estacas - Uma apreciação Histórica ". Solos e Rochas. Vol. 13, único.

VARGAS, M. (1996). A história da matematização dos fenômenos geotécnicos. INFOGEO 96. pp 83-98.

VANMARCKE, E. H. (1977). Probabilistic Modeling of soil profiles. Journal of the Geotechnical Engineering Division (ASCE). November 1977, vol. 103, pp. 1227-1246.

VIANNA, A. P. F. (2000). Análise de Provas de Carga Estática em Estacas PréMoldadas Cravadas na Cidade de Curitiba e Região Metropolitana. Dissertação de Mestrado, USP / São Carlos.

VELLOSO, D. A. (1987). Ainda sobre a segurança nas Fundações, Ciclo de Palestras sobre Engenharia de Fundações, ABMS - Núcleo Regional do Nordeste, Recife. 
VELLOSO, D. A.; LOPES, F. (1996) Fundações superficiais. COOPE, vol. 1, Rio de Janeiro.

VESIC, A. S. (1975). Principles of Pile Foundation Design. Lecture Series on Deep Foundation. Geotechnical Group: Boston Society of Civil Engineers Section (BSCES), American Society of Civil Engineers (ASCE) in cooperation with MIT. Soil mechanics Series - Lecture 1 and 2, no 38, pp. 01-46. Duke University School of Engineering, March 1975.

WHITE, W. (1993). Soil variability: Characterization and modelling. Probabilistic Methods in Geotechnical Engineering, Li \& Lo editors, 1993 Balkema, Rotterdam, pp. 111-120.

WHITMAN, R. V. (1984). Evaluating Calculated Risk in Geotechnical Engineering. Journal of Geotechnical Engineering (ASCE), vol. 110, n. 2, February, pp. 314-357.

WHITMAN, R. V. (2000). Organizing and Evaluating Uncertainty in Geotechnical Engineering. Journal of Geotechnical and Geoenvironmental Engineering, July 2000, pp. 583-592. 